\title{
Development and Calibration of a Heat Release Rate Measurement System for an Experimental Atrium
}

\author{
A thesis submitted to \\ the Faculty of Graduate Studies and Research \\ in partial fulfillment of the requirements for the degree \\ Master of Applied Science \\ by \\ Richard Michels, B.Eng. \\ Department of Civil and Environmental Engineering \\ Carleton University \\ Ottawa-Carleton Institute of Civil and Environmental Engineering \\ Ottawa, Ontario, Canada
}

August 2009

(C) Richard Michels 


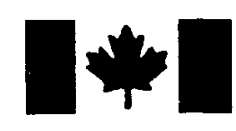

Library and Archives
Canada

Published Heritage

Branch

395 Wellington Street Ottawa ON K1A ON4

Canada
Bibliotheque et

Archives Canada

Direction du

Patrimoine de l'édition

395, rue Wellington

Ottawa ON K1A ON4

Canada
Your file Votre référence
ISBN: $978-0-494-60219-5$
Our file Notre référence
ISBN: $978-0-494-60219-5$
NOTICE:

The author has granted a nonexclusive license allowing Library and Archives Canada to reproduce, publish, archive, preserve, conserve, communicate to the public by telecommunication or on the Internet, loan, distribute and sell theses worldwide, for commercial or noncommercial purposes, in microform, paper, electronic and/or any other formats.

The author retains copyright ownership and moral rights in this thesis. Neither the thesis nor substantial extracts from it may be printed or otherwise reproduced without the author's permission.
AVIS:

L'auteur a accordé une licence non exclusive permettant à la Bibliothèque et Archives Canada de reproduire, publier, archiver, sauvegarder, conserver, transmettre au public par télécommunication ou par l'Internet, prêter, distribuer et vendre des thèses partout dans le monde, à des fins commerciales ou autres, sur support microforme, papier, électronique et/ou autres formats.

L'auteur conserve la propriété du droit d'auteur et des droits moraux qui protège cette thèse. $\mathrm{Ni}$ la thèse ni des extraits substantiels de celle-ci ne doivent être imprimés ou autrement reproduits sans son autorisation.

Conformément à la loi canadienne sur la protection de la vie privée, quelques formulaires secondaires ont été enlevés de cette thèse.

Bien que ces formulaires aient inclus dans la pagination, il n'y aura aucun contenu manquant.
While these forms may be included removal does not represent any loss of content from the thesis. 


\begin{abstract}
The work presented in this thesis includes the design, installation, programming and calibration of a fire Heat Release Rate (HRR) measurement system for Carleton University's large-scale experimental atrium. HRR is considered the most important parameter in characterizing a fire. The system uses the concept of oxygen consumption calorimetry, which is based on the assumption that any material being burned releases the same amount of heat per unit of oxygen consumed in the reaction. The system consists of a set of thermocouples to measure temperatures, bi-directional probes and pressure transducers for velocity measurements and a gas analyzer to record $\mathrm{O}_{2}, \mathrm{CO}_{2}$ and $\mathrm{CO}$ concentrations in the gas exhausted through the ventilation chamber.

Various Fire Dynamics Simulator (FDS) simulations and manual velocity measurements were carried out in order to determine the optimum design for the instrumentation in the fan chamber. Labview 8.6 was then programmed to receive and analyze the data from these sensors in order to provide a near real-time display of HRR as well as various other important variables. Labview 8.6 also writes all raw data and calculated values to a file that can be used for further analysis. A total of 14 propane calibration experiments and 3 heptane pool fires, as well as several FDS simulations, were carried out for the calibration of the system for the atrium. The system is accurate for most fire scenarios.

The results of the calibration tests were used to determine the time delays between the actual HRR and the measured HRR as well as a correction factor that characterizes the overall system.
\end{abstract}




\section{ACKNOWLEDGEMENTS}

I would like to thank Dr. George V. Hadjisophocleous, supervisor of this thesis, for his support, guidance and advice.

Thanks to Yoon Ko for her valuable advice and constant help throughout the project, and to Ba Lamthien for his tireless work and support ... and for letting me light the fires.

Thanks to the NRC staff at the National Fire Laboratory for all of their help and advice.

Thanks also to all the graduate students and staff of the Department of Civil \& Environmental Engineering at Carleton University. We keep each other sane.

Last but not least, I would like to thank my parents for their support and encouragement throughout my studies. 


\section{Table of Contents}

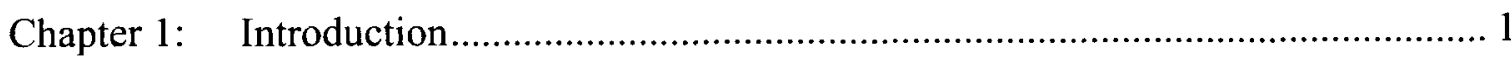

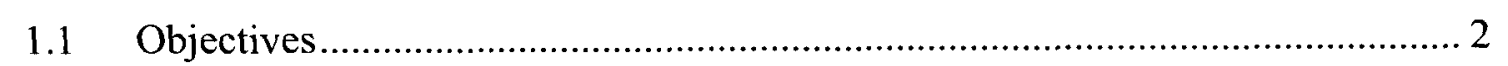

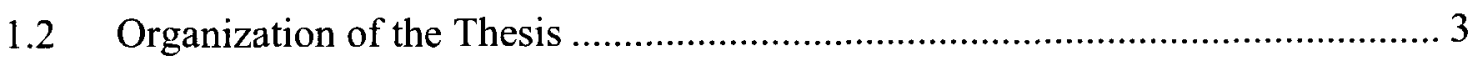

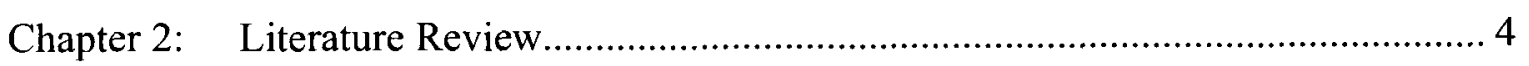

2.1 Development of Oxygen Consumption Calorimetry ….................................... 4

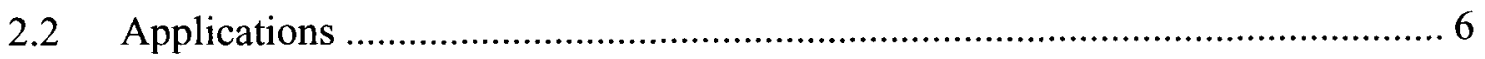

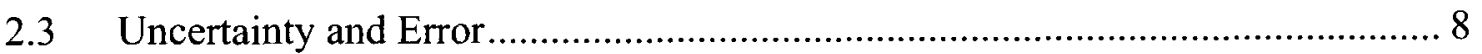

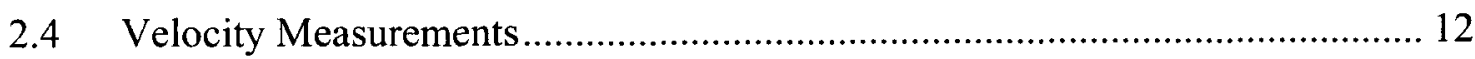

2.5 Pool Fires

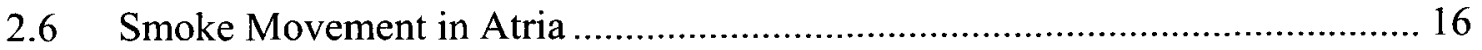

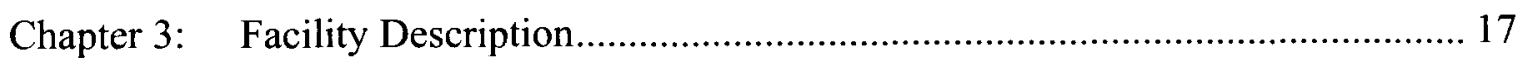

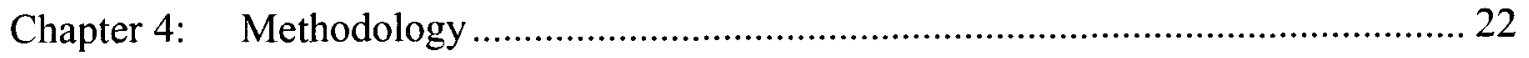

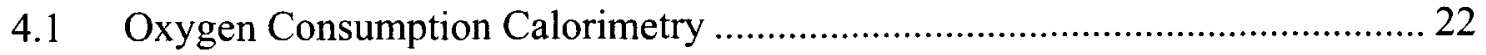

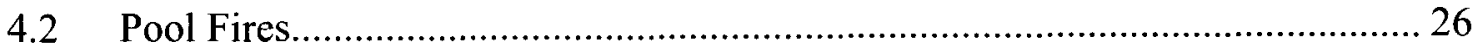

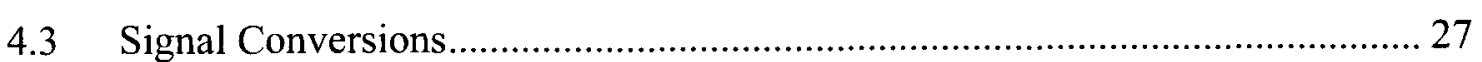

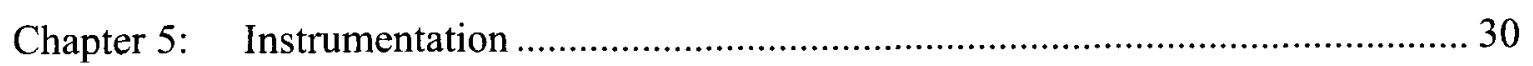

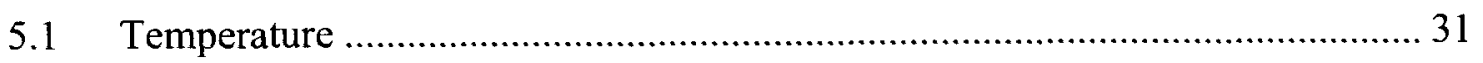

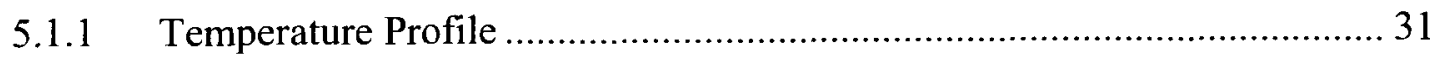

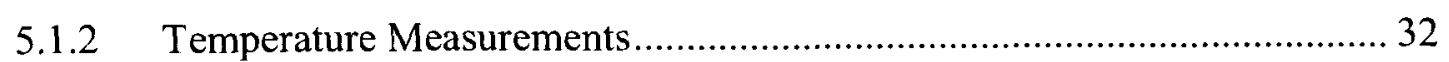

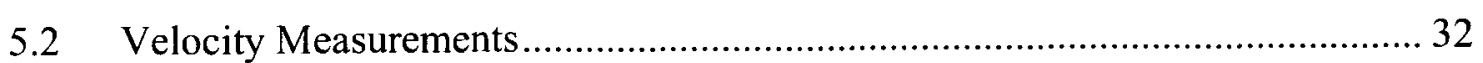


5.2.1 Manual Velocity Measurements ..................................................... 34

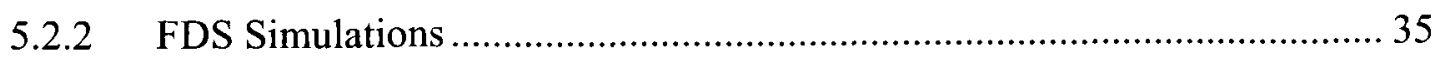

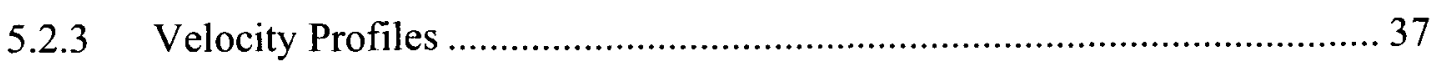

5.2.4 Probe Location Combinations............................................................... 38

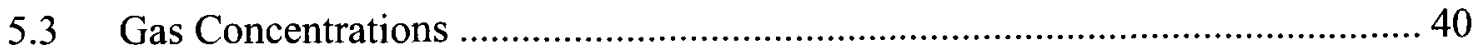

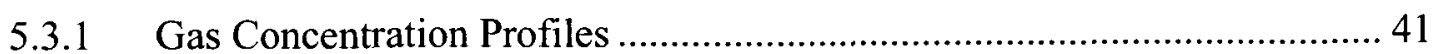

5.3.2 Gas Concentration Measurements ................................................. 42

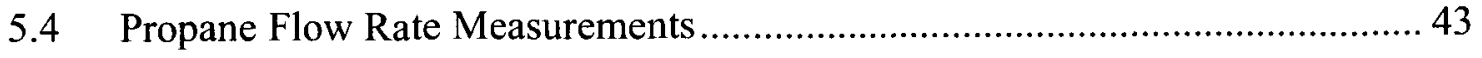

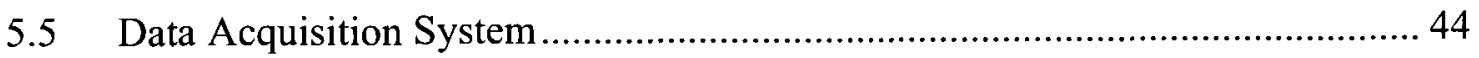

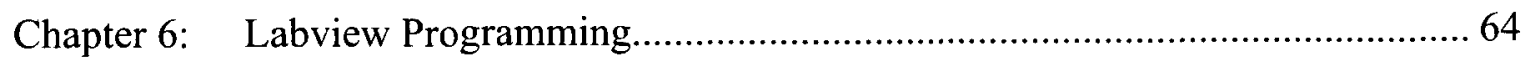

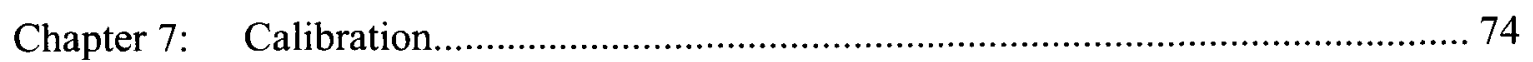

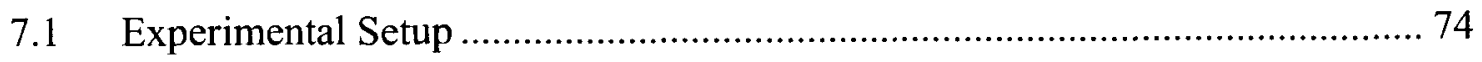

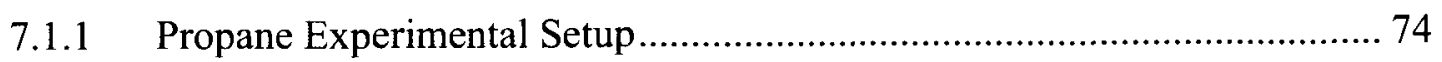

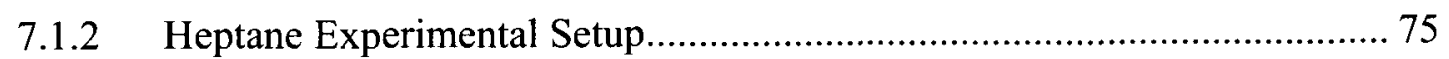

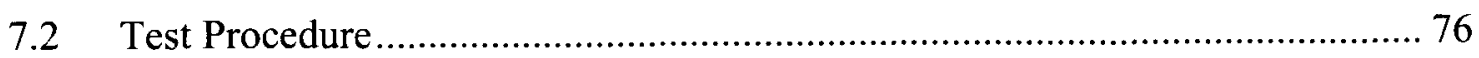

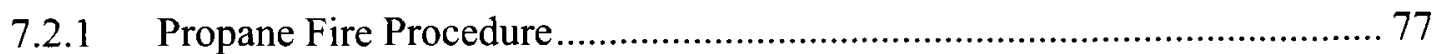

7.2.2 Heptane Pool Fire Procedure ............................................................. 78

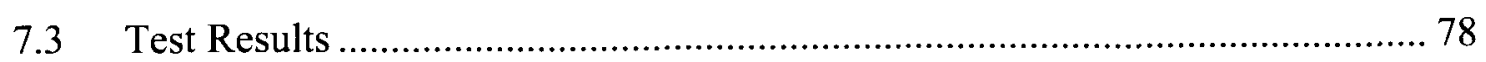

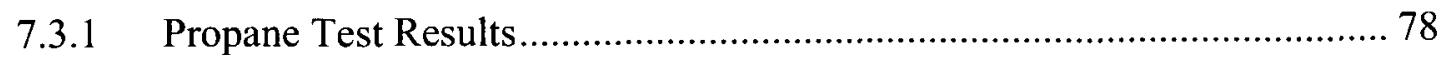

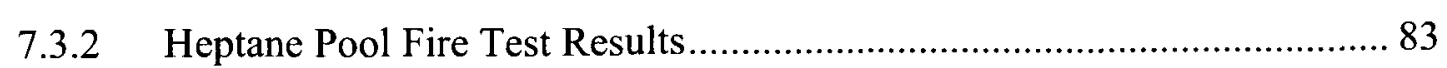




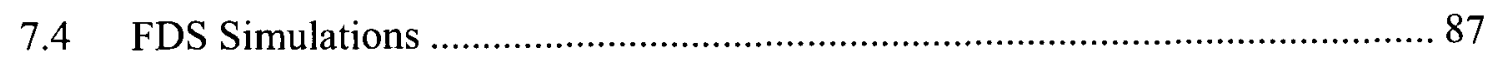

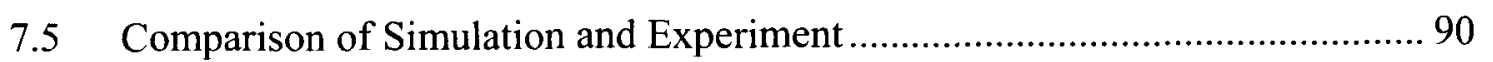

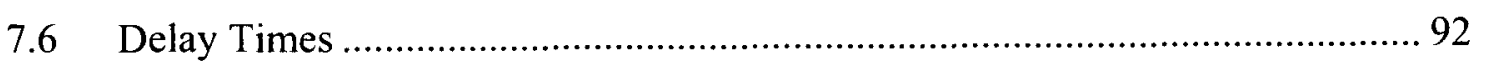

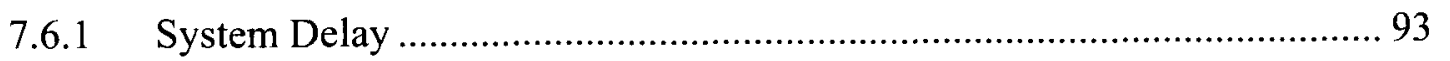

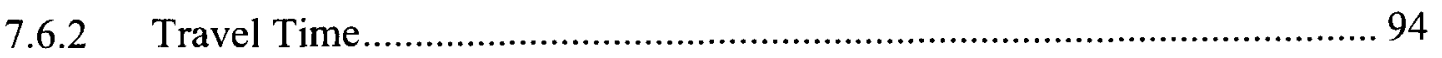

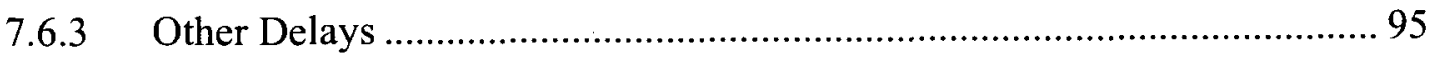

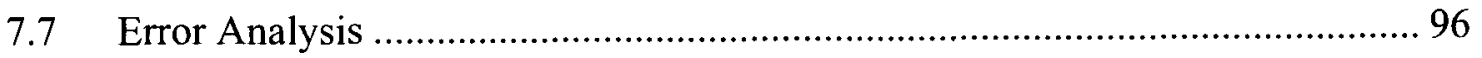

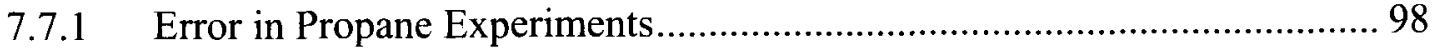

7.7.2 Error in Heptane Pool Fire Experiments............................................ 100

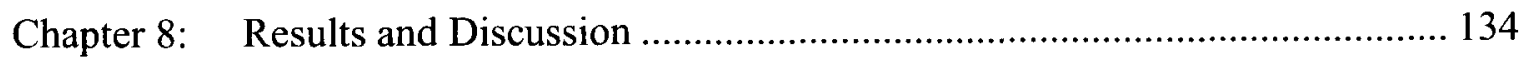

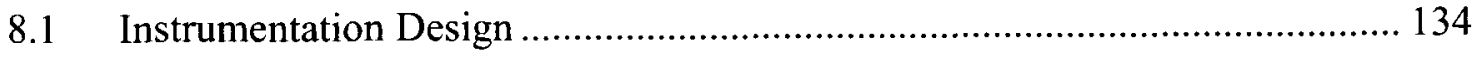

8.2 Data Acquisition and Processing (DAS) …............................................ 135

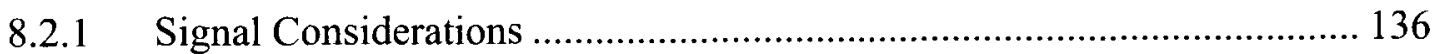

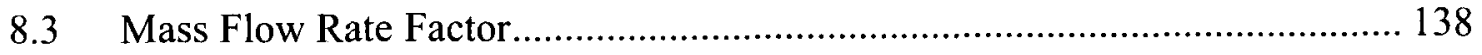

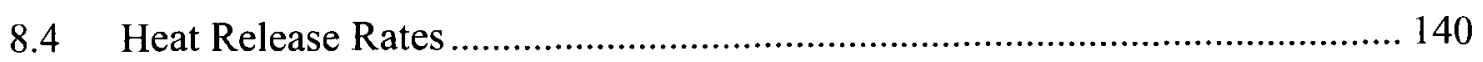

8.4.1 Propane Calibration Fires ........................................................... 141

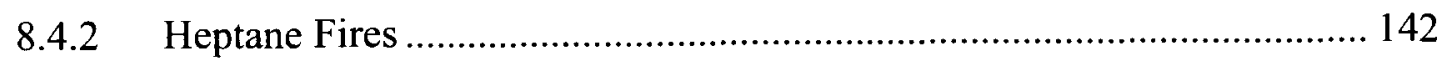

8.4.3 General Heat Release Rate Advice ..................................................... 143

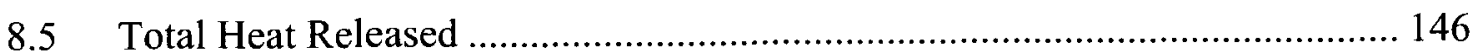

Chapter 9: Summary, Conclusions and Recommendations.................................... 148 


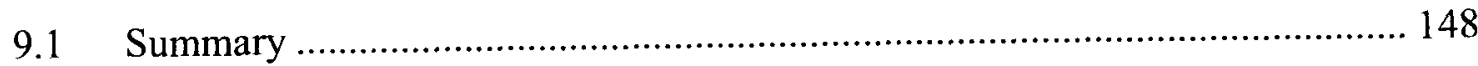

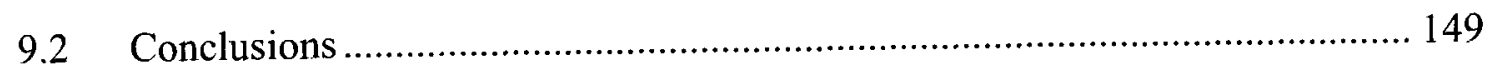

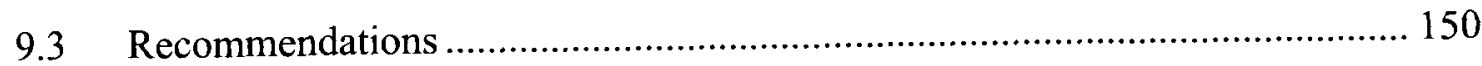




\section{List of Tables}

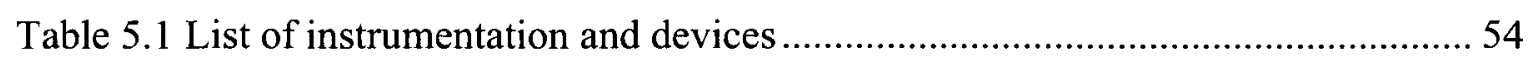

Table 5.2 List of simulations and measurements for instrumentation design [40]

Table 5.3 Velocity errors of all probe location combinations for $25 \%$ fan speed scenarios

Table 5.4 Velocity errors of all probe location combinations for $50 \%$ fan speed scenarios

Table 5.5 Velocity errors of all probe location combinations for $75 \%$ fan speed scenarios

Table 5.6 Velocity errors of all probe location combinations for $100 \%$ fan speed scenarios 60

Table 5.7 Percent error values for velocity probe combination \#22 for all considered scenarios

Table 5.8 Average percent error values for velocity probe combination $\# 22$ for general categories compared to average of all combinations ................................... 62

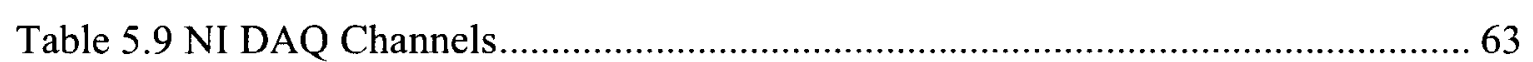

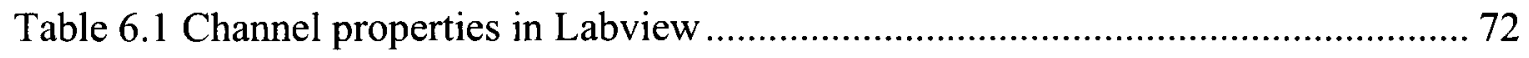

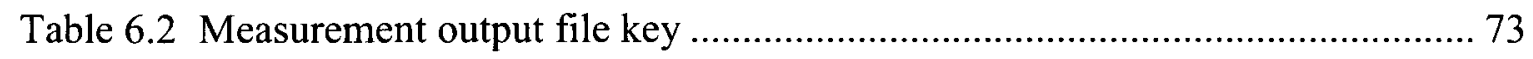

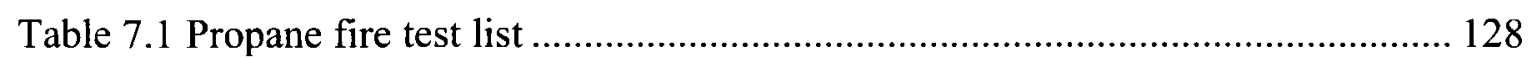

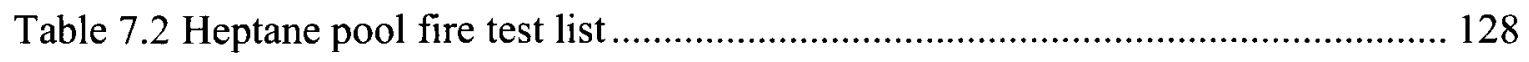

Table 7.3 FDS simulation list for calibration purposes ......................................... 129

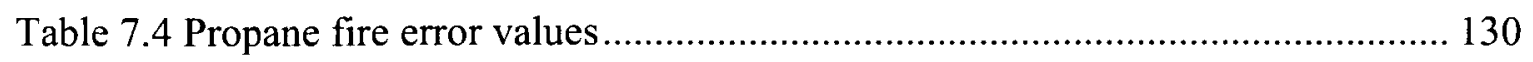


Table 7.5 Heptane pool fire error values

Table 7.6 HRR error values for 600 s FDS simulations...

Table 7.7 Observed delay times of propane tests sorted by fan speed

Table 7.8 Accuracy of instrumentation.

Table 7.9 Fluctuation analysis of time-averaged velocities used in HRR calculations .. 133

Table 8.1 Expected delay times of measurement system 147

Table 8.2 Suggested minimum fan speeds. 147 


\section{List of Figures}

Figure 3.1 Smokeview view of experimental tunnel, fan chamber and atrium .............. 19

Figure 3.2 Pyrosim view of experimental atrium, tunnel and fan chamber.................. 19

Figure 3.3 Tunnel and fan chamber cross-sections............................................. 20

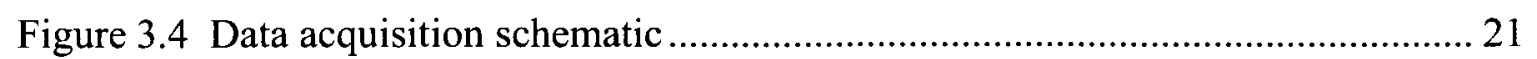

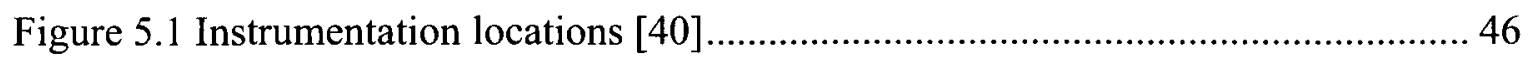

Figure 5.2 Vertical temperature profiles from a $10 \mathrm{MW}$ fire in the tunnel at different fan speeds [40] 46

Figure 5.3 Temperature-time curve for $300 \mathrm{~s} 10 \mathrm{MW}$ FDS simulation at 50\% fan speed showing the uniformity of temperature across the cross-section 47

Figure 5.4 Thermocouple locations 47

Figure 5.5 Vertical velocity profiles at $50 \%$ fan speed without and with a $2.5 \mathrm{MW}$ fire in the tunnel. 48

Figure 5.6 Vertical velocity profiles drawn from the atrium at $50 \%$ fan speed from a simulation and manual measurements 48

Figure 5.7 Velocity probe location combinations in a $0.25 \mathrm{~m}$ grid across the fan chamber cross-section 49

Figure 5.8 Five most accurate velocity probe combinations [40] 50

Figure 5.9 Comparison of the five most accurate velocity probe combinations 50

Figure 5.10 Bi-directional probe locations 51

Figure 5.11 Vertical profiles of oxygen mass fraction of the flow from a $10 \mathrm{MW}$ fire in the tunnel under different fan speeds 51 
Figure 5.12 Oxygen concentration-time curve for 300 s 10 MW FDS simulation at $50 \%$ fan speed showing the uniformity of oxygen concentration across the crosssection

Figure 5.13 CO concentration-time curve for a 300-s 10 MW FDS simulation at 50\% fan speed showing the uniformity of CO concentration across the cross-section 52

Figure $5.14 \mathrm{CO}_{2}$ concentration-time curve for 300 s $10 \mathrm{MW}$ FDS simulation at $50 \%$ fan speed showing the uniformity of $\mathrm{CO}_{2}$ concentration across the cross-section 53 53

Figure 7.1 Propane calibration burner... 102

Figure 7.2 Example screenshot of propane fire experiment . 103

Figure 7.3 Example screenshot from heptane pool fire experiment 103

Figure 7.4 Type A propane calibration experiment 104

Figure 7.5 Type B propane calibration experiment 104

Figure 7.6 HRR measurements of propane experiment A3 showing the effect of the factor of 0.75 105

Figure 7.7 THR measurements of propane experiment A3 showing the effect of the factor of 0.75 105

Figure 7.8 HRR curves for propane test Al 106

Figure 7.9 THR curves for propane test A1 106

Figure 7.10 HRR curves for propane test A2 107

Figure 7.11 THR curves for propane test A2. 107

Figure 7.12 HRR curves for propane test A3 108 
Figure 7.13 THR curves for propane test A3 ……………………………………... 108

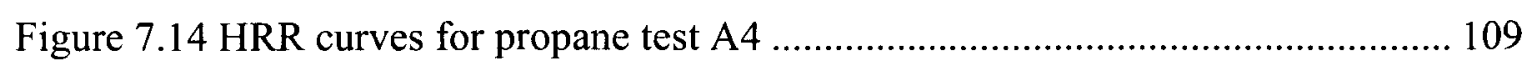

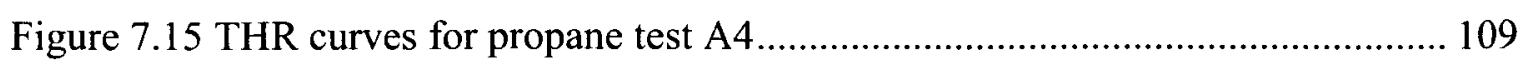

Figure 7.16 HRR curves for propane test A5 ...................................................... 110

Figure 7.17 THR curves for propane test A5 ......................................................... 110

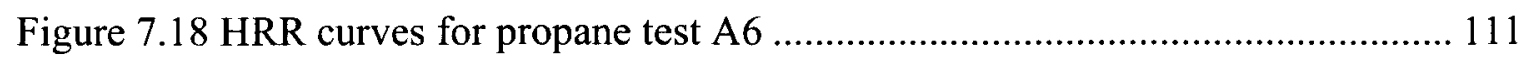

Figure 7.19 THR curves for propane test A6 ......................................................... 111

Figure 7.20 HRR curves for propane test A7 ...................................................... 112

Figure 7.21 THR curves for propane test A7 ......................................................... 112

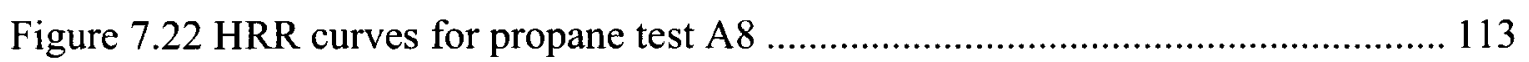

Figure 7.23 THR curves for propane test A8 …………………………………….. 113

Figure 7.24 HRR curves for propane test A9 …………………………………..... 114

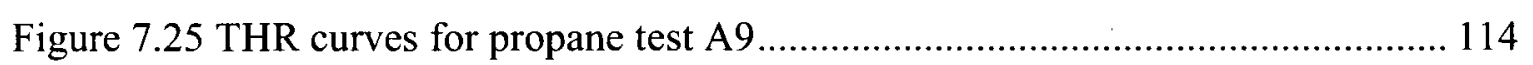

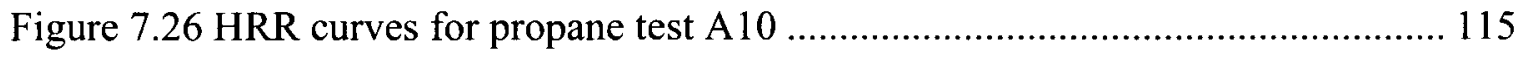

Figure 7.27 THR curves for propane test A10............................................................ 115

Figure 7.28 HRR curves for propane test A11 ………………………………….... 116

Figure 7.29 THR curves for propane test A11 _......................................................... 116

Figure 7.30 HRR curves for propane test A12 ……………………………………. 117

Figure 7.31 THR curves for propane test A12 ........................................................ 117

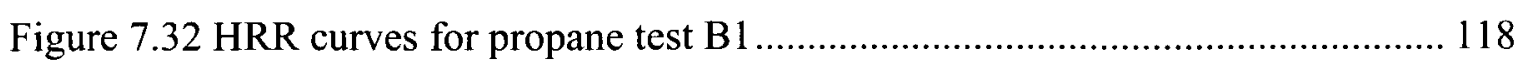

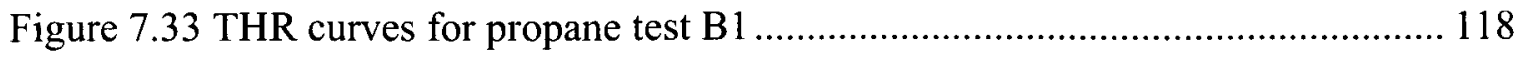

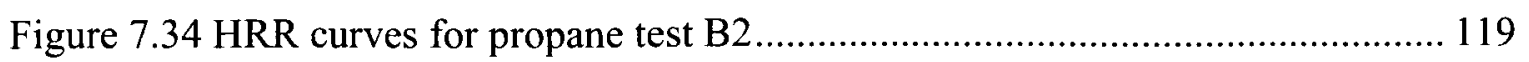


Figure 7.35 THR curves for propane test B2

Figure $7.36 \mathrm{HRR}$ comparison of heptane pool fires $\mathrm{H} 1$ and $\mathrm{H} 2$

Figure 7.37 THR comparison of heptane pool fires $\mathrm{H} 1$ and $\mathrm{H} 2$

Figure 7.38 HRR curve of heptane pool fire H3

Figure 7.39 THR curve of heptane pool fire H3

Figure 7.40 Instrumentation locations for FDS simulations 122

Figure 7.41 Comparison of $300 \mathrm{~s} 5 \mathrm{MW}$ fire simulations at different fan speeds 123

Figure 7.42 Comparison of $300 \mathrm{~s}$ simulations of different fire sizes at $50 \%$ fan speed 123

Figure 7.43 Comparison of HRR calculations in simulation of $600 \mathrm{~s} 5 \mathrm{MW}$ fires at $50 \%$ and $100 \%$ fan speeds. 124

Figure 7.44 Comparison of HRR calculations in simulation of different fire sizes at $50 \%$ fan speed 124

Figure 7.45 Comparison of HRR for simulated and real $600 \mathrm{~s} 5 \mathrm{MW}$ fires at $50 \%$ fan speed 125

Figure 7.46 Comparison of average temperature for simulated and real $600 \mathrm{~s} 5 \mathrm{MW}$ fires at $50 \%$ fan speed 125

Figure 7.47 Comparison of temperature increase for simulated and real $600 \mathrm{~s} 5 \mathrm{MW}$ fires at $50 \%$ fan speed 126

Figure 7.48 Comparison of time-averaged velocity for simulated and real $600 \mathrm{~s} 5 \mathrm{MW}$ fires at $50 \%$ fan speed.. 126

Figure 7.49 Comparison of mass flow rate for simulated and real $600 \mathrm{~s} 5 \mathrm{MW}$ fires at $50 \%$ fan speed 
Figure 7.50 Comparison of oxygen depletion for simulated and real $600 \mathrm{~s} 5 \mathrm{MW}$ fire at $50 \%$ fan speed.......... 127 


\section{List of Appendices}

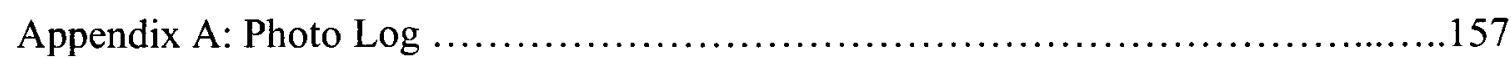

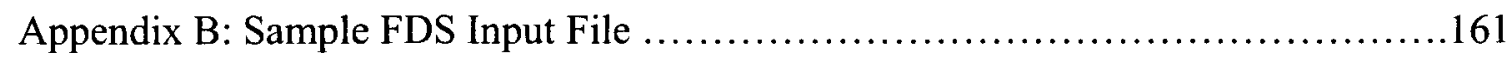

Appendix C: Views of Labview Front Panel and Block Diagram...................169

Appendix D: Operator Checklist....... 


\section{List of Symbols}
A $\quad-$ Area $\left(m^{2}\right)$
$A_{f} \quad-\quad$ Area of the pool fire $\left(\mathrm{m}^{2}\right)$
D - Diameter of pool (m)
- Heat release per unit mass of $\mathrm{O}_{2}$ consumed in the reaction $(\mathrm{MJ} / \mathrm{kg}$ of

$\mathrm{O}_{2}$ )

$\mathrm{E}_{\mathrm{CO}} \quad-\quad$ Net heat release per unit mass of $\mathrm{O}_{2}$ consumed for combustion of $\mathrm{CO}$ to $\mathrm{CO}_{2}\left(\mathrm{MJ} / \mathrm{kg}\right.$ of $\left.\mathrm{O}_{2}\right)$

$\mathrm{H}_{\mathrm{c}} \quad-\quad$ Net heat of combustion $(\mathrm{kJ} / \mathrm{g})$

$\mathrm{H}_{\mathrm{ch}} \quad-$ Actual (effective) heat of combustion $(\mathrm{kJ} / \mathrm{g}$ )

$\dot{m}_{e} \quad-$ Mass flow rate of exhaust gases $(\mathrm{kg} / \mathrm{s})$

$\dot{m}^{\prime \prime} \quad$ - Mass loss rate of fuel $\left(\mathrm{kg} / \mathrm{s} \cdot \mathrm{m}^{2}\right)$

$\dot{m}_{\infty}^{\prime \prime} \quad$ - Mass loss rate of very large diameter fire $\left(\mathrm{kg} / \mathrm{s} \cdot \mathrm{m}^{2}\right)$

$\dot{m} \quad-$ Mass flow rate $(\mathrm{kg} / \mathrm{s})$

$M_{\text {dry }} \quad-$ Molecular weight of dry air $(\mathrm{kg} / \mathrm{mol})$

$\mathrm{M}_{\mathrm{a}} \quad-$ Molecular weight of incoming air $(\mathrm{g} / \mathrm{mol})$

$\mathrm{M}_{\mathrm{e}} \quad$ - Molecular weight of exhaust gases $(\mathrm{g} / \mathrm{mol})$

$M_{\mathrm{H}_{2} \mathrm{O}} \quad-$ Molecular weight of $\mathrm{H}_{2} \mathrm{O}(\mathrm{g} / \mathrm{mol})$

$\mathrm{M}_{\mathrm{O} 2} \quad$ - Molecular weight of $\mathrm{O}_{2}(\mathrm{~g} / \mathrm{mol})$

$M_{\text {prop }} \quad$ - Molecular weight of propane ( $\left.\mathrm{g} / \mathrm{mol}\right)$

$\Delta p \quad$ - Differential pressure across the probe ( $\mathrm{Pa})$

$\mathrm{p}_{\mathrm{a}} \quad-\quad$ Air pressure $(\mathrm{Pa})$ 


\begin{tabular}{|c|c|}
\hline$p_{s}\left(T_{a}\right)$ & - Saturation pressure of water vapour at $\mathrm{T}_{\mathrm{a}}(\mathrm{Pa})$ \\
\hline$\dot{Q}$ & - Heat release rate $(\mathrm{kW})$ \\
\hline RH & - Relative humidity (\%) \\
\hline $\mathrm{T}_{\mathrm{e}}$ & - Temperature of exhaust gases $(\mathrm{K})$ \\
\hline $\mathrm{T}_{\mathrm{a}}$ & - Temperature of ambient air $(\mathrm{K})$ \\
\hline $\mathrm{V}$ & - Average velocity $(\mathrm{m} / \mathrm{s})$ \\
\hline$X_{\mathrm{H}_{2} \mathrm{O}}$ & - Mole fraction of $\mathrm{H}_{2} \mathrm{O}$ \\
\hline$X_{\mathrm{CO}_{2}}^{\mathrm{A}}$ & - Mole fraction of $\mathrm{CO}_{2}$ in exhaust gases \\
\hline$X_{C O}^{A}$ & - Mole fraction of $\mathrm{CO}$ in exhaust gases \\
\hline$X_{O_{2}}^{A}$ & - Mole fraction of $\mathrm{O}_{2}$ in exhaust gases \\
\hline$X_{O_{2}}^{A^{o}}$ & - Mole fraction of $\mathrm{O}_{2}$ in incoming air (ambient) \\
\hline$X_{\mathrm{CO}_{2}}^{\mathrm{A}^{o}}$ & - Mole fraction of $\mathrm{CO}_{2}$ in incoming air (ambient) \\
\hline$\alpha$ & - Expansion factor \\
\hline$\beta$ & - Mean beam length corrector \\
\hline $\mathrm{k}$ & - Flame extinction coefficient $\left(\mathrm{m}^{-1}\right)$ \\
\hline$\varphi$ & - Oxygen depletion factor \\
\hline$x$ & - Combustion efficiency \\
\hline$\rho_{a}$ & - Density of ambient air $\left(\mathrm{kg} / \mathrm{m}^{3}\right)$ \\
\hline
\end{tabular}




\section{Chapter 1: Introduction}

The Heat Release Rate (HRR) is the most important parameter in characterizing a fire. Methods for determining heat release rates using an energy balance approach can be effective and accurate for some fire tests, but can require large amounts of instrumentation and provide questionable results in large-scale tests, such as room fire experiments. Because of this, oxygen consumption calorimetry is the most common method for measuring HRR as it is accurate and economical. The concept of oxygen consumption calorimetry is based on the assumption that all materials being burned release the same amount of heat per unit of oxygen consumed in the reaction [1]. In order to calculate the heat released using this method, all combustion products must be collected and accurate measurements of gas temperature, flow rate and $\mathrm{O}_{2}$ concentration must be taken. For increased accuracy, measurements of $\mathrm{CO}_{2}, \mathrm{CO}$ and $\mathrm{H}_{2} \mathrm{O}$ concentrations can also be taken.

Carleton University has a large-scale fire research facility in Almonte, Ontario, Canada. In addition to a burn hall and an experimental tunnel, the facility has a 10-story experimental atrium which is the focus of this thesis. The atrium shares a set of three large exhaust fans and a fan chamber with the tunnel. HRR measurements can be taken for both the atrium and the tunnel using instrumentation in the fan chamber, through which all combustion products pass. This thesis discusses the equipment design and programming, and calibration procedures carried out to develop an accurate and reliable HRR measurement system for future large-scale fire experiments. 


\subsection{Objectives}

Carleton University's fire research laboratory contains a large experimental atrium with a mechanical exhaust system in which large-scale fire experiments can be carried out. The objective of this study is to design, install, program and calibrate the equipment and instrumentation required to measure the HRR of fires in the atrium. The facility will be used for research projects, hence an accurate, near real-time display of the HRR and other parameters is important. HRR measurements will allow for close monitoring of the progress of experiments and act as a safety system allowing the operator to feel comfortable that the facility can handle the fire or indicate if suppression is required. The measured data will also be written to a file for further analysis.

In order to calculate the HRR, instrumentation must be installed in a location through which all combustion products move. Sampling should be done in such a way that the measurements are representative of the average variable over the entire cross-section of the fan chamber. In addition, delay times in the system must be accounted for so that the calculations are being carried out with synchronized data and the results are better

understood. Fire Dynamics Simulator (FDS) simulations and manual velocity measurements were carried out to determine the best locations for the instrumentation in the fan chamber.

After the design and installation of the sensors and the Data Acquisition System (DAS), Labview 8.6 was programmed to collect data, perform various calculations, display results in near real-time and write raw data and calculated values to a file. 
Having computer software that performs all these functions will save researchers hours of analyzing data. However, custom calculations can still be carried out using the raw data.

Once the instrumentation was installed and Labview was programmed, fire tests using heptane pool fires and a propane burner were carried out in order to calibrate the system. A total of 14 propane and 3 heptane experiments were conducted to provide enough data to cover a large range of potential tests. FDS simulations were also conducted for calibration purposes.

\subsection{Organization of the Thesis}

Chapter 2 consists of a literature review of studies of interest regarding oxygen consumption calorimetry and applicable instrumentation. Chapter 3 provides a general description of the facility. Chapter 4 provides an overview of the methodology used in the development of the HRR measurement system. Chapter 5 describes the design of the instrumentation used for measurements in the fan chamber. Chapter 6 describes the Labview programming carried out to perform the HRR and other calculations and provide a real time display of various variables. Chapter 7 provides details on the experimental calibration process using heptane pool fires and propane fires. Chapter 8 provides results and discussion. Chapter 9 consists of the summary, conclusions and recommendations. 


\section{Chapter 2: Literature Review}

HRR is widely accepted as the most important parameter in defining the severity of fires. Oxygen consumption calorimetry has become the dominant technique for measuring HRR over the last couple of decades. Extensive research and development of the techniques used in oxygen consumption calorimetry has been carried out by various researchers throughout this period. This literature review summarizes some of the more notable advancements of this very useful scientific technique.

\subsection{Development of Oxygen Consumption Calorimetry}

Oxygen consumption calorimetry was originally conceptualized by Thornton as early as 1917 [2] but was not immediately accepted by the scientific community as a feasible method to calculate HRRs. Thornton's rule states that heat release is proportional to oxygen consumption for complete combustion of most organic liquid and gaseous compounds [2]. In 1980, Huggett showed that Thornton's rule is also applicable to organic solids. It was not until Huggett discussed the simplicity, versatility, and power of the use of oxygen consumption calorimetry and published his 1980 paper entitled Estimation of the Rate of Heat Release by Means of Oxygen Consumption [1] that it began to gain recognition as a useful tool. Huggett discusses possible sources of error, such as incomplete combustion resulting in an increased yield of $\mathrm{CO}$ and the charring of cellulosic fuels, but goes on to show that these sources of error are generally small and do not affect the rate of heat release in a significant way. He also notes that the accuracy of oxygen consumption calorimetry is directly related to the accuracy of measurements taken. So diligence must be practiced if the results are to be of value. 
An important finding by Huggett is that, despite large variations in composition, almost all organic molecules, which make up the bulk of fuels in most fires, have net heats of complete combustion per unit mass of oxygen consumed falling within the range of $13.1 \pm 5 \% \mathrm{~kJ} \mathrm{~g}^{-1} \mathrm{O}_{2}$. This means that good accuracy can be obtained if all combustion products are collected and analyzed, even from a fire with various fuels of unknown composition, such as a house fire. Tewarson suggests that for a larger array of materials, a range of $12.8 \pm 7 \%$ is appropriate, but also notes that the variation of $7 \%$ would be much lower if only "values for low molecular weight hydrocarbons with small amounts of $\mathrm{O}$, $\mathrm{N}$, and halogen were used in averaging" [3]. Propane fits this definition and has a value of $12.9 \mathrm{~kJ} \mathrm{~g}^{-1} \mathrm{O}_{2}$, falling well within the range suggested by Tewarson. For incomplete combustion, which occurs in most fires, measurements of $\mathrm{CO}, \mathrm{CO}_{2}$ and $\mathrm{O}_{2}$ can be taken to determine the combustion efficiency and a more accurate measure of the HRR.

In 1984, Parker published a paper entitled Calculations of the Heat Release Rate by Oxygen Consumption for Various Applications [4], providing a set of general formulae for determining the rate of heat release which can be easily manipulated for various applications. Different formulae are required for different tests, depending on scale, available instrumentation and whether the system is open or closed. These formulae further reinforce Huggett's claim that oxygen consumption calorimetry can be easily used and it is accurate. Parker's equations are based on measurements of $\mathrm{O}_{2}$ concentration in the exhaust duct, volumetric flow of air into the system and volumetric flow of gases into the exhaust duct [4]. Parker recognized that volumetric flow into the system is not 
always feasible to measure and he developed a relationship for these applications between the flow rate into and out of the system.

Early formulae and methods were best suited to small-scale experiments. In order to further the usefulness of the method, in 1991 Janssens provided a series of equations for determining heat release rates in full-scale fire tests using various gas analyzer combinations [5]. The distinction that makes it suitable for full-scale tests is the use of mass flow rates as opposed to volumetric flow rates. Step-by-step procedures are provided for four different cases of gas analysis settings: only $\mathrm{O}_{2}$ measured; $\mathrm{O}_{2}$ and $\mathrm{CO}_{2}$ measured; $\mathrm{O}_{2}, \mathrm{CO}$ and $\mathrm{CO}_{2}$ measured; and $\mathrm{O}_{2}, \mathrm{CO}, \mathrm{CO}_{2}$ and $\mathrm{H}_{2} \mathrm{O}$ measured. In general, the procedure includes calculating the mass flow rate through the duct, finding the molar fraction of $\mathrm{H}_{2} \mathrm{O}$ and the molecular weight of air entering the duct, calculating the oxygen depletion factor and finally, calculating the HRR.

Researchers continue to refine the oxygen consumption method and provide guidance for more situations. In 2000, Brohez et. al published a paper on the measurement of HRR in very sooty fires [6]. The method presented takes into account the energy required to produce soot and it is suggested that significant error can occur if this energy is ignored. The amount of soot produced during combustion is affected by factors such as the material being burned and ventilation conditions. Carbon monoxide and water vapour generation are also considered.

\subsection{Applications}

One of the first common uses for the technique was in bench-scale analysis of materials. In 1984 Babrauskas [7] developed the cone calorimeter, which uses a radiant 
heat source of up to $100 \mathrm{~kW} / \mathrm{m}^{2}$ to assess the ignition and subsequent HRR of a small sample of material that can be oriented either horizontally or vertically, depending on material behaviour and the desired results. The exhaust flow rate and oxygen depletion are measured in this device and the HRR is then calculated. This device is widely used for materials testing.

Since Babrauskas developed the cone calorimeter in the early 80 's, many more applications for oxygen consumption calorimetry have been developed. Applications such as furniture calorimeters [8], wall furnaces [9], [10], intermediate-scale calorimeters [11], larger-scale burn facilities [12] and single burning item (SBI) tests [13], have been developed and are in service. Some of these tests are now governed by various standards including the cone calorimeter [14], the room corner test [15], and the SBI test [16].

In 2001 , NIST completed the construction of a facility capable of accurately measuring the HRR of burning objects quantitatively up to 3 Megawatts [12]. A document was published in order to provide a description of the facility as well as the procedures used and guidance for the operation of the facility [12]. The facility employs a $6 \mathrm{~m} \times 6 \mathrm{~m}$ hood that collects the combustion gases and contains the instrumentation required to measure all necessary parameters. A computer program provides a nearly real-time display of heat release rates. NIST's document describes in detail the facility, its capabilities, the instrumentation, devices and other equipment used, the data acquisition process and the calibration of the facility. It also provides information on operation and safety. 
NIST also has a facility that employs three exhaust hoods for HRR calculations using oxygen consumption calorimetry [17]. In these hoods, thermocouples, bidirectional probes and gas samplers take measurements in the exhaust ducts for the necessary calculations. Flow straightening vanes straighten the flow just before the bidirectional probes in order to provide a reasonably uniform cross-sectional velocity [17]. The three hoods are known as the $50 \mathrm{~kW}, 500 \mathrm{~kW}$ and main hoods. Both the $50 \mathrm{~kW}$ and $500 \mathrm{~kW}$ have one bi-directional probe and one thermocouple each, in the center of the duct. The main hood has an array of 9 thermocouples and 9 bi-directional probes. In order to calibrate the hoods, at least three fire experiments were carried out for each hood using natural gas burners. With natural gas, component values are required daily from the local utility in order to accurately calculate the heat of combustion. Uncertainties in measurements and calculations were also considered. There are various sources of uncertainty in such a system, including gas flow conditions, instrument accuracy, flow coefficients, expansion factors, delay times, peak value dilution, and heats of combustion [17]. These uncertainties cannot be eliminated, but they can be reduced by calibration.

\subsection{Uncertainty and Error}

Accuracy and reliability of HRR measurements in fire experiments are extremely important for various reasons. Fire experiments are very expensive, so repeating an experiment is usually unacceptable. In addition, manufacturers require accurate data on their products in order to rate their fire safety, and when experiments are used to validate or calibrate quantitative models, the accuracy of measurements must be known [18]. 
Some studies have been conducted on uncertainties in HRR measurements under different conditions and for different types of experiments.

In 1986, Yeager published a paper after an analysis of uncertainties in room fires using the oxygen consumption method. He found that at different flow rates and different oxygen consumption levels, the level of uncertainty and the governing factor of the uncertainty would differ. Uncertainty can be dominated by either instrument uncertainty or inherent uncertainty in the oxygen consumption method. Delay times for equipment can be determined experimentally by suddenly increasing or lowering the fuel flow rate (methane in their case) and seeing how long it takes for the instruments to respond [19]. He concluded that, as long as all uncertainties are studied and understood, good agreement between known and measured HRR can be achieved.

Lyon and Abramowitz found, in 1995, that significant error can occur in HRR measurements when the delay time of the system is of the order of magnitude of the time of the heat event [20]. That is, if the delay time is long or the HRR changes quickly, there will be a "smearing" of the results. The longer and more constant the HRR is, the more accurate the measurements will be.

Further guidance for uncertainties in HRR measurements, specifically for room fire tests and SBI tests, is available in Axelsson et. al's 2001 document Uncertainties in measuring heat and smoke release rates in the Room/Corner Test and the SBI [21].

Brohez further analyzed his 2000 findings on very sooty fires in his 2005 paper entitled Uncertainty analysis of heat release rate measurement from oxygen consumption calorimetry [22]. Until this study, uncertainties had only been studied for basic oxygen 
consumption calorimetry tests, taking into account only the $\mathrm{O}_{2}$ concentration measurements. Brohez considered uncertainties from soot and $\mathrm{CO}$ generation. He found that "the uncertainty of the energy correction associated with the $\mathrm{CO}$ and soot generations are very high when the average value of the calorimetric coefficient $E$ is used" [22].

Brohez points out that, in more open fire tests where oxygen depletion is relatively low, the HRR uncertainty is most likely dominated by uncertainty in the oxygen measurement. A method to check the importance of this parameter is introduced. In other situations, the assumed heat of combustion, the assumed combustion expansion factor, or the mass flow rate of the combustion gases could be the most important factor in determining the uncertainty of HRR measurements [22].

In Bryant and Mulholland's 2008 paper entitled $A$ guide to characterizing heat release rate measurement uncertainty for full-scale fire tests, reasons for the significant uncertainty in oxygen consumption calorimetry that arise from oxygen concentration and flow rates are demonstrated [18]. Other sources of error including operator error and environmental influences were also discussed. Bryant looked at various uncertainty analyses for experiments varying in fire size, configuration, objectives, fuel etc. He also built on these other papers by performing experiments from $0.05 \mathrm{MW}$ to $2.7 \mathrm{MW}$ using gas burners at NIST's full-scale HRR facility. Bryant notes that "even with the best precautions, it is possible that instruments may suffer significant drift during long test periods. Unfortunately, the instrument drift does not become apparent until the test is completed" [18]. Background drift increased throughout Bryant's tests. Measurement drift should be accounted for in HRR measurements, which can be done by assuming a 
linear increase in drift throughout the test. Since HRR is a function of so many variables with different types of errors, it can be difficult to quantify the uncertainty. Adding to this difficulty is the fact that in facilities where a gas calibration burner is used, the uncertainty is also related to the input accuracy of the burners, which may be affected by factors such as incomplete combustion [18].

In order to provide the most accurate HRR measurements possible, it is important that the measurements of temperature, gas concentrations and mass flow rate be synchronized and represent the same gas sample for calculation. The movement of gases to the sampling point and instrumentation such as gas samplers has delays that must be known in order to synchronize measurements. Messerschmidt and Van Hees published a paper in 2000 providing guidance for time-shifting measurements based on a round-robin of SBI tests performed in 1997 [23]. They note that "The size of the delay times is not so critical for the calculation of HRR (as long as no extreme values are used), what is important is that the oxygen and carbon dioxide data are shifted so that they are synchronized" [23]. It was also found that differences in response time of different laboratories can have a large impact on the results of experiments. A response time of the gas analyzers between 9 and $12 \mathrm{~s}$ is suggested.

Some studies have been conducted attempting to determine estimates of the theoretical uncertainties of different oxygen consumption calorimeters, including cone calorimeters, room fire tests, single burning item tests and a $10 \mathrm{MW}$ calorimeter [24]. The theoretical uncertainties varied from $2.5 \%-7 \%$. However, results from round robins of tests done on the same materials at different laboratories using various test methods 
show much more uncertainty than this in the repeatability standard deviations. These poor results may have been due to the choice of materials or the laboratories not following the standards. Results of small-scale tests using the cone calorimeter generally showed the most precision while larger scale tests had inferior results [24].

\subsection{Velocity Measurements}

Velocity measurements are very important for HRR measurement systems as the flow rate through the sampling location directly affects the HRR calculation. In most fluid flow situations, the flow is turbulent. Whether a flow is laminar, transitional, or turbulent can be determined by the Reynold's Number (Re), which is a "dimensionless relative ratio of inertial forces to viscous forces" [25]. Re can be determined if the fluid and duct properties and the fluid velocity are known. Generally, a Re of less than about 2000 indicates laminar flow and Re greater than 10,000 indicates turbulent flow, with a transition area in between. The turbulence of a system has implications for velocity measurements. The velocity profile of a laminar flow is more pointed and a turbulent flow tends to be flatter [25]. The boundary layer, or the area near the duct wall where wall friction affects the flow, should also be considered in such systems [25].

In 1976, McCaffrey and Heskestad published a description and the necessary equation for a device to measure gas flow velocities in a fire environment [26]. Such a device was needed because the devices available at the time to measure velocities, such as pitot tubes, were sensitive to high temperatures and could become clogged in sooty environments. The bi-directional probes they developed are both insensitive to small changes in angle and have the ability to measure velocity in two directions. They also 
have an inlet diameter large enough to lower the risk of being clogged by soot or other debris. These probes work on the principle that the difference between the dynamic pressure on the wind side of an object and the static pressure at the downstream side can be converted into a velocity based on fluid density and Re. As such, the probes are attached to two hoses which are then connected to a pressure transducer where the pressure differences are converted into an electric current which runs into the data acquisition system.

There are some important considerations when using bi-directional probes to measure velocity [27]. Angular changes of the probes, the range of air speeds (and in effect $\mathrm{Re}$ ), as well as other factors can affect the error in measurements. Sette found that changes in the angle of the probe or the angle at which the gas impinges on the probe will cause an overestimation of velocity. When Re is very low (less than approximately 200), the 'Barker Effect' causes large errors. The Barker Effect is a phenomenon where the viscosity of a fluid causes an additional apparent pressure that changes the measured value and can cause error [28]. In the wind tunnel Sette used, this corresponded to velocities below $0.8 \mathrm{~m} / \mathrm{s}$. Sette also determined the probe factor, $\mathrm{k}_{\mathrm{p}}$, for much higher Re's than McCaffrey and Heskestad so the values could be better known and used for larger scale fire tests.

The placement of the flow measuring devices is also an important issue that must be looked at in any system where accuracy is important. The ASHRAE Handbook [29] suggests that the log-Tchebycheff $(\log -\mathrm{T})$ rule be used with rectangular ducts with height and width greater than $45 \mathrm{~cm}$ (18 inches). The log-T rule is designed to minimize the 
error of the average velocity measurement over the cross-section of the duct. A minimum of 25 probes are required to use this rule in a rectangular duct. It is also suggested that straightening vanes be used in order to straighten the flow before the measurement area. If negative velocity measurements are encountered, a value of zero should be used.

\subsection{Pool Fires}

One type of fire that is extremely important for fire safety in many different settings is the liquid pool fire. Babrauskas provides guidance for estimating burning rates and HRRs of pool fires with a diameter greater than $0.2 \mathrm{~m}$ in his 1983 paper Estimating Large Pool Fire Burning Rates [30]. The values provided by Babrauskas are useful for "steady-state fires, in a wind-free environment and in a [container] without excessive lip height" [30]. Therefore, in order to use the correlations presented, care must be taken to decrease the effects due to these factors, which can, in certain situations, be considerable.

Babrauskas notes that burning does not reach steady-state immediately for various reasons, such as the variability in heat losses due to several mechanisms. Ten minutes or more may be required before steady burning occurs [30].

A small-scale study of the effects of transverse air flow on the burning rates of methanol pool fires was carried out in 2006 [31]. This study used square and rectangular pools and studied the effects of different pan sizes and orientations and different air velocities. The results of this study showed that burning rates at this size scale either increase or are unaffected by transverse air flow. The smallest pool used in the experiment increased its burning rate by approximately 2.5 times when subjected to an air 
velocity of $5.5 \mathrm{~m} / \mathrm{s}$. However, the largest pool, which was square with $30 \mathrm{~cm}$ side lengths, was unaffected in terms of the burning rate. The study also found that orientation of the pool with respect to the wind direction is a very important parameter affecting the burning rate [31].

For larger pool fires, different phenomena occur. For example, flames become more turbulent and radiation takes over as the dominant form of heat transfer. Because of these phenomena, small scale results cannot be extrapolated into larger scale fires [32]. A study of large-scale gasoline and diesel oil pool fires ranging from pool diameters of $1.5 \mathrm{~m}$ to $4 \mathrm{~m}$ was carried out by Chatris et al. in 2001 [32]. This study showed that, similar to other fires such as building fires, pool fires have three distinct stages. Early on, the flames spread across the surface of the fuel and then the burning intensity increases and the fire develops, similar to a growth phase. After this there is a period of steady burning when the fire is fully developed. Finally, when the fuel is almost completely consumed, there is a decay phase before the fire finally extinguishes. This study also showed that wind speeds up to $2 \mathrm{~m} / \mathrm{s}$ had a negligible effect on burning rates for these pool sizes. One case was observed where a wind of higher than $2 \mathrm{~m} / \mathrm{s}$ did increase the burning rate of the fuel [32].

Wind effects on pool fires are still not fully understood. While higher winds increase the entrainment of oxygen into the flames, they also push the flames over, decreasing the amount of radiant feedback on the liquid fuel [33]. Experiments show that in small-scale experiments, an increase in wind speed can decrease the fuel regression 
rate while the opposite may occur in large-scale experiments. Further research is required to fully understand these phenomena [33].

\subsection{Smoke Movement in Atria}

Considerable research has also been completed regarding smoke accumulation and movement in large atria. A model was developed for smoke flow and filling of an atrium by Morgan in 1987 [34]. Chow et al. looked at smoke filling due to liquid pool fires in 2001 [35]. Gutierrez-Montes et al. used numerical modeling and experiments to look at smoke movement in an atrium in 2008 [36]. FDS simulations were used by Qin et al. in 2008 for smoke filling in an atrium [37]. An interesting finding by Qin is that the descending process of the hot smoke layer is fastest when the fire is central in the atrium, slower when against the wall and slowest when in the corner. The purpose of this report is to investigate HRR in atria, and is not as concerned with smoke movement. However, it is understood that these are closely related subjects and it is important to understand that research regarding both has been completed and more is underway. 


\section{Chapter 3: Facility Description}

Carleton University's experimental atrium measures approximately $20 \mathrm{~m}$ long by $20 \mathrm{~m}$ wide by $25 \mathrm{~m}$ high. Fresh air is available by means of four large rolling doors approximately $3.6 \mathrm{~m} \mathrm{x} 4.2 \mathrm{~m}$ totaling about $60 \mathrm{~m}^{2}$. There is also a smaller rolling door and a large door connecting the atrium to the tunnel if even more ventilation is required. See Figure 3.1 to Figure 3.3 for views of the facility. An exterior view of the facility is provided in Photo 1 of Appendix A. An interior view of the atrium is provided in Photo

2. The structure of the atrium is constructed of steel columns and bracing. The floor and one wall are constructed of concrete.

The mechanical exhaust system consists of three fans capable of moving approximately $44.8 \mathrm{~m}^{3} / \mathrm{s}(95,000 \mathrm{cfm})$ of gas each, for a total of approximately 134.5 $\mathrm{m}^{3} / \mathrm{s}(285,000 \mathrm{cfm})$. The fan speeds can be controlled manually from a control room. All three fans are normally running during experiments and are set to $25,50,75$ or $100 \%$ speed depending on the purpose of the experiment, the size of the fire, and the preference of the researcher.

Combustion gases move up through six square openings with $1.85 \mathrm{~m}$ sides (total area approximately $20.5 \mathrm{~m}^{2}$ ) in the $25 \mathrm{~m}$ high ceiling of the atrium. From this chamber, the gases are pulled downward through an approximately $17 \mathrm{~m}$ long duct measuring approximately $7 \mathrm{~m}$ by $3 \mathrm{~m}$. The gases leave the duct and enter a larger room where they are channeled into the upper-middle fan chamber, measuring approximately $11 \mathrm{~m}$ long by $5.56 \mathrm{~m}$ wide by $2.94 \mathrm{~m}$ high (cross-sectional area approximately $16.3 \mathrm{~m}^{2}$ ). It is at the end of this fan chamber that the instrumentation is located to measure the HRR. A view 
of the fan chamber is provided in Photo 3 of Appendix A. The gases are then exhausted to the outside.

The measurement section is located at the downstream end of the fan chamber as shown in Figure 3.2 and Figure 3.3. Through the work carried out for this thesis, six thermocouples, four bi-directional probes connected to pressure transducers and a gassampling grid were installed in this location to take measurements of the exhaust gases. This data is collected by a DAS and fed into a computer where Labview 8.6 has been programmed to calculate and display the HRR and various other results in near real-time. In addition, Labview writes calculated and raw data to a file for further analysis. A schematic of the data acquisition is provided in Figure 3.4. Labview is described further in Chapter 6.

The fan chamber is actually split into six sections (three upper and three lower sections). The three lower sections are for use only with the tunnel and are currently closed. The two outside upper sections are also closed, leaving only the upper-middle chamber open. The arrangement will be left like this for the foreseeable future, as for most tests this is a large enough area.

The experimental tunnel facility is located directly beneath the fan chamber and shares the fan chamber with the atrium. Large manually operated vents can control the flow so that gas is either being collected from the atrium or the tunnel. Since the fan chamber is shared, and the instrumentation is fixed in place, consideration had to be given to both facilities when considering location and quantity of instrumentation for oxygen consumption calorimetry data. 


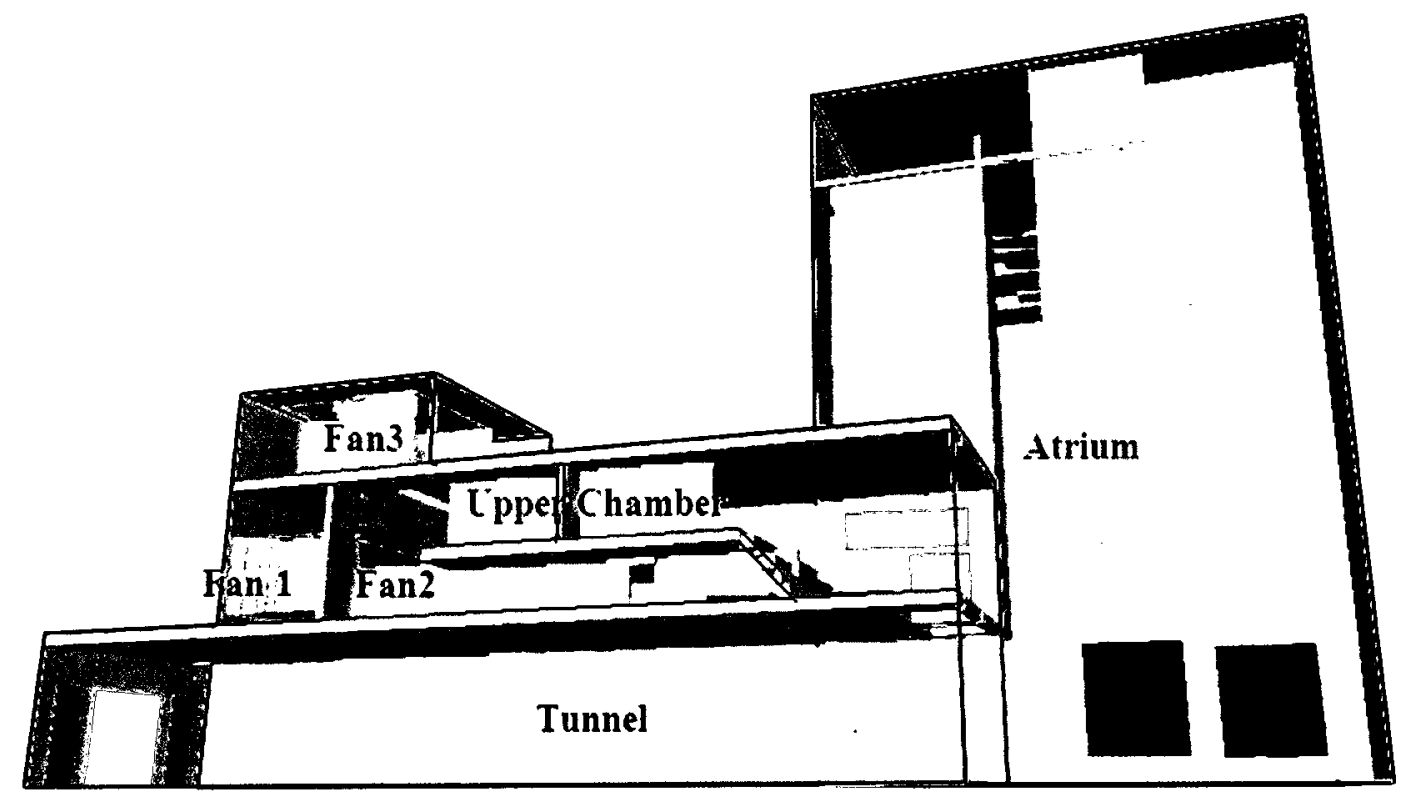

Figure 3.1 Smokeview view of experimental tunnel, fan chamber and atrium

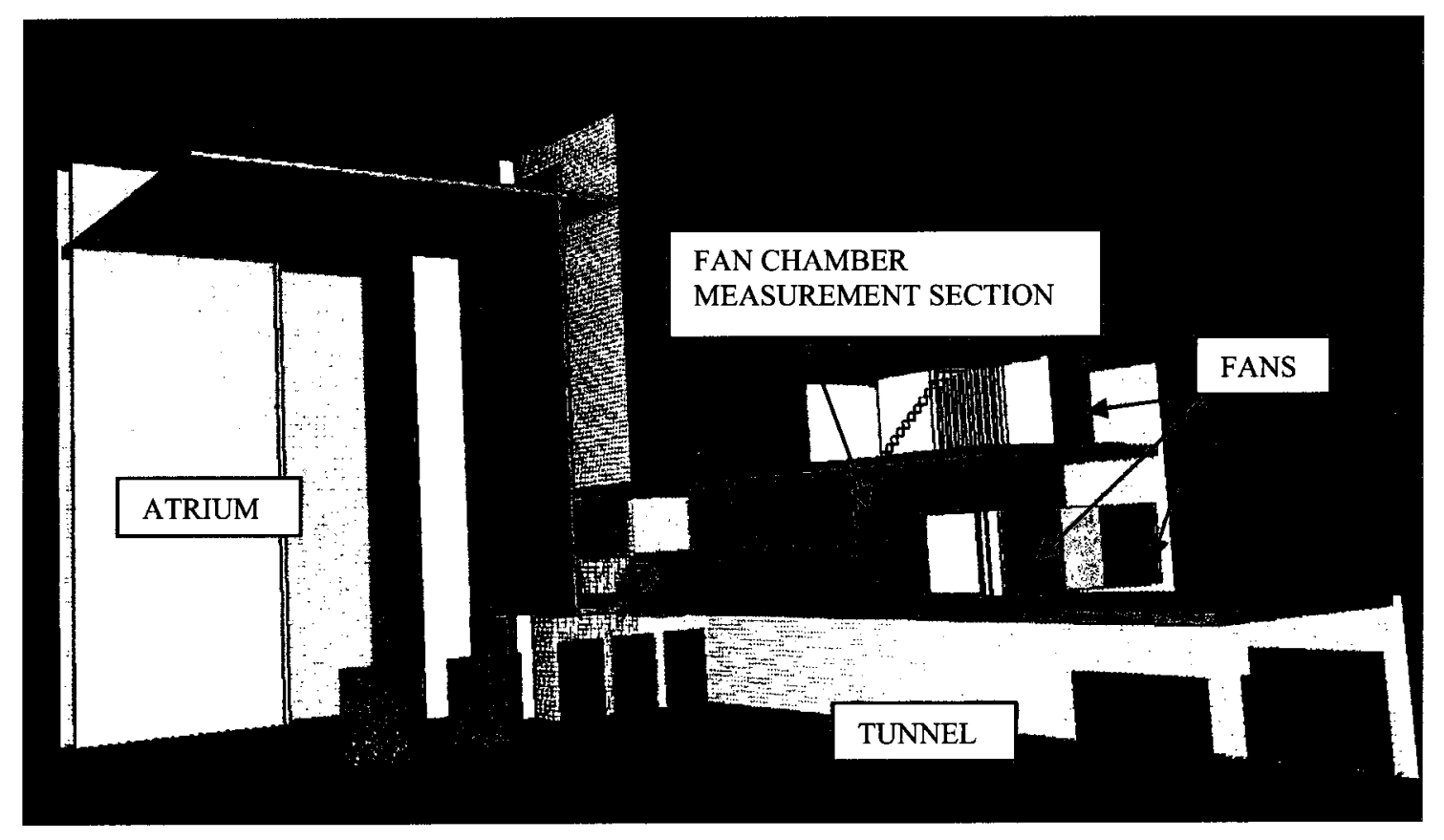

Figure 3.2 Pyrosim view of experimental atrium, tunnel and fan chamber 


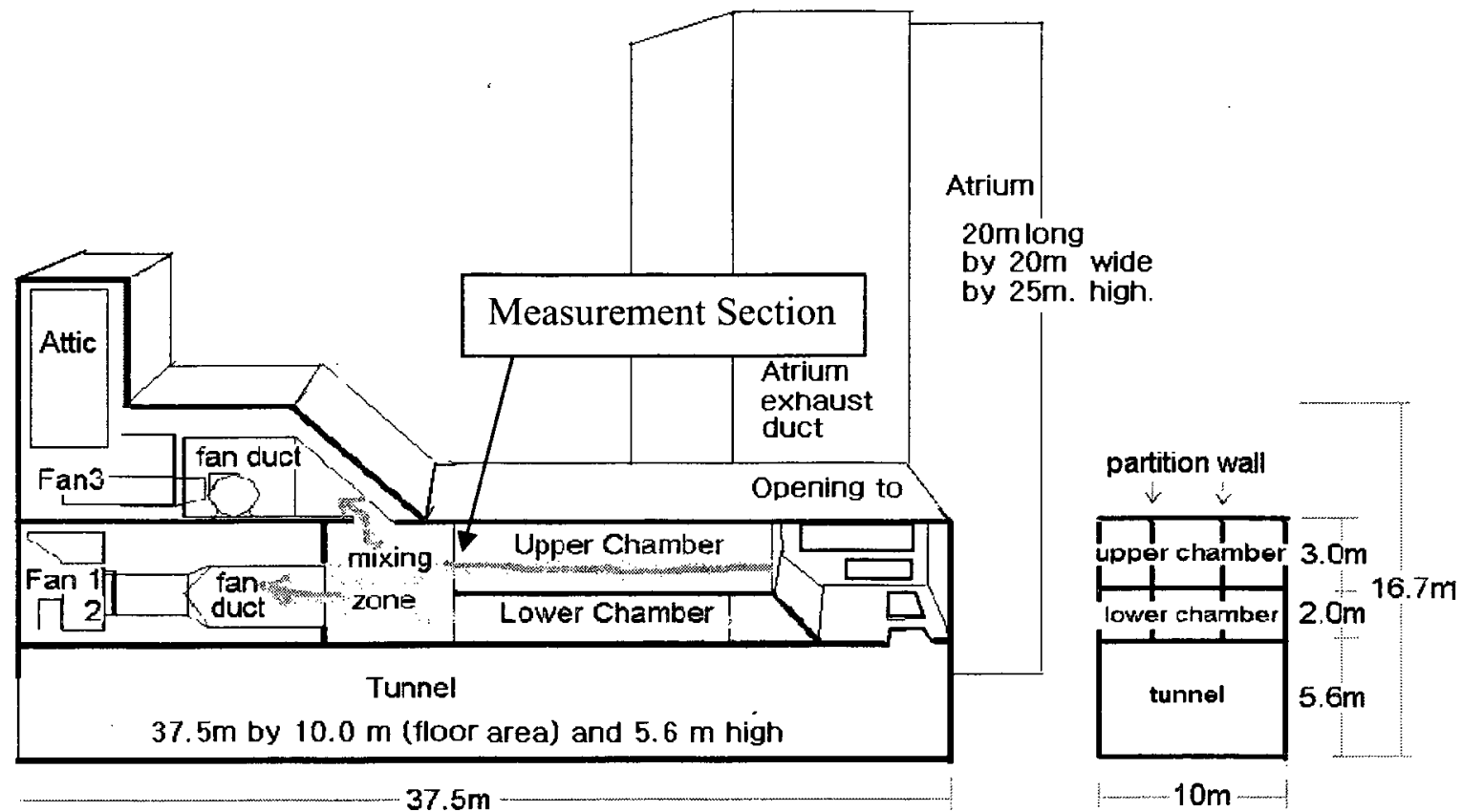

Figure 3.3 Tunnel and fan chamber cross-sections 


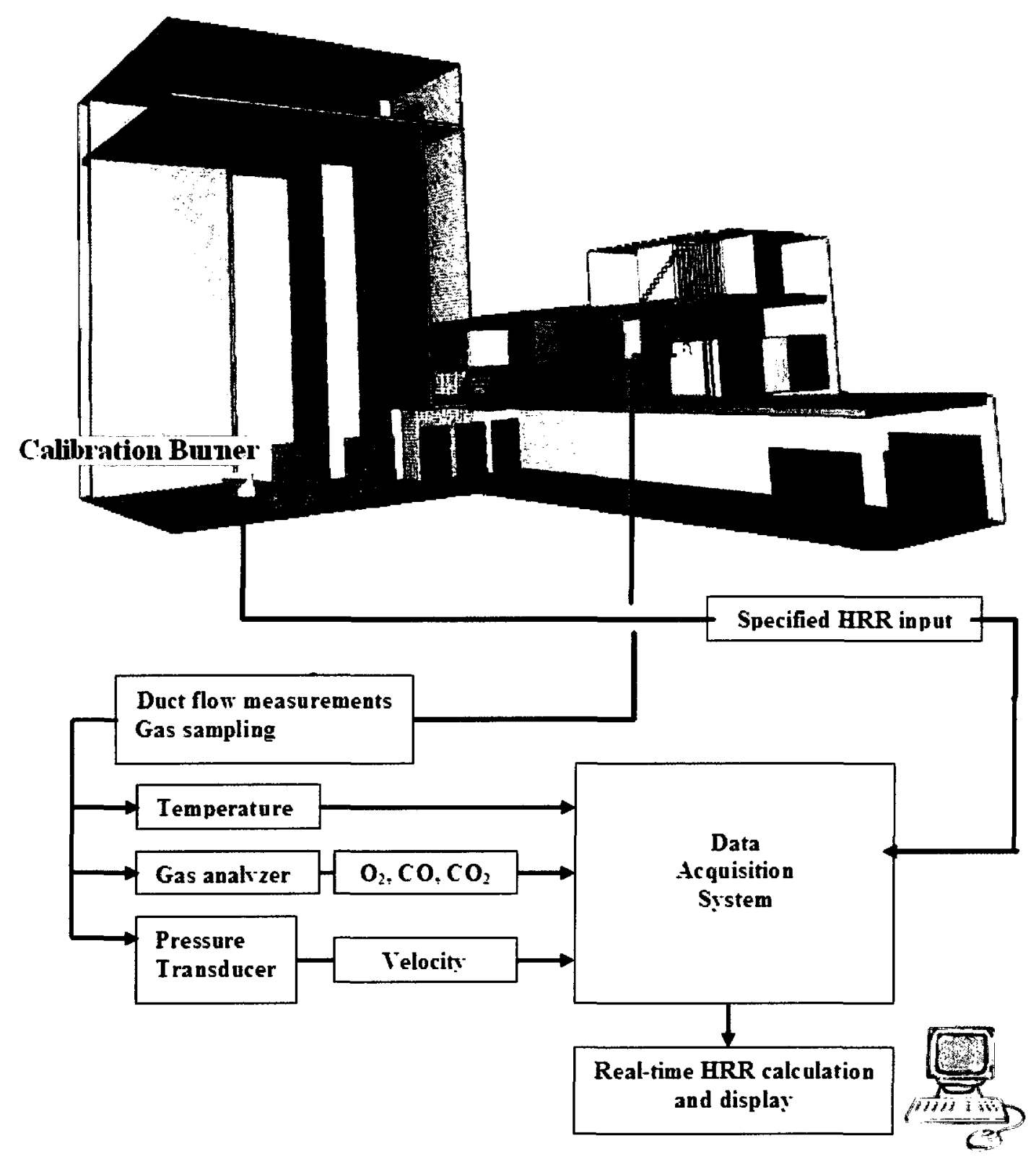

Figure 3.4 Data acquisition schematic 


\section{Chapter 4: Methodology}

\subsection{Oxygen Consumption Calorimetry}

The concept of oxygen consumption calorimetry is based on the assumption that all materials being burned release the same amount of heat per unit of oxygen consumed in the reaction [1]. In order to calculate the heat released using this method, all combustion products must be collected and accurate measurements of gas temperature, flow rate and $\mathrm{O}_{2}$ concentration must be taken. For increased accuracy, measurements of $\mathrm{CO}_{2}, \mathrm{CO}$ and $\mathrm{H}_{2} \mathrm{O}$ can also be taken. Measurements of all variables must be representative of the average over the cross section of the duct through which all combustion gases flow. This ensures that all the consumed oxygen is accounted for.

Various forms of the oxygen consumption calorimetry formulae have been developed for various applications. In some systems different parameters are more important, uncertainties and tolerances vary and different equipment is available. Scales of the test facility or apparatus, material being tested and the purpose of experiments also

vary. However, all systems are similar in that all combustion gases must be collected and measurements taken of flow rate and gas concentrations in one way or another.

In the case of this facility, volumetric concentrations of $\mathrm{O}_{2}, \mathrm{CO}_{2}$ and $\mathrm{CO}$ are measured and $\mathrm{H}_{2} \mathrm{O}$ concentration is not. This corresponds to Case 3 of Janssens' guidance on measuring HRR by oxygen consumption calorimetry [5].

First, gas density must be calculated using: 


$$
\rho_{e}=\frac{\rho_{a} T_{a}}{T_{e}}
$$

Where $\rho_{a}=1.203 \mathrm{~kg} / \mathrm{m}^{3}$ at a temperature of $\mathrm{T}_{\mathrm{a}}=293 \mathrm{~K}, \rho_{e}=$ density of exhaust gas $\left(\mathrm{kg} / \mathrm{m}^{3}\right)$ and $\mathrm{T}_{\mathrm{e}}=$ temperature of exhaust gas $(\mathrm{K})$.

Next, air velocity through the duct must be calculated. Bi-directional probes work on the principle that the difference between the dynamic pressure on the wind side of an object and the static pressure at the downstream side can be converted into a velocity based on fluid density and Reynolds number. McCaffrey and Heskestad developed these probes and the following formula for their use [26]:

$$
\begin{aligned}
\frac{\left(\frac{2 \Delta p}{\rho}\right)^{1 / 2}}{V}=1.533-1.366 \times 10^{-3} R e+1.688 \times 10^{-6} R e^{2} \\
-9.706 \times 10^{-10} R e^{3}+2.555 \times 10^{-14} R e^{4} \\
-2.484 \times 10^{-17} R e^{5}
\end{aligned}
$$

Where $\Delta p=$ pressure difference $(\mathrm{Pa}), \rho=$ gas density $\left(\mathrm{kg} / \mathrm{m}^{3}\right), \mathrm{V}=$ gas velocity $(\mathrm{m} / \mathrm{s})$ and $\operatorname{Re}=$ Reynolds number

The right side of this equation is a function of $\mathrm{Re}$ that should be used for $40<\operatorname{Re}<3800$. However, for more turbulent systems, this reaches an asymptotic value of approximately 1.08. For the purposes of these experiments with high values of Re, a value of 1.1 will be assumed. The following equation is then used to calculate the velocity. 


$$
V=0.91 \sqrt{\frac{2 \Delta p}{\rho}}
$$

Generally, because the probes can only provide point measurements, multiple probes are used and their measurements averaged in order to provide a representative value of the entire cross-section. Care must be taken to understand the velocity profile in the sampling location of the duct in a given system to ensure that the velocity does represent that average. This is especially important as the oxygen consumption calorimetry method is very sensitive to the flow rate of the gases.

The next step is to calculate the mass flow rate of the gas through the duct. This can be done using the following formula:

$$
\dot{m}=A V \rho
$$

Where $\dot{m}=$ mass flow rate $(\mathrm{kg} / \mathrm{s}), \mathrm{V}=$ average velocity $(\mathrm{m} / \mathrm{s})$ and $\mathrm{A}=$ area of fanchamber $\left(16.3 \mathrm{~m}^{2}\right)$.

The molar fraction of $\mathrm{H}_{2} \mathrm{O}$ in the incoming air is required in order to determine the molecular weight of the incoming air. It is calculated using the following formula:

$$
X_{H_{2} O}^{o}=\frac{R H \times p_{s}\left(T_{a}\right)}{p_{a}}
$$

Where $X_{\mathrm{H}_{2} \mathrm{O}}^{o}=$ molar fraction of $\mathrm{H}_{2} \mathrm{O}$ in the incoming air, $\mathrm{RH}=$ Relative humidity (\%), $p_{s}\left(T_{a}\right)=$ saturation pressure of water vapour at $\mathrm{T}_{\mathrm{a}}(\mathrm{Pa}), \mathrm{T}_{\mathrm{a}}=$ air temperature $(\mathrm{K})$ and $\mathrm{p}_{\mathrm{a}}=$ air pressure $(\mathrm{Pa})$

The sensitivity of HRR calculations to $\mathrm{RH}, p_{s}\left(T_{a}\right)$ and $\mathrm{p}_{\mathrm{a}}$, and by extension, $X_{\mathrm{H}_{2} O}^{o}$, is very small. As such, for the purposes of this facility, $\mathrm{RH}$ is assumed to be $50 \%, p_{s}\left(T_{a}\right)$ 
is assumed to be $2.5 \mathrm{kPa}$ and $\mathrm{p}_{\mathrm{a}}$ is assumed to be $101.5 \mathrm{kPa}$, which yields a $X_{\mathrm{H}_{2} \mathrm{O}}^{o}$ of 0.0123. These are reasonable values that can be expected during normal operation of the facility.

The next step is to calculate the molecular weight of incoming air using the following formula developed by Janssens [5]:

$$
M_{a}=M_{d r y}\left(1-X_{H_{2} O}^{o}\right)+M_{H_{2} O} X_{H_{2} O}^{o}
$$

Where $\mathrm{M}_{\mathrm{a}}=$ molecular weight of incoming air $(\mathrm{g} / \mathrm{mol}), M_{d r y}=$ molecular weight of dry air $(28.95 \mathrm{~g} / \mathrm{mol})$ and $M_{\mathrm{H}_{2} \mathrm{O}}=$ molecular weight of $\mathrm{H}_{2} \mathrm{O}(18 \mathrm{~g} / \mathrm{mol})$.

Next, the oxygen depletion factor must be calculated using the following formula:

$$
\varphi=\frac{X_{O_{2}}^{A^{o}}\left(1-X_{C O_{2}}^{A}-X_{C O}^{A}\right)-X_{O_{2}}^{A}\left(1-X_{C O_{2}}^{A^{o}}\right)}{\left(1-X_{O_{2}}^{A}-X_{C O_{2}}^{A}-X_{C O}^{A}\right) X_{O_{2}}^{A^{o}}}
$$

Where $\varphi=$ oxygen depletion factor, $X_{\mathrm{CO}_{2}}^{A}=$ measured mole fraction of $\mathrm{CO}_{2}$ in exhaust gases, $X_{C O}^{A}=$ measured mole fraction of $\mathrm{CO}$ in exhaust gases, $X_{O_{2}}^{A}=$ measured mole fraction of $\mathrm{O}_{2}$ in exhaust gases, $X_{O_{2}}^{A^{o}}=$ measured mole fraction of $\mathrm{O}_{2}$ in incoming air (ambient), $\mathrm{X}_{\mathrm{CO}_{2}}^{\mathrm{o}_{2}}=$ measured mole fraction of $\mathrm{CO}_{2}$ in incoming air (ambient).

The oxygen depletion factor represents the fraction of incoming air that is depleted of oxygen [12].

Now the HRR can be calculated using the following formula:

$$
\dot{Q}=\left[E \varphi-\left(E_{C O}-E\right) \frac{(1-\varphi) X_{C O}^{A}}{2 X_{O_{2}}^{A}}\right] \frac{\dot{m}_{e}}{1+\varphi(\alpha-1)} \frac{M_{O_{2}}}{M_{a}}\left(1-X_{H_{2} o}^{o}\right) X_{O_{2}}^{A^{o}}
$$


Where $\dot{Q}=$ HRR $(\mathrm{kW}), \mathrm{E}=$ heat release per unit mass of $\mathrm{O}_{2}$ consumed in the reaction $\left(\mathrm{MJ} / \mathrm{kg}\right.$ of $\left.\mathrm{O}_{2}\right), \mathrm{E}_{\mathrm{CO}}=$ net heat release per unit mass of $\mathrm{O}_{2}$ consumed for combustion of $\mathrm{CO}$ to $\mathrm{CO}_{2}\left(17.6 \mathrm{MJ} / \mathrm{kg}\right.$ of $\left.\mathrm{O}_{2}\right), \alpha=$ expansion factor.

The expansion factor, $\alpha$, can be determined only if the composition of the fuel is known. For the HRR calibration experiments presented in this thesis using propane, a value of 1.084 is used [4]. For the heptane pool fire experiments, a value of 1.105 is used, which is recommended as a reasonable average for most fires [5].

Similarly, for $\mathrm{E}$, a value of $12.9 \mathrm{MJ} / \mathrm{kg}$ of $\mathrm{O}_{2}$ is used for the propane experiments as it is exact for propane. However, a value of $13.1 \mathrm{MJ} / \mathrm{kg}$ is recommended [1] as an average and is used for the heptane tests. This value is recommended for future fire tests where the exact composition of the combustibles is not known.

\subsection{Pool Fires}

In addition to the propane tests, three pool fires using heptane were carried out for further calibration of the system. The HRR of a pool fire is governed by the heat of combustion and other properties of the fuel and the area of the pool. The duration of burning is dictated by the depth of the fuel. Babrauskas provided guidance for estimating the HRR of large pool fires with a diameter greater than $0.2 \mathrm{~m}$ [30]. The values represent the steady-state burning of the liquid. The first step is to determine the mass loss rate of the fuel using the following formula:

$$
\dot{m}^{\prime \prime}=\dot{m}_{\infty}^{\prime \prime}\left(1-e^{-k \beta D}\right)
$$


Where $\dot{m}^{\prime \prime}=$ mass loss rate of fuel $\left(\mathrm{kg} / \mathrm{s} \cdot \mathrm{m}^{2}\right), \dot{m}_{\infty}^{\prime \prime}=$ mass loss rate of a very large diameter fire $\left(\mathrm{kg} / \mathrm{s} \cdot \mathrm{m}^{2}\right), \mathrm{k}=$ flame extinction coefficient $\left(\mathrm{m}^{-1}\right), \beta=$ mean beam length corrector (dimensionless) and $\mathrm{D}=$ diameter of pool $(\mathrm{m})$.

As it is difficult to differentiate between $\mathrm{k}$ and $\beta$, they are usually taken together and most literature provide these values in the form $k \beta$. Therefore, for this calculation one must look up this value and $\dot{m}_{\infty}^{\prime \prime}$ for the particular fuel and know the diameter of the pool. For heptane, $\dot{m}_{\infty}^{\prime \prime}=0.101 \mathrm{~kg} / \mathrm{s} \cdot \mathrm{m}^{2}$ and $k \beta=1.1 \mathrm{~m}^{-1}[30]$.

The HRR of the fire can then be calculated using:

$$
\dot{Q}=H_{c h} \dot{m}^{\prime \prime} A_{f}
$$

Where $\dot{Q}=\mathrm{HRR}(\mathrm{kW}), \mathrm{H}_{\mathrm{ch}}=$ the actual (effective) heat of combustion of the fuel $(\mathrm{kJ} / \mathrm{g})$ and $A_{t}=$ the area of the fire $\left(\mathrm{m}^{2}\right)$.

The net heat of combustion, $\mathrm{H}_{\mathrm{c}}$, for heptane is $44.6 \mathrm{~kJ} / \mathrm{g}$. However, the effective heat of combustion, $\mathrm{H}_{\mathrm{ch}}$, will never reach this level due to imperfect combustion efficiency. For heptane, $\mathrm{H}_{\mathrm{ch}}$ is $41.2 \mathrm{~kJ} / \mathrm{g}$ [38] with combustion efficiency defined as:

$$
x=\frac{H_{c h}}{H_{c}}
$$

Where $x=$ combustion efficiency. This becomes 0.924 for heptane.

\subsection{Signal Conversions}

All of the signals from the sensors except the thermocouples are received as electrical currents that linearly represent the value of the variable. These values must be converted in order to be of use. Labview 8.6 has been programmed to convert these 
electrical current values back into their respective variable values using the equations presented in this section.

The pressure transducers convert the differential pressure from the bi-directional probes into a current. There are four of them, all Omega PX-274s, factory calibrated for measurements from 0-254 Pa (0-1" Water Column). They output a current signal of 4-20 $\mathrm{mA}$. In order to convert this value back into a differential pressure, the following formula must be used:

$$
\Delta p=15875 I-63.5
$$

Where $\mathrm{I}=$ DAS input signal $(\mathrm{A})$

The differential pressure can then be converted to a velocity using equation (4-3).

In order to carry out the calibration, the calculated HRRs must be compared to a known HRR. The source of this information is the propane flow meter. The propane flow meter is a Sierra Steel-Mass Model 640S insertion mass flow meter, which ideally measures mass flow rates from $0-30 \mathrm{~kg} / \mathrm{min}$ and outputs a current of $4-20 \mathrm{~mA}$. This flow meter works using a probe that measures the gas temperature and a velocity sensor that is heated to a constant differential temperature above the gas temperature. The meter measures the cooling effect of the moving gas and correlates that to a velocity [39]. By knowing the flow rate of propane at a given time, we can calculate the real HRR by using the heat of combustion of propane (effective heat of combustion, $\mathrm{H}_{\mathrm{ch}}$ for propane is 43.7 $\mathrm{kJ} / \mathrm{g}$ ). The system uses a rounded value of $44 \mathrm{~kJ} / \mathrm{g}$. This means that the flow meter is capable of measuring the flows that yield fires up to $22 \mathrm{MW}$. It is possible that some time in the future, $20 \mathrm{MW}$ fires may be used for tests in the facility. 
The flow meter is calibrated and certified to measure flows up to $22.02 \mathrm{MW}$ and output a signal of 4-20.05 mA. The equation that correlates the signal directly into a HRR is:

$$
\dot{Q}=1372 I-5.49
$$

Where $\dot{Q}=$ HRR (MW), I = signal current (A).

Similarly, the gas analyzer, and ABB EL 3020 converts the $\mathrm{O}_{2}, \mathrm{CO}_{2}$ and $\mathrm{CO}$ volumetric concentrations into currents that feed into the data acquisition system.

The $\mathrm{O}_{2}$ is set at a range of $0-25 \%$ and the signal output is $4-20 \mathrm{~mA}$. Therefore, the equation used to convert the current to the volumetric concentration is:

$$
X_{O_{2}}^{A}=(1562.5 I-6.25) / 100
$$

The $\mathrm{CO}_{2}$ is set at a range of $0-30 \%$ and the signal output is $4-20 \mathrm{~mA}$. Therefore, the equation used to convert the current to the volumetric concentration is:

$$
X_{\mathrm{CO}_{2}}^{A}=(1875 I-7.5) / 100
$$

The CO is set at a range of $0-2000 \mathrm{ppm}$ and the signal output is $4-20 \mathrm{~mA}$. Therefore, the equation used to convert the current to the volumetric concentration is:

$$
X_{C O}^{A}=(125000 I-500) / 10^{6}
$$




\section{Chapter 5: Instrumentation}

In order to measure the HRR of a burning item, all combustion products must be collected and directed through an area where instrumentation exists to measure various variables of the gas. Only the mass flow rate and $\mathrm{O}_{2}$ concentration are required to provide an estimation of $\mathrm{HRR}$. However, if $\mathrm{CO}_{2}$ and $\mathrm{CO}$ concentrations are also measured, a more accurate calculation of the HRR can be obtained. This chapter describes the instrumentation and equipment used and the reasoning behind the use of this particular arrangement of instruments. A view of all instrumentation in the fan chamber is provided in Figure 5.1. A list of the devices used is provided in Table 5.1. Since the experimental atrium and the experimental tunnel of the facility share the same fan chamber, permanent locations for the instrumentation had to be suitable to both. As such, the process of determining these locations was done with ventilation open to either the atrium or the tunnel for the various simulations and manual measurements. To find the optimum solution a number of computational fluid dynamics simulations were carried out.

In addition to the simulations, seven sets of manual measurements were carried out. Of the 17 simulations, ten had ventilation open to the atrium and seven to the tunnel. Of the seven manual measurements, two were open to the atrium and five to the tunnel. See Table 5.2 for a list of these data sets. Additional information on the instrumentation design for the facility is available in Michels and Ko's paper Instrumentation Design for HRR Measurements in a Large-Scale Fire Facility [40]. 


\subsection{Temperature}

In order to calculate the mass flow rate of gases through the fan chamber, accurate measurements of gas temperature must be taken. The density of the gas relates directly to the temperature.

\subsubsection{Temperature Profile}

All FDS simulations, as well as manual observations, indicate that for any fire scenario, there is a great deal of time available for mixing of the combustion gases. This is due to the large distance travelled and the high amount of turbulence experienced by the gases. Because of this, the temperature in all scenarios was relatively uniform across the entire cross-section of the fan chamber.

An example of temperature profiles from FDS simulations of $10 \mathrm{MW}$ fires in the tunnel at different fan speeds is shown in Figure 5.2 [40]. At lower fan speeds with the same fire size, the temperature is higher as less fresh air is mixed with the products of combustion.

For each simulation, it can be seen that the profiles are very close to uniform both vertically and horizontally. This trend has been found to be consistent in all situations. Since fires in the atrium have an even longer travel distance, the gases have a longer time to mix and are uniform also. Figure 5.3 shows the temperature with time of six thermocouples in a simulation with a $10 \mathrm{MW}$ fire in the atrium, once again showing uniform results at any given time. 


\subsubsection{Temperature Measurements}

Six Type $\mathrm{J}$ thermocouples were installed across the cross-section, capable of measuring temperatures between 0 and $760^{\circ} \mathrm{C}$ with an accuracy of $\pm 0.1^{\circ} \mathrm{C}$. See Figure 5.4 for a diagram of thermocouple locations. The average value for these six thermocouples is employed to calculate the density of the gases at any given time. This is more than enough thermocouples to provide very accurate measurements of average gas temperature.

The thermocouples are wrapped around the steel gas sampler tubing and are configured in such a way as to only measure the gas in the compartment and not the temperature of the steel tubing. Temperatures in the fan chamber can range from approximately $-20^{\circ} \mathrm{C}$ in the winter to over $100^{\circ} \mathrm{C}$ during a large fire test in the atrium.

Higher temperatures will be reached in the chamber with fires in the tunnel. It is important to ensure that the temperature does not reach higher than $300^{\circ} \mathrm{C}$ to protect the fans from damage.

\subsection{Velocity Measurements}

In order to calculate the mass flow rate of combustion gases through the fan chamber, the average velocity of the gas must be known as well as the density. Manual measurements and FDS simulations were carried out in order to analyze the velocity profile in the fan chamber for different scenarios including different fire sizes, fan speeds and ventilation arrangements. The purpose of this study was to find an accurate and economical combination of velocity measurement locations that will provide accurate measurements for any scenario in the facility. 
The large amount of turbulence in the system combined with the uncertainty of the cross-sectional velocity profile means that the velocity instrumentation has to be considered very closely. Oxygen consumption calorimetry calculations are highly sensitive to changes in velocity. Therefore accurate measurements are critical.

Bi-directional probes provide robust, accurate velocity measurements that are not badly hindered by slight changes in angle that can be caused by the turbulence of highspeed winds [26]. These probes work on the principle that the difference between the dynamic pressure on the wind side of an object and the static pressure at the downstream side can be converted into a velocity based on fluid density and Reynolds number. The full equation is provided in equation (4-2) and a simplified version of the equation is provided in equation (4-3). The probes are attached to two tubes which are then connected to a pressure transducer where the pressure differences are converted into an electric current which runs into the data acquisition system.

Four bi-directional probes and four pressure transducers were installed in the fan chamber and used for all calibration tests. The reason that this arrangement is used is discussed below in section 5.2.4. The probes were fabricated by a technician working at the lab.

The bi-directional probes are held in place by steel supports spaced approximately $10 \mathrm{~cm}$ from the probe so that the turbulence caused by the support does not affect the velocity measured by the probe. Copper tubing is used inside the fan chamber so that it will withstand the high temperatures. Outside the fan chamber, the copper tubing is connected to flexible plastic tubing and run to the pressure transducers located just 
outside the fan chamber. Each probe has equal weight in the calculation of the average velocity across the cross-section.

The average velocities in the fan chamber range from approximately $2 \mathrm{~m} / \mathrm{s}$ (at $25 \%$ fan speed) to $8 \mathrm{~m} / \mathrm{s}$ (at 100\% fan speed). Although gusts and eddies cause higher and lower localized velocities. The system cannot accurately measure velocities below this level for various reasons. First, the system is designed so that whenever a probe has a negative pressure, or flow is moving backwards in the fan chamber (which can occur from turbulence at lower speeds), a velocity of $0 \mathrm{~m} / \mathrm{s}$ is assumed. Since the average of the probe values is then taken, this average will be higher than reality. Secondly, at low velocities, the Reynolds number becomes low and the "Barker Effect" can cause error [27]. Additionally, the probe factor is different at lower Re's and the system is not designed to compensate for this. At very low gas velocities, the pressure transducers are taking measurements at the very lowest end of their measurement range, which may yield further questionable results. It is therefore recommended that all three fans are running during an experiment at or above $25 \%$ fan speed.

\subsubsection{Manual Velocity Measurements}

Seven sets of manual velocity measurements were carried out in the fan chamber. Two of these had the ventilation open to the atrium and five were open to the tunnel. The measurements were carried out at 25, 50,75 and $100 \%$ fan speeds using a hot-wire anemometer at a $0.25 \mathrm{~m}$ grid spacing across the cross-section ( 21 measurements across the width by 11 measurements across the height for a total of 231 measurements in each set). 
A pole with marks on it every $0.25 \mathrm{~m}$ was used in the fan chamber to ensure accurate locations of the measurements. The anemometer's probe was held approximately $10 \mathrm{~cm}$ away from the pole to ensure the pole did not interfere with the flow. One person was required to hold the anemometer and another one to read and record the measurements.

Approximate time averages of the wind speed were taken after watching the display on the anemometer for approximately five to ten seconds. The data was then transferred into Microsoft Excel for analysis. See Table 5.2 for a complete list of manual measurements and FDS simulations carried out to determine the velocity profiles in the fan chamber.

\subsubsection{FDS Simulations}

The CFD simulations were done using the computer model Fire Dynamics Simulator (FDS) Version 5. FDS is large eddy simulation CFD model developed by NIST specifically designed for fire simulations [41]. FDS5 was used to model the facility in order to provide more insight into the velocity profile of the fan chamber. The FDS input files were generated by Pyrosim Version 2007.1. Pyrosim is a graphical user interface used to generate FDS input files. It is a more user-friendly and intuitive way of generating a model than the traditional text-based programming method. A grid size of $0.25 \mathrm{~m}$ was used throughout the entire computational domain. Many FDS simulations have been carried out in the past of both the tunnel and atrium facilities and this grid size was found to yield reasonable values [42]. For the simulations of the atrium, two meshes were used, totaling $1,028,480$ cells. One of these meshes corresponded to the atrium and 
the other corresponded to the fan chamber. The ceiling and the south and east walls as well as part of the west wall of the atrium are modeled as inert boundaries. The section of the west wall where the elevator is located is modeled as $10 \mathrm{~cm}$ thick concrete and the part of the north wall where the rolling doors are located is modeled as sheet metal. The north and west walls of the fan chamber are inert boundaries, or boundaries through which no heat can flow. The fan enclosures and the closed ventilation openings were modeled as sheet metal. All other walls and partitions are modeled as $10 \mathrm{~cm}$ thick concrete. Because temperatures in the system are not very high and the purpose of the simulations is to simulate the flow of the combustion gases rather than to accurately account for heat transfer, the material properties are not as vital as the geometry of the model.

The three fans were modeled as vents with constant volumetric flow rates corresponding to those of the actual fans. For $25 \%$ fan speed, each fan moved $11.1 \mathrm{~m}^{3} / \mathrm{s}$ and at $100 \%$ fan speed, each moved $44.4 \mathrm{~m}^{3} / \mathrm{s}$. The calibration burners were modeled as burner surfaces with constant HRRs per unit area that output 2.5 MW each. For a 10 MW fire, four of these surfaces were used. Propane is the default fuel in FDS5 and was used for these simulations. A sample FDS input file is available in Appendix B.

A total of 17 simulations were carried out with varying fan speeds, fire sizes and ventilation arrangements for velocity profile comparison. Ten of these simulations had ventilation open to the atrium with fires from $2.5 \mathrm{MW}$ to $20 \mathrm{MW}$. The simulations were, for the most part, run for approximately $300 \mathrm{~s}$ and a time average of wind speed was taken over at least $30 \mathrm{~s}$ for each in a time period where average velocity had reached 
steady state. The $0.25-\mathrm{m}$ grid size meant that the data could be directly compared with the manual measurements. Table 5.2 provides a complete list of manual measurements and FDS simulations carried out for instrumentation design purposes.

\subsubsection{Velocity Profiles}

Using the data from simulations and manual measurements, velocity profiles were compared for different scenarios in order to determine the governing factors that affect the velocity profiles and determine the number and locations for placement of the bidirectional probes.

Figure 5.5 compares vertical velocity profiles of the flow velocities at $50 \%$ fan speed with and without a $2.5 \mathrm{MW}$ fire in the tunnel [40]. Regardless of the presence of fire, a similar pattern of the velocity profile was obtained from all scenarios. This indicates that the velocity is not greatly affected by the fire size but is dominated by the exhaust fan speed and ventilation arrangement. Both simulation and measurement results show that the vertical velocity profiles obtained at $1.25 \mathrm{~m}$ left from the centre are almost mirrored to those obtained at $1.25 \mathrm{~m}$ right from the centre. This is due to the fact that the ventilation openings are horizontally uniform in the tunnel. However, this is not the case with the atrium.

Figure 5.6 compares vertical velocity profiles of the flow drawn from the atrium by the fan system at 50\% fan speed from a simulation and manual measurements [40]. Results from simulations and measurements agree in that the velocities are lower in the upper part of the fan chamber. One reason for this is that two of the fans are below the fan chamber and only one is above. However, it appears that the fact that the flow is 
from the atrium affects the profile as well. The duct from the atrium's ceiling chamber to the fan chamber is a long vertical duct with a cross section only slightly larger than the sampling location (approximately $3 \mathrm{~m} \times 7 \mathrm{~m}$ for an area of $21 \mathrm{~m}^{2}$ ). This gives the gas a large vertical component to its velocity, which affects the velocity profile in the system.

The non-uniform flow pattern exists also in the horizontal profiles. As shown in Figure 5.6, the vertical velocity profile obtained at $1.25 \mathrm{~m}$ left and $1.25 \mathrm{~m}$ right from the centre are different. This difference is increased with reduced fan speed. The ventilation openings to the tunnel are arranged such that the gases enter the fan chamber moving upwards and they are more or less horizontally uniform. However, the openings from the atrium enter the fan chamber horizontally and perpendicular to the direction of the fan chamber, which accounts for this difference in horizontal velocity distribution [40].

Overall, the velocity profiles with ventilation open to the atrium are very different from those with ventilation open to the tunnel. This made it a challenge to determine the appropriate locations for velocity measurements using the least number of probes, being appropriate for different fan speeds, fire sizes and ventilation configurations, and that can serve both the atrium and the tunnel.

\subsubsection{Probe Location Combinations}

For each FDS simulation and manual measurement, various combinations of probes were compared in order to find the most accurate, as well as the most economical, solution for the facility. The goal was to find a combination of probes that, when the values from them were averaged, would provide an accurate representation of the 
average velocity across the entire cross-section of the fan chamber for every fan speed, fire size and ventilation arrangement.

A total of 28 probe combinations were compared, ranging from two to 30 probes. The various combinations are provided in Figure 5.7 and the five most accurate are shown in Figure 5.8. As few probes as possible were to be used that would yield accurate measurements. Probe combinations \#10 and \#13, using 30 and 25 probes respectively, used the closest approximation of the log-Tchebycheff rule [29] as possible in the $25 \mathrm{~cm}$ grid. This rule is suggested as an accurate way to measure velocities in rectangular and circular ducts, but requires a very large number of probes. These two combinations were used to compare and gage the accuracy of alternative combinations.

One combination of probes stood out among the others as very accurate for every situation while utilizing a reasonable number of probes. Combination \#22 has four probes spaced symmetrically in the fan chamber. The top two are located $0.5 \mathrm{~m}$ down from the ceiling and $1 \mathrm{~m}$ out from the center. The bottom two are located $0.5 \mathrm{~m}$ up from the floor and $1 \mathrm{~m}$ out from the center. For all 24 scenarios considered, this provided an error of less than $6 \%$, which is comparable to some of the other combinations with many more probes.

Table 5.3 through Table 5.6 show the velocity errors of each velocity probe combination for each scenario. Figure 5.9 graphically compares the five most accurate combinations for all scenarios, showing that probe combination 22 performs similarly to the combinations with many more probes. These five combinations include the two log-T combinations (combinations 10 and 13 with 30 and 25 probes, respectively), 
combination 12 with 20 probes, combination 18 with 8 probes and combination 22 with four probes. The manual measurements with the $2.5 \mathrm{MW}$ fire could not be used to compare probe combinations because the data was not complete due to poor working conditions in the fan chamber.

The performance of probe combination \#22 was analyzed for various fan speeds and ventilation arrangements. The percent errors were calculated using the absolute deviations for each scenario. At all fan speeds, the average percent error was between $2.6-4.9 \%$ with the highest error values at $25 \%$ fan speed and lowest at $100 \%$ in general. The performances were relatively consistent from both ventilation from the tunnel and the atrium. Table 5.7 shows percent errors of probe combination $\# 22$ for all considered scenarios and Table 5.8 shows average percent errors for combination $\# 22$ for different categories compared to the average of all considered combinations. Figure 5.10 shows the final installed locations of the four bi-directional probes in the fan chamber.

\subsection{Gas Concentrations}

Oxygen concentration is required for the calculation of HRR by oxygen consumption calorimetry. However, a greater accuracy can be achieved with the additional measurement of carbon dioxide and carbon monoxide. Janssens provides a method to calculate the HRR based on the measurement of these three variables for large fire test facilities [5].

HRR calculations through oxygen consumption are very sensitive to the oxygen concentration. It is therefore critical that the oxygen concentration measurements be accurate and representative of the entire cross-section of the sampling location. 


\subsubsection{Gas Concentration Profiles}

All preliminary FDS simulations, as well as manual observations, indicate that for any fire scenario, there is a great deal of time available for mixing of the combustion gases. This is due to the large distance travelled and the high amount of turbulence experienced by the gases. Because of this, the gas concentrations are relatively uniform by the time the combustion gases reach the sampling location.

Figure 5.11 compares vertical profiles of oxygen mass fraction of the flow from a simulated $10 \mathrm{MW}$ fire in the tunnel under different fan speeds [40]. It can be seen that the oxygen concentration is uniform both horizontally and vertically across the cross-section. This trend is consistent in general for the system.

The oxygen concentration of the flow from lower fan speeds is lower than that from the $100 \%$ fan speed although the fire sizes were the same. The reason is that the high fan speeds entrained a higher amount of fresh air resulting in higher oxygen concentrations. In principle, dilution by an unknown quantity of air does not affect the validity of the HRR measurements [1]. The fan chamber needs to collect all combustion products as well as entrained air in order to obtain an accurate estimation of HRR.

It was found that the gas concentrations are uniform under each fan speed, which means that by the time the combustion gases reach the sampling location, they are well mixed. Figure 5.12 shows oxygen concentration vs. time of nine point measurements across the cross-section of the fan chamber of a simulation with a $10 \mathrm{MW}$ fire. This reinforces the uniformity of the oxygen concentration. Figure 5.13 and Figure 5.14 show 
the $\mathrm{CO}$ and $\mathrm{CO}_{2}$ concentrations, respectively, of the same simulation. These are also uniform for the same reasons as the $\mathrm{O}_{2}$.

\subsubsection{Gas Concentration Measurements}

To collect gases for analysis, a steel gas sampling grid is used which spans the cross-section of the fan chamber with 66 holes having a diameter of $1.09 \mathrm{~mm}$ for a total sampling area of $61.6 \mathrm{~mm}^{2}$. The tubing has an outside diameter of $6.35 \mathrm{~mm}(1 / 4 ")$ and brass fittings are used at the connections. The holes are on the downstream side to avoid being clogged with soot and other debris. They are closer together at the farther reaches from the central sampling tube to get a more uniform sample. A drawing of the gas grid is provided in Figure 5.15. The gas enters the tubing and is mixed into a single tube. The sample then moves through a cotton soot filter which is checked and replaced regularly.

To remove any water in the gas sample, the gas moves through a condenser coil that is submerged in a bucket of ice water during experiments. The coil is made of copper tubing of $6.35 \mathrm{~mm}$ (1/4") diameter with seven windings of $127 \mathrm{~mm}(5$ ") diameter. In addition to the condenser coil, the gas moves through a Drierite gas drying unit that uses desiccant that changes from blue to pink when it absorbs moisture. The desiccant should be replaced after turning pink. More information on devices used is available in Table 5.1. From here, the sample enters the gas analyzer.

The gas analyzer is an ABB model EL 3020, which is set to measure $\mathrm{O}_{2}, \mathrm{CO}_{2}$, and CO concentrations. The oxygen analyzer in this unit is a Magnos206 which uses the paramagnetic behaviour to measure $\mathrm{O}_{2}$ concentration. It is set to measure a range of 
concentrations from $0-25 \%$. An Uras 26 Infrared Photometer is used to measure $\mathrm{CO}$ and $\mathrm{CO}_{2}$ concentrations. It works by "non-dispersive infrared absorption in the $\lambda=2.5-8 \mu \mathrm{m}$ wavelength range" [43].

The gas analyzer is calibrated on every day there is an experiment using a zeropoint and span calibration for each gas. For the zero-point for all gases, $100 \% \mathrm{~N}_{2}$ is used. For the span calibrations, cylinders with $901 \mathrm{ppm} \mathrm{CO}$ and $4.98 \% \mathrm{CO}_{2}$ are used. These concentrations were certified by the supplier, Praxair, in July 2007. The oxygen span calibration is done by turning on the gas pump and calibrating the fan chamber ambient gas to $20.95 \% \mathrm{O}_{2}$. Sufficient warm-up time is provided to ensure accurate measurements (the gas analyzer is left on overnight during the week). Sampling rate is kept at approximately $1.5 \mathrm{~L} / \mathrm{min}$. The sampling pump is an Air Cadet model 420-2901.

Delay time from the sampling location to the first recognition of change by the gas analysis is approximately 40 seconds. This time is accounted for by Labview in the calculation of HRR.

\subsection{Propane Flow Rate Measurements}

The propane flow rate measurements must be precise and reliable, as the propane burners are used for calibration of the system. The flow meter is a Sierra Steel-Mass Model 640S insertion mass flow meter, which measures the mass flow rate of the propane in the main line. The flow rate is converted to an electrical signal. This electrical signal is then converted directly to a HRR using equation (4-13). The effective heat of combustion of propane $(44 \mathrm{~kJ} / \mathrm{g})$ is built into this equation and combined with the mass flow rate to directly yield the HRR. This flow meter works using a probe that 
measures the gas temperature and a velocity sensor that is heated to a constant differential temperature above the gas temperature. The meter measures the cooling effect of the moving gas and correlates that to a velocity and by extension, a mass flow rate [39].

\subsection{Data Acquisition System}

The signals from the various measurement devices are collected by a Data Acquisition System (DAS) and from there relayed to the computer for input into the developed Labview software. The DAS, developed by National Instruments (NI), is a model cDAQ-9172. This chassis has eight slots for analog signal input modules and connects to the desktop computer via a USB cable.

The input modules used include two NI 9211 thermocouple modules with 4 thermocouple inputs each for a total of 8 thermocouple channels and an NI 9203 current module with 8 differential input channels. See Table 5.9 for a list of channels. Six thermocouple channels are dedicated to the six thermocouples and two are not used. All 8 current channels are in use. Four are connected to the pressure transducers, three to the gas analyzer for $\mathrm{O}_{2}, \mathrm{CO}$ and $\mathrm{CO}_{2}$ measurements, and one is dedicated to the propane flow meter. The DAS is connected to a desktop computer running Windows XP through a USB cable. Labview 8.6 collects the data through a DAQ Assistant Express VI. Labview programming is discussed further in Chapter 6 of this thesis. Signal cables from the pressure transducers, gas analyzer and propane flow meter are shielded cables. The purpose of the shielding is to help reduce radio frequency interference (RFI) from outside sources. RFI can be generated from electrical devices 
such as radios and electric motors and can cause adverse effects in sensitive devices [44]. In the case of this system, RFI is generated when the fans are turned on. This causes some noise in the signals received by the DAS. Because the DAS has only a 2-prong plug, partial shielding practice is used where only one end of the wire shield is grounded. This results in a partial reduction of the signal noise from RFI. However, some noise still exists in the system. Since there is no shift in the average, this small amount of noise is not considered a large problem. 


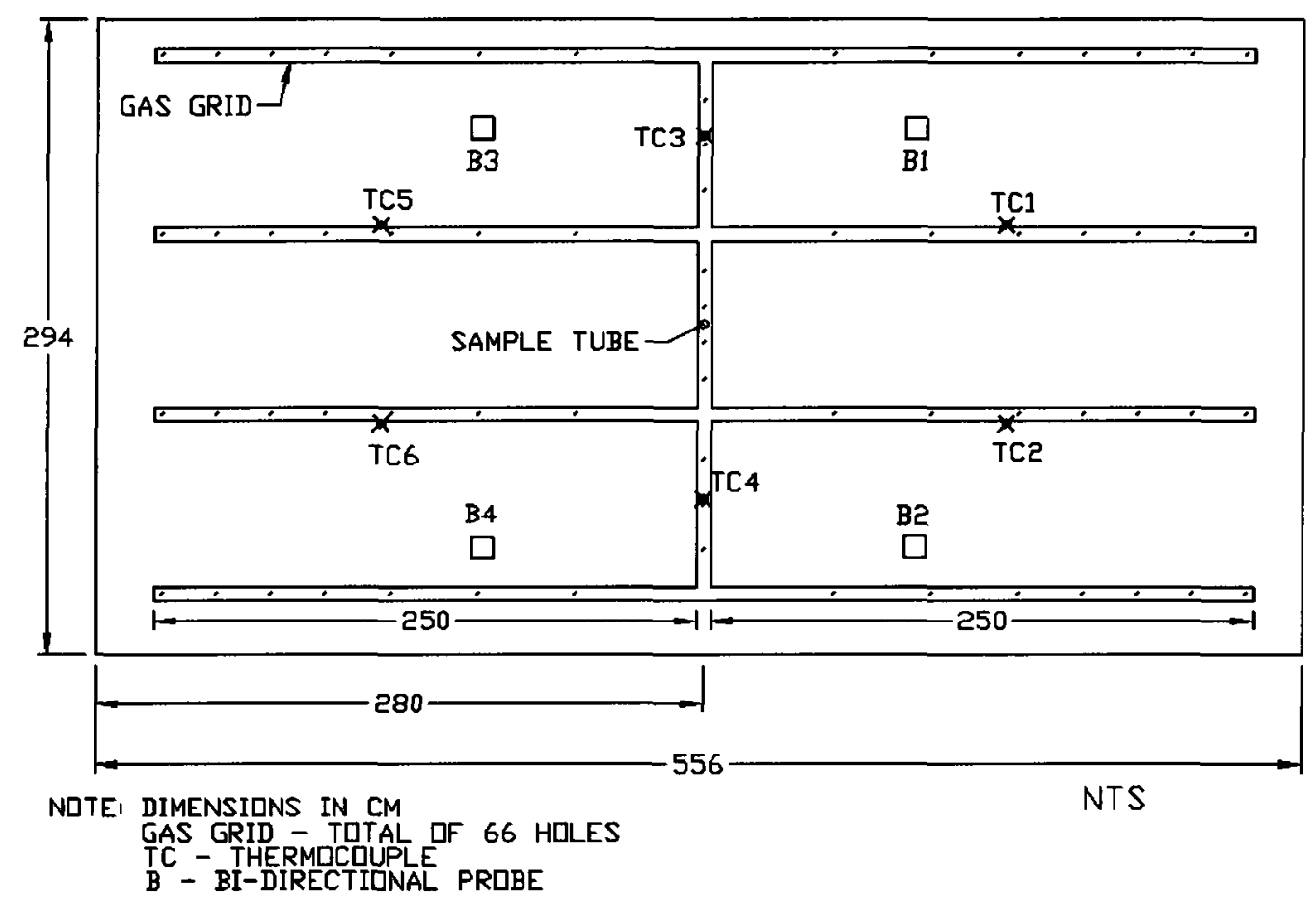

Figure 5.1 Instrumentation locations [40]
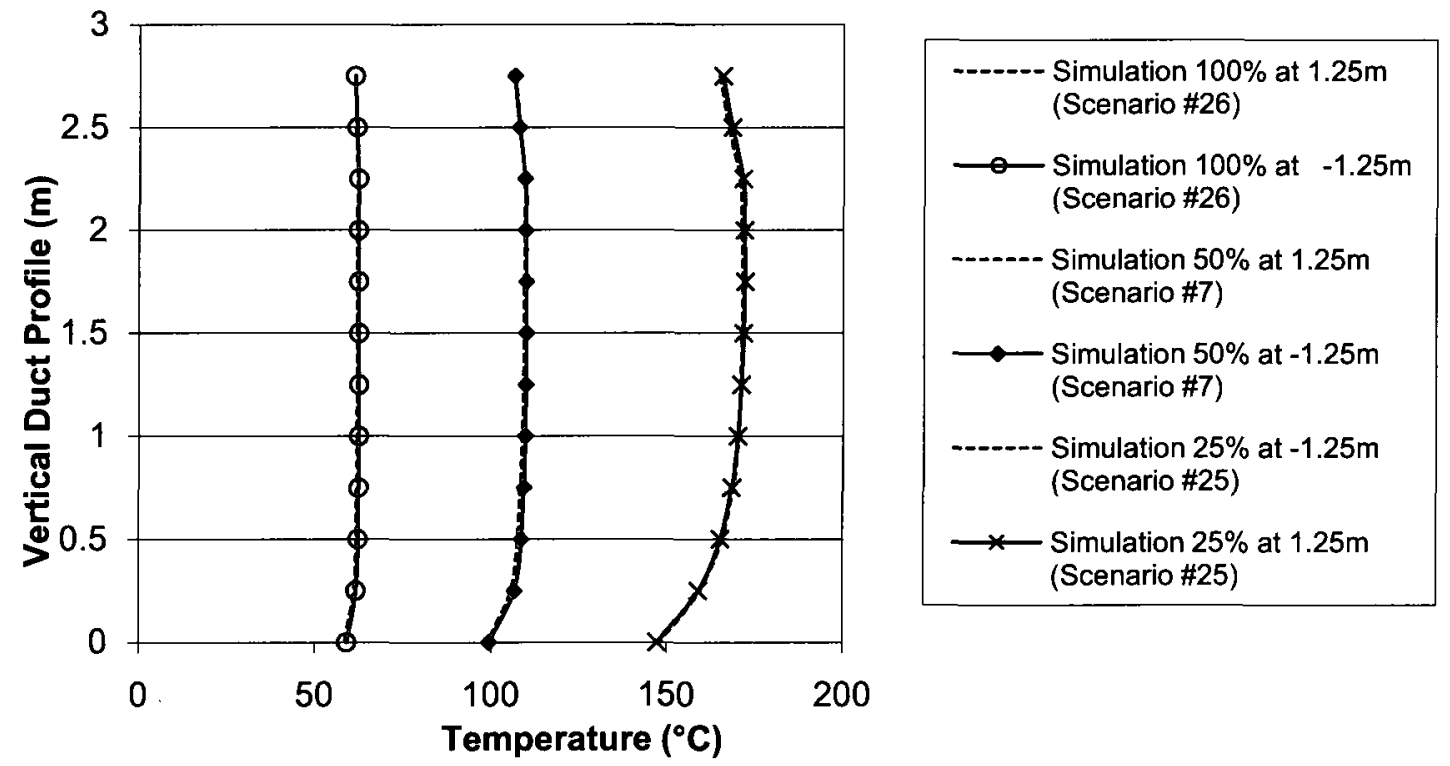

Figure 5.2 Vertical temperature profiles from a $10 \mathrm{MW}$ fire in the tunnel at different fan speeds [40]

(Note : values in the legend refer $1.25 \mathrm{~m}$ left and $1.25 \mathrm{~m}$ right from the centre, respectively) 


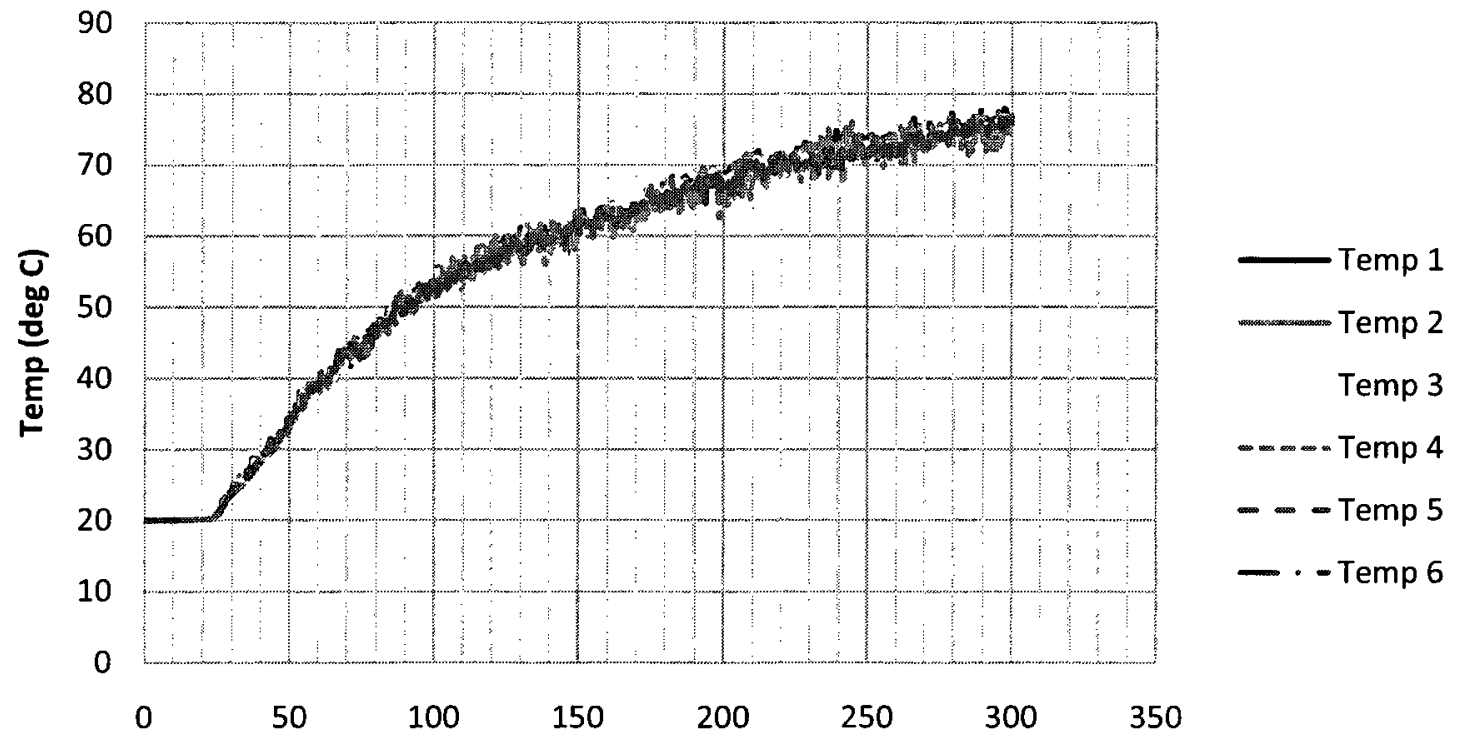

time (s)

Figure 5.3 Temperature-time curve for $300 \mathrm{~s} 10 \mathrm{MW}$ FDS simulation at $50 \%$ fan speed showing the uniformity of temperature across the cross-section

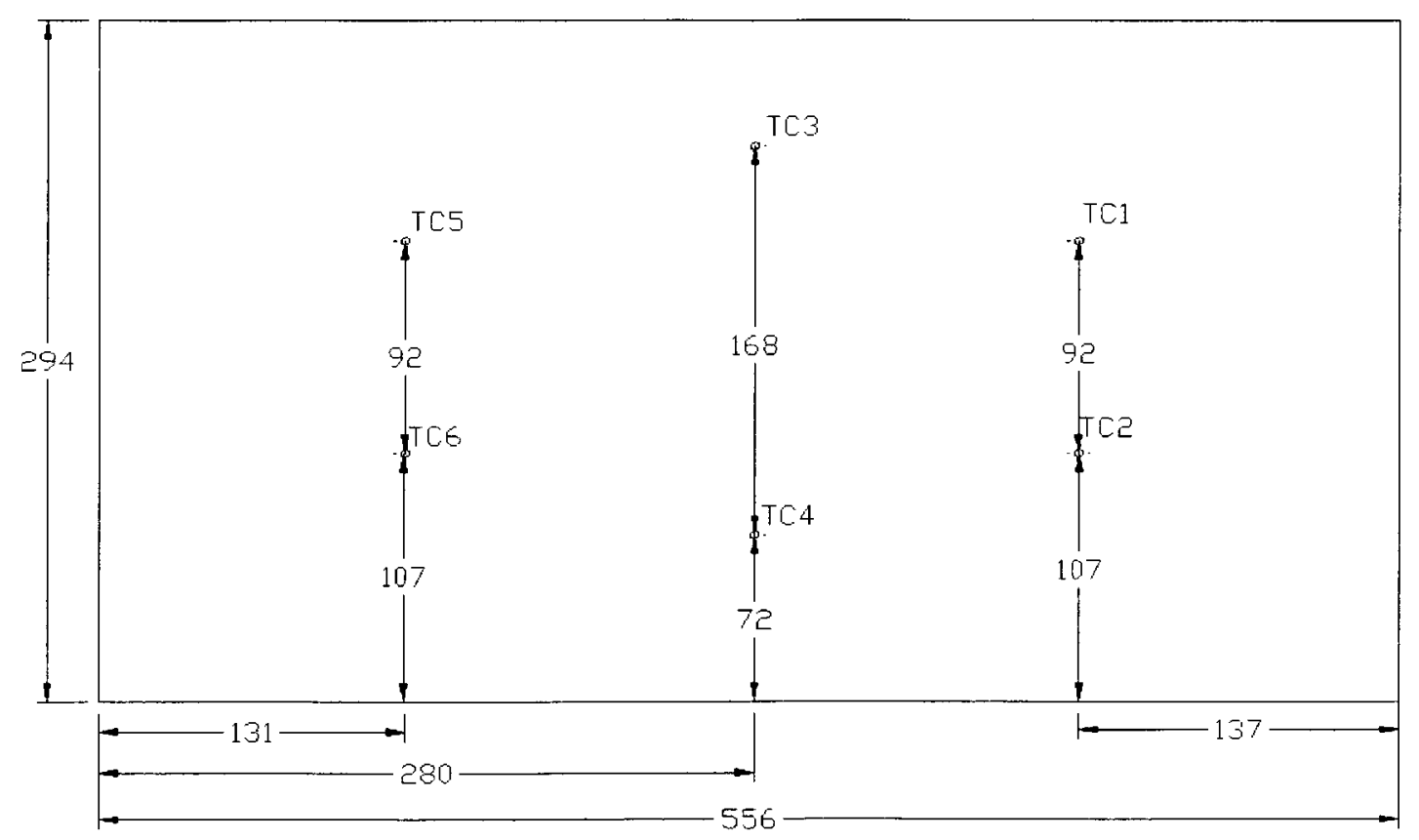

Note: Dimensions in $\mathrm{CM}$

Figure 5.4 Thermocouple locations 


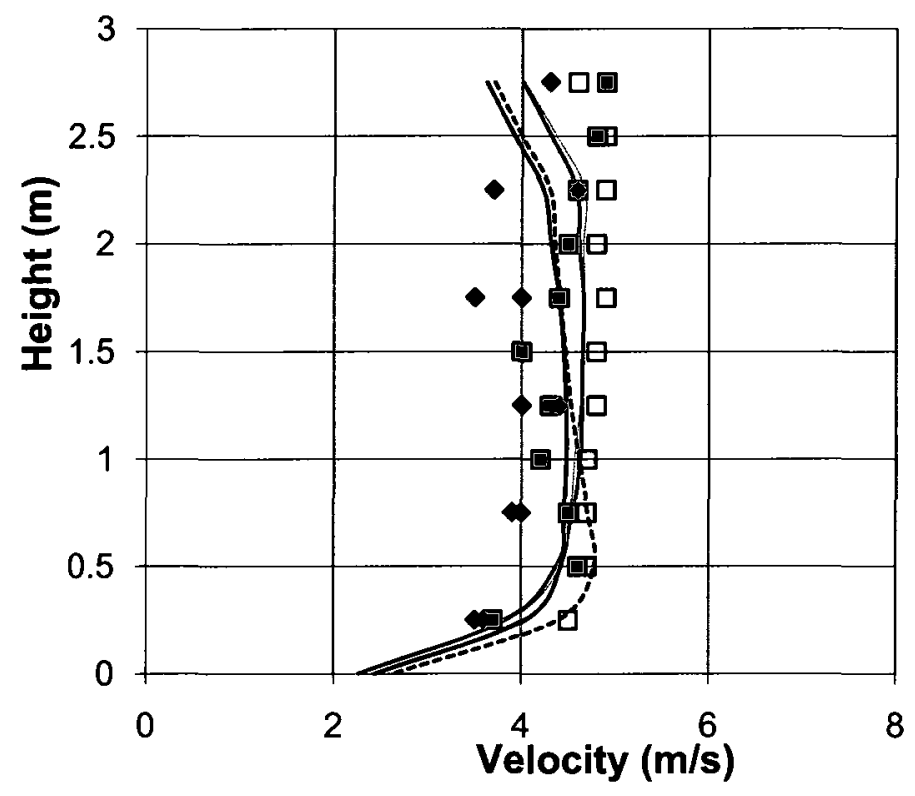

\begin{tabular}{|c|c|}
\hline & $\begin{array}{l}\text { - Simulation 2.5MW@-1.25 } \\
\text { (Scenario\#6) }\end{array}$ \\
\hline & $\begin{array}{l}\text { - Simulation 2.5MW@ } 1.25 \\
\text { (Scenario\#6) }\end{array}$ \\
\hline & $\begin{array}{l}\text { - Simulation 0 MW@-1.25 } \\
\text { (Scenario\#5) }\end{array}$ \\
\hline & $\begin{array}{l}\text { - Simulation 0 MW@ } 1.25 \\
\text { (Scenario\#5) }\end{array}$ \\
\hline$\square$ & $\begin{array}{l}\text { Measurment } 0 \text { MW@-1.25 } \\
\text { (Scenario\#9) }\end{array}$ \\
\hline$\square$ & $\begin{array}{l}\text { Measurment 0 MW@ } 1.25 \\
\text { (Scenario\#9) }\end{array}$ \\
\hline & $\begin{array}{l}\text { Measurment 0 MW@-1.25 } \\
\text { (Scenario\#24) }\end{array}$ \\
\hline & $\begin{array}{l}\text { Measurment 0 MW@ } 1.25 \\
\text { (Scenario\#24) }\end{array}$ \\
\hline
\end{tabular}

Figure 5.5 Vertical velocity profiles at $50 \%$ fan speed without and with a $2.5 \mathrm{MW}$ fire in the tunnel

(Note: -1.25 and 1.25 refer $1.25 \mathrm{~m}$ left and $1.25 \mathrm{~m}$ right from the centre, respectively)

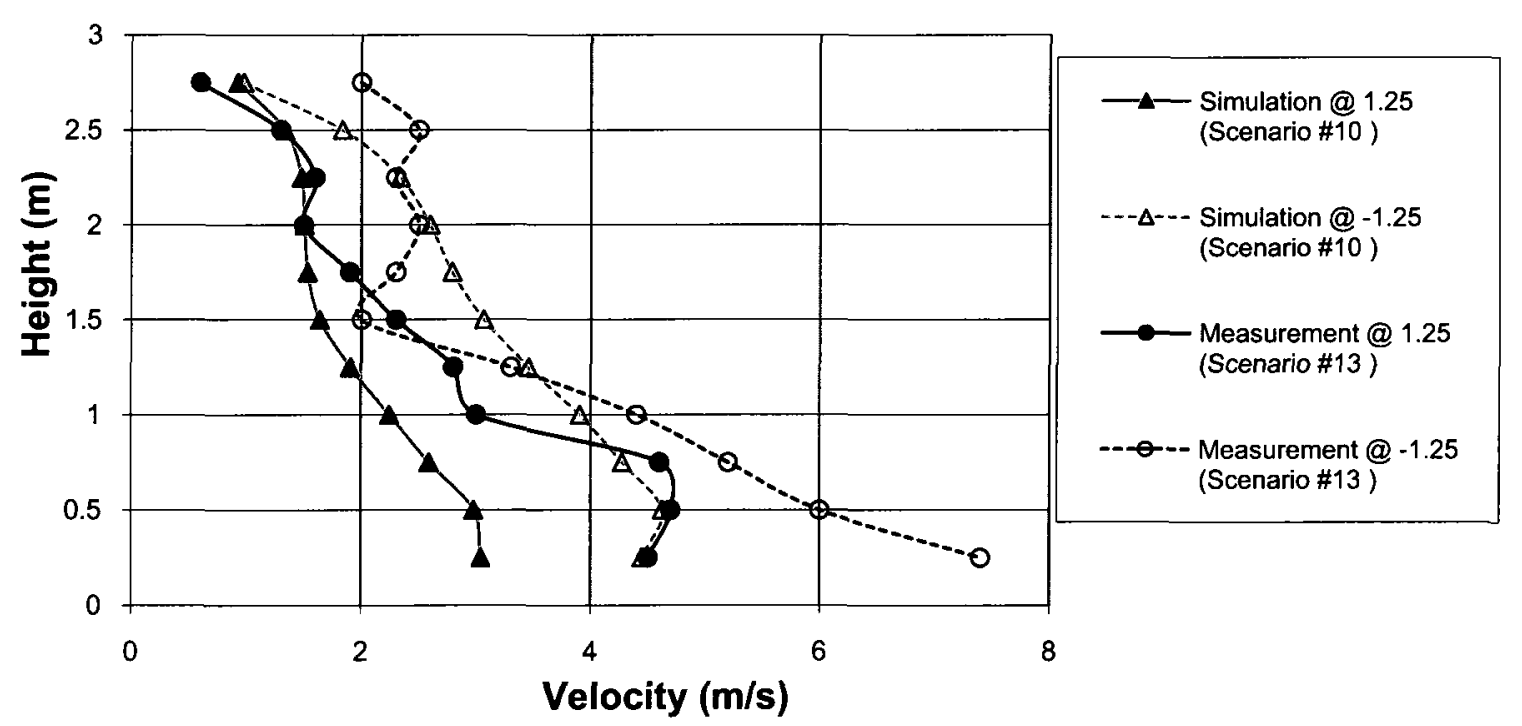

Figure 5.6 Vertical velocity profiles drawn from the atrium at $50 \%$ fan speed from a simulation and manual measurements

(Note : -1.25 and 1.25 refer $1.25 \mathrm{~m}$ left and $1.25 \mathrm{~m}$ right from the centre, respectively) 


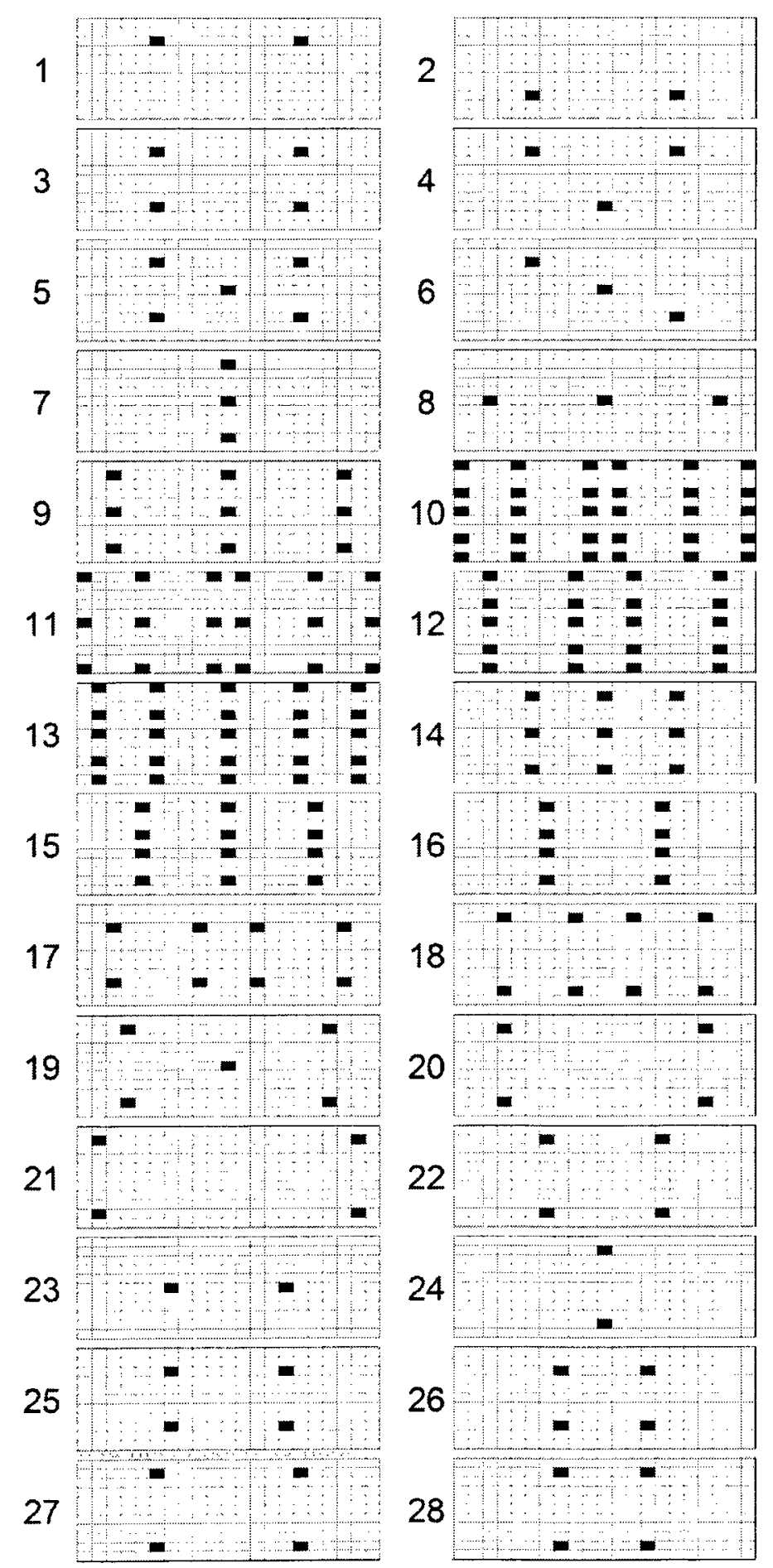

Figure 5.7 Velocity probe location combinations in a $0.25 \mathrm{~m}$ grid across the fan chamber cross-section 

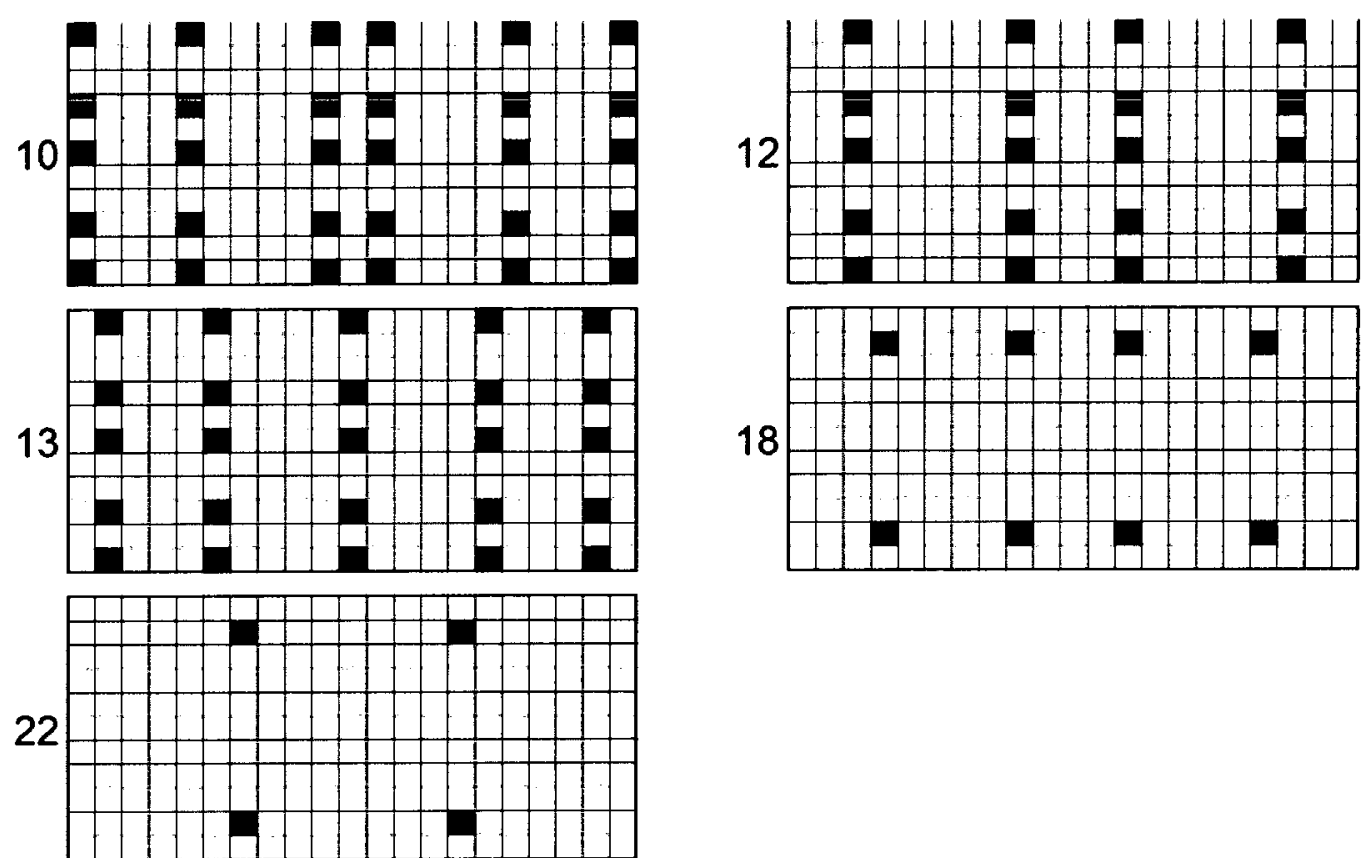

Figure 5.8 Five most accurate velocity probe combinations [40]

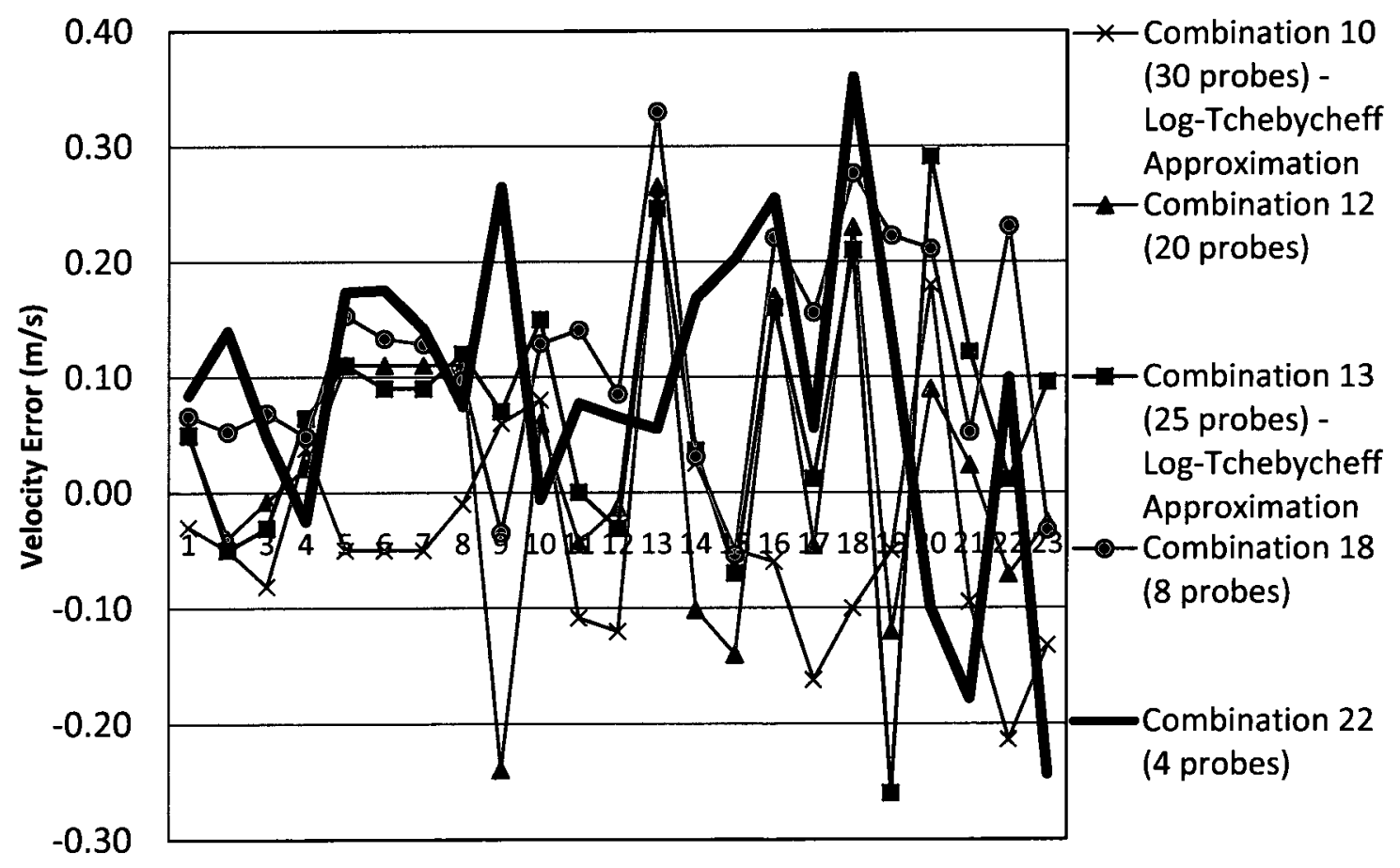

Figure 5.9 Comparison of the five most accurate velocity probe combinations

Note: The $\mathrm{X}$-axis refers to the scenarios in Table 5.2 


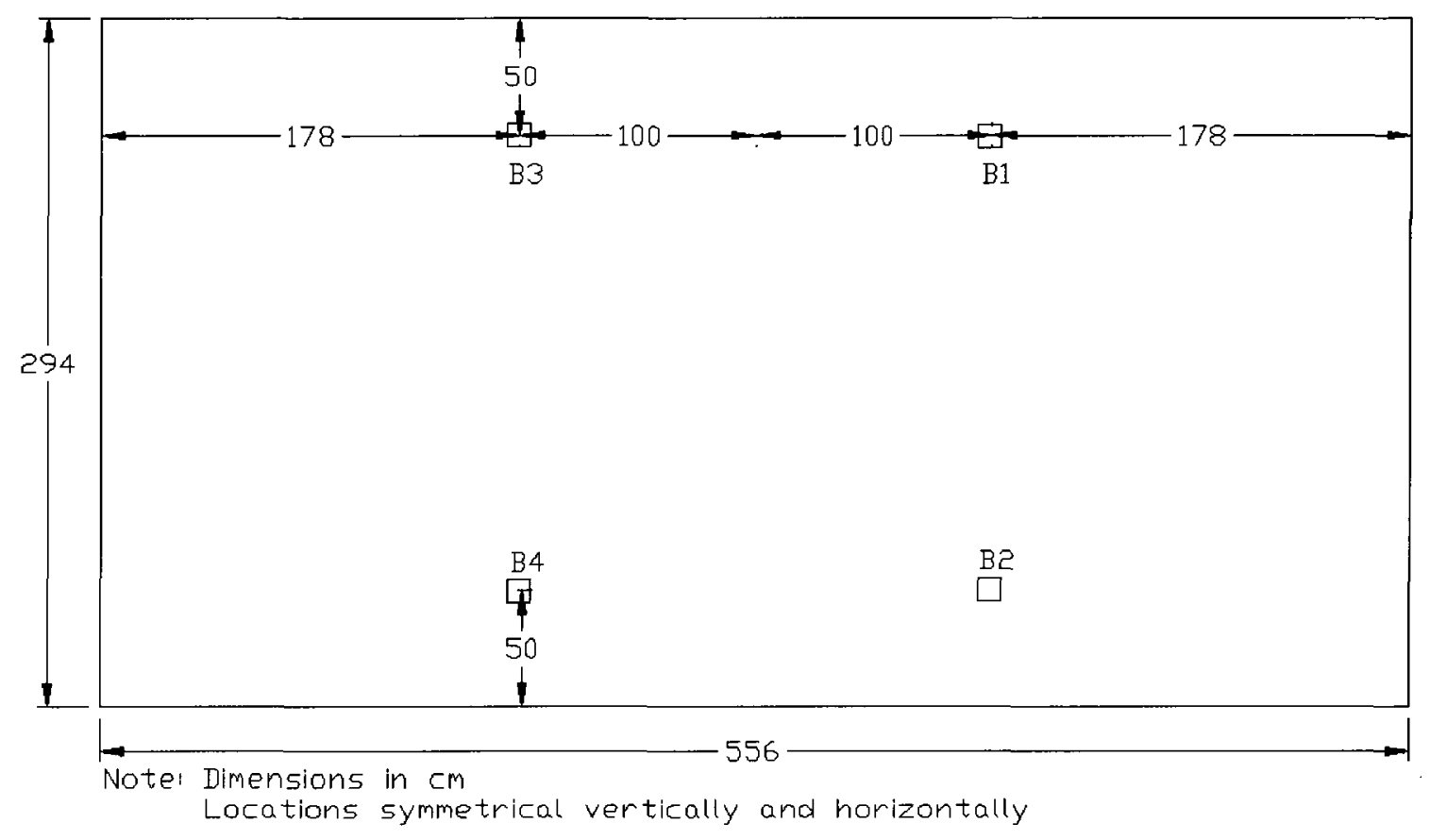

Figure 5.10 Bi-directional probe locations

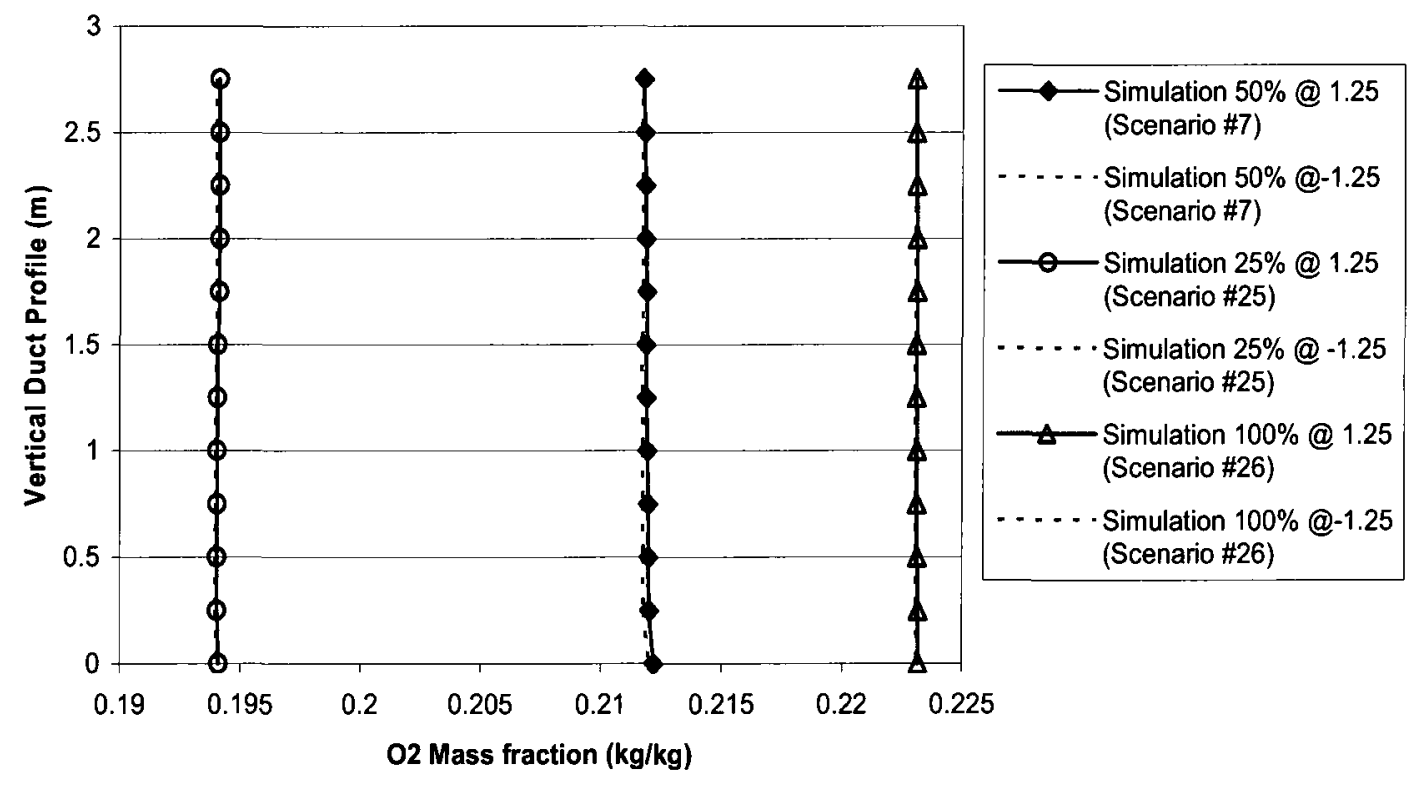

Figure 5.11 Vertical profiles of oxygen mass fraction of the flow from a $10 \mathrm{MW}$ fire in the tunnel under different fan speeds

Note: values in legend refer $1.25 \mathrm{~m}$ left and $1.25 \mathrm{~m}$ right from the centre 


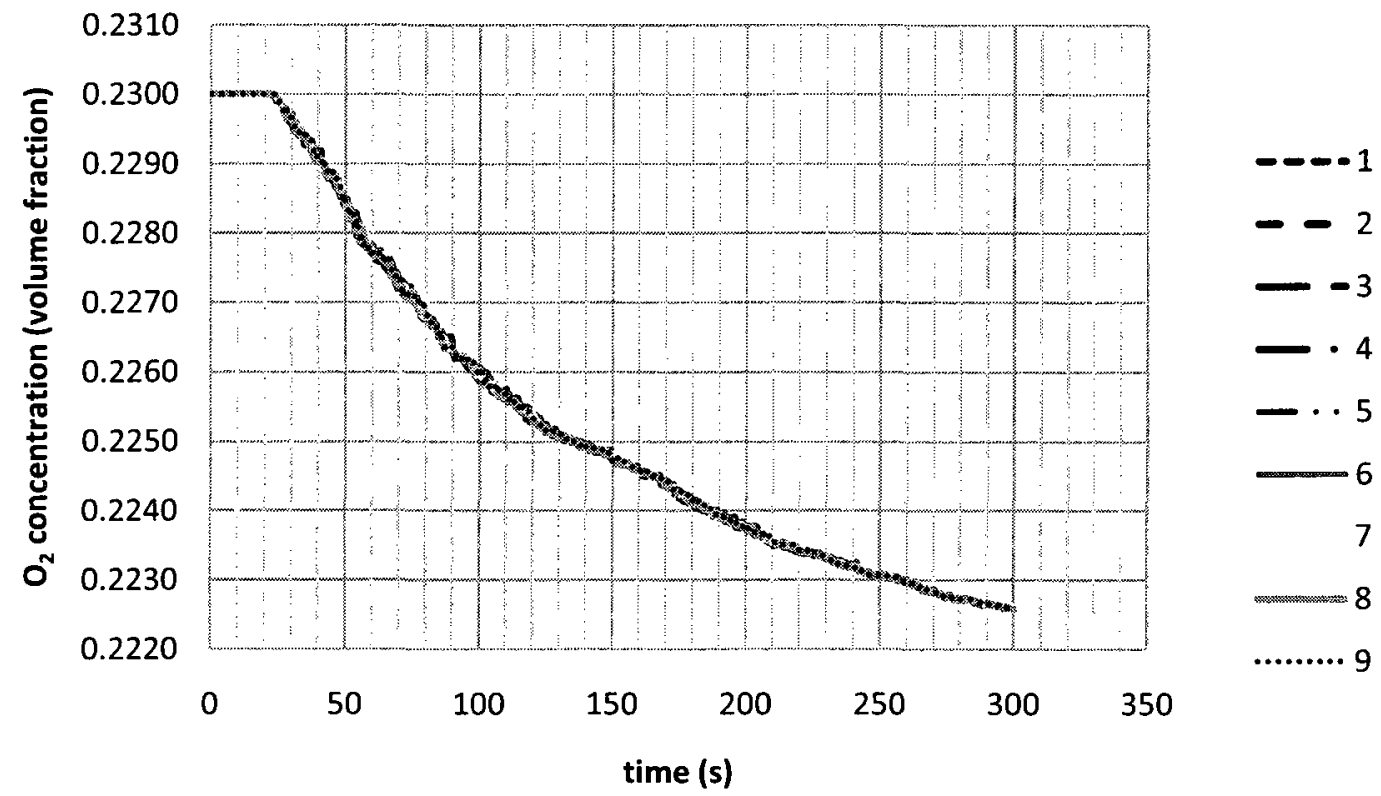

Figure 5.12 Oxygen concentration-time curve for 300 s 10 MW FDS simulation at $50 \%$ fan speed showing the uniformity of oxygen concentration across the cross-section

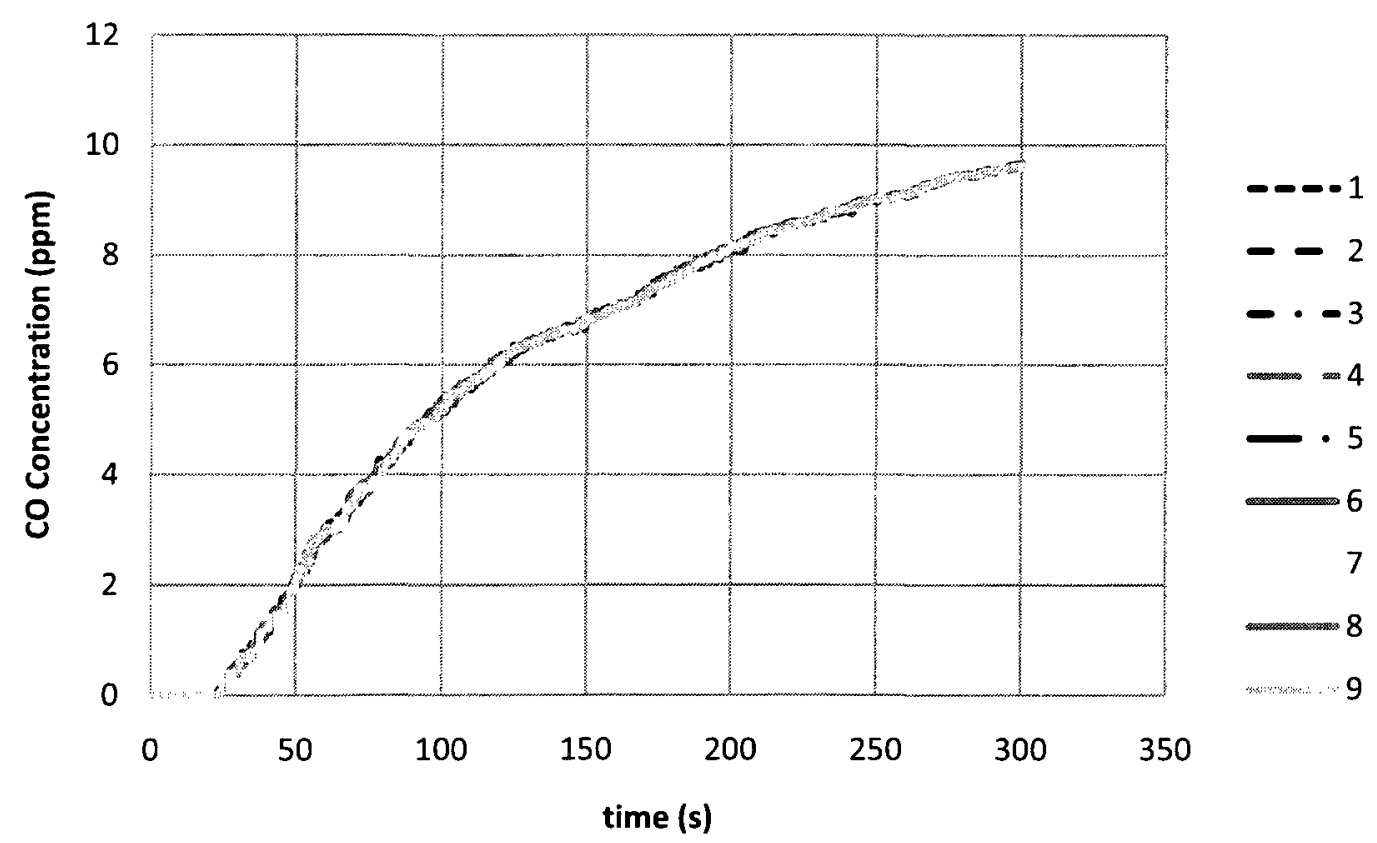

Figure $5.13 \mathrm{CO}$ concentration-time curve for a 300 -s $10 \mathrm{MW}$ FDS simulation at $50 \%$ fan speed showing the uniformity of $\mathrm{CO}$ concentration across the cross-section 


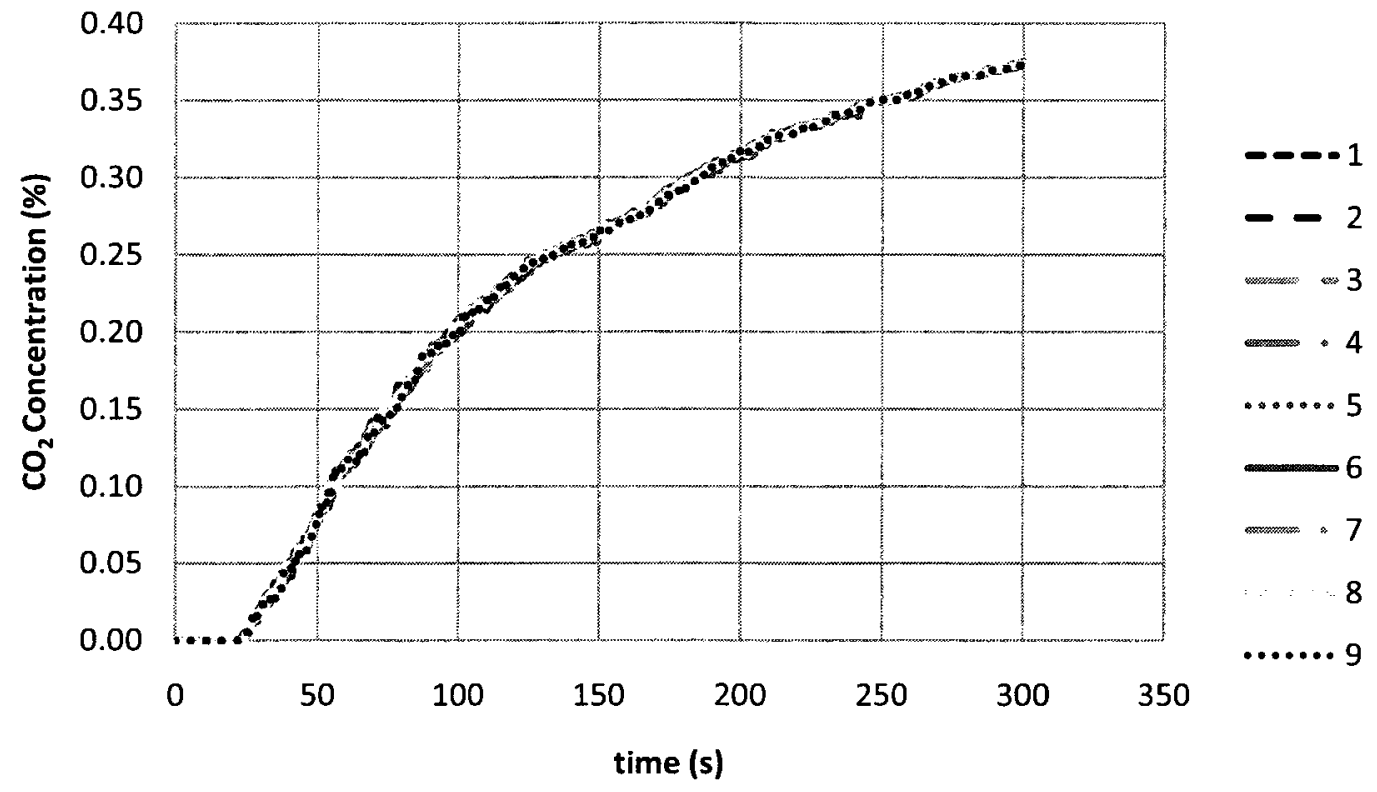

Figure $5.14 \mathrm{CO}_{2}$ concentration-time curve for 300 s $10 \mathrm{MW}$ FDS simulation at $50 \%$ fan speed showing the uniformity of $\mathrm{CO}_{2}$ concentration across the cross-section

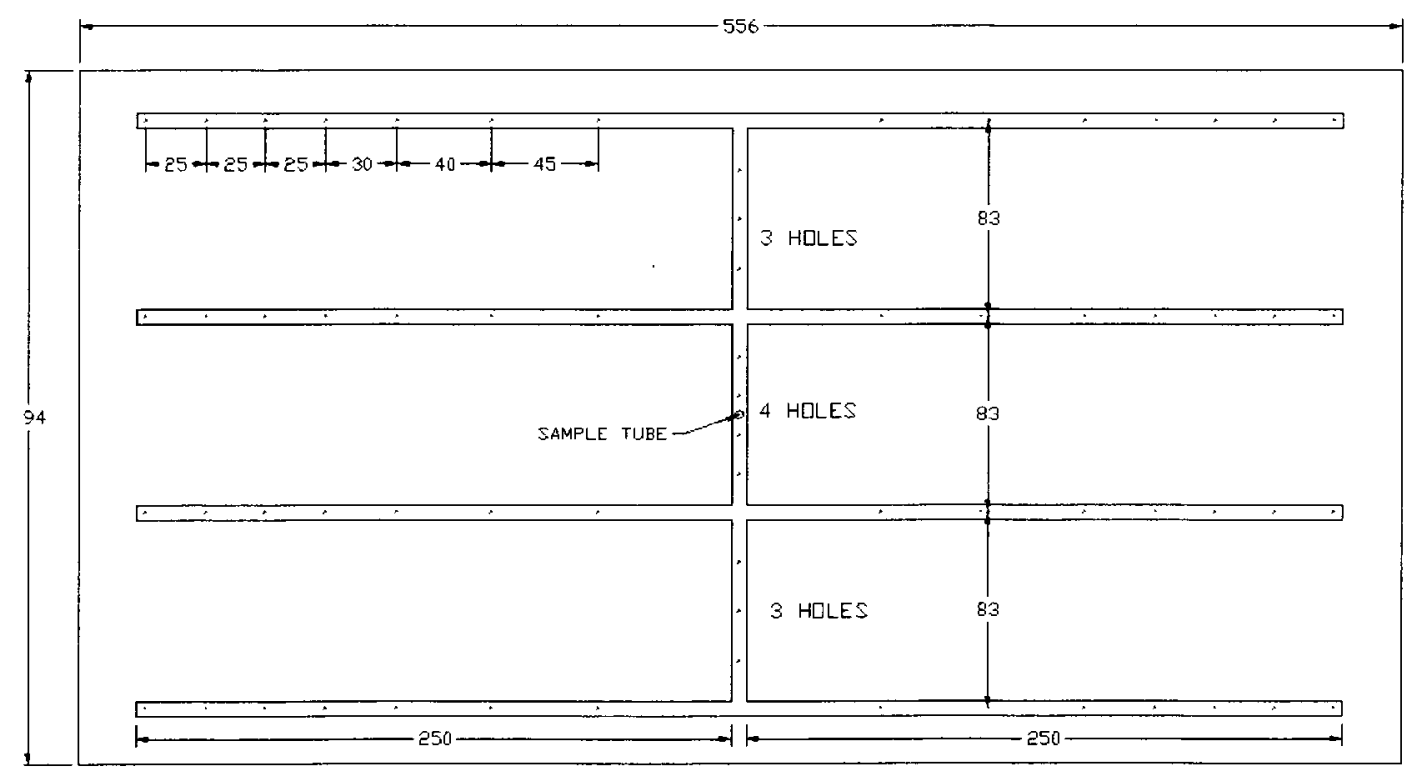

NDTES: 7 HOLES IN EACH BRANCH SYMMETRICAL

NIS

HOLES QN CENTER COLUMN EQUALLY SPACED

66 HOLES W L.09MM DIAMETER (TOTAL AREA 61.6mM?)

TUBING $316 S S$ QD $1 / 4^{\prime \prime}$ W/ BRASS FITTINGS

ALL DIMENSIONS IN CM.

Figure 5.15 Gas grid 
Table 5.1 List of instrumentation and devices

\begin{tabular}{|c|c|c|c|c|}
\hline Device & Quantity & Brand & Model & $\begin{array}{l}\text { Variables } \\
\text { Measured } \\
\end{array}$ \\
\hline Gas Analyzer & 1 & $\mathrm{ABB}$ & EL 3020 & $\begin{array}{c}\mathrm{O}_{2}, \mathrm{CO}, \mathrm{CO}_{2} \\
\text { Concentrations }\end{array}$ \\
\hline $\begin{array}{c}\text { Gas Analyzer Flow } \\
\text { Meter }\end{array}$ & 1 & Dwyer & RMA-26 & Gas Flow Rate \\
\hline Gas Grid & 1 & N/A (Custom) & $\mathrm{N} / \mathrm{A}$ & $\begin{array}{c}\mathrm{O}_{2}, \mathrm{CO}, \mathrm{CO}_{2} \\
\text { Concentrations } \\
\end{array}$ \\
\hline Gas Sampling Pump & 1 & $\begin{array}{l}\text { Dual Head Air } \\
\text { Cadet Pump }\end{array}$ & $\begin{array}{l}420- \\
2901 \\
\end{array}$ & N/A \\
\hline Gas Dryer & 1 & Drierite & $\mathrm{N} / \mathrm{A}$ & $\mathrm{N} / \mathrm{A}$ \\
\hline Condenser Coil & 1 & N/A (Custom) & N/A & $\mathrm{N} / \mathrm{A}$ \\
\hline Pressure Transducer & 4 & Omega & PX-274 & $\begin{array}{l}\text { Differential } \\
\text { Pressure }\end{array}$ \\
\hline Bi-Directional Probe & 4 & N/A (Custom) & N/A & $\begin{array}{c}\text { Differential } \\
\text { Pressure }\end{array}$ \\
\hline Thermocouple & 6 & Omega & Type J & Temperature \\
\hline Propane Burner & 1 & N/A (Custom) & N/A & $N / A$ \\
\hline Propane Flow Meter & 1 & $\begin{array}{c}\text { Sierra Steel- } \\
\text { Mass }\end{array}$ & $640 S$ & $\begin{array}{c}\text { Propane Flow } \\
\text { Rate }\end{array}$ \\
\hline $\begin{array}{c}\text { Data Acquisition } \\
\text { System }\end{array}$ & 1 & $\begin{array}{c}\text { National } \\
\text { Instruments }\end{array}$ & $\begin{array}{l}\text { CDAQ- } \\
9172\end{array}$ & $\begin{array}{l}\text { All variables input } \\
\text { into channels }\end{array}$ \\
\hline $\begin{array}{c}12.00 \% \mathrm{O}_{2} \text { Calibration } \\
\text { Gas }\end{array}$ & 1 & Praxair & Size A3 & N/A \\
\hline $\begin{array}{c}4.98 \% \mathrm{CO}_{2} \text { Calibration } \\
\text { Gas }\end{array}$ & 1 & Praxair & $\begin{array}{c}\text { NI CD5C- } \\
\mathrm{A3}\end{array}$ & $N / A$ \\
\hline $\begin{array}{l}\text { 901ppm CO } \\
\text { Calibration Gas }\end{array}$ & 1 & Praxair & $\begin{array}{c}\mathrm{NICO} \\
900 \mathrm{C}-\mathrm{A3} \\
\end{array}$ & $\mathrm{N} / \mathrm{A}$ \\
\hline $\begin{array}{c}99.999 \% \mathrm{~N}_{2} \text { 0-point } \\
\text { Calibration Gas }\end{array}$ & 1 & Praxair & $\begin{array}{c}\mathrm{NI} \\
5.0 \mathrm{UH}- \\
\mathrm{A3}\end{array}$ & $N / A$ \\
\hline
\end{tabular}


Table 5.2 List of simulations and measurements for instrumentation design [40]

\begin{tabular}{|c|c|c|c|c|}
\hline Scenario & $\begin{array}{c}\text { Fire Size } \\
(\mathbf{M W})\end{array}$ & $\begin{array}{c}\text { Ventilation } \\
\text { Configuration }\end{array}$ & $\begin{array}{c}\text { Fan speed } \\
(\mathbf{\%})\end{array}$ & $\begin{array}{c}\text { Simulation/ } \\
\text { Measurement }\end{array}$ \\
\hline 1 & 0 & Tunnel & 25 & Simulation \\
\hline 2 & 0 & Tunnel & 25 & Measurement \\
\hline 3 & 2.5 & Atrium & 25 & Simulation (OD) \\
\hline 4 & 0 & Atrium & 25 & Simulation \\
\hline 5 & 0 & Tunnel & 50 & Simulation \\
\hline 6 & 2.5 & Tunnel & 50 & Simulation \\
\hline 7 & 10 & Tunnel & 50 & Simulation \\
\hline 8 & 20 & Tunnel & 50 & Simulation \\
\hline 9 & 0 & Tunnel & 50 & Measurement \\
\hline 10 & 0 & Atrium & 50 & Simulation \\
\hline 11 & 0 & Atrium & 50 & Simulation (OD) \\
\hline 12 & 10 & Atrium & 50 & Simulation (OD) \\
\hline 13 & 0 & Atrium & 50 & Measurement \\
\hline 14 & 0 & Atrium & 50 & Measurement (OD) \\
\hline 15 & 0 & Tunnel & 75 & Measurement \\
\hline 16 & 0 & Tunnel & 75 & Simulation \\
\hline 17 & 10 & Atrium & 75 & Simulation (OD) \\
\hline 18 & 0 & Tunnel & 100 & Simulation \\
\hline 19 & 0 & Tunnel & 100 & Measurement \\
\hline 20 & 0 & Atrium & 100 & Simulation \\
\hline 21 & 10 & Atrium & 100 & Simulation \\
\hline 22 & 20 & Atrium & 100 & Simulation (OD) \\
\hline 23 & 20 & Atrium & 100 & Simulation \\
\hline 24 & 2.5 & Tunnel & 50 & Measurement \\
\hline 25 & 10 & Tunnel & 25 & Simulation \\
\hline 26 & 10 & Tunnel & 100 & Simulation \\
\hline
\end{tabular}

Note: OD refers to both doors from the atrium vent into the fan chamber open, as opposed to only the small one

Table is organized by fan speed except for last three scenarios. Scenario 24 had incomplete data and could not be used for some analyses and scenarios 25 and 26 were used for temperature profile purposes, not velocity. 
Table 5.3 Velocity errors of all probe location combinations for $25 \%$ fan speed scenarios

\begin{tabular}{|c|c|c|c|c|c|}
\hline \multirow{2}{*}{\multicolumn{2}{|c|}{ Scenario }} & \multicolumn{4}{|c|}{ Fan $25 \%$} \\
\hline & & 1 & 2 & 3 & 4 \\
\hline $\begin{array}{c}\text { Probe } \\
\text { Combination }\end{array}$ & $\begin{array}{l}\text { No. of } \\
\text { Probes }\end{array}$ & $\begin{array}{l}0 \text { MW } \\
\text { Tun } \\
25 \% \\
\text { Sim } \\
\end{array}$ & $\begin{array}{c}\text { O MW } \\
\text { Tun } \\
25 \% \\
\text { Meas } \\
\end{array}$ & $\begin{array}{c}2.5 \mathrm{MW} \\
\text { Atr } \\
25 \% \\
\text { Sim } \\
\text { (OD) } \\
\end{array}$ & $\begin{array}{l}0 \text { MW } \\
\text { Atr } \\
25 \% \\
\text { Sim } \\
\end{array}$ \\
\hline \multicolumn{2}{|c|}{ Average Velocity } & 2.04 & 2.66 & 1.9 & 1.3 \\
\hline 1 & 2 & 0.07 & -0.01 & 0.24 & -0.31 \\
\hline 2 & 2 & 0.27 & 0.14 & 0.15 & 0.40 \\
\hline 3 & 4 & 0.17 & 0.06 & 0.19 & 0.04 \\
\hline 4 & 3 & 0.06 & -0.13 & 0.23 & -0.12 \\
\hline 5 & 5 & 0.15 & -0.04 & 0.20 & -0.02 \\
\hline 6 & 3 & 0.15 & -0.09 & 0.28 & -0.14 \\
\hline 7 & 3 & 0.02 & -0.33 & 0.16 & -0.18 \\
\hline 8 & 3 & 0.21 & -0.09 & 0.24 & 0.12 \\
\hline 9 & 9 & 0.10 & -0.03 & 0.12 & 0.13 \\
\hline 10 & 30 & -0.03 & -0.05 & -0.08 & 0.04 \\
\hline 11 & 18 & -0.10 & -0.09 & -0.24 & -0.04 \\
\hline 12 & 20 & 0.05 & -0.04 & -0.01 & 0.02 \\
\hline 13 & 25 & 0.05 & -0.05 & -0.03 & 0.06 \\
\hline 14 & 9 & 0.09 & -0.06 & 0.13 & -0.04 \\
\hline 15 & 12 & 0.12 & -0.06 & 0.15 & 0.01 \\
\hline 16 & 8 & 0.12 & 0.06 & 0.18 & -0.07 \\
\hline 17 & 8 & 0.13 & -0.09 & 0.23 & 0.09 \\
\hline 18 & 8 & 0.07 & 0.05 & 0.07 & 0.05 \\
\hline 19 & 5 & 0.11 & -0.06 & 0.08 & 0.10 \\
\hline 20 & 4 & 0.11 & 0.04 & 0.03 & 0.19 \\
\hline 21 & 4 & 0.02 & -0.04 & 0.01 & 0.32 \\
\hline 22 & 4 & 0.08 & 0.14 & 0.05 & -0.03 \\
\hline 23 & 2 & 0.15 & 0.14 & 0.31 & -0.11 \\
\hline 24 & 2 & -0.01 & -0.26 & 0.12 & -0.13 \\
\hline 25 & 4 & 0.15 & 0.22 & 0.22 & -0.04 \\
\hline 26 & 4 & 0.12 & 0.06 & 0.25 & -0.10 \\
\hline 27 & 4 & 0.11 & 0.09 & 0.03 & 0.04 \\
\hline 28 & 4 & 0.05 & 0.09 & 0.08 & -0.07 \\
\hline
\end{tabular}

Note: Bold values represent the five most accurate combinations 
Table 5.4 Velocity errors of all probe location combinations for $50 \%$ fan speed scenarios

\begin{tabular}{|c|c|c|c|c|c|c|}
\hline \multirow{2}{*}{\multicolumn{2}{|c|}{ Scenario }} & \multicolumn{5}{|c|}{ Fan $50 \%$} \\
\hline & & 5 & 6 & 7 & 8 & 9 \\
\hline $\begin{array}{c}\text { Probe } \\
\text { Combination }\end{array}$ & $\begin{array}{l}\text { No. of } \\
\text { Probes }\end{array}$ & $\begin{array}{l}\text { OMW } \\
\text { Tun } \\
\mathbf{5 0 \%} \\
\text { Sim } \\
\end{array}$ & $\begin{array}{c}2.5 \mathrm{MW} \\
\text { Tun } \\
\mathbf{5 0} \% \\
\text { Sim } \\
\end{array}$ & $\begin{array}{c}\text { 10MW } \\
\text { Tun } \\
50 \% \\
\text { Sim } \\
\end{array}$ & $\begin{array}{c}20 M W \\
\text { Tun } \\
50 \% \\
\text { Sim } \\
\end{array}$ & $\begin{array}{c}\text { OMW } \\
\text { Tun } \\
50 \% \\
\text { Meas } \\
\end{array}$ \\
\hline \multicolumn{2}{|c|}{ Average Velocity } & 4.07 & 4.18 & 4.16 & 4.27 & 4.56 \\
\hline 1 & 2 & 0.20 & 0.45 & 0.47 & 0.41 & 0.19 \\
\hline 2 & 2 & 0.51 & 0.35 & 0.30 & 0.30 & 0.04 \\
\hline 3 & 4 & 0.35 & 0.40 & 0.39 & 0.36 & 0.12 \\
\hline 4 & 3 & 0.20 & 0.32 & 0.38 & 0.29 & -0.03 \\
\hline 5 & 5 & 0.33 & 0.41 & 0.38 & 0.34 & 0.12 \\
\hline 6 & 3 & 0.34 & 0.40 & 0.35 & 0.33 & 0.14 \\
\hline 7 & 3 & 0.11 & 0.21 & 0.22 & 0.10 & 0.07 \\
\hline 8 & 3 & 0.41 & 0.48 & 0.49 & 0.53 & 0.07 \\
\hline 9 & 9 & 0.21 & 0.22 & 0.23 & 0.25 & -0.12 \\
\hline 10 & 30 & -0.05 & -0.05 & -0.05 & -0.01 & 0.06 \\
\hline 11 & 18 & -0.19 & -0.21 & -0.22 & -0.17 & -0.02 \\
\hline 12 & 20 & 0.11 & 0.11 & 0.11 & 0.11 & -0.24 \\
\hline 13 & 25 & 0.11 & 0.09 & 0.09 & 0.12 & 0.07 \\
\hline 14 & 9 & 0.21 & 0.26 & 0.24 & 0.18 & 0.07 \\
\hline 15 & 12 & 0.26 & 0.31 & 0.30 & 0.26 & 0.04 \\
\hline 16 & 8 & 0.24 & 0.33 & 0.28 & 0.23 & 0.13 \\
\hline 17 & 8 & 0.29 & 0.35 & 0.36 & 0.36 & -0.01 \\
\hline 18 & 8 & 0.15 & 0.13 & 0.13 & 0.10 & -0.03 \\
\hline 19 & 5 & 0.21 & 0.22 & 0.17 & 0.19 & 0.16 \\
\hline 20 & 4 & 0.20 & 0.17 & 0.12 & 0.16 & 0.17 \\
\hline 21 & 4 & 0.00 & -0.02 & -0.04 & 0.15 & 0.14 \\
\hline 22 & 4 & 0.17 & 0.18 & 0.14 & 0.07 & 0.27 \\
\hline 23 & 2 & 0.30 & 0.49 & 0.40 & 0.39 & 0.09 \\
\hline 24 & 2 & 0.05 & 0.09 & 0.15 & 0.01 & 0.04 \\
\hline 25 & 4 & 0.31 & 0.38 & 0.37 & 0.31 & 0.14 \\
\hline 26 & 4 & 0.26 & 0.37 & 0.36 & 0.27 & -0.01 \\
\hline 27 & 4 & 0.21 & 0.19 & 0.15 & 0.12 & 0.19 \\
\hline 28 & 4 & 0.14 & 0.14 & 0.13 & 0.05 & 0.07 \\
\hline
\end{tabular}

Note: Highlighted values represent the five most accurate combinations 
Table 5.4 (Continued) Velocity errors of all probe location combinations for $50 \%$ fan speed scenarios

\begin{tabular}{|c|c|c|c|c|c|c|}
\hline & & \multicolumn{5}{|c|}{ Fan $50 \%$} \\
\hline \multicolumn{2}{|c|}{ Scenario } & 10 & 11 & 12 & 13 & 14 \\
\hline $\begin{array}{c}\text { Probe } \\
\text { Combination }\end{array}$ & $\begin{array}{l}\text { No. of } \\
\text { Probes }\end{array}$ & $\begin{array}{c}\text { OMW } \\
\text { Atr } \\
50 \% \\
\text { Sim }\end{array}$ & $\begin{array}{c}\text { OMW } \\
\text { Atr } \\
50 \% \\
\text { Sim } \\
\text { (OD) }\end{array}$ & $\begin{array}{c}\text { 10MW } \\
\text { Atr } \\
50 \% \\
\text { Sim } \\
\text { (OD) }\end{array}$ & $\begin{array}{c}\text { OMW } \\
\text { Atr } \\
50 \% \\
\text { Meas }\end{array}$ & $\begin{array}{c}\text { OMW } \\
\text { Atr } \\
50 \% \\
\text { Meas } \\
\text { (OD) }\end{array}$ \\
\hline \multicolumn{2}{|c|}{ Average Velocity } & 2.56 & 3.68 & 3.88 & 3.57 & 4.23 \\
\hline 1 & 2 & -0.65 & 0.60 & 0.14 & -1.62 & -1.08 \\
\hline 2 & 2 & 0.87 & 0.06 & 0.42 & 1.33 & 0.87 \\
\hline 3 & 4 & 0.11 & 0.33 & 0.28 & -0.15 & -0.11 \\
\hline 4 & 3 & -0.24 & 0.31 & 0.29 & -0.74 & -0.53 \\
\hline 5 & 5 & -0.06 & 0.27 & 0.34 & -0.33 & -0.19 \\
\hline 6 & 3 & -0.32 & 0.18 & 0.54 & -0.44 & -0.16 \\
\hline 7 & 3 & -0.43 & -0.01 & 0.29 & -0.64 & 0.00 \\
\hline 8 & 3 & 0.20 & 0.50 & 0.57 & -0.20 & 0.00 \\
\hline 9 & 9 & 0.28 & 0.31 & 0.24 & 0.26 & 0.11 \\
\hline 10 & 30 & 0.08 & -0.11 & -0.12 & 0.25 & 0.03 \\
\hline 11 & 18 & -0.09 & -0.38 & -0.42 & 0.20 & -0.15 \\
\hline 12 & 20 & 0.06 & -0.04 & -0.01 & 0.27 & -0.10 \\
\hline 13 & 25 & 0.15 & 0.00 & -0.03 & 0.25 & 0.04 \\
\hline 14 & 9 & -0.13 & 0.11 & 0.21 & -0.50 & -0.15 \\
\hline 15 & 12 & -0.04 & 0.21 & 0.28 & -0.28 & -0.17 \\
\hline 16 & 8 & -0.16 & 0.10 & 0.26 & -0.61 & 0.04 \\
\hline 17 & 8 & 0.22 & 0.37 & 0.35 & 0.06 & 0.12 \\
\hline 18 & 8 & 0.13 & 0.14 & 0.08 & 0.33 & 0.03 \\
\hline 19 & 5 & 0.21 & 0.25 & 0.17 & 0.37 & -0.05 \\
\hline 20 & 4 & 0.45 & 0.30 & 0.06 & 0.73 & 0.07 \\
\hline 21 & 4 & 0.73 & 0.33 & 0.04 & 1.18 & 0.17 \\
\hline 22 & 4 & -0.01 & 0.08 & 0.07 & 0.06 & 0.17 \\
\hline 23 & 2 & -0.39 & 0.10 & 0.48 & -1.12 & -0.23 \\
\hline 24 & 2 & -0.26 & -0.03 & 0.13 & -0.42 & 0.27 \\
\hline 25 & 4 & -0.05 & 0.24 & 0.30 & -0.32 & 0.12 \\
\hline 26 & 4 & -0.18 & 0.18 & 0.32 & -0.62 & -0.01 \\
\hline 27 & 4 & 0.13 & 0.14 & 0.04 & 0.06 & -0.21 \\
\hline 28 & 4 & -0.11 & 0.03 & 0.09 & 0.21 & 0.14 \\
\hline
\end{tabular}

Note: Highlighted values represent the five most accurate combinations 
Table 5.5 Velocity errors of all probe location combinations for $75 \%$ fan speed scenarios

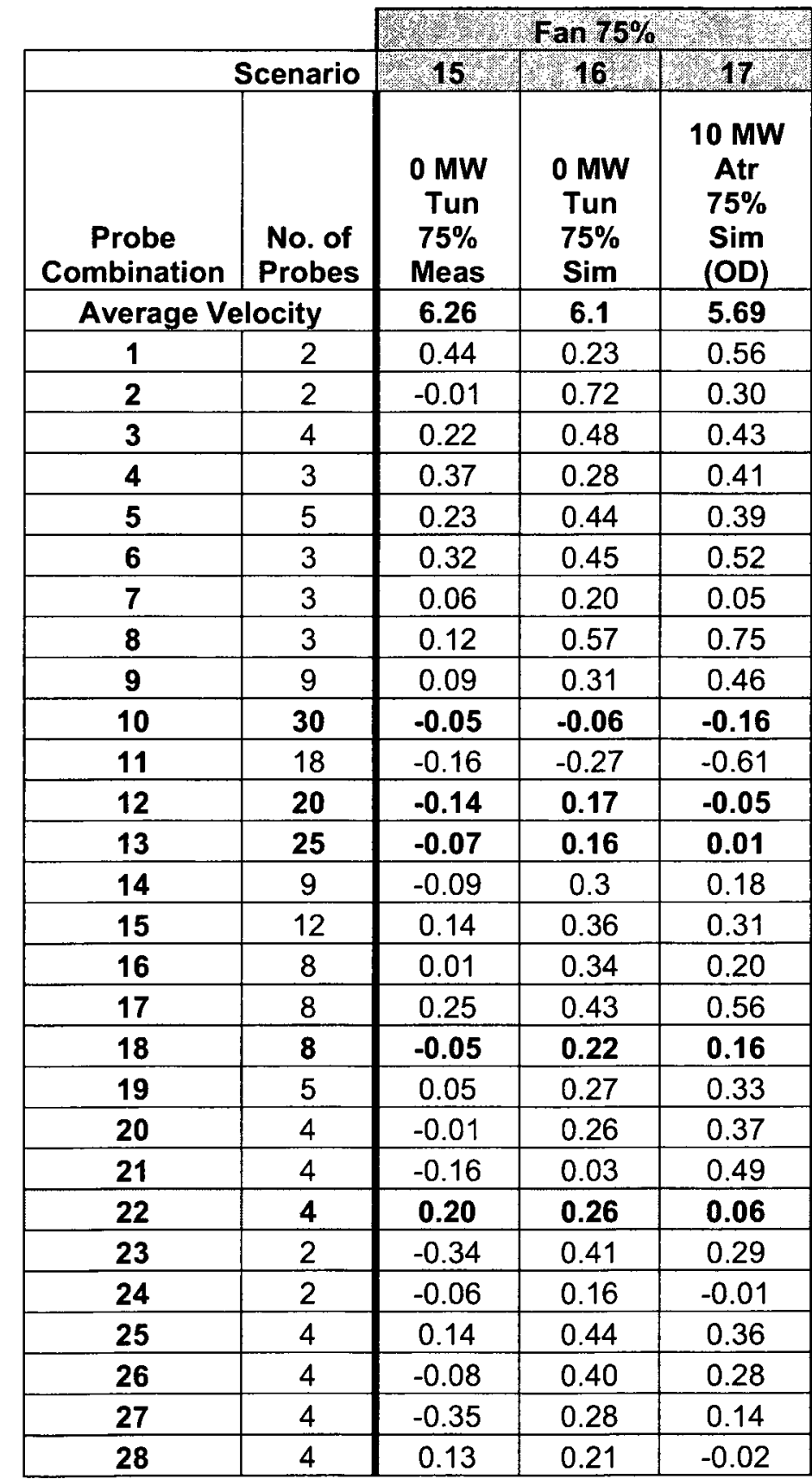

Note: Highlighted values represent the five most accurate combinations 
Table 5.6 Velocity errors of all probe location combinations for $100 \%$ fan speed scenarios

\begin{tabular}{|c|c|c|c|c|c|c|c|}
\hline & \multicolumn{6}{|c|}{ 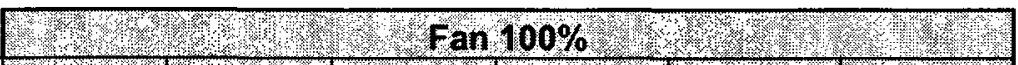 } \\
\hline & & \multirow{2}{*}{$\begin{array}{c}18 \\
0 \mathrm{MW} \\
\text { Tun } \\
100 \% \\
\text { Sim }\end{array}$} & \multirow{2}{*}{$\begin{array}{c}19 \\
0 \text { MW } \\
\text { Tun } \\
100 \% \\
\text { Meas }\end{array}$} & \multirow{2}{*}{$\begin{array}{l}020 \\
\\
0 \mathrm{MW} \\
\text { Atr } \\
100 \% \\
\text { Sim }\end{array}$} & \multirow{2}{*}{$\begin{array}{l}21 \\
10 \mathrm{MW} \\
\text { Atr } \\
100 \% \\
\text { Sim }\end{array}$} & \multirow{2}{*}{$\begin{array}{c}22 \\
20 \mathrm{MW} \\
\text { Atr } \\
100 \% \\
\text { Sim } \\
(\mathrm{OD}) \\
\end{array}$} & \multirow{2}{*}{$\begin{array}{c}23 \\
20 \mathrm{MW} \\
\text { Atr } \\
100 \% \\
\text { Sim }\end{array}$} \\
\hline $\begin{array}{c}\text { Probe } \\
\text { Combination }\end{array}$ & $\begin{array}{l}\text { No. of } \\
\text { Probes }\end{array}$ & & & & & & \\
\hline \multicolumn{2}{|c|}{ Average Velocity } & 8.13 & 7.64 & 5.2 & 6.92 & 7.56 & 6.98 \\
\hline 1 & 2 & 0.40 & 0.46 & -1.37 & -1.49 & 1.18 & -1.41 \\
\hline 2 & 2 & 1.00 & -0.01 & 1.70 & 1.79 & 0.08 & 2.11 \\
\hline 3 & 4 & 0.70 & 0.22 & 0.17 & 0.15 & 0.63 & 0.35 \\
\hline 4 & 3 & 0.47 & 0.16 & -0.55 & -0.46 & 0.62 & -0.36 \\
\hline 5 & 5 & 0.66 & 0.08 & -0.13 & -0.05 & 0.51 & 0.16 \\
\hline 6 & 3 & 0.69 & -0.06 & -0.59 & -0.64 & 0.23 & -0.16 \\
\hline 7 & 3 & 0.33 & -0.24 & -0.82 & -0.56 & -0.06 & -0.60 \\
\hline 8 & 3 & 0.82 & 0.06 & 0.47 & 0.84 & 1.00 & 0.93 \\
\hline 9 & 9 & 0.39 & 0.06 & 0.57 & 0.53 & 0.63 & 0.47 \\
\hline 10 & 30 & -0.10 & -0.05 & 0.18 & -0.09 & -0.21 & -0.13 \\
\hline 11 & 18 & -0.39 & -0.18 & -0.16 & -0.59 & -0.80 & -0.71 \\
\hline 12 & 20 & 0.23 & -0.12 & 0.09 & 0.02 & -0.07 & -0.03 \\
\hline 13 & 25 & 0.21 & -0.26 & 0.29 & 0.12 & 0.01 & 0.10 \\
\hline 14 & 9 & 0.44 & 0.19 & -0.23 & -0.14 & 0.19 & -0.09 \\
\hline 15 & 12 & 0.52 & 0.13 & -0.01 & 0.05 & 0.35 & 0.16 \\
\hline 16 & 8 & 0.51 & -0.01 & -0.33 & -0.21 & 0.21 & -0.03 \\
\hline 17 & 8 & 0.58 & 0.20 & 0.40 & 0.47 & 0.80 & 0.51 \\
\hline 18 & 8 & 0.28 & 0.22 & 0.21 & 0.05 & 0.23 & -0.03 \\
\hline 19 & 5 & 0.32 & 0.08 & 0.44 & 0.19 & 0.42 & 0.24 \\
\hline 20 & 4 & 0.28 & 0.22 & 0.88 & 0.46 & 0.53 & 0.44 \\
\hline 21 & 4 & -0.08 & -0.52 & 1.49 & 0.93 & 0.74 & 0.75 \\
\hline 22 & 4 & 0.36 & 0.14 & -0.10 & -0.18 & 0.10 & -0.24 \\
\hline 23 & 2 & 0.65 & 0.09 & -0.62 & -0.26 & 0.28 & 0.20 \\
\hline 24 & 2 & 0.25 & -0.12 & -0.57 & -0.40 & -0.08 & -0.61 \\
\hline 25 & 4 & 0.65 & 0.19 & -0.20 & -0.12 & 0.47 & 0.08 \\
\hline 26 & 4 & 0.58 & 0.37 & -0.47 & -0.30 & 0.37 & -0.10 \\
\hline 27 & 4 & 0.38 & 0.54 & 0.19 & 0.05 & 0.21 & -0.04 \\
\hline 28 & 4 & 0.32 & 0.16 & -0.31 & -0.31 & 0.01 & -0.41 \\
\hline
\end{tabular}

Note: Highlighted values represent the five most accurate combinations 
Table 5.7 Percent error values for velocity probe combination \#22 for all considered scenarios

\begin{tabular}{|c|c|}
\hline Scenario & $\begin{array}{c}\text { Combo 22 } \\
\text { \% Error }\end{array}$ \\
\hline 1 & 4.1 \\
\hline 2 & 5.3 \\
\hline 3 & 2.5 \\
\hline 4 & 1.9 \\
\hline 5 & 4.3 \\
\hline 6 & 4.2 \\
\hline 7 & 3.4 \\
\hline 8 & 1.7 \\
\hline 9 & 5.8 \\
\hline 10 & 0.2 \\
\hline 11 & 2.1 \\
\hline 12 & 1.7 \\
\hline 13 & 1.5 \\
\hline 14 & 4.0 \\
\hline 15 & 3.2 \\
\hline 16 & 4.2 \\
\hline 17 & 1.0 \\
\hline 18 & 4.4 \\
\hline 19 & 1.8 \\
\hline 20 & 1.9 \\
\hline 21 & 2.6 \\
\hline 22 & 1.3 \\
\hline 23 & 3.5 \\
\hline
\end{tabular}


Table 5.8 Average percent error values for velocity probe combination \#22 for general categories compared to average of all combinations

\begin{tabular}{|c|c|c|c|}
\hline \multirow{4}{*}{ All Results } & Fan Speed & $\begin{array}{c}\text { Combination } \\
\mathbf{2 2}\end{array}$ & $\begin{array}{c}\text { Average of all } \\
\mathbf{2 8} \\
\text { Combinations }\end{array}$ \\
\hline & $25 \%$ & 3.8 & 5.7 \\
\cline { 2 - 4 } & $50 \%$ & 3.1 & 6.2 \\
\cline { 2 - 4 } & $75 \%$ & 2.8 & 4.3 \\
\hline \multirow{4}{*}{ Tunnel } & $100 \%$ & 2.6 & 5.5 \\
\cline { 2 - 4 } & $25 \%$ & 4.8 & 4.2 \\
\cline { 2 - 4 } & $50 \%$ & 3.9 & 5.0 \\
\cline { 2 - 4 } & $75 \%$ & 3.7 & 3.8 \\
\hline \multirow{4}{*}{ Atrium } & $100 \%$ & 3.1 & 4.0 \\
\cline { 2 - 4 } & $25 \%$ & 2.3 & 7.9 \\
\cline { 2 - 4 } & $50 \%$ & 2.1 & 7.5 \\
\cline { 2 - 4 } & $75 \%$ & 1.0 & 5.3 \\
\cline { 2 - 4 } & $100 \%$ & 2.3 & 6.4 \\
\hline
\end{tabular}


Table 5.9 NI DAQ Channels

\begin{tabular}{|c|c|c|c|c|c|}
\hline $\begin{array}{c}\text { Channel } \\
\text { No. }\end{array}$ & Channel Type & $\begin{array}{c}\text { Input } \\
\text { Module }\end{array}$ & Device & $\begin{array}{c}\text { Variable } \\
\text { measured }\end{array}$ & $\begin{array}{c}\text { Device } \\
\text { ID }\end{array}$ \\
\hline 0 & Thermocouple & NI 9211 (1) & $\begin{array}{c}\text { Type J } \\
\text { Thermocouple }\end{array}$ & Temperature & $\mathrm{T} 1$ \\
\hline 1 & Thermocouple & NI 9211 (1) & $\begin{array}{c}\text { Type J } \\
\text { Thermocouple }\end{array}$ & Temperature & $\mathrm{T} 2$ \\
\hline 2 & Thermocouple & NI 9211 (1) & $\begin{array}{c}\text { Type J } \\
\text { Thermocouple }\end{array}$ & Temperature & T3 \\
\hline 3 & Thermocouple & NI 9211 (1) & $\begin{array}{c}\text { Type J } \\
\text { Thermocouple }\end{array}$ & Temperature & T4 \\
\hline 0 & Thermocouple & NI $9211(2)$ & $\begin{array}{c}\text { Type J } \\
\text { Thermocouple }\end{array}$ & Temperature & T5 \\
\hline 1 & Thermocouple & NI $9211(2)$ & $\begin{array}{c}\text { Type J } \\
\text { Thermocouple }\end{array}$ & Temperature & T6 \\
\hline 0 & Current & NI 9203 & Gas Analyzer & $\mathrm{O}_{2}$ Concentration & $\mathrm{O}_{2}$ \\
\hline 1 & Current & NI 9203 & Gas Analyzer & $\begin{array}{c}\mathrm{CO} \\
\text { Concentration } \\
\end{array}$ & $\mathrm{CO}$ \\
\hline 2 & Current & NI 9203 & Gas Analyzer & $\begin{array}{c}\mathrm{CO}_{2} \\
\text { Concentration }\end{array}$ & $\mathrm{CO}_{2}$ \\
\hline 3 & Current & NI 9203 & $\begin{array}{l}\text { Pressure } \\
\text { Transducer }\end{array}$ & Velocity & B1 \\
\hline 4 & Current & NI 9203 & $\begin{array}{l}\text { Pressure } \\
\text { Transducer }\end{array}$ & Velocity & $\mathrm{B} 2$ \\
\hline 5 & Current & NI 9203 & $\begin{array}{l}\text { Pressure } \\
\text { Transducer }\end{array}$ & Velocity & B3 \\
\hline 6 & Current & NI 9203 & $\begin{array}{l}\text { Pressure } \\
\text { Transducer }\end{array}$ & Velocity & B4 \\
\hline 7 & Current & N1 9203 & $\begin{array}{c}\text { Propane Flow } \\
\text { Meter }\end{array}$ & $\begin{array}{c}\text { Propane flow } \\
\text { rate }\end{array}$ & $\mathrm{P}$ \\
\hline
\end{tabular}




\section{Chapter 6: Labview Programming}

One of the objectives of this project is to provide a near real-time display of the HRR of any fire being run in the experimental atrium at Carleton University's fire research laboratory. In order to provide this, Labview version 8.6 was programmed to receive data from the NI DAS, analyze the data received at every time-step during a test, provide graphic displays of the results and write the data to a file. Labview is a platform and development environment which is used to develop virtual instrument panels that can be used for data acquisition, instrument control and various other applications. Labview uses a data flow system which logically moves data through routes called wires to various functions and other applications called Virtual Instruments (VIs). Labview is developed by NI and is designed to be compatible with the NI DAS employed for this purpose.

Labview has two main screens. The block diagram is where the user programs and wires all the VIs together in order to build the system. The front panel is the visual representation or display where the user can input data, use controls and view results in real time. Every object, display, control, etc. on the front panel has a corresponding icon on the block diagram into or out of which the appropriate variables are wired. Views of the block diagram and front panel are shown in Appendix C.

A "DAQ Assistant Express" VI is used to collect the raw data from all sensors and deliver them into Labview for processing. Inside this VI, the channels can be configured and the frequency and number of samples can be set. The channel configuration is shown in Table 6.1. Through a trial and error process, it was found that using a frequency of $2000 \mathrm{~Hz}$ and collecting 400 samples to be averaged at every time 
step yielded a signal with the least noise. In order to control the timing of the program, a "Case Structure" was placed around the bulk of the code. The purpose of the case structure is to run the entire program every time it receives a Boolean "true" value and do nothing when "false" is received. An "Elapsed Time" VI provides a "true" value every time step, signaling the entire process of data acquisition and processing, display and writing to file to occur once. The program will then wait for another "true" value. At the beginning of a time step, 400 samples are sent from the "DAQ Assistant Express" VI for each of the 14 sensors in the form of a 2-D array. The 400 values are averaged in order to reduce as much random and periodic signal noise as possible. The result of this process is a 1-D array with a single value from each sensor from which the rest of the program can take the required data in order to process it.

The first six channels are dedicated to the six thermocouples. Indicators for all current temperature values and the maximum and minimum values are provided on the Front Panel. These values are then sent through a formula VI which calculates the average of the six. This value is then used for calculating the gas density using equation (4-1).

The next four channels are dedicated to the four pressure transducers receiving data from the bi-directional probes. The raw current values must first be converted into differential pressures using equation (4-12) and then from there into velocities using equation (4-3). Indicators and a graph for individual velocities are provided on the Front Panel. The four velocity values are then averaged and then time-averaged over ten time 
steps in order to smooth out the data. The mass flow rate can then be calculated using equation (4-4).

The next three channels are dedicated to $\mathrm{O}_{2}, \mathrm{CO}$, and $\mathrm{CO}_{2}$ concentrations. The raw current values must first be converted into volumetric fractions using equations (414), (4-15) and (4-16). Indicators and graphs of the maximum, minimum and current values for each are available on the Front Panel. These values are then used to calculate the oxygen depletion factor required for the final HRR calculation.

Next, the oxygen depletion factor, $\varphi$, must be calculated using equation (4-7). The oxygen depletion factor represents the fraction of incoming air that is depleted of oxygen.

The HRR is calculated using equation (4-8). All of the above values are required for this calculation as well as the $\mathrm{E}$ and $\alpha$ values and the molar fraction of incoming $\mathrm{H}_{2} \mathrm{O}$ which is calculated using the relative humidity and the saturation and ambient pressures. All of these values are assumed to be constant. This can be done because the $\mathrm{E}$ and $\alpha$ values are constant and the sensitivity of the HRR calculations to the rest of these variables is very low as discussed in section 4.1 .

The delay time required for the exhaust gases to move from the sampling location to the first indication of change by the gas analyzer has been determined to be approximately $40 \mathrm{~s}$. This was found by directly injecting a calibration gas containing 901 ppm CO into the gas tube connected to the center of the gas grid. In order to ensure that the calculations being carried out are using data from the same time, or the data is synchronized, this delay time must be accounted for. There is negligible delay time for 
both thermocouple and bi-directional probe measurements. Therefore, to synchronize the data, a "Delay Values" VI was used to delay mass flow rate by $45 \mathrm{~s}$. The extra five seconds is to give time for gas from the far reaches of the gas grid to reach the center. This results in an accurate and synchronized HRR calculation, but it also means that the screen display and measurement output of HRR is $45 \mathrm{~s}$ behind. The operator should be aware of this, as with a fast growing fire, the combination of this delay and the travel time for the gases means that the HRR may be much higher than the display currently indicates. More discussion of delay times can be found in section 7.6.

Because of the high number of calculations involved in one time step and the 0.2 seconds required to take the 400 samples at $2000 \mathrm{~Hz}$, the computer cannot perform all the calculations in 1 second. Therefore a time step of 1.5 seconds is used in this system. Because tests performed in this facility are relatively long and of a very large scale, receiving a data point every 1.5 seconds is more than adequate. If a researcher desires a smaller output file and more time between measurements, this can be changed quite easily by reconfiguring the "Elapsed Time" VI and adjusting the number of time steps in the "Delay Values" VI to match the 45 second delay to the gas analyzer. With the 1.5 second time steps, the "Delay Values" VI is configured to delay the values by 30 time steps to match the 45 seconds.

Because of the high level of turbulence in the system, even though the bidirectional probe locations were chosen carefully, there are significant oscillations in the measurements. The velocities from the four probes are averaged to abate this somewhat. On top of that, a "Time Average" VI has been utilized which provides a running time 
average of the velocity values over ten time steps ( 15 seconds) in order to smooth out the data and give a more reasonable representation of the HRR. During an experiment, the fans never change speed and the effects from the fire have a very small effect on the velocity profile. Therefore the average velocity is almost constant and using this timeaverage will not add significant error to the system.

For record keeping and future analysis, Labview also writes the data to a file. The program is designed to write all raw data, as well as important calculated values such as HRR, average velocities and temperatures, to a spreadsheet file. Every column in the output file represents a different measurement result including calculated and raw data. Table 6.2 provides a description of the variables of each column.

At very low fan speeds and when the fans are turned off, the noise in the system often indicates a negative differential pressure from the pressure transducers. Since it is necessary to take the square root of the differential pressure to convert it to a velocity, a negative value cannot be used. In order to deal with this, Labview has been programmed so that any negative values are eliminated and a zero is used. The implication of this is that noise at very low and zero fan speeds will always be positive and the program will therefore indicate some positive velocity even when fans are off. This should not be a problem for experiments however, as fans are usually set to at least $25 \%$, which generally yields acceptable results. At fan speeds lower than this, other issues may also cause questionable velocity measurement results including the "Barker Effect", as discussed in section 2.4 [28] and the fact that the pressure transducers are at the lowest end of their measurement range and are very sensitive at these values. The lower Re at low fan 
speeds may also cause a change in the probe factor which is not accounted for in the programming. It is therefore recommended that, when using the system for experiments, the fans are all running at or above $25 \%$ fan speed.

When the program is running, the front panel displays various useful values that can be monitored in near real time throughout the test. Charts and numeric indicators can be viewed for temperatures (both individual thermocouples and average), velocities (individual probes, average and time-average, as discussed above), mass flow rate, gas concentrations and HRR. Maximum and minimum displays of key variables such as temperature, HRR and gas concentrations are also provided so the operator can view peaks. A warning light comes on when temperature in the fan chamber reaches $300^{\circ} \mathrm{C}$ at any point so the operator knows that the fans may be damaged. Another warning light will come on if $\mathrm{CO}$ concentration reaches $500 \mathrm{ppm}$, indicating a potential safety hazard or a spike in the data that could be caused by some electrical disturbance. A table is also provided on the front panel showing some important data in near real time in addition to writing it to file.

There are some variables that the user can change if required. The ambient $\mathrm{O}_{2}$ and $\mathrm{CO}_{2}$ levels should be set to the levels that the gas analyzer indicates in the fan chamber just before an experiment. The net heat release per unit of oxygen consumed (E) should be set to 12.9 for propane fires or 13.1 for other fires with fuels of unknown composition [1]. Other values can be used if the composition of the test materials is known. The expansion factor $(\alpha)$ can also be changed. A value of 1.084 is suggested for propane [4] and 1.105 for other fuels of unknown composition [5]. The relative humidity 
and ambient pressure can also be set if required for additional precision. However, the HRR has a low sensitivity to these variables and it is not likely that changing them will be necessary. Defaults have been set at $50 \%$ and $101.5 \mathrm{kPa}$, respectively. The temperature-dependent saturation pressure has been set at a default of $2.5 \mathrm{kPa}$ and also has low sensitivity for HRR calculations. However, it can be set if necessary and Janssens suggests a curve to determine this value [5].

In some of the signals there is some drift between the measured value and the signal that is picked up by the DAS and fed into Labview. The drifts from the gas analyzer and the propane flow meter can be seen directly by comparing the value in Labview and the displays. In addition, when no propane is flowing, the propane flow rate should show as zero in Labview. To account for this, some very small adjustments are built into the Labview programming.

The gas values have constant drift. The $\mathrm{O}_{2}$ signal is adjusted by $0.017 \%$ and the $\mathrm{CO}_{2}$ signal is adjusted by $0.01 \%$. The $\mathrm{CO}$ is not adjusted. When these adjustments are employed, the values shown by the system match the values shown on the gas analyzer's display.

Because of the very long cable from the propane flow meter to the DAS, the noise and drift changes very slightly on different days. To account for this, before a calibration experiment the propane signal was occasionally adjusted slightly to bring the value to zero when no flow existed.

Two final Labview VIs are available for use on the system. One is to be used when running a propane test because it includes the propane HRR from the propane flow 
meter and it uses the $\mathrm{E}$ and $\alpha$ values for propane. The other VI is to be used for other fuels as no indication of propane is used and suggested $\mathrm{E}$ and $\alpha$ for other fuels are used. 
Table 6.1 Channel properties in Labview

\begin{tabular}{|c|c|c|c|c|}
\hline Order & Variable & ID & $\begin{array}{c}\text { Physical } \\
\text { Channel }\end{array}$ & $\begin{array}{c}\text { Signal input } \\
\text { Range }\end{array}$ \\
\hline 0 & Temperature & $\mathrm{T} 1$ & cDAQ1Mod5/ai0 & $0-100^{\circ} \mathrm{C}$ \\
\hline 1 & Temperature & $\mathrm{T} 2$ & cDAQ1Mod5/ai1 & $0-100^{\circ} \mathrm{C}$ \\
\hline 2 & Temperature & $\mathrm{T} 3$ & cDAQ1Mod5/ai2 & $0-100^{\circ} \mathrm{C}$ \\
\hline 3 & Temperature & $\mathrm{T} 4$ & cDAQ1Mod5/ai3 & $0-100^{\circ} \mathrm{C}$ \\
\hline 4 & Temperature & $\mathrm{T} 5$ & cDAQ1Mod2/ai0 & $0-100^{\circ} \mathrm{C}$ \\
\hline 5 & Temperature & $\mathrm{T} 6$ & cDAQ1Mod2/ai1 & $0-100^{\circ} \mathrm{C}$ \\
\hline 6 & Velocity & $\mathrm{V} 1$ & cDAQ1Mod3/ai3 & $0-20 \mathrm{~mA}$ \\
\hline 7 & Velocity & $\mathrm{V} 2$ & cDAQ1Mod3/ai4 & $0-20 \mathrm{~mA}$ \\
\hline 8 & Velocity & $\mathrm{V} 3$ & cDAQ1Mod3/ai5 & $0-20 \mathrm{~mA}$ \\
\hline 9 & Velocity & $\mathrm{V} 4$ & cDAQ1Mod3/ai6 & $0-20 \mathrm{~mA}$ \\
\hline 10 & $\mathrm{O}_{2}$ Concentration & $\mathrm{O}_{2}$ & cDAQ1Mod3/ai0 & $0-20 \mathrm{~mA}$ \\
\hline 11 & CO Concentration & $\mathrm{CO}$ & CDAQ1Mod3/ai1 & $0-20 \mathrm{~mA}$ \\
\hline 12 & CO ${ }_{2}$ Concentration & $\mathrm{CO} 2$ & cDAQ1Mod3/ai2 & $0-20 \mathrm{~mA}$ \\
\hline 13 & Propane flow rate & Propane & cDAQ1Mod3/ai7 & $0-20 \mathrm{~mA}$ \\
\hline
\end{tabular}


Table 6.2 Measurement output file key

\begin{tabular}{|c|l|}
\hline Column & Output Value \\
\hline A & time (s) \\
\hline B & HRR Calculated (MW) \\
\hline C & HRR Propane (MW) \\
\hline D & O2 (fraction) \\
\hline E & CO2 (fraction) \\
\hline F & CO (fraction) \\
\hline G & Avg. Temp (C) \\
\hline H & Avg. Vel (m/s) \\
\hline I & Time Avg Vel (m/s) \\
\hline J & Mass Flow Rate $(\mathrm{kg} / \mathrm{s})$ \\
\hline K & Velocity $1(\mathrm{~m} / \mathrm{s})$ \\
\hline L & Velocity $2(\mathrm{~m} / \mathrm{s})$ \\
\hline M & Velocity $3(\mathrm{~m} / \mathrm{s})$ \\
\hline $\mathbf{N}$ & Velocity $4(\mathrm{~m} / \mathrm{s})$ \\
\hline $\mathbf{O}$ & T1 \\
\hline P & T2 \\
\hline Q & T3 \\
\hline R & T4 \\
\hline S & T5 \\
\hline T & T6 \\
\hline U & V1 \\
\hline V & V2 \\
\hline W & V3 \\
\hline $\mathbf{X}$ & V4 \\
\hline Y & O2 \\
\hline Z & CO \\
\hline AA & CO2 \\
\hline AB & Propane \\
\hline AC & Elapsed time (time \\
step) \\
\hline
\end{tabular}

Note: Columns $\mathrm{O}-\mathrm{AB}$ are raw data 


\section{Chapter 7: Calibration}

In order to ensure that the HRR system provides accurate results, various calibration experiments were carried out using propane calibration burners and heptane pool fires. In addition, FDS simulations were used to obtain additional calibration information. A list of propane experiments is provided in Table 7.1, heptane experiments in Table 7.2 and FDS simulations in Table 7.3.

\subsection{Experimental Setup}

All calibration experiments consisted of fires using either propane gas or liquid heptane as fuel. The fires were located near the centre of the experimental atrium. All experiments were run with four large rolling doors either fully or partially open so that there was ample oxygen available for combustion. The doors were often adjusted during tests to limit blowing of the flame to prevent damage to the building. The HRR measurement system developed through the work in this thesis was running and collecting data during every test.

\subsubsection{Propane Experimental Setup}

In order to carry out the calibration, the calculated HRRs must be compared to a known HRR. For the propane tests, the source of this information is the propane flow meter. The propane flow meter is a Sierra Steel-Mass Model 640S insertion mass flow meter, which measures mass flow rate and converts it into a current which is picked up by the DAS and converted to HRR as discussed in section 4.3 . 
For the propane experiments, the HRR per unit mass of $\mathrm{O}_{2}$, E, was set to 12.9

$\mathrm{MJ} / \mathrm{kg}$ and the expansion factor, $\alpha$, was set to 1.084 . These are the actual values specific to propane.

A drawing of one of the calibration burners, capable of $2.5 \mathrm{MW}$, is provided in Figure 7.1. Four of these burners are placed together in the atrium, providing a possibility for a $10 \mathrm{MW}$ fire. A photo of the burners in the atrium is provided in Photo 4 of Appendix A. The burners are made of steel tubing with $31.75 \mathrm{~mm}\left(1 \frac{1 / 4}{4}\right)$ inside diameter. Each has 456 holes of $4.76 \mathrm{~mm}$ (3/16") diameter, for a total area of approximately $8120 \mathrm{~mm}^{2}$ through which the propane is released.

The burners are supplied by a large propane tank with a vapourizer that vapourizes the liquid propane before it enters the lines. The vapourizer is left running to ensure it is always ready to use. The main propane line is a $101.6 \mathrm{~mm}$ (4") rigid pipe. The propane flow meter is attached to the main line. The propane then moves through a valve into a $50.8 \mathrm{~mm}$ (2") flexible hose and then through the valves into the burner. Insulation is provided underneath the burners to protect the concrete floor from the very high heat fluxes produced.

\subsubsection{Heptane Experimental Setup}

The pan used for the fires was a square steel pan with side lengths of $1.22 \mathrm{~m} \mathrm{x}$ $1.22 \mathrm{~m}\left(4^{\prime} \times 4^{\prime}\right)$ for an area of $1.49 \mathrm{~m}^{2}$. In order to protect the floor from the high heat fluxes produced, approximately $3 \mathrm{~cm}$ of water was placed in the bottom of the pan and sheets of insulation were placed on the floor around the outside of the pan. 


\subsection{Test Procedure}

A checklist for consideration before using the system presented in this thesis for running an experiment is provided in Appendix D. This checklist should remain posted in the control room for easy reference.

At the beginning of any day when calibration tests were planned, the gas analyzer was calibrated using both a zero-point and span calibration as discussed in section 5.3.2. When multiple tests were run in a single day, it was sometimes necessary to recalibrate the oxygen level, the most important gas variable, back to ambient value between tests as a small amount of drift sometimes occurred during a test. This drift never reached more than $0.02 \% \mathrm{O}_{2}$. Ice was then added to the condensation system, the desiccant visually inspected and the soot filter replaced.

A new folder is created before each test on the desktop computer for the data, the VI used for the experiment and any screenshots that were taken. The measurement output file was then renamed and relocated into the folder to keep the data organized. This is done by double clicking the "Write to Measurement File" express VI located on the far right side of the main VI's block diagram and changing the file name. The technician should also ensure that under the heading "if a file already exists", the button next to "use next available file name" is checked so that if the VI needs to be restarted for any reason, no data are lost. The data acquisition system is activated, running and recording data at least one minute before the fire is ignited. At least one person remained in the control room during every test to ensure that the data was being recorded and to monitor the test progress. 
The fans were turned on to run at the desired speed at least two minutes before a test to ensure that steady flow is reached.

Following all experiments, the DAS was left to run until the fan chamber and gas line were purged of almost all smoke and the oxygen concentration had once again reached very close to ambient. It generally took about 10 minutes for the system to fully reset itself to ambient values after a test. The higher the fan speed the less time this took. The next experiment could then be set up and performed.

Screenshots were taken at various times during tests to keep a record of what can be expected or any unusual occurrences during a test. Sample screenshots of a propane test and a heptane test are provided in Figure 7.2 and Figure 7.3. After testing, all the data as well as the particular VI used for the test were backed up so they are available for further analysis. Using Excel, the charts created by Labview can easily be recreated, manipulated and further analyzed if required.

\subsubsection{Propane Fire Procedure}

To begin each propane test, the technician turned on the gas and began opening the four gas valves as evenly as possible until a flow rate corresponding to the desired HRR was achieved. The person monitoring the system from the control room used a 2way radio to tell the technician controlling the valves when the flow rate was adequate. As soon as flow began, the propane was ignited manually using a small propane torch with a safety extension. A heat shield was used to protect the technician controlling the valves from excessive heat. 
During the test, the fire was watched from one of the air inlet doors. For the stepup tests (Type B tests), the flow rate was increased at 10 minute intervals. At the end of the test, the master valve was closed, extinguishing the fire. All other valves were then closed.

At the end of a test day, the propane system was shut off and all valves were checked to ensure that they were closed.

\subsubsection{Heptane Pool Fire Procedure}

For the heptane fires, the pan was prepared and set approximately in the center of the atrium. Approximately $3 \mathrm{~cm}$ of water was placed in the pan to protect the pan and the floor beneath from excessive heat.

When the measurement system, the fans, the ventilation setup and the pan were ready, the required mass of heptane was weighed and poured into the pan. The fire was then ignited with a propane torch as soon as possible so that very little evaporation of the fuel occurred. The fire then ran until the heptane ran out so the fire extinguished.

\subsection{Test Results}

\subsubsection{Propane Test Results}

Several experiments were carried out to calibrate the experimental atrium for HRR measurements using propane. A photo of a propane fire is provided in Photo 5 of Appendix A. The experiments used fan speeds of 25,50 , and $100 \%$ and propane fires between $1 \mathrm{MW}$ and $10 \mathrm{MW}$. A list of propane experiments is provided in Table 7.1. 
Undocumented preliminary tests and the simulations indicate that approximately 10 minutes of burning is required for the HRR system to reach a relatively steady level. For this reason, most tests were run for at least 10 minutes. Tests were also run for less time that confirm the response time required for the system and ensure that the Total Heat Released (THR), or the area under the HRR curve, matches the propane consumed. If these values match, it means that the system is accounting for all of the combustion gases and oxygen consumed.

Two types of propane calibration experiments were carried out as shown in Figure 7.4 and Figure 7.5. Type A experiments had a constant HRR. These were used for the bulk of the calibration to ensure the instrumentation was working properly, to work out any bugs in the data acquisition and analysis and to determine and analyze error and any required adjustments to the system. Type $B$ experiments started with a low HRR and the HRR was then increased in a stepwise fashion. These tests highlighted delay times and relative errors for different fire sizes. They also showed that the system worked well in longer duration tests.

Tests A1 through A7 were fully successful with constant flow rates achieved for 10 minutes. In some of the propane tests, it was not possible to reach the desired flow rate of propane as the propane system could not continually provide the required pressure. In those tests the valves were fully open and the flow was governed by the available pressure in the system rather than the valve. Tests that could not reach or maintain the desired level are tests A8 through A12 and test B1. Tests A8 through A12 were attempts to run a $10 \mathrm{MW}$ fire for 10 minutes and test $\mathrm{B} 1$ should have stepped up from 2-4-6 MW 
at 10 minute intervals but problems arose at the $6 \mathrm{MW}$ level and the fire was extinguished shortly thereafter.

Test A8 was originally intended to be a $10 \mathrm{MW}$ test but at the time only $6 \mathrm{MW}$ could be achieved. Test A9 reached $10 \mathrm{MW}$ for the first 215 seconds but then had to be lowered to $6 \mathrm{MW}$ for the remaining time. Tests A10 through A12 were run at $10 \mathrm{MW}$, but only for 120-150 seconds and then they were extinguished.

Test B2 was a successful step-up test run at $100 \%$ fan speed with the same fire sizes as test $\mathrm{B} 1$.

After some tests were run it became clear that the system was overestimating the HRR and the THR. Figure 7.6 and Figure 7.7 show the HRR calculated and the THR, respectively, for test A3. These figures also include the curves adjusted by a factor of 0.75 , which causes both the HRR and the THR to match the values from the propane flow meter. This factor results in accurate measurements and it will be shown that this factor can be used for all tests within the capacity of the system. From here on, all HRR and THR measurements will use this factor and any discrepancies and error will be discussed.

Figure 7.8 through Figure 7.35 show the HRR and THR values from all propane fire experiments conducted. From almost all of the propane tests it appears that the factor of 0.75 is accurate in terms of the THR to within $\pm 4 \%$. The THR values are considered most important to gage the accuracy as they can be calculated for all tests and HRR can only be considered for tests that ran long enough to reach steady state. An accurate THR value also indicates that the system is accounting for all combustion gases and oxygen depleted. A summary of error for both values for all tests is provided in Table 7.4. The 
error is discussed further in section 7.7.1. Trends for delay times also became clear after running a few tests. These delays are discussed in section 7.6.

Tests A1 and A2 were $1 \mathrm{MW}$ fires. Figure 7.8 and Figure 7.9 show the results of test A1. At the beginning of the experiment, some large oscillations can be seen in the data from the propane flow meter. The valves controlling the flow the propane are controlled manually and can be touchy and somewhat difficult to control. These oscillations represent real fluctuations in the propane flow rate due to operator error. This 1 MW test resulted in an overestimation of both HRR and THR when the system became steady. Figure 7.10 and Figure 7.11 show very similar results for test A2 but with less delay in the measurement system due to the higher fan speed.

Tests A3 and A4 were 2.5 MW fires. Figure 7.12 and Figure 7.13 show the results from test A3. The results are very accurate for both HRR and THR. Figure 7.14 and Figure 7.15 show the results of test A4, which are also very accurate and have a lower delay time due to the higher fan speed.

Tests A5 through A7 were $5 \mathrm{MW}$ fires. Figure 7.16 and Figure 7.17 show the results of test A5. Because this test was run at $25 \%$ fan speed, the measured HRR never reached a steady level. The final THR shows only a slight underestimation, which may be attributed to the loss of combustion products because of the low fan speed. Figure 7.18 through Figure 7.21 show the results of tests $\mathrm{A} 6$ and A7, run at $50 \%$ and $100 \%$ fan speeds, respectively. Both of these tests had very accurate results that are as expected.

Tests A6 through A12 were attempts at $10 \mathrm{MW}$ fires. However, as discussed, problems occurred with the propane supply system that caused problems with these tests. 
Figure 7.22 and Figure 7.23 show the results of Test A8, which ended up being an approximately $6 \mathrm{MW}$ test. Results of HRR and THR are slightly underestimated. This error is discussed more in section 7.7.1. Figure 7.24 and Figure 7.25 show results of Test A9. The fluctuations in the propane flow meter data were due to pressure problems in the system. The HRR in this test did not reach steady state due to the short time the fire was at each HRR. The THR is quite accurate. Figure 7.26 through Figure 7.31 show the results for Tests $\mathrm{A} 10, \mathrm{~A} 11$ and $\mathrm{A} 12$. All of these tests were run at $10 \mathrm{MW}$ at $100 \%$ fan speed but the propane supply system could only keep up for a short time. Therefore the HRR values never reach a steady state, but the THR values are quite accurate.

Figure 7.32 and Figure 7.33 show the results of Test B1. The fluctuations in the HRR at the times when HRR was changed are due to operator error but represent real changes in propane flow. After 20 minutes, the test was supposed to step up to $6 \mathrm{MW}$, but the propane supply system could not handle the flow at the time so the test was cut short. However, good estimations of HRR and THR can be observed. Figure 7.34 and Figure 7.35 show the results of test B2. This was a successful test stepping up from 2 MW to $4 \mathrm{MW}$ to $6 \mathrm{MW}$ at 10 minute intervals. The HRR curve is a good example of how, at lower HRRs, the measurement system shows a slightly higher value of HRR than at higher HRRs. However, the THR remains quite accurate. The combustion products build up and become trapped more with larger fires.

From the propane fire tests, it appears that the smallest fire for which THR and HRR can accurately be measured is $2 \mathrm{MW}$. These values seem to be overestimated with smaller fires than this. It should be noted that the accuracy of the propane flow 
meter is also questionable at flows lower than $2 \mathrm{MW}$. This adds to the uncertainty of the HRR and THR calculations. Similarly, the largest fire that was run for the full 10 minutes was a $6 \mathrm{MW}$ fire which yielded reasonable results for both HRR and THR. The $10 \mathrm{MW}$ fires were not run long enough for the HRR measurement system to reach a steady level, but the THR values seem quite good. Therefore it is probable that the system is capable of measuring HRRs at least as large as $10 \mathrm{MW}$ accurately, but this has not been seen explicitly in these experiments.

\subsubsection{Heptane Pool Fire Test Results}

Three experiments using heptane were carried out for calibration of the system. Photos of heptane pool fires are provided in Photos 6 and 7 of Appendix A. The purpose of these experiments was to use a different fuel and method of calculating the HRR than the propane flow meter and to see how the two fuels compared in terms of expected and calculated HRR. Heptane pool fires are very predictable and reproducible. A list of parameters for these tests is provided in Table 7.2. A screenshot from test $\mathrm{H} 3$ is provided in Figure 7.3.

The theoretical HRR and burning duration for the pool fires were calculated using equations (4-9) and (4-10). Heptane has an effective heat of combustion of $41.2 \mathrm{~kJ} / \mathrm{g}$ [38]. For a pan this size (area $1.49 \mathrm{~m}^{2}$ ), the theoretical steady state HRR for the heptane fires is approximately 4.8 MW. This was calculated using equation (4-10). It should be noted that the fire was not burning at steady state throughout the test and it is possible that true steady burning was never actually reached. Ten minutes or more may be 
required before steady burning occurs [30]. These correlations are also for wind-free environments and some wind does exist in the atrium.

For all three experiments, a fan speed of $50 \%$ was used. As in all propane experiments, all the appropriate checks and calibrations were carried out the day of the experiment. The HRR per unit mass of $\mathrm{O}_{2}, \mathrm{E}$, was set to $13.1 \mathrm{MJ} / \mathrm{kg}$ and the expansion factor, $\alpha$, was set to 1.105 . These are the average values suggested by Huggett [1] for most fires.

The first two experiments were run on the same day and used 20.34 and $20.65 \mathrm{~kg}$, respectively. All parameters for these two tests were identical and their purpose was to measure the reproducibility of tests by the system. They both ran for approximately 5 minutes, which is not enough time for the HRR being measured by the system to reach a steady state. The measured HRR curves are provided in Figure 7.36. The areas under the curves for both tests were calculated to be $772 \mathrm{MJ}$, showing very consistent results. The theoretical values for THR are approximately $840 \mathrm{MJ}$ and $850 \mathrm{MJ}$ for the two tests, indicating that for both tests, the THR appears to be underestimated. As can be seen in Figure 7.36 and Figure 7.37 , the data gathered from these tests is almost identical.

The third test was run with approximately $53 \mathrm{~kg}$ of heptane. This test ran for 580 s, providing enough time for the system to reach a steady-state so the HRR could be considered. Figure 7.38 and Figure 7.39 show the results for this test. The theoretical and measured values of HRR and THR are provided in Table 7.5.

A maximum HRR of approximately 4.4 MW was measured and stayed relatively steady for a short time until the fire burned out and the HRR quickly dropped. This value 
is slightly below the theoretical HRR of $4.8 \mathrm{MW}$. This was not reached until approximately 450 seconds into the test and only lasted about 40 seconds. It should be noted that in Figure 7.38 and Figure 7.39, the theoretical values of the HRR and THR shown assume a constant HRR throughout the test which is not quite realistic. Some time was required for the fire to reach steady burning.

All three heptane tests provided extremely good data consistent with what was expected from the system. Heptane fires produce a lot of smoke and soot and at $50 \%$ fan speed much of the atrium was filled with smoke. However, it was still safe to stand inside the atrium as the smoke layer did not come that low. The accumulation of smoke accounts for some of the delay in reaching steady measurements and accounting for all of the combustion gases. The large amount of smoke produced indicates that the combustion was incomplete. This means that the theoretical HRR is below $4.8 \mathrm{MW}$.

The time-averaged velocity was quite consistent for all three tests at approximately $4.4 \mathrm{~m} / \mathrm{s}$. In the longer heptane test, $\mathrm{H} 3$, the oxygen concentration reached a low of $20.53 \%, \mathrm{CO}$ reached a peak of $15 \mathrm{ppm}$ and $\mathrm{CO}_{2}$ reached a peak of $0.34 \%$. The ambient temperature during these tests was approximately $0^{\circ} \mathrm{C}$ and the maximum temperature reached in the fan chamber was $27.5^{\circ} \mathrm{C}$, which is not of concern for safety considerations.

The burn durations for the shorter tests were theoretically calculated at 175 seconds. However, these tests lasted longer than this at 290 and 300 seconds. The reason for this is that is takes time for the fire to ramp up and it does not burn steady all the way 
until the fuel is exhausted. The heat release rate was therefore lower than $4.8 \mathrm{MW}$ throughout most, if not all, of the test.

Babrauskas notes that burning does not reach steady-state immediately for various reasons. Ten minutes or more may be required before steady burning occurs [30]. Therefore it is possible that steady-state was never reached in the heptane fire experiments.

There is a short time at the end when the fire size decreases and then the fire extinguishes. The pan used for the tests is a square pan. An equivalent diameter was used for the calculations by simply equating the areas. These factors are not considered in the theoretical calculations.

The third heptane test, H3, had a theoretical burn duration of 450 seconds and lasted 580 seconds in reality. These values are proportionately closer than those in the shorter tests because the fire has more time to burn and reach a steady state, resulting in a larger fire for most of the test. Babrauskas' correlations, which were used to obtain the theoretical HRR of 4.8 MW and therefore the theoretical mass loss rate, are for use in a wind-free environment. The steady burning assumption of the theoretical equations is not valid in this case, but does provide quite a good approximation. The wind from the fans likely caused an increase of the evaporation rate of the fuel but since the flames are being blown, the radiation feedback from them to the fuel is lower than with no wind. At this time the wind effects on liquid fuelled pool fires are not fully understood. 
The results obtained from the measurement system underestimated the theoretical THR by between 5 and $9 \%$. These error values are provided in Table 7.5 and are discussed in detail in section 7.7.2.

\subsection{FDS Simulations}

Several FDS simulations were carried out with instrumentation that mimics the instrumentation in the fan chamber. FDS version 5.2.0 Serial with a compilation date of July 20, 2008, was used. The FDS input files were generated by Pyrosim Version 2007.1. For simulated gas concentration measurements, 9 point values were taken. Because of the turbulence and long distance travelled by the gas, these are more than enough measurements to obtain a good representation of concentrations. For the temperature and velocity measurements, the virtual instruments were placed in the same locations as in the actual fan chamber, with 6 thermocouples and 4 bi-directional probes. See Figure 7.40 for instrumentation used in the simulations.

A grid size of $0.25 \mathrm{~m}$ was used throughout the entire computational domain. Various FDS simulations have been carried out for both the tunnel and atrium facilities and this grid size has been shown to yield reasonable results. Two meshes were used, totaling $1,028,480$ cells. One of these meshes corresponded to the atrium and the other corresponded to the fan chamber. The ceiling and the south and east walls as well as part of the west wall of the atrium are modeled as inert boundaries, or boundaries through which no heat can flow. The section of the west wall where the elevator is located is modeled as $10 \mathrm{~cm}$ thick concrete and the part of the north wall where the rolling doors are located is modeled as sheet metal. The north and west walls of the fan chamber were 
inert boundaries. The fan enclosures and the closed ventilation openings were modeled as sheet metal. All other walls and partitions are modeled as $10 \mathrm{~cm}$ thick concrete. Because temperatures in the system are not very high and the purpose of the simulations is to simulate the flow of the combustion gases rather that to accurately account for heat transfer, the material properties are not as vital as the geometry of the model.

The three fans were modeled as vents with constant volumetric flow rates equivalent to those of the actual fans. For $25 \%$ fan speed, each fan moved $11.1 \mathrm{~m}^{3} / \mathrm{s}$ and at $100 \%$ fan speed, each moved $44.4 \mathrm{~m}^{3} / \mathrm{s}$. The calibration burners were modeled as burner surfaces with constant HRRs per unit area that output $2.5 \mathrm{MW}$ each. For a 10 MW fire, four of these objects were used. Propane is the default fuel in FDS5 and was used for these simulations. A sample FDS input file is available in Appendix B.

One important consideration when looking at the results of these simulations is that there is no delay time from the sampling location to the gas analyzer. This means that the measurements are automatically synchronized and no adjustments need to be made. For each simulation, the HRR provided by FDS is compared to the HRR calculated using the instruments. The calculations were done in an Excel spreadsheet using the same formulas and methodology as the experiments. The velocities were time-averaged over 10 time steps in order to reduce the fluctuations and provide a more reasonable HRR measurement.

Many simulations were carried out using steady fires of sizes from 2.5-10 MW for $300 \mathrm{~s}$. See Table 7.3 for a list of simulations. The HRR measurements from these $300 \mathrm{~s}$ simulations never reached the value given by FDS. This proved that $300 \mathrm{~s}$ of constant 
burning is not long enough for the system to catch up due to mixing, trapping of gases and smoke and a long travel distance to the measurement location. Figure 7.41 shows a comparison of $300 \mathrm{~s} 5 \mathrm{MW}$ fire simulations at different fan speeds and Figure 7.42 shows a comparison of $300 \mathrm{~s}$ simulations of different fire sizes at $50 \%$ fan speed.

Longer simulations lasting $600 \mathrm{~s}$ were run in order to give the simulated HRR measurement system enough time to reach steady state. These simulations agreed well with experiments in terms of the time required for the system to become steady. The results obtained from these simulations showed underestimations of the HRR by between 3 and $10 \%$. Table 7.6 shows the error values for $600 \mathrm{~s}$ simulations based on the average measured HRR value in the steady area compared to the actual HRR value provided by FDS. The largest underestimation occurred in simulation S20, which was a $10 \mathrm{MW}$ fire at $50 \%$ fan speed. It is likely that the combination of the large fire with the low fan speed caused a lot of smoke and combustion gases to be lost through the inlet doors, accounting for the larger underestimation. All of the other simulations showed errors of $6 \%$ or less. This underestimation can likely be attributed to a combination of incomplete combustion and error due to the instrumentation locations. At the end of these simulations the fire was still running, so all of the combustion gases had not yet moved through the measurement system. THR could therefore not be considered in the simulations.

Figure 7.43 and Figure 7.44 show comparisons of calculated HRR curves with the same fire sizes and fan speeds, respectively, of $600 \mathrm{~s}$ simulations. It can be seen that the main factor in response time of the system is fan speed. These curves indicate that at $100 \%$ fan speed, a steady-state is generally reached by the measurement system in about 
$300 \mathrm{~s}$. At $50 \%$ fan speed, steady-state is not reached until near the end of the $600 \mathrm{~s}$. At $25 \%$ fan speed, the system cannot reach steady state in $600 \mathrm{~s}$.

\subsection{Comparison of Simulation and Experiment}

One scenario was chosen for a detailed comparison of the simulation and the calibration test. The chosen scenario was a 10 minute long $5 \mathrm{MW}$ fire at $50 \%$ fan speed. This scenario is chosen because it is a realistic scenario that will likely be encountered in future experiments. A comparison of the HRR for each is provided in Figure 7.45. This figure shows the theoretical HRRs provided by FDS in the simulation and the propane flow meter in the experiment as well as the calculated HRRs by the instrumentation in the fan chamber both in the simulation and the experiment. Note that the experimental HRR measurement is adjusted by a factor of 0.75 as discussed in section 7.3. The FDS HRR prediction is approximately a $4.8 \mathrm{MW}$ fire, but in reality it is difficult to control the propane valves and the fire was larger than this at approximately 5.3 MW. The specific variables that cause the need for this factor are discussed in this section.

Figure 7.46 compares the average temperatures of each. The ambient temperature for the experiment was approximately $5^{\circ} \mathrm{C}$ and the simulation was set at $20^{\circ} \mathrm{C}$, which means that the density of the gases is higher throughout the experiment. The ambient temperature during the experiment could not be predicted at the time the simulation was carried out. Figure 7.47 shows the FDS predicted and experimental temperature rise during the test. It can be seen that the predicted increase of temperature compares well with the experimental values. 
Figure 7.48 shows the predicted and experimental time-averaged velocities. The two start out essentially identical but the velocity in the system rises slightly when the hot gases reach the fan chamber. Figure 7.49 compares the mass flow rates. The slightly higher velocity and density in the experiment caused a higher mass flow rate averaging about $90 \mathrm{~kg} / \mathrm{s}$ compared to approximately $78 \mathrm{~kg} / \mathrm{s}$ in the simulation. As the HRR is sensitive to the mass flow rate, this will cause a proportionately higher HRR calculation. However, this difference of $15 \%$ is only slightly larger than the $10 \%$ larger HRR in the experiment compared to the simulation and only accounts for a small portion of the overestimation of HRR by the system, which is the reason that the factor of 0.75 is required.

Figure 7.50 compares the experimental and predicted percentage of oxygen depletion. It is immediately obvious from this comparison that the overestimation of the HRR is governed by the lower $\mathrm{O}_{2}$ levels in the system as compared to the simulation. When the $\mathrm{O}_{2}$ depletion levels out, the experimental value is $75 \%$ of the simulated value.

Small differences in other factors such as $\mathrm{CO}$ and $\mathrm{CO}_{2}$ values, and ambient $\mathrm{H}_{2} \mathrm{O}$ and pressure may cause additional differences between measurement and simulation, but these variables have very low impact on the HRR calculations.

The principle behind oxygen consumption calorimetry is that the fuel being burned will release heat proportional to the amount of oxygen consumed. Therefore, if both the simulated and the real propane fires were approximately $5 \mathrm{MW}$, it means that the same amount of oxygen was consumed by both. Since the measurement of gas concentrations is reliable, the error must originate from the mass flow rate measurements. Therefore, the 
factor of 0.75 that needs to be applied to the system should be applied to the mass flow rate. This lowered mass flow rate will result in the oxygen concentration in experiments matching those of the simulation.

The differences between the FDS results and the experimental results could be due to many factors. It is possible that a finer grid size near the fire or near the sampling location would have yielded results that were closer to reality. In the FDS simulations, the ventilation conditions did not change and leakage in the system was not considered. Whereas in the experiments, ventilation was changed often during the experiments in order to better control the direction that the flames were being blown to avoid damage to the facility. There was always enough ventilation to provide ample air to the flames.

More accurate material properties and a closer approximation of the burner geometry could also make a difference to the simulation results. Also, the behaviour of the gas sampling system would not be exactly the same as in the simulations. During the time that the gas is moving through the tube to the gas sampling system, a certain amount of dilution would take place. Finally, environmental conditions, including temperature, wind, RH and other factors are not considered in the simulations and can cause some error in the measurements by the system that changes from day to day.

\subsection{Delay Times}

There are two components to the delay in the HRR measurement system. The first is the travel time, or the time for the gases to move from the flame to the sampling location in the fan chamber, which is mainly affected by the fan speed. The second is the system delay, which represents the time for the combustion gases to be pumped from the 
gas sampling grid down to the gas analyzer, which is constant. The travel time can be further broken down into two components. The first is the time for the first response of the system, or when the first gas with depleted oxygen reaches the sampling grid. The second is the time for the gas movement to reach steady-state or match the actual heat being released. The reason this takes time is that there is a large distance for the gases to move and dilution and accumulation of combustion gases can occur in various locations along the path. Observed delay times for propane experiments are provided in Table 7.7.

\subsubsection{System Delay}

For the purpose of this facility, considering the large size of fires and long times involved in the experiments, the delay time of the movement of gases from the sampling location to the gas analyzer and the delay in the gas analyzer itself are considered together. During all of the experiments, a flow of approximately $1.5 \mathrm{~L} / \mathrm{min}$ of exhaust gas was pumped through the gas measurement system. Because of this consistent flow rate and the system's lack of dependence on any other factors, including fire size, fan speed and atmospheric conditions, a constant delay is assumed for the gas measurements. By directly injecting a calibration gas with $901 \mathrm{ppm} \mathrm{CO}$ into the center of the gas grid, this delay was found to be approximately 45 seconds.

This time was subsequently programmed into Labview as a constant delay to the mass flow rate in order to synchronize the calculations. All results and graphs presented in this Thesis from experimental data have been shifted to compensate for this delay. During an experiment, the displays of mass flow rate and measured HRR are delayed by 45 seconds. 


\subsubsection{Travel Time}

Delay time for the combustion gases to reach the sampling location, or travel time, change slightly depending on the fire size and atmospheric conditions. However, the most important factor is the fan speed. For the experimental atrium, the travel time can be considered in two separate parts; the delay to first detection and the delay to steady state. Because of dilution, the long travel time and the geometry of the flow path that the gases move through before reaching the sampling location, the measurement system cannot accurately detect sudden changes in HRR in the atrium and is takes some time to catch up.

Table 7.7 provides the travel time delays for each experiment. The time to first detection of oxygen consumption ranges from approximately $10-15$ seconds at $100 \%$ fan speed to about 20 seconds at $50 \%$ and $35-40$ seconds at $25 \%$ fan speed. The delay from that time until a steady state is reached at steady burning as was the case with the experiments presented in this Thesis, are approximately $190-240$ seconds at $100 \%$ fan speed and about $430-450$ seconds at $50 \%$ fan speed. This means that at least 200 seconds of steady burning is required at $100 \%$ fan speed and at least 450 seconds at $50 \%$ fan speed in order to get an accurate measurement of HRR. No tests were run long enough to reach steady state at $25 \%$ fan speed. It is therefore suggested that a high fan speed be used when possible to lower the travel time of the system and yield faster results that more closely resemble the real HRR curve of the fire. The observed delay times for each test are provided in Table 7.7. Accurate THR values, however, can still be obtained from 
shorter tests as all of the combustion products are still accounted for by the system, only over a longer time.

It must also be noted that the HRR and THR curves presented in this thesis from the calibration experiments have been shifted by 45 seconds to account for the delay of mass flow rate built into Labview for the time from the gas grid to the gas analyzer. This means that at $50 \%$ fan speed it could take as long as 500 seconds before a technician running the system during a test will be reading good results in a steady fire test.

The delay of the system should theoretically not cause error in the calculation of the HRR if steady burning occurs for a long enough time, but will affect the apparent time at which the fire was at that HRR. When the current HRR display shows a certain value, this may be the value for as long as 500 seconds ago or more at a lower fan speed. During this time, the fire may have grown significantly.

\subsubsection{Other Delays}

There are some other potential sources of delay, all of which are negligible but should be mentioned. These include delay of the gas analyzer, thermocouples, pressure transducers, propane flow meter and the computer itself.

Delays from the thermocouples and pressure transducers are fractions of a second and are not considered. As mentioned in section 7.6.1, any delay by the gas analyzer is built into the system delay. Also, as discussed in Chapter 6, a time step of 1.5 seconds was built into Labview because the computer could not handle the large number of calculations that take place in a time step of 1 second. Again, this is not an issue as receiving a data point every 1.5 seconds is more than adequate for this system. If a 
longer time before readings is desired for a smaller output file, Labview can easily be customized as required as discussed in Chapter 6.

The flow of propane through the pipes is assumed to be constant everywhere in the pipe such that the flow at the flow meter is equal to the flow at the burner and therefore the current HRR. This is generally a good assumption, especially since there is no time variation in the flow during the tests except when a large jump is made and then it goes back to being constant.

\subsection{Error Analysis}

There are many potential sources of error in the system developed in this thesis and future researchers must be careful to understand and properly analyze their results. Periodic calibration tests and maintenance should be carried out to ensure the system is still working properly. All of the instrumentation has inherent uncertainty. These uncertainties are generally provided by the manufacturer. Accuracies of the various instruments are provided in Table 7.8 .

Mass flow rate and oxygen concentration are the two most important and highly sensitive variables for HRR calculation. Small fluctuations in either of these variables greatly affect the ultimate accuracy of the HRR measurement system. By the time the gas reaches the sampling location it is very well mixed and the gas sampling grid spans almost the entire cross-section of the fan chamber. For these reasons and because the gas analyzer provides very accurate measurements, the accuracies of $\mathrm{O}_{2}$ and other gas concentrations are very high and very reliable. Similarly, the temperature is uniform 
across the profile and the six thermocouples provide reliable data. Therefore, the limiting factor for accuracy of the system is the velocity.

Turbulence and an uneven velocity profile in the fan chamber cause a high potential degree of error in the velocity measurements. To attempt to mitigate this, the locations of the bi-directional probes were carefully chosen (see section 5.2). The four probes are equally weighted and the time average over 10 time steps is taken for HRR measurements. The high frequency rate of sampling also lowers the unwanted noise significantly. It is difficult to differentiate signal noise error and real velocity changes in the remaining velocity fluctuations. Experiments indicated that fires have very little effect on the velocity in the fan chamber. Therefore average velocity is almost constant throughout the experiments.

The fluctuations in the time-averaged velocity used for HRR calculations for all tests are summarized in Table 7.9. The values used for this analysis were taken over 600 time steps where available. The total fluctuation in the measurements, or the difference between the maximum and minimum values, ranges from $0.5-1.15 \mathrm{~m} / \mathrm{s}$ and does not appear to be affected greatly by either fire size or fan speed. Therefore, at lower fan speeds a larger percentage of fluctuation can be expected throughout the test resulting in a larger apparent fluctuation of HRR. These fluctuations ranged from up to $\pm 7 \%$ at $100 \%$ fan speed to $\pm 16 \%$ at $25 \%$ fan speed.

Although the gas sampler is calibrated every day of testing, some error is inherent. Accuracies of the three measured gases are $0.01 \%\left(\mathrm{O}^{2}\right), 0.1 \%\left(\mathrm{CO}^{2}\right)$, and $0.02 \%(\mathrm{CO})$ by volume. These are well within the acceptable range for this system. 
The type $\mathbf{J}$ thermocouples are capable of measuring temperatures between 0 and $760^{\circ} \mathrm{C}$ with an accuracy of $\pm 0.1^{\circ} \mathrm{C}$

Especially for larger fires, some smoke and other combustion products may be lost through the fresh air supply vents. This in theory will result in an underestimation of HRR. In addition to this, some degree of smoke accumulation always occurs, causing some combustion products to take longer to reach the sampling location. This causes some delay as discussed in section 7.6.2. However, this is not expected to affect the accuracy of the THR or the HRR measurements after steady state has been reached.

Since the measured HRR is quite variable and in some cases does not reach a steady state in the short time provided by the tests it is not always easy to determine a fixed value for the total error for a given test. However, where possible, these errors were calculated by averaging values over the time that the system appears to be at steady state and comparing this value to either the average value from the propane flow meter for the propane tests or the theoretical value of $4.8 \mathrm{MW}$ for the heptane tests. Error values are provided in Table 7.4 for propane fires and Table 7.5 for heptane fires.

For all tests, the error in THR was calculated by comparing the final value of the measured heat and the value from the propane flow meter or the theoretical values obtained from the weight of heptane used.

\subsubsection{Error in Propane Experiments}

Using the factor of 0.75 on the HRR and, by extension, the THR, yields very accurate data for the propane experiments as compared to the flow rate of the propane out 
of the calibration burner provided by the propane flow meter. Error values are provided in Table 7.4. Most tests show errors of less than $4 \%$.

The propane fires that yielded the largest errors were those in which there were problems with the propane pressure (tests A8-A12) and those with very small fires (tests $\mathrm{A} 1$ and $\mathrm{A} 2$ ).

Test A8 was originally intended to be a $10 \mathrm{MW}$ test but at the time only $6 \mathrm{MW}$ could be achieved. This test ran for 10 minutes and resulted in a THR error of $-5.6 \%$ and a HRR error of $-4.0 \%$. Test A9 reached $10 \mathrm{MW}$ for the first 215 seconds but then had to be lowered to $6 \mathrm{MW}$ for the remaining time. It resulted in an error of $-3.72 \%$ for THR and HRR could not be measured accurately due to the short duration at each HRR. Tests A10 through A12 were run at $10 \mathrm{MW}$, but only for 120-150 seconds and then they were extinguished. These have lower error values for THR, but only because they were very short tests. The additional error in these tests may be partially due to error caused by the propane flow meter because of the difficulties in maintaining pressure in the main line.

Tests A1 and A2 were $1 \mathrm{MW}$ fires at $50 \%$ and $100 \%$ fan speeds. These yielded errors of 10.6 and $12.1 \%$ for total heat and $7.8 \%$ and $7.5 \%$ for HRR, respectively. This indicates that the system may not be sensitive enough to accurately measure these values for small fires in the atrium. It is therefore suggested that the measurement system not be used, when possible, for fires smaller than $2 \mathrm{MW}$. Another consideration here is that the propane flow meter's accuracy is questionable below $10 \%$ of its span, or $2 \mathrm{MW}$. With this uncertainty in the calibration system, it is difficult to say whether the error lies in the HRR measurement system or in the propane flow meter. 
Test $\mathrm{B} 1$ ran at $2 \mathrm{MW}$ for 10 minutes and was then stepped up to $4 \mathrm{MW}$ for 10 minutes. When the $2 \mathrm{MW}$ fire reached a steady measurement, the HRR was slightly overestimated by $2.7 \%$ and during the $4 \mathrm{MW}$ portion the HRR was underestimated by $6.9 \%$. Similarly, test B2 stepped up from $2 \mathrm{MW}$ to $4 \mathrm{MW}$ to $6 \mathrm{MW}$ with errors of $0.3 \%$, $-3.0 \%$ and $-3.9 \%$, respectively. From these results and from the general trend of the type A tests, it can be concluded that the system measures a slightly lower value relative to the propane flow rate the larger the fire gets. This is likely a result of a larger amount of trapped and accumulated smoke and combustion gases in the various chambers in large fire tests. The THR values do not appear to be greatly affected by this because after the test a longer time is required to clear the smoke and the oxygen consumption from these gases is still accounted for.

For the type B tests B1 and B2, the THR error values were $1.9 \%$ and $-3.9 \%$, respectively. This is encouraging because it does not appear that long tests yield larger errors.

The calculations carried out by Labview do not account for incomplete combustion or soot production. However, since the maximum CO detected by the gas analyzer was $5 \mathrm{ppm}$ from a large fire, the effects of incomplete combustion are quite small.

\subsubsection{Error in Heptane Pool Fire Experiments}

Theoretical values of HRR and total heat for the heptane pool fires were calculated using Babrauskas' pool fire correlations [30]. These values were then compared to the values measured by the system. 
Tests $\mathrm{H} 1$ and $\mathrm{H} 2$, which both lasted approximately 5 minutes, yielded apparent errors of $-7.9 \%$ and $-9.3 \%$ for total heat, respectively. HRRs could not be measured accurately for these tests due to their short duration. However, it is noted that the curves that were calculated match very well (see Figure 7.36). Test H3, which ran for approximately 10 minutes resulted in an error of $-5.5 \%$ for total heat and $-8.3 \%$ for HRR. The HRR used was the average value over 45 seconds of data that appeared to be at a steady state.

There are a few factors that likely contributed to the underestimation of these values. First, the system's calculations do not account for incomplete combustion. A large amount of smoke was produced by these fires. This means that the burning of the heptane was incomplete and some of the energy went into generating soot.

Another factor is the fact that after the heptane was poured into the pan, some time was required to finish preparations before the heptane could be ignited. During this time some liquid would have evaporated and some volatiles would have been lost.

Because the fire took time to ramp up and may have never, in fact, reached steady state, the calculated value of HRR used for error analysis may not be accurate. 


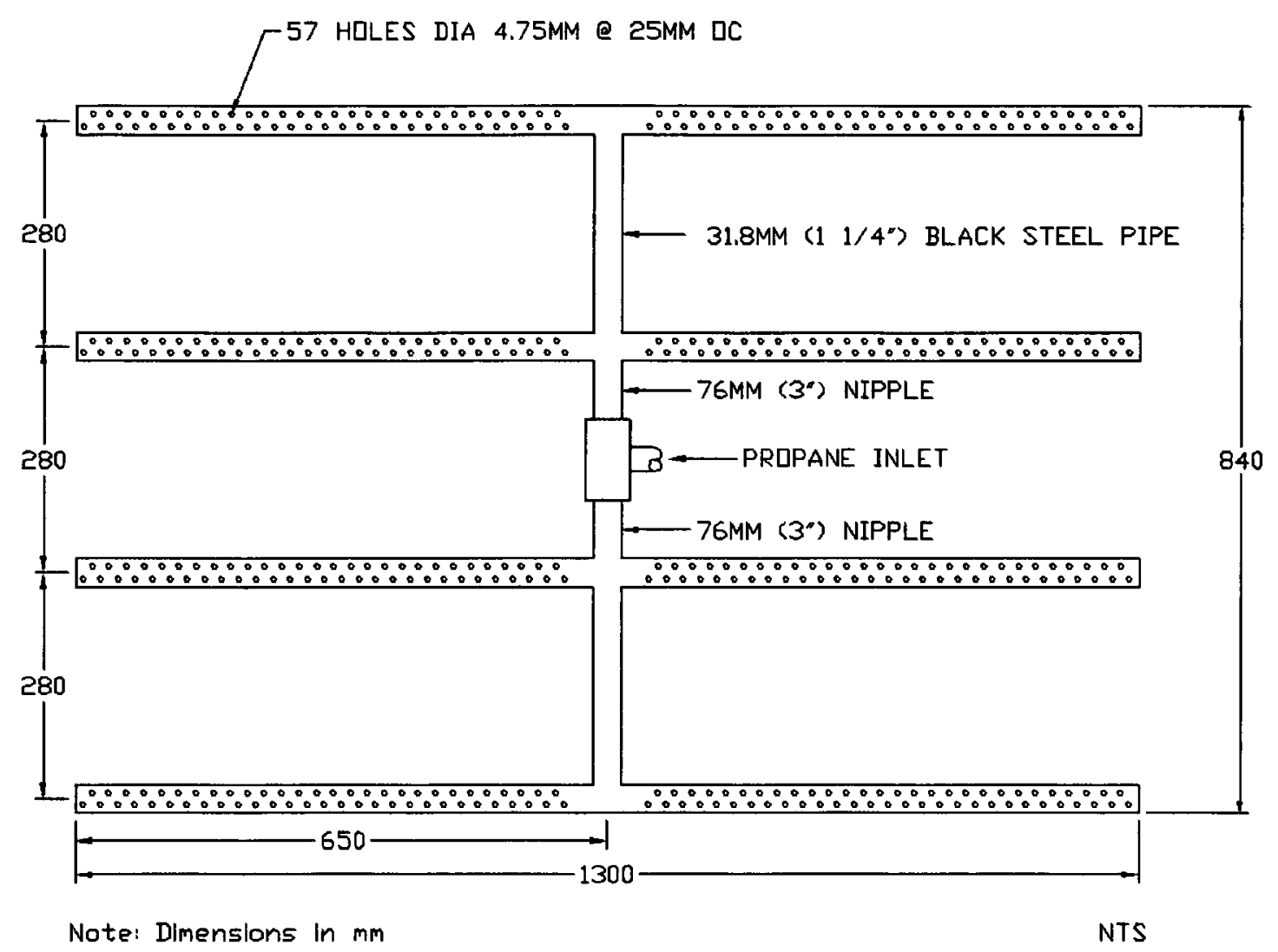

Figure 7.1 Propane calibration burner 


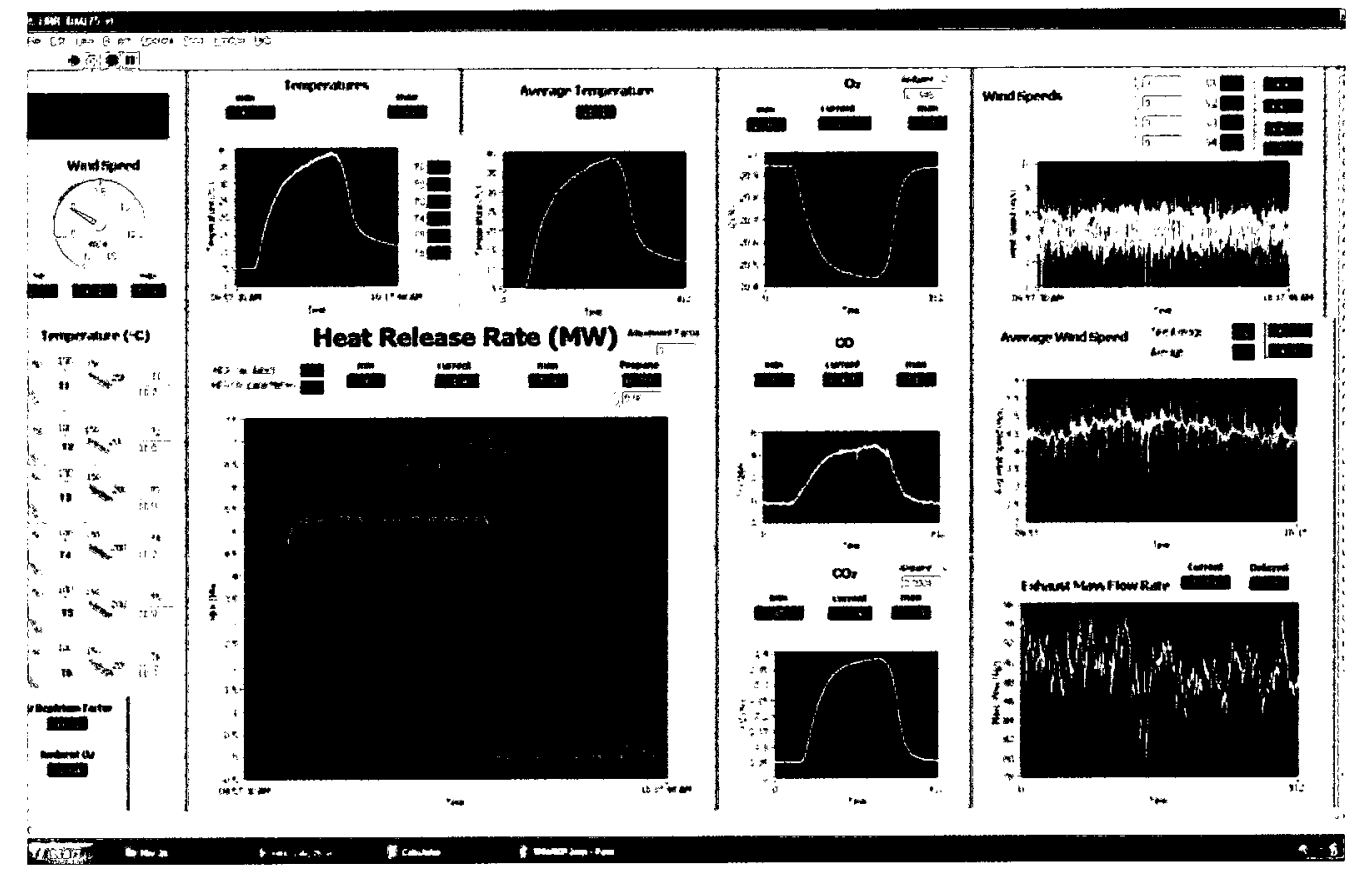

Figure 7.2 Example screenshot of propane fire experiment

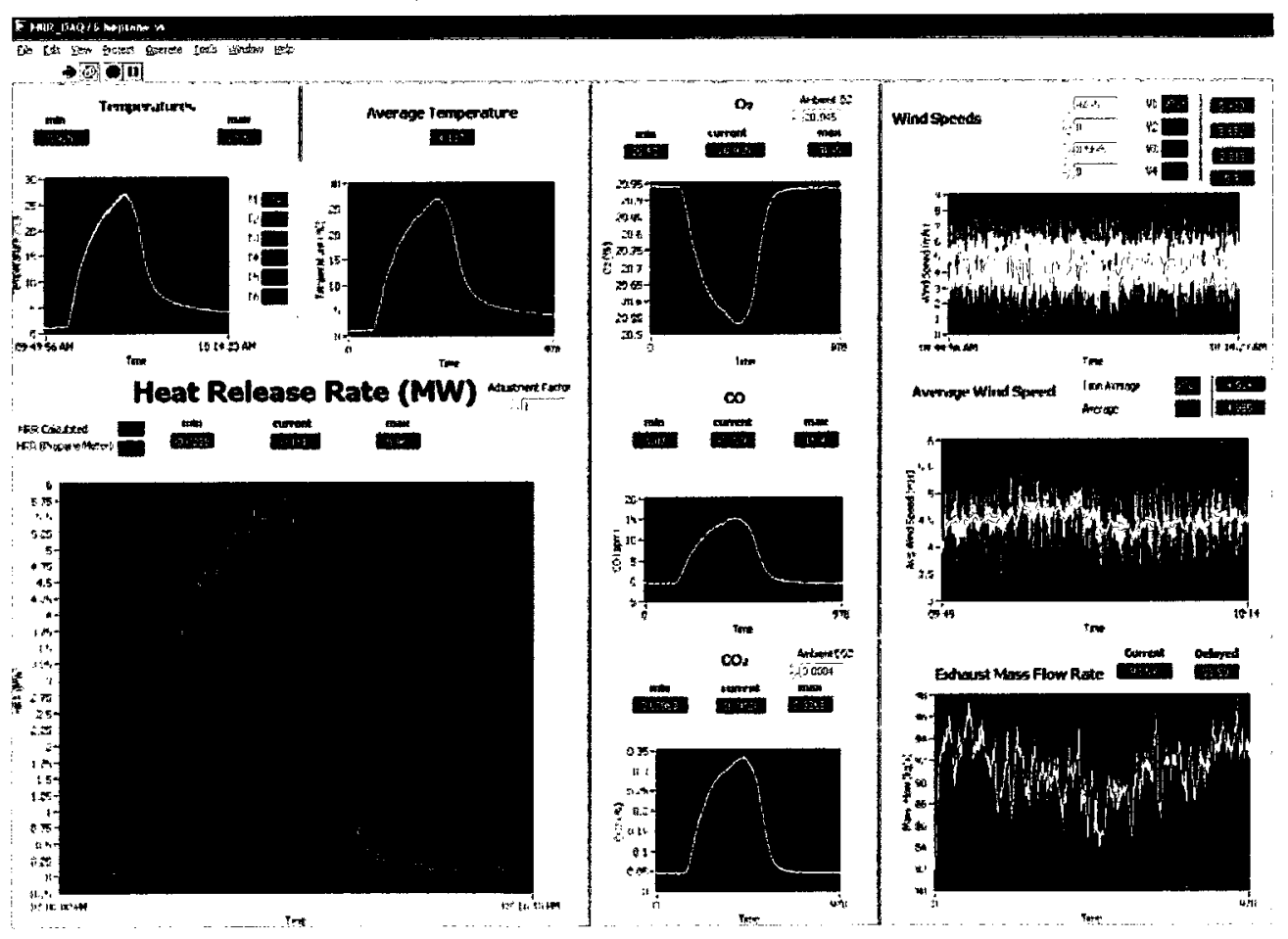

Figure 7.3 Example screenshot from heptane pool fire experiment 


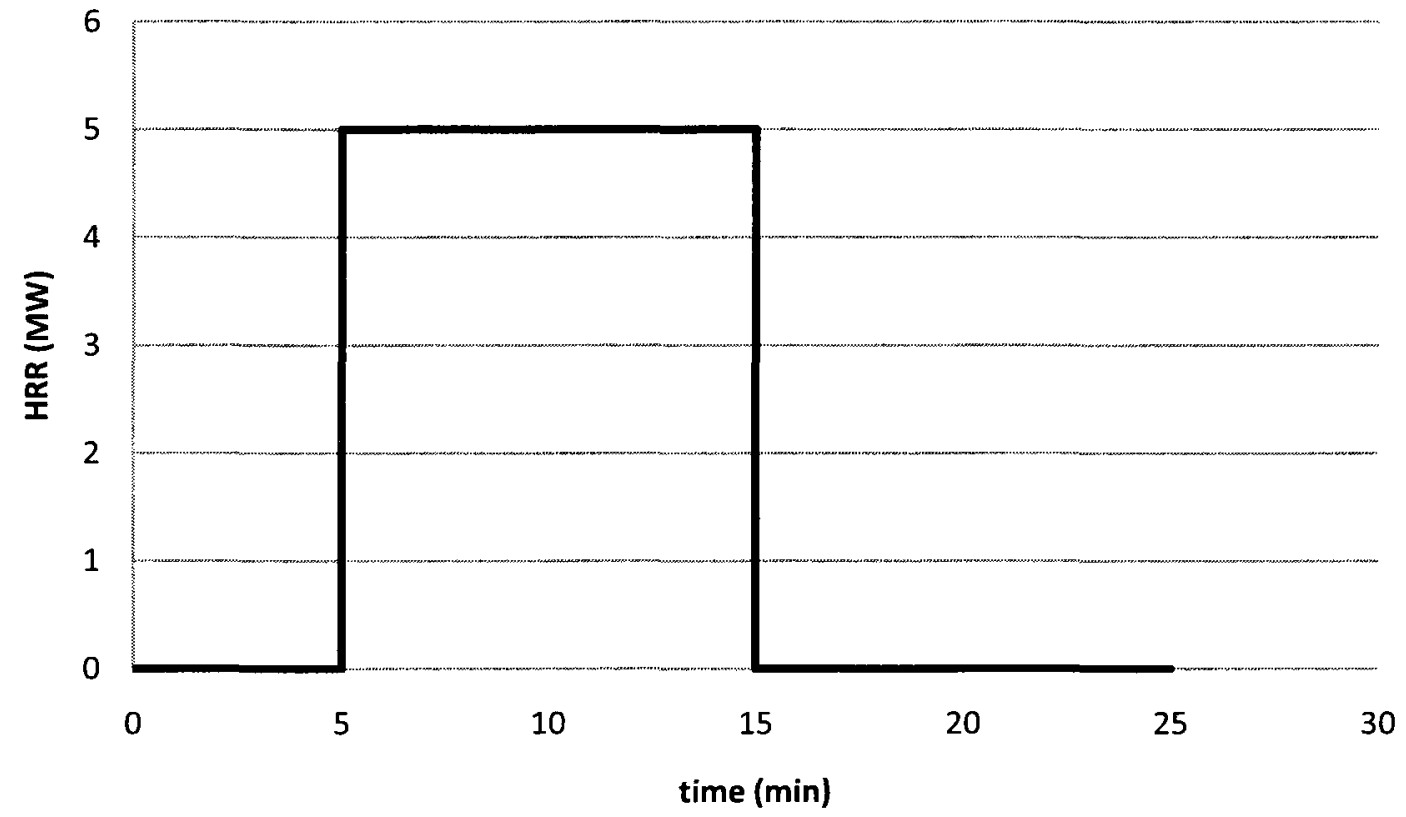

Figure 7.4 Type A propane calibration experiment

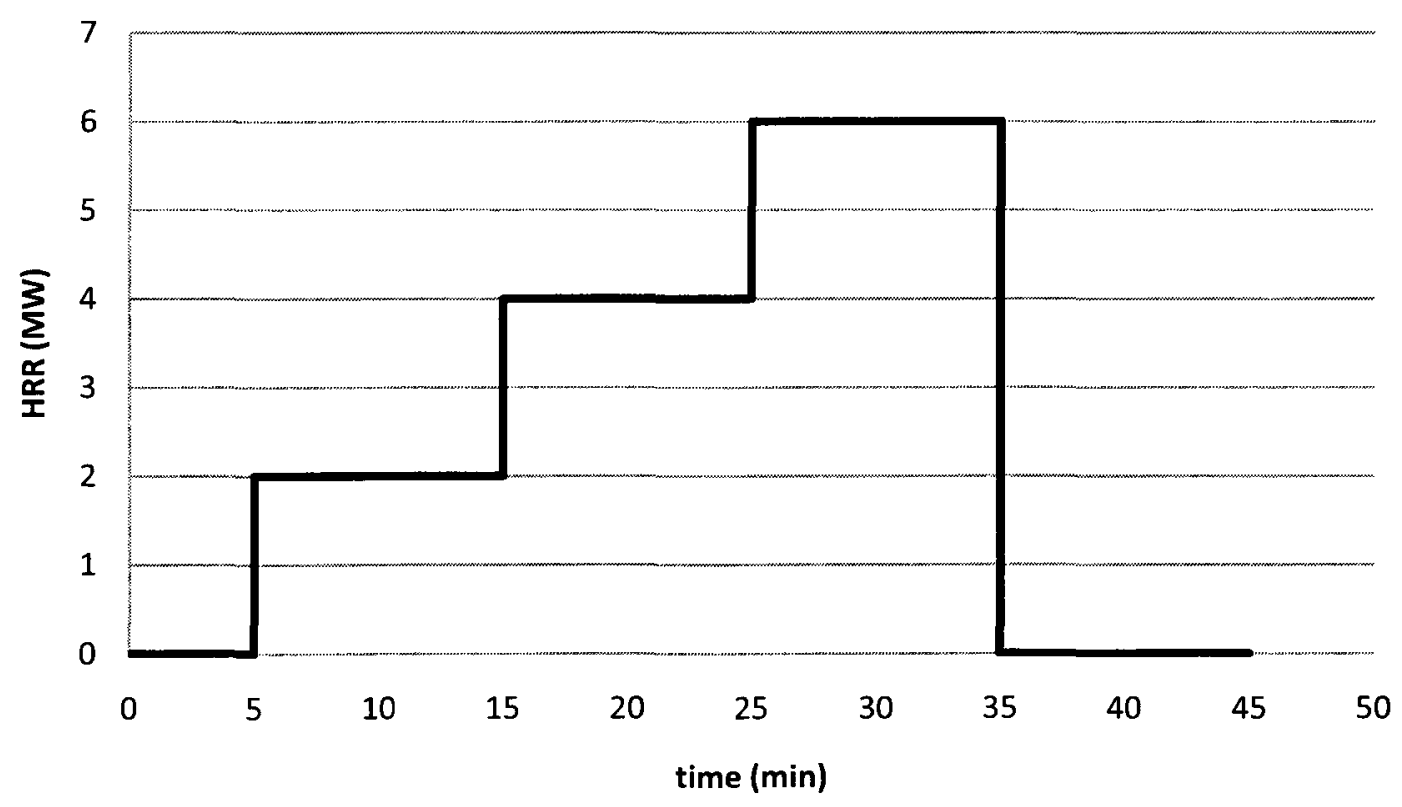

Figure 7.5 Type B propane calibration experiment 


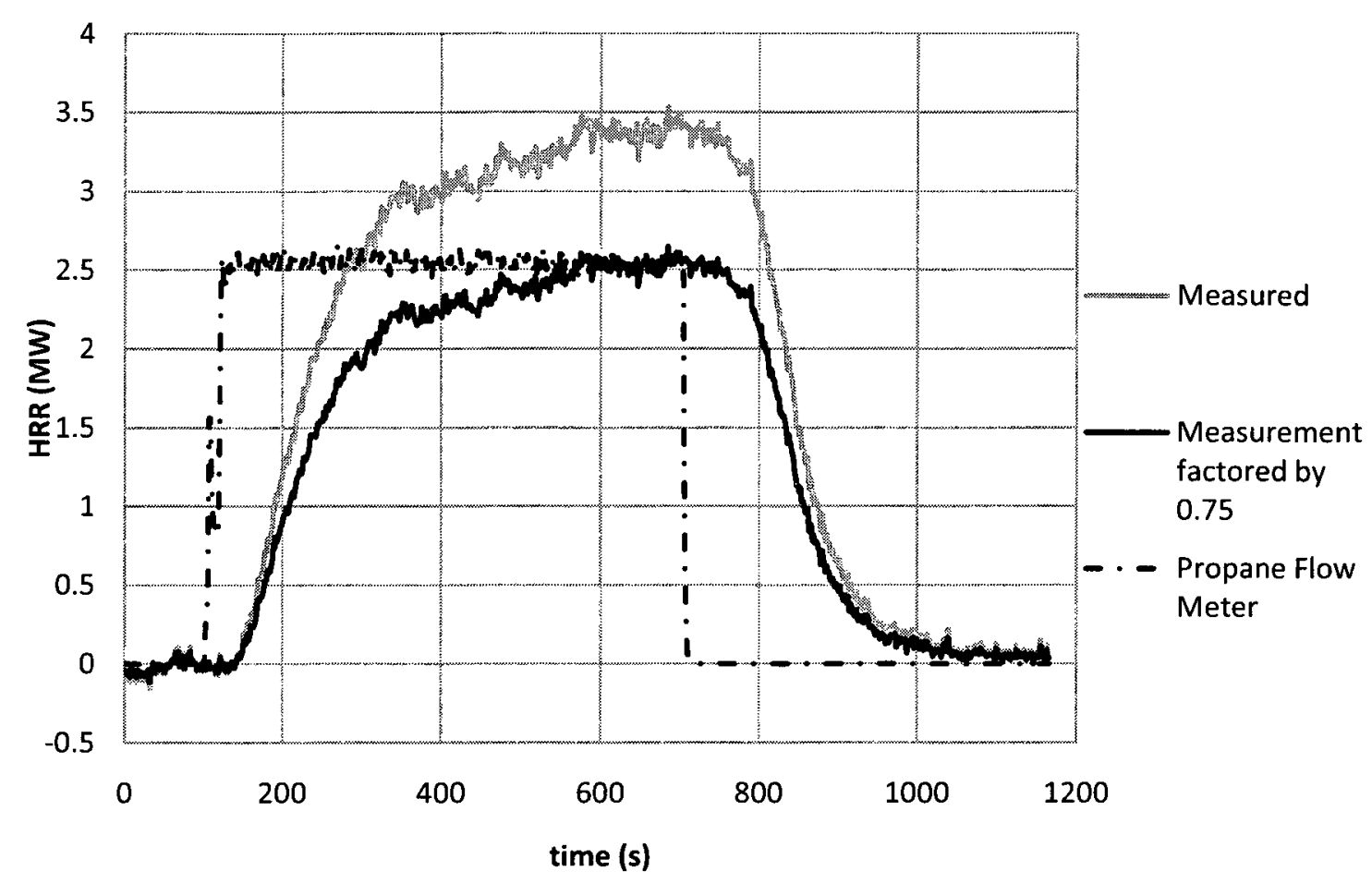

Figure 7.6 HRR measurements of propane experiment A3 showing the effect of the factor of 0.75
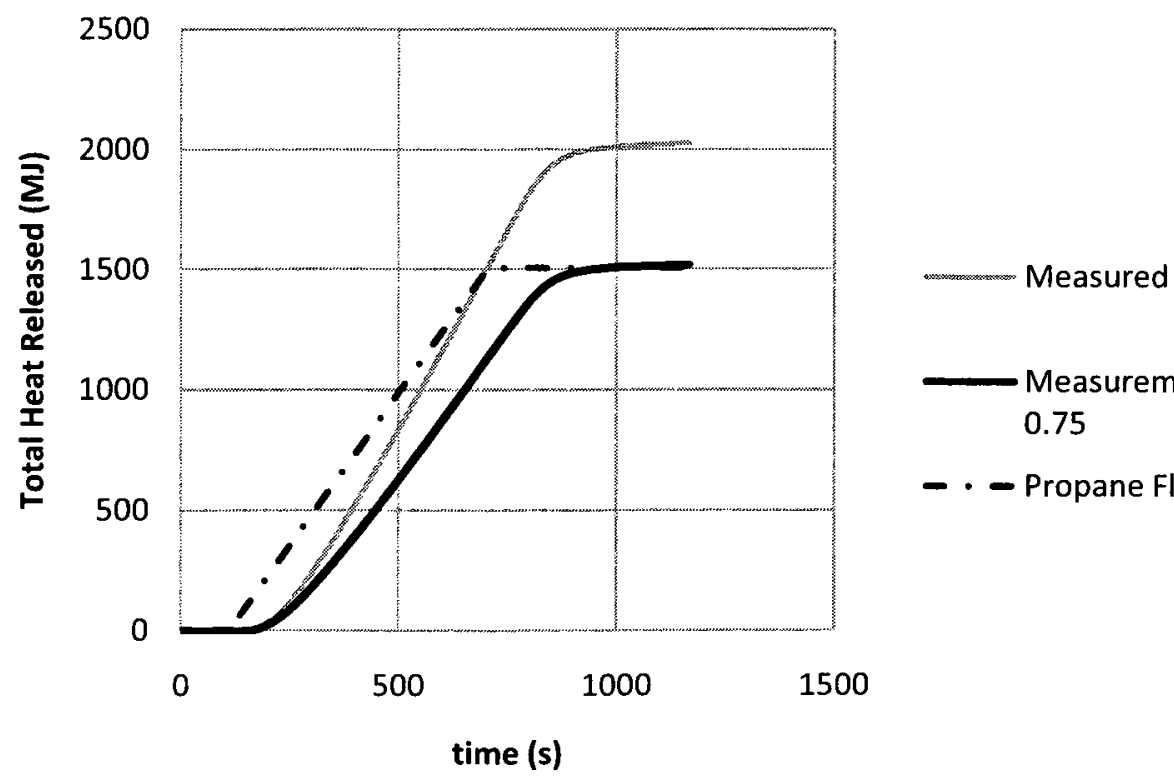

Measurement factored by 0.75

- - Propane Flow Meter

Figure 7.7 THR measurements of propane experiment A3 showing the effect of the factor of 0.75 


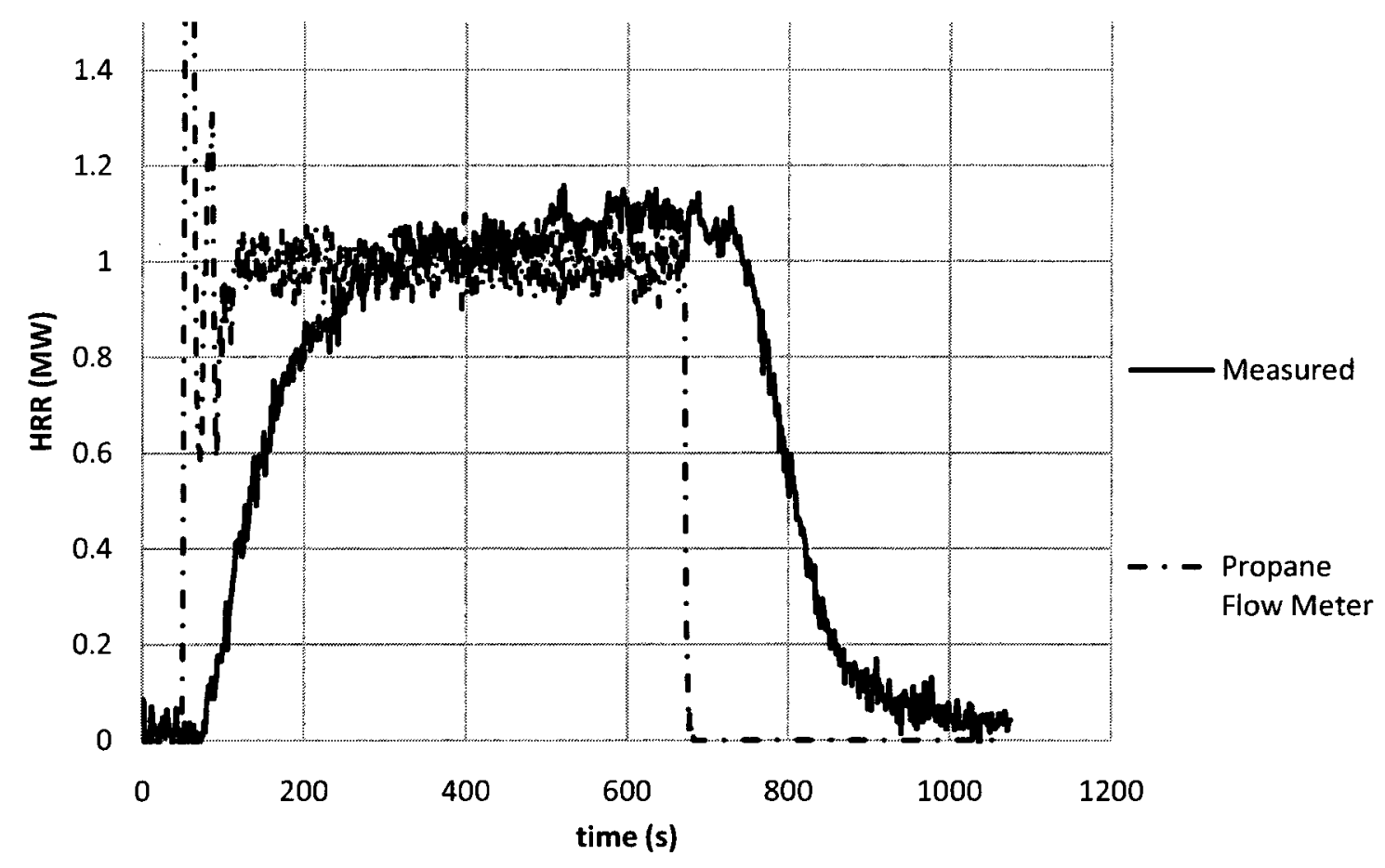

Figure 7.8 HRR curves for propane test A1

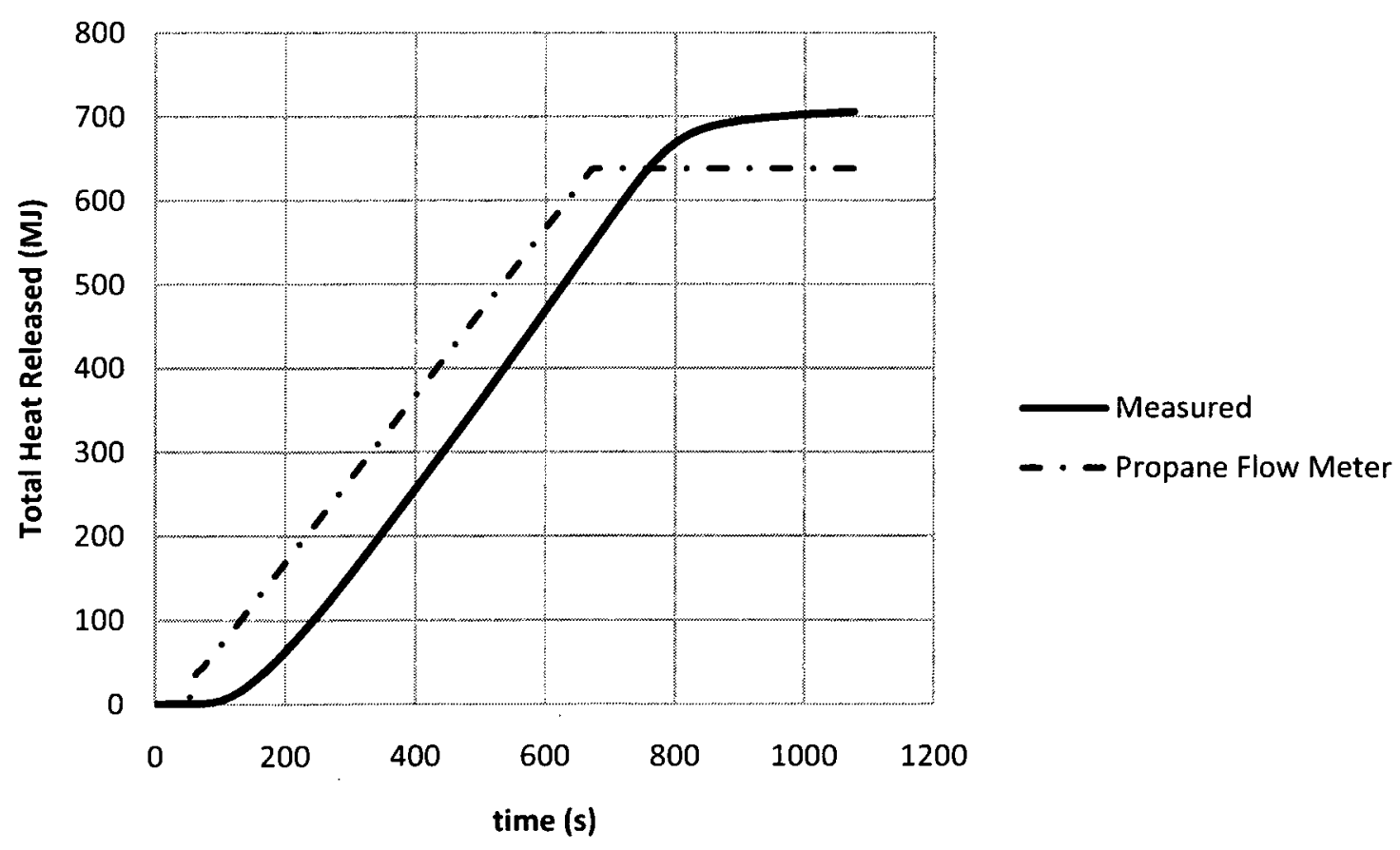

Figure 7.9 THR curves for propane test Al 


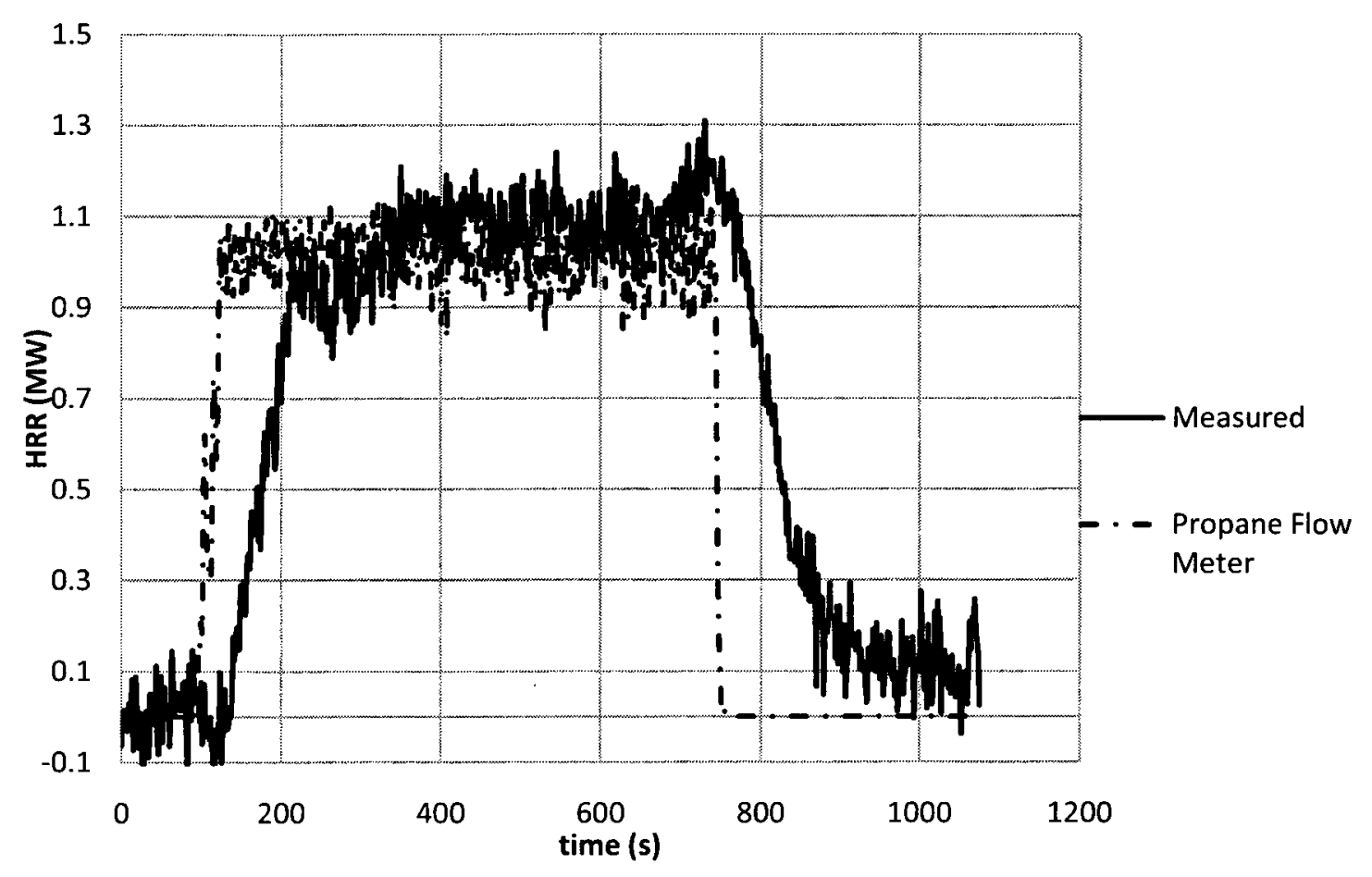

Figure 7.10 HRR curves for propane test A2

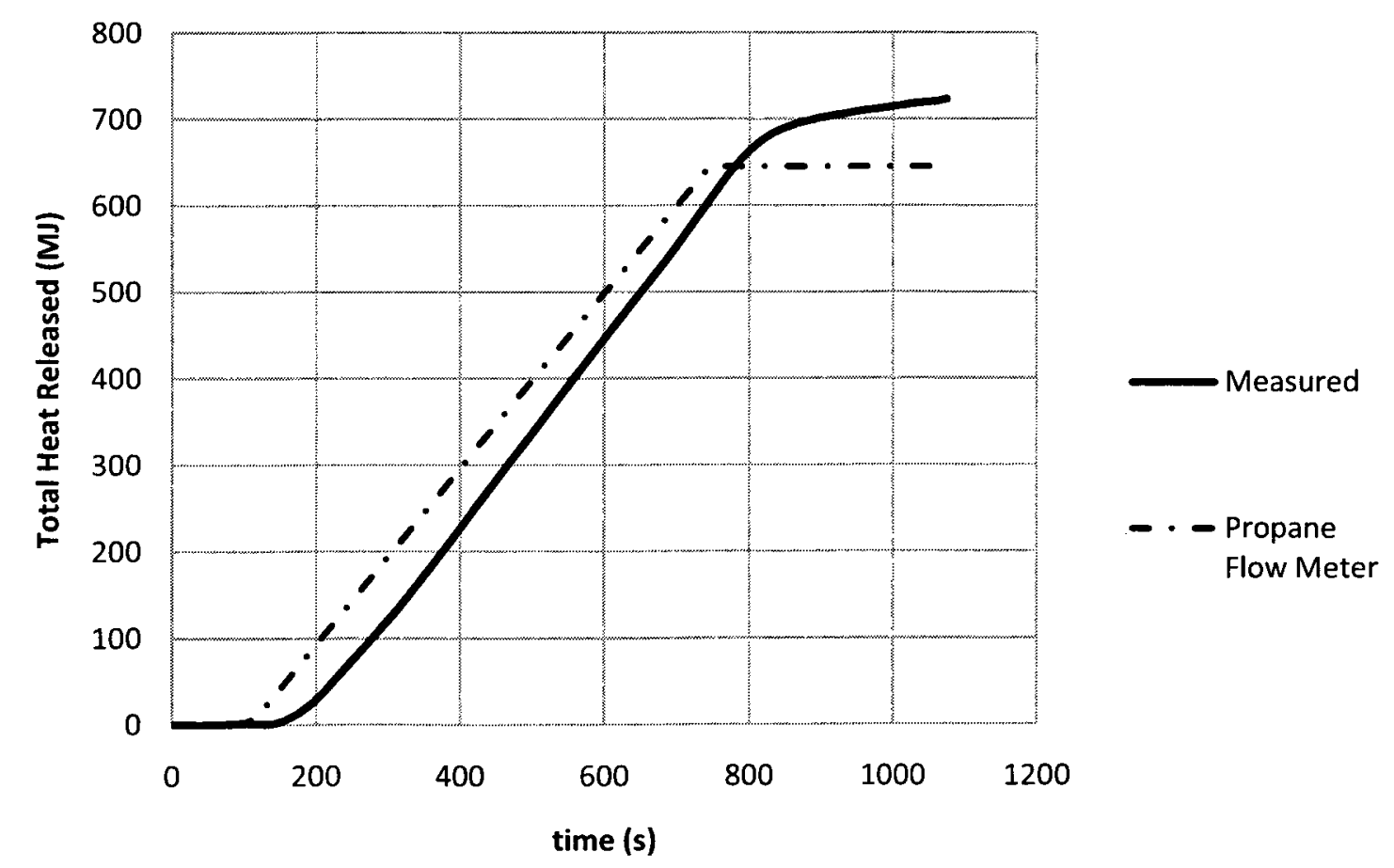

Figure 7.11 THR curves for propane test A2 


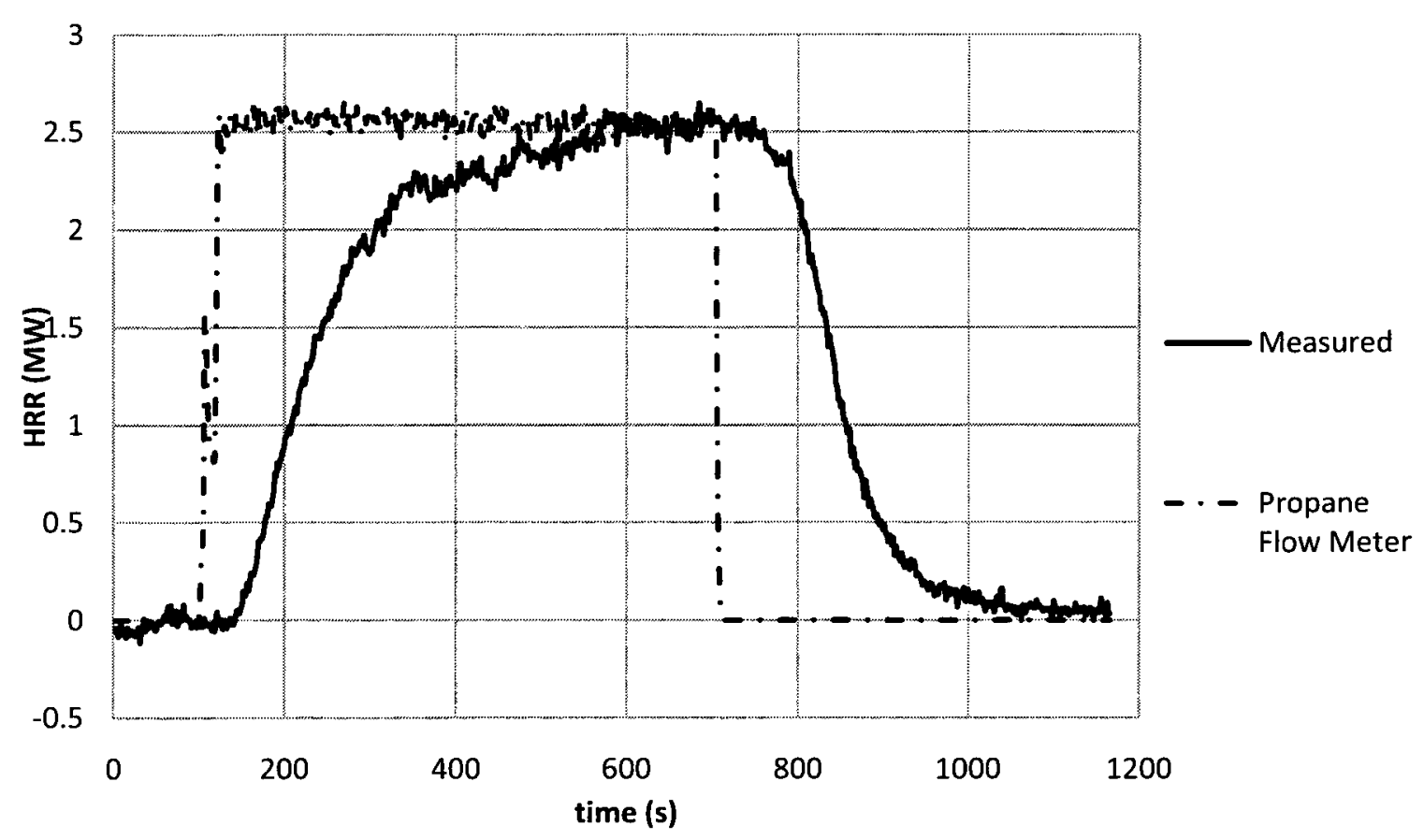

Figure 7.12 HRR curves for propane test A3

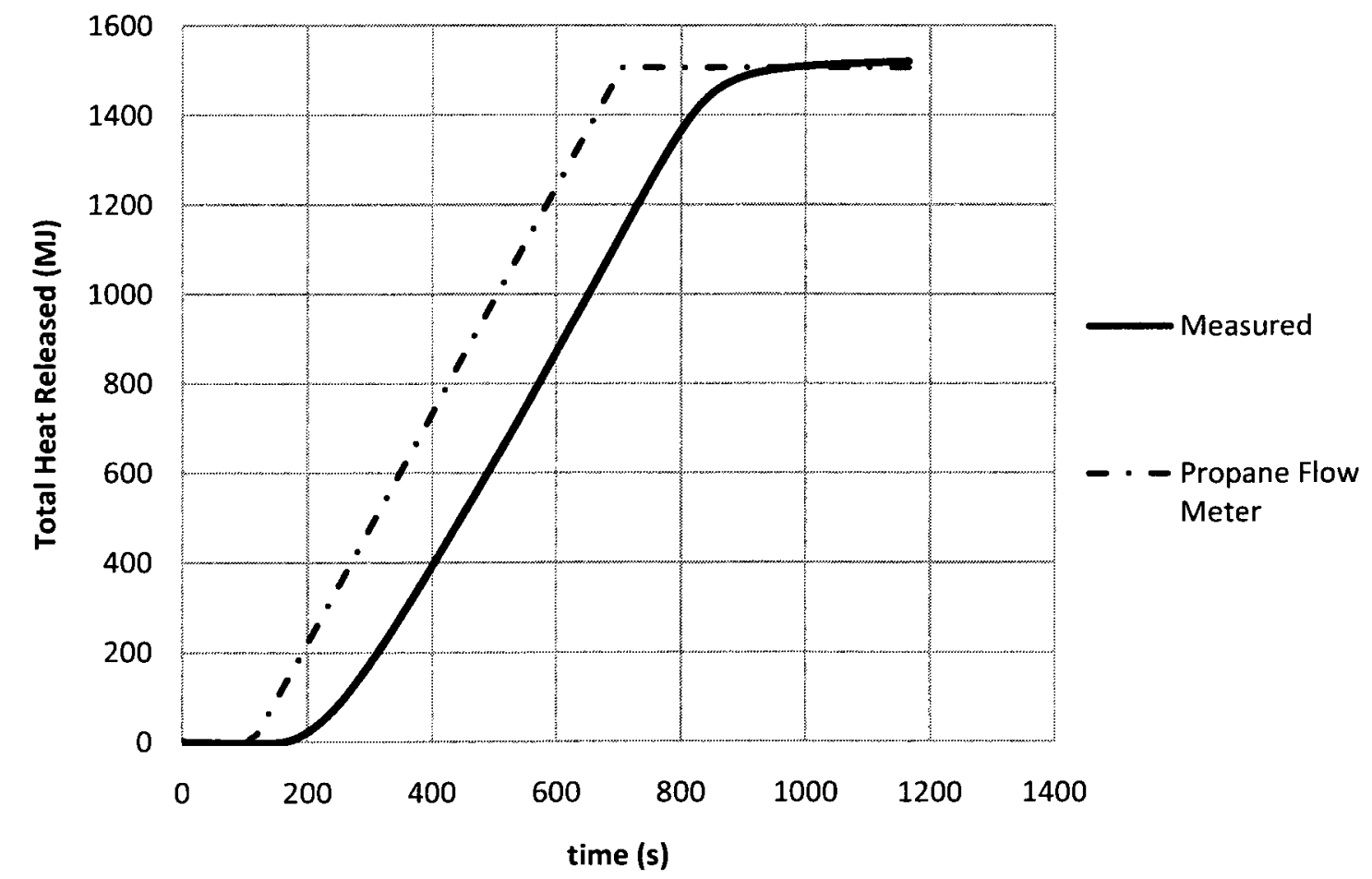

Figure 7.13 THR curves for propane test A3 


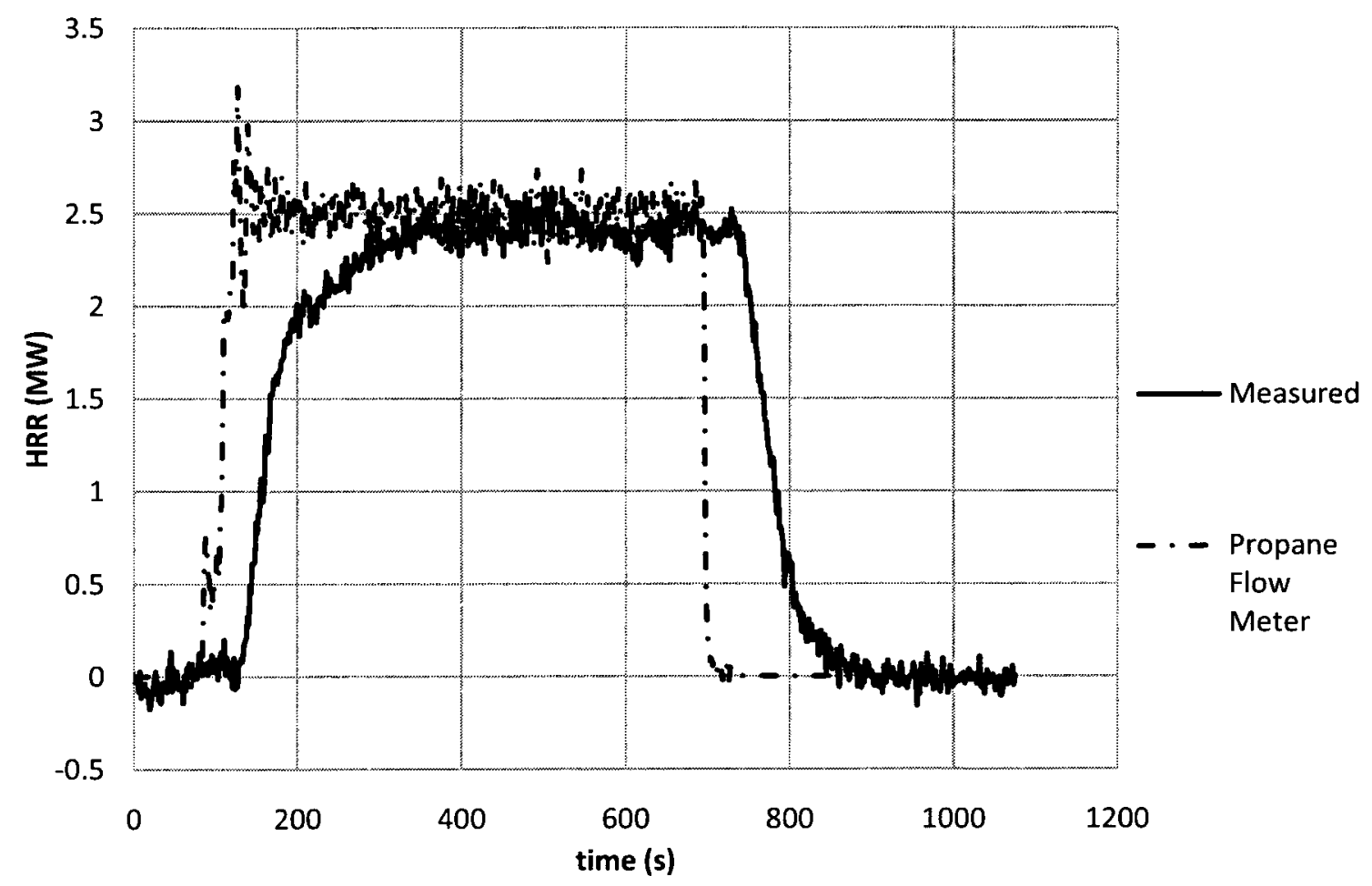

Figure 7.14 HRR curves for propane test A4

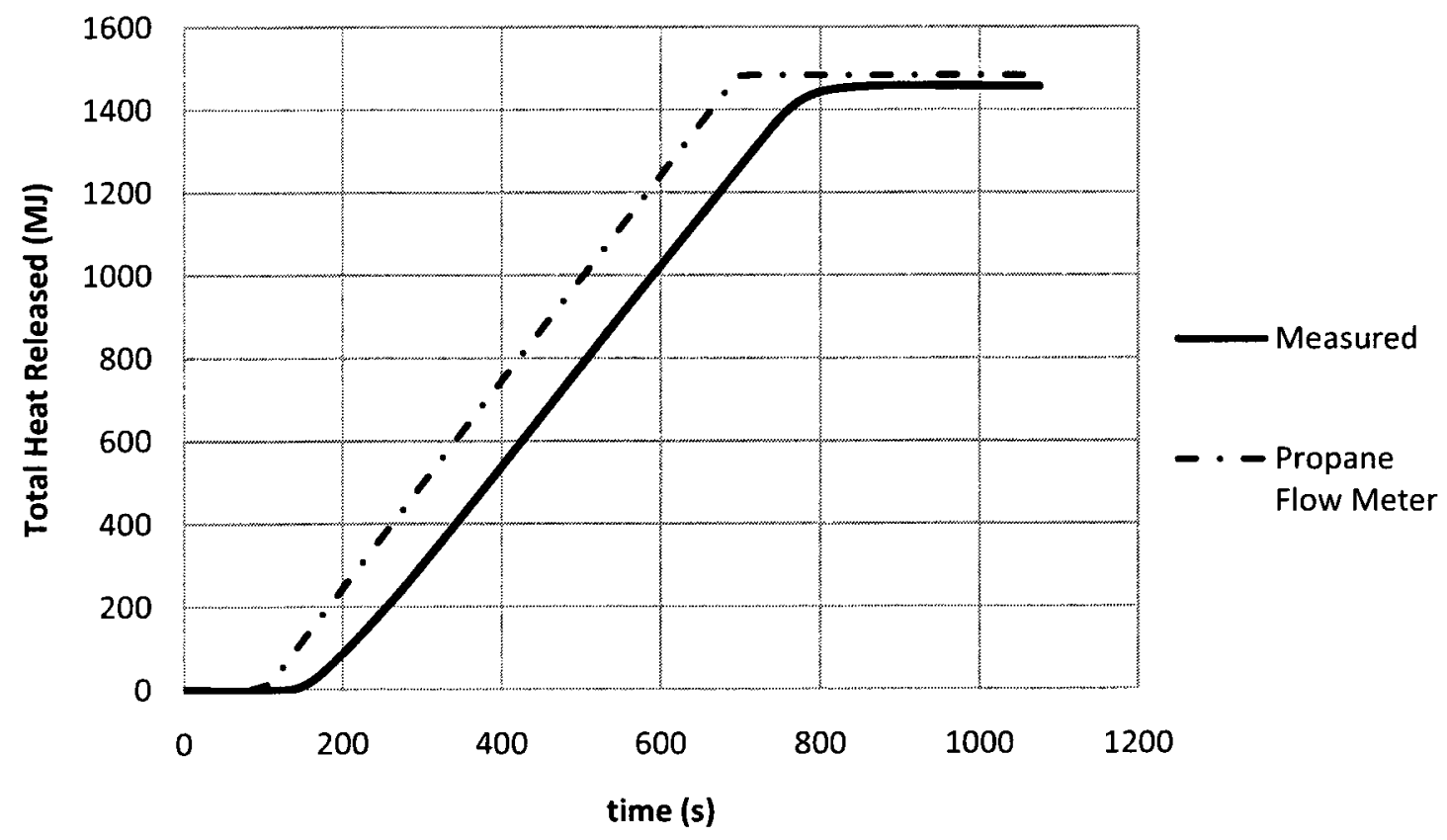

Figure 7.15 THR curves for propane test A4 


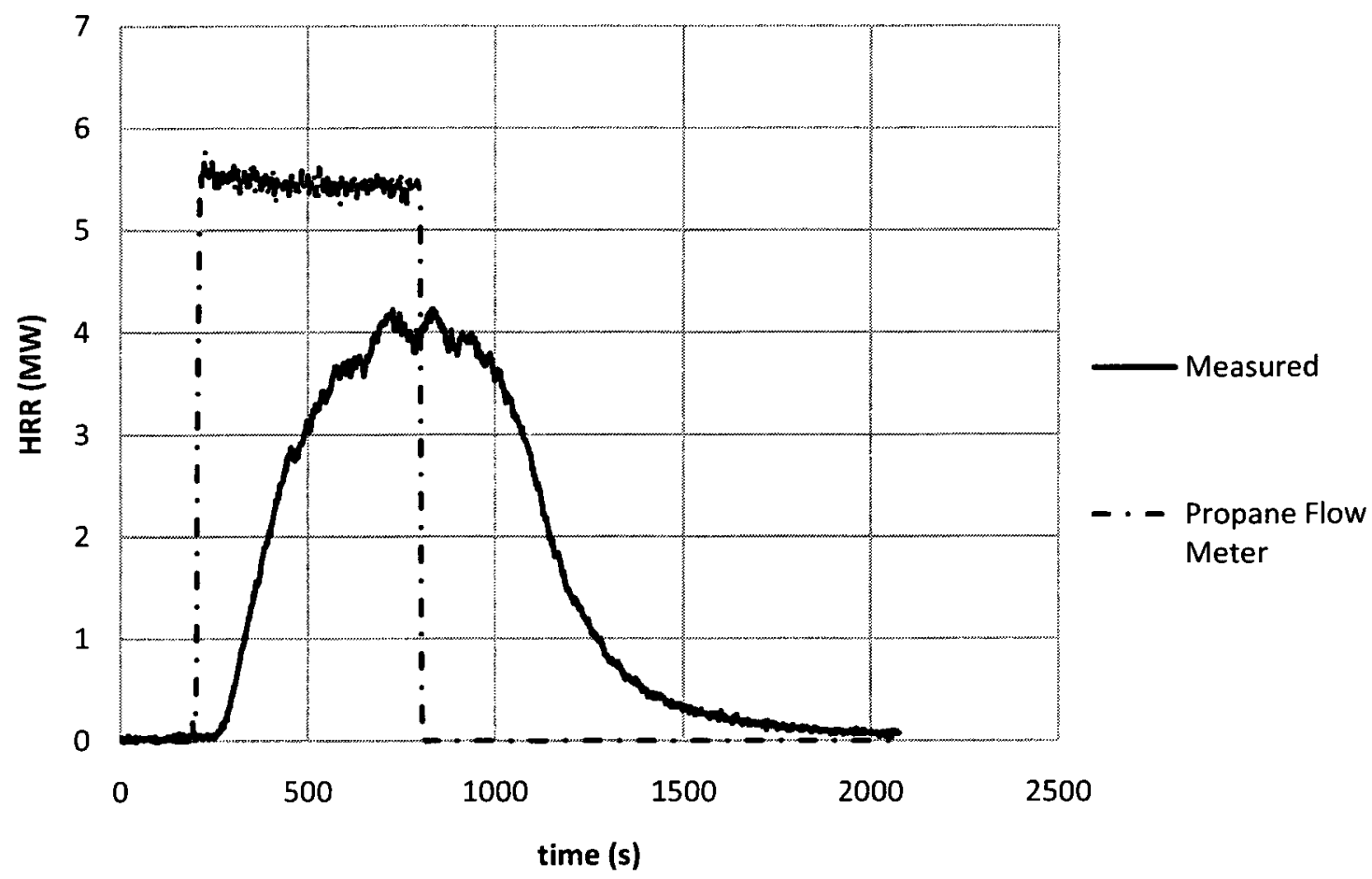

Figure 7.16 HRR curves for propane test A5

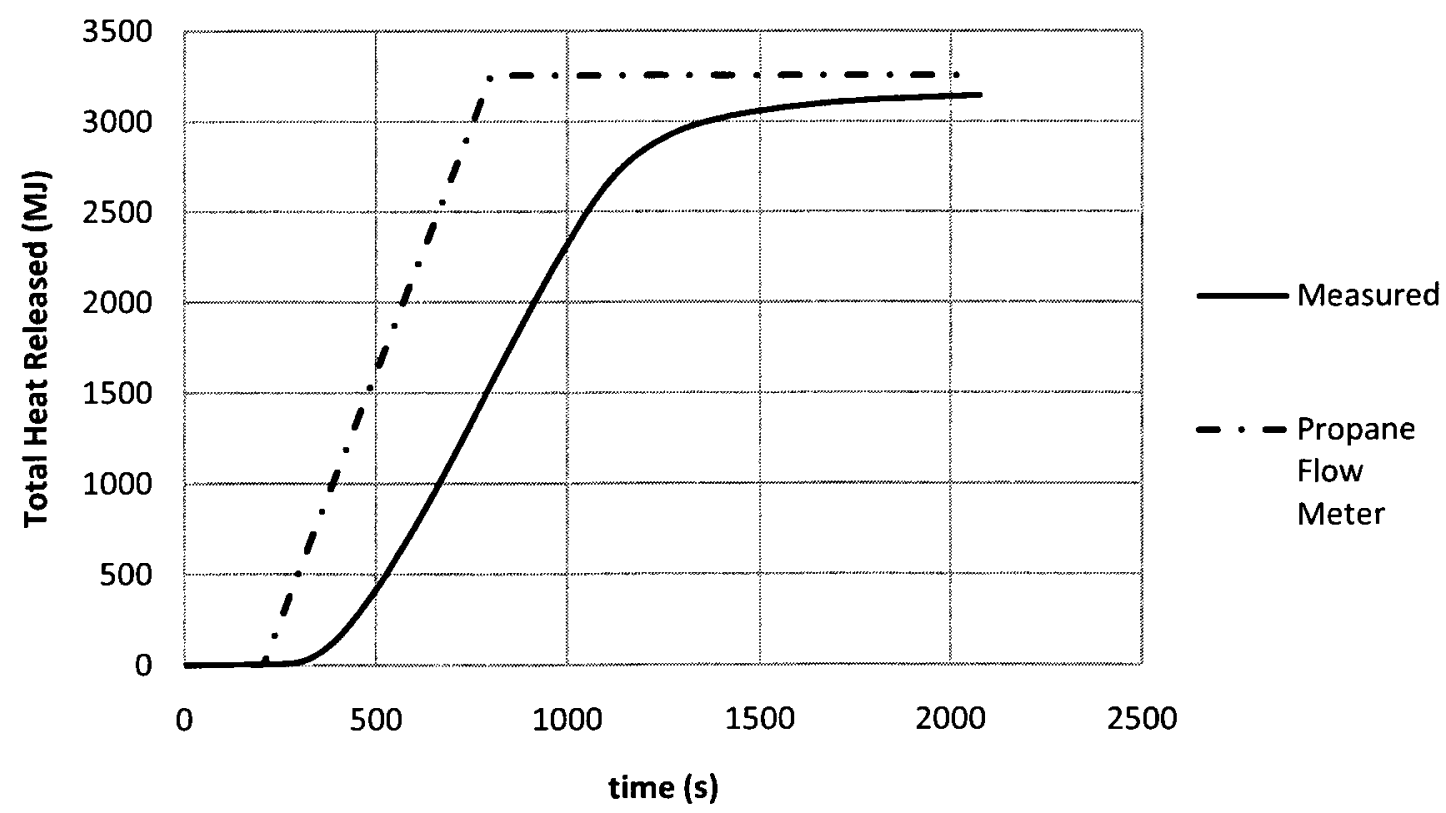

Figure 7.17 THR curves for propane test A5 


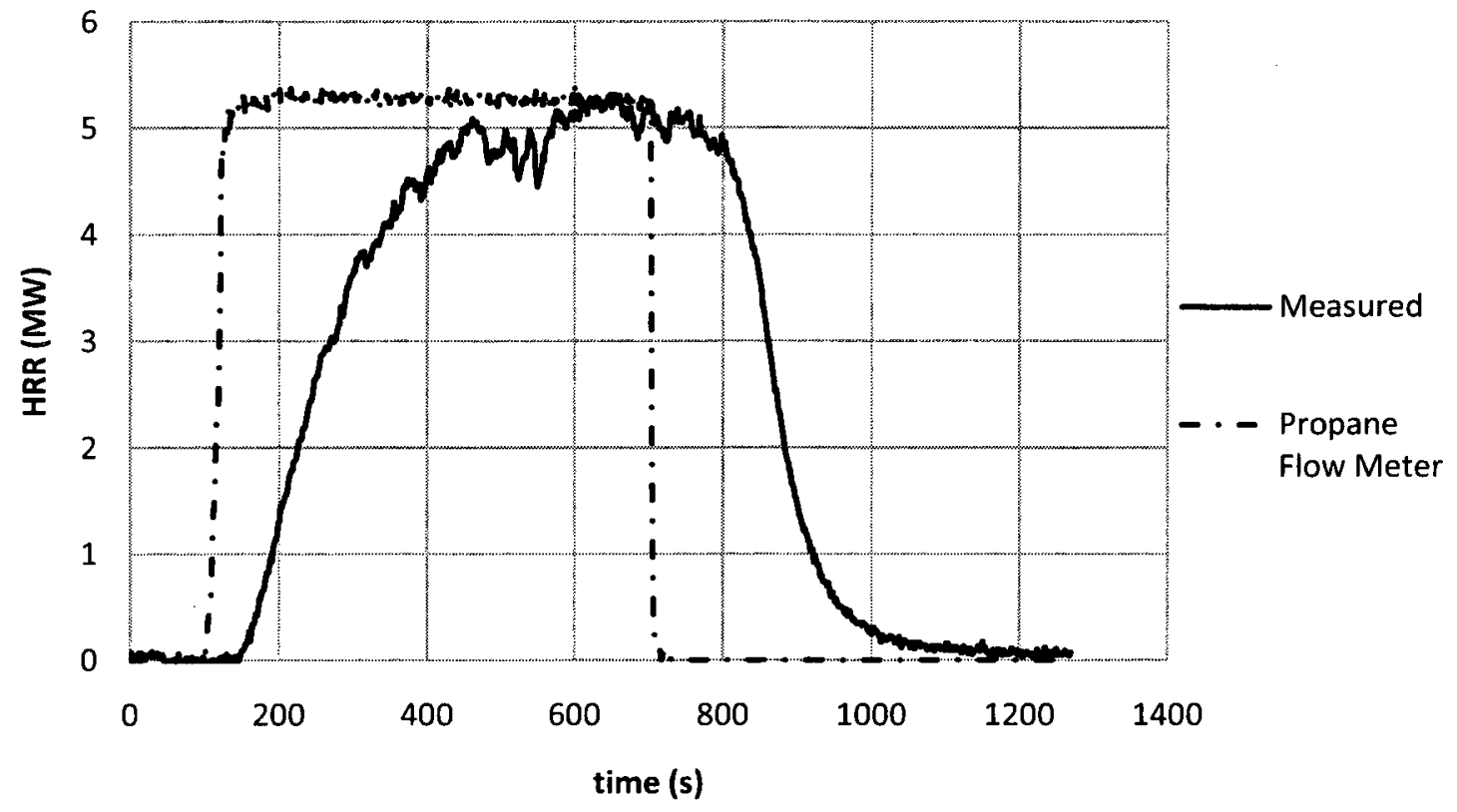

Figure 7.18 HRR curves for propane test A6

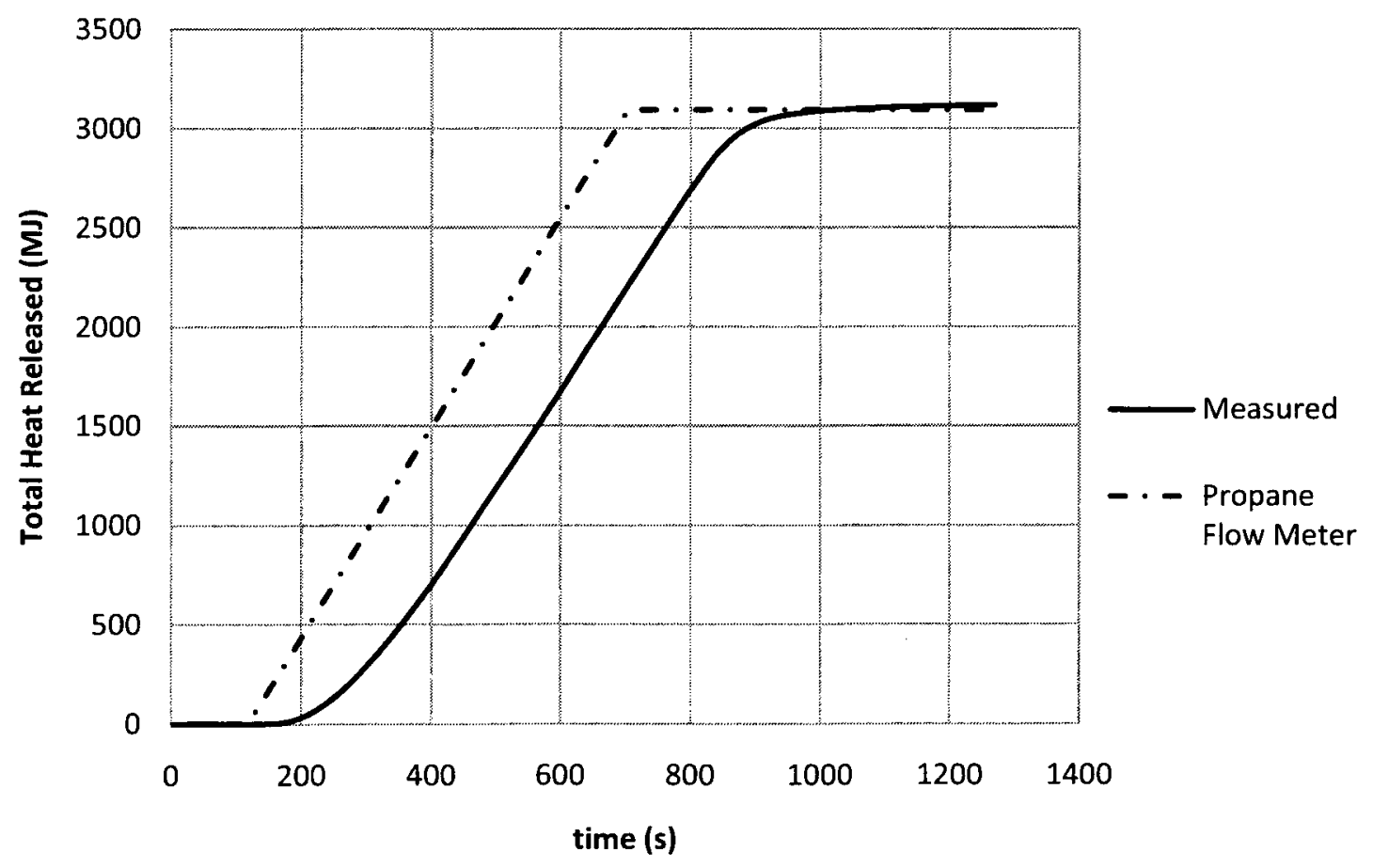

Figure 7.19 THR curves for propane test A6 


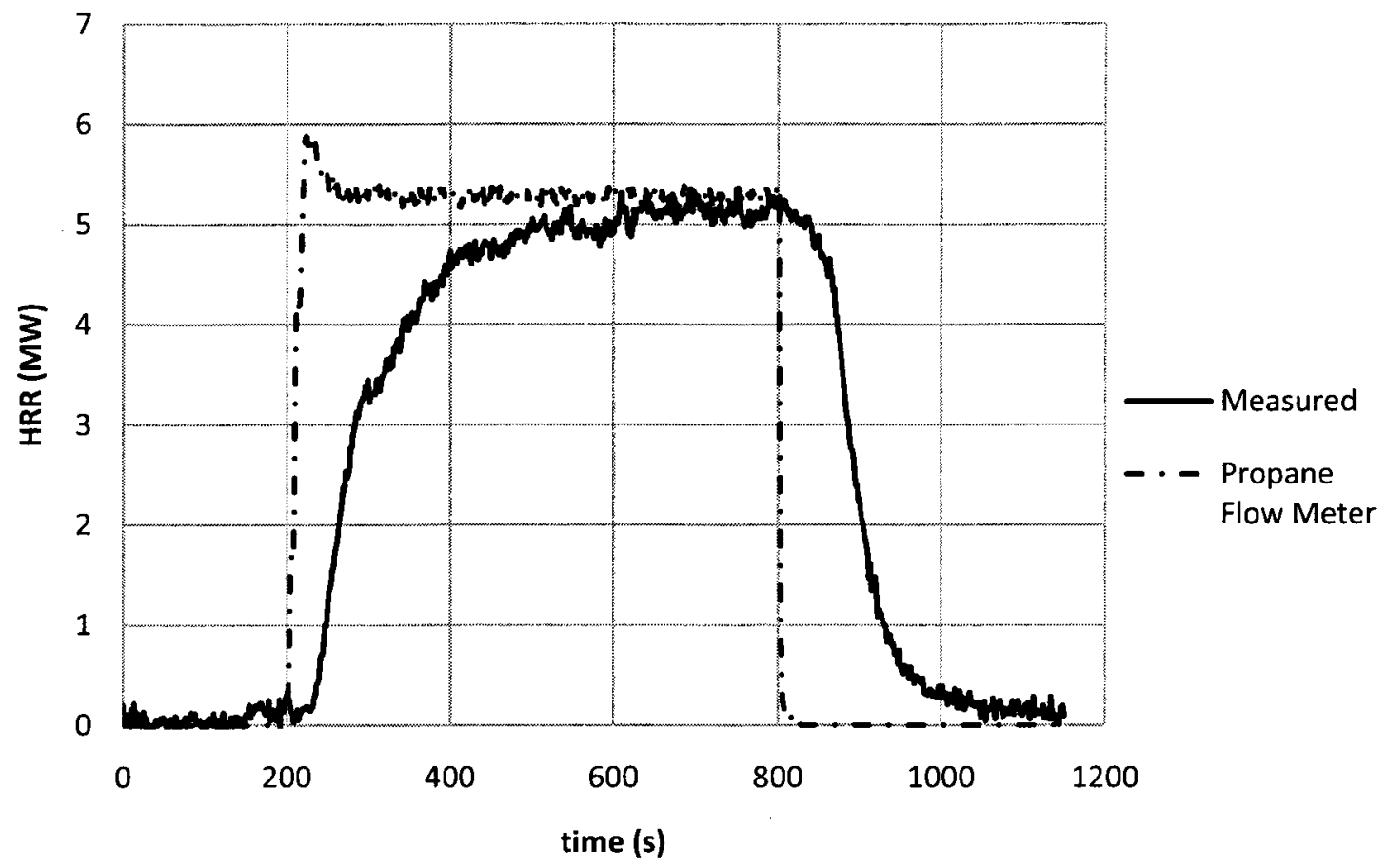

Figure 7.20 HRR curves for propane test A7

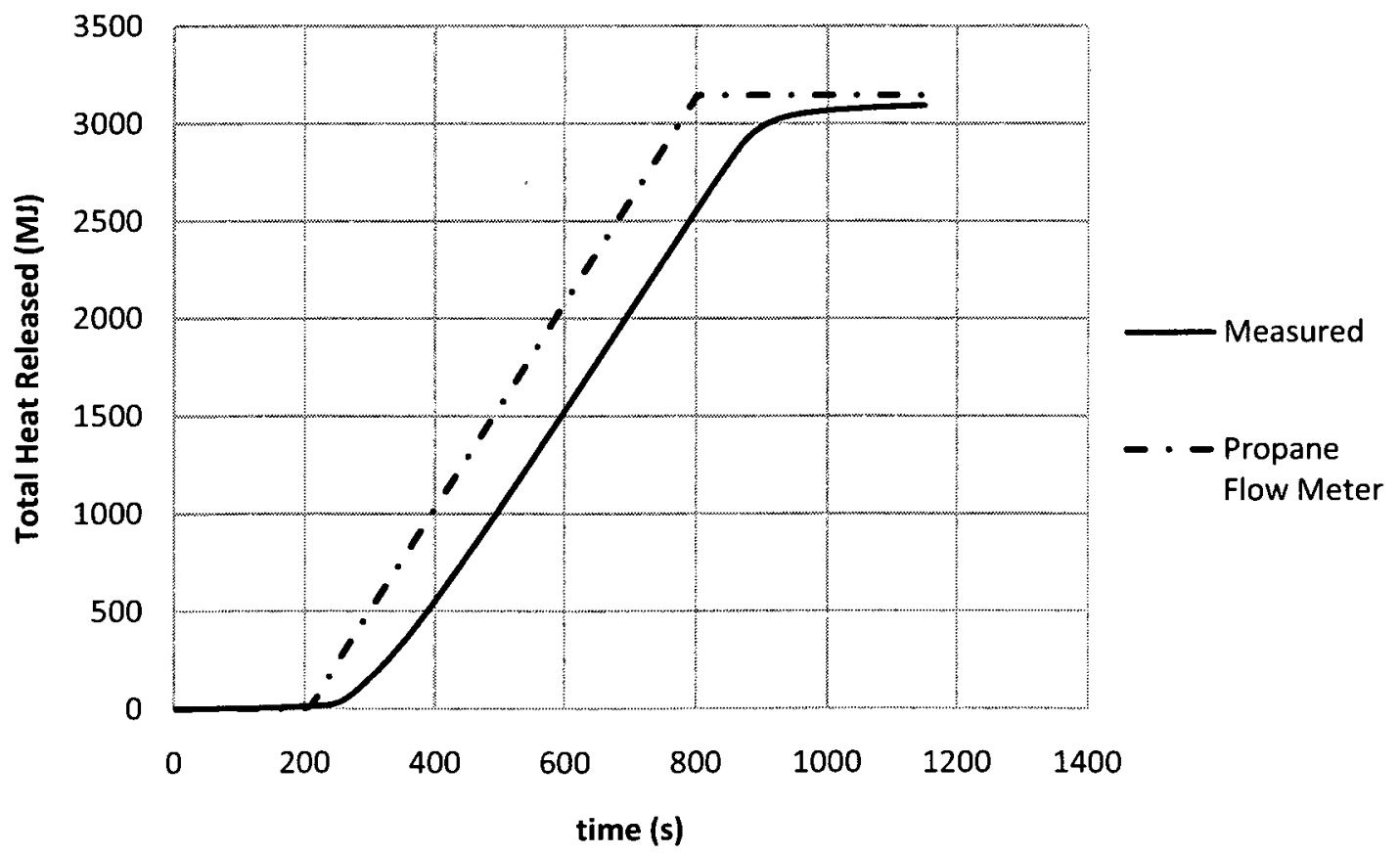

Figure 7.21 THR curves for propane test A7 


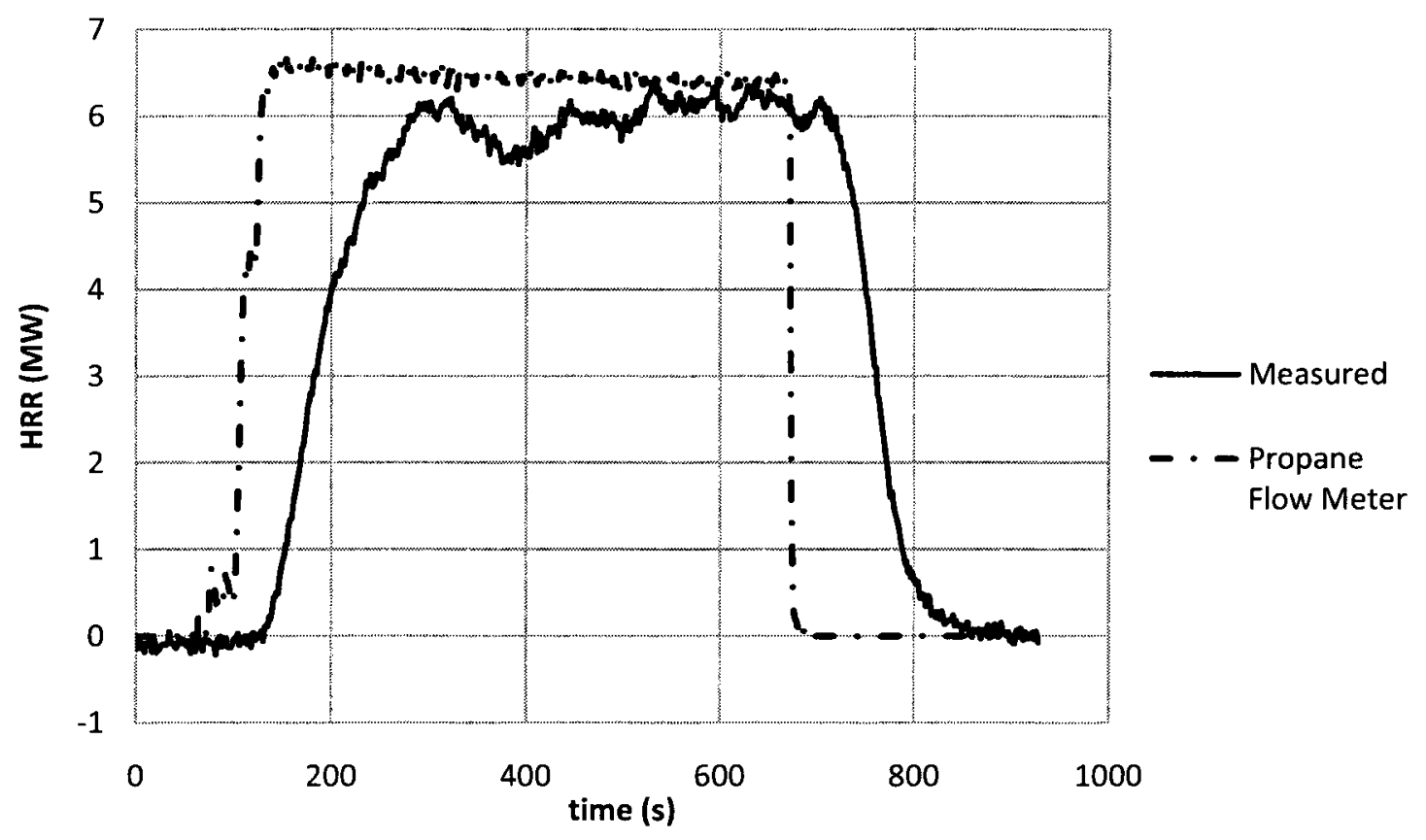

Figure 7.22 HRR curves for propane test A8

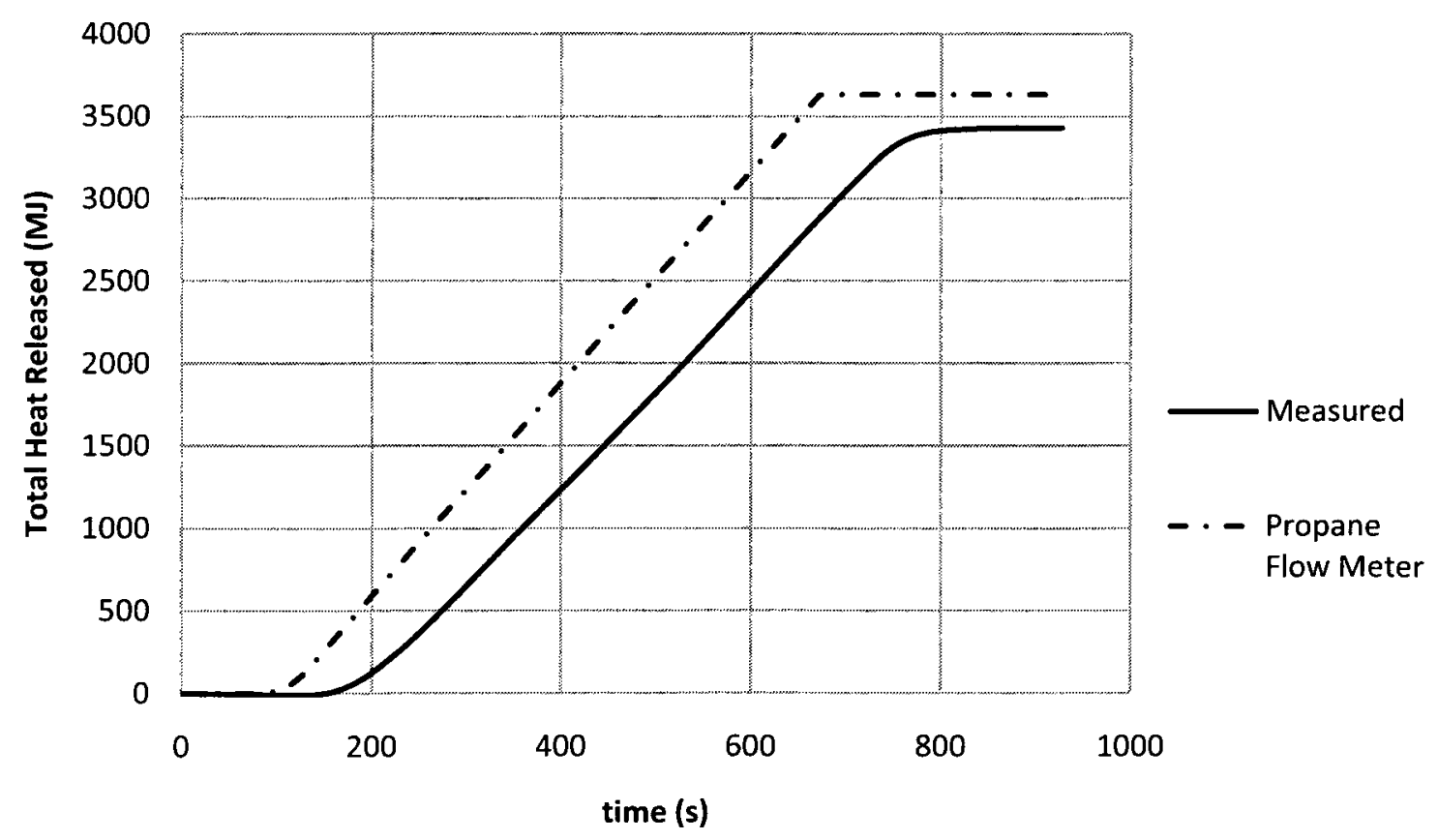

Figure 7.23 THR curves for propane test A8 


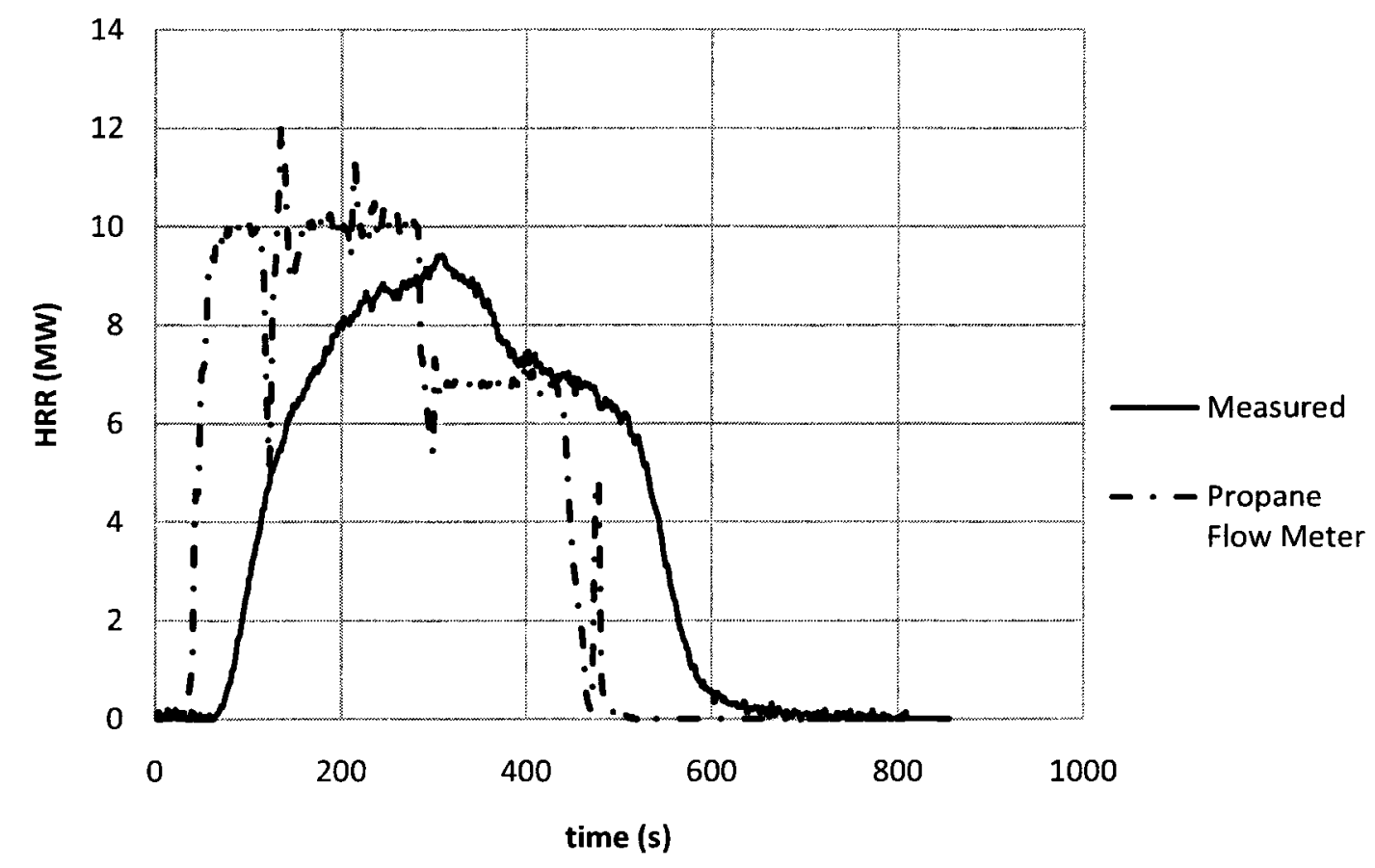

Figure 7.24 HRR curves for propane test A9

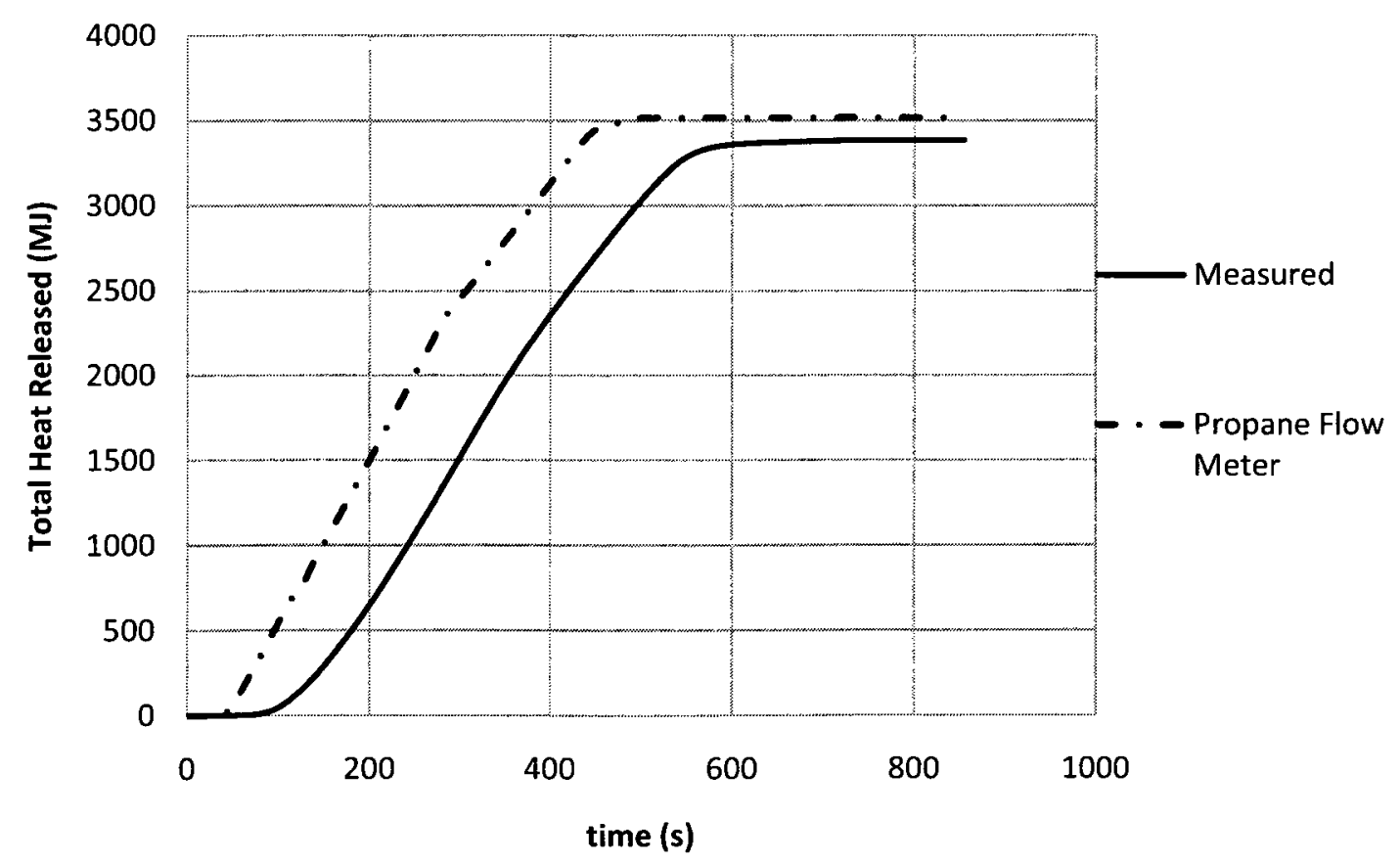

Figure 7.25 THR curves for propane test A9 


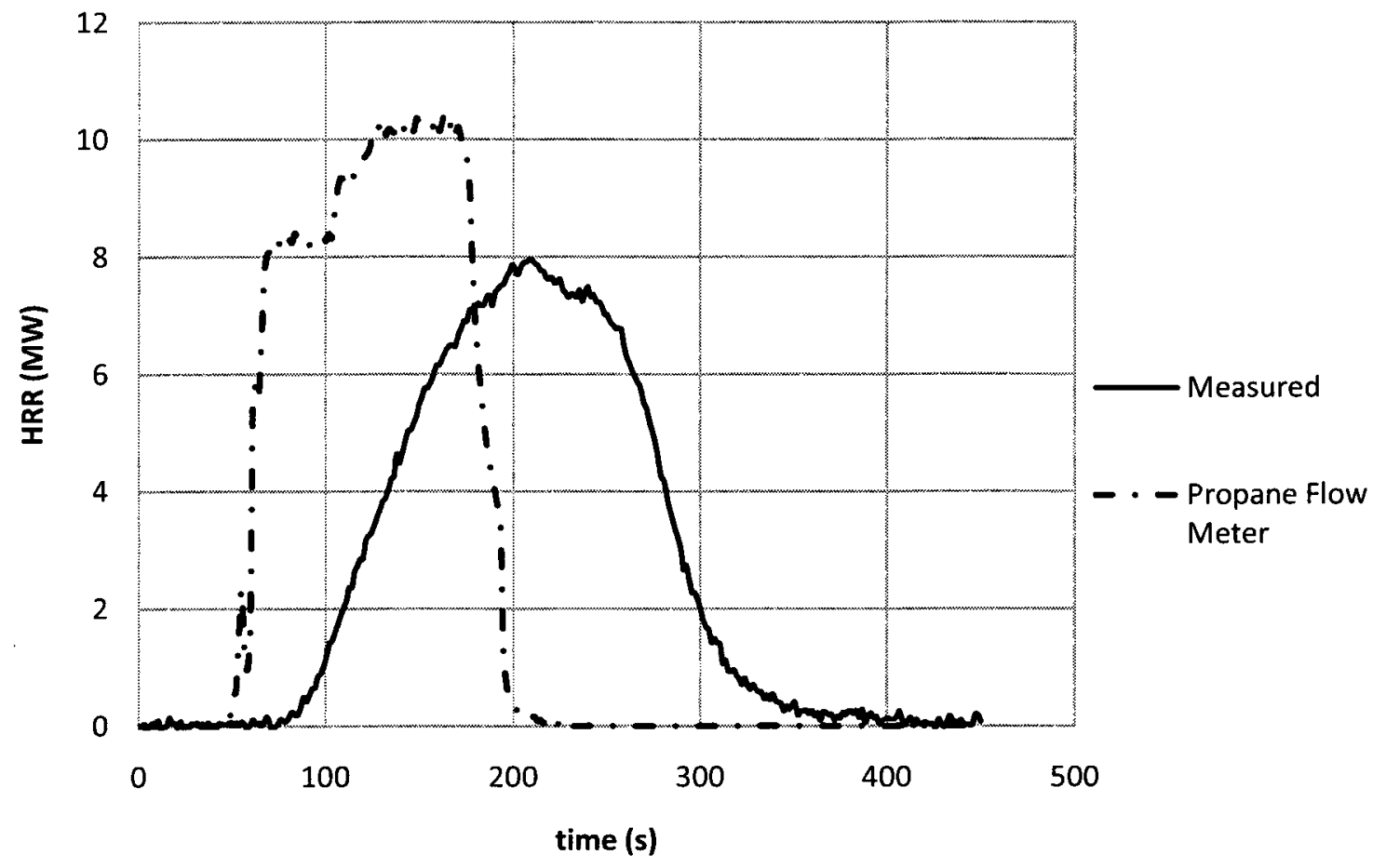

Figure 7.26 HRR curves for propane test A10

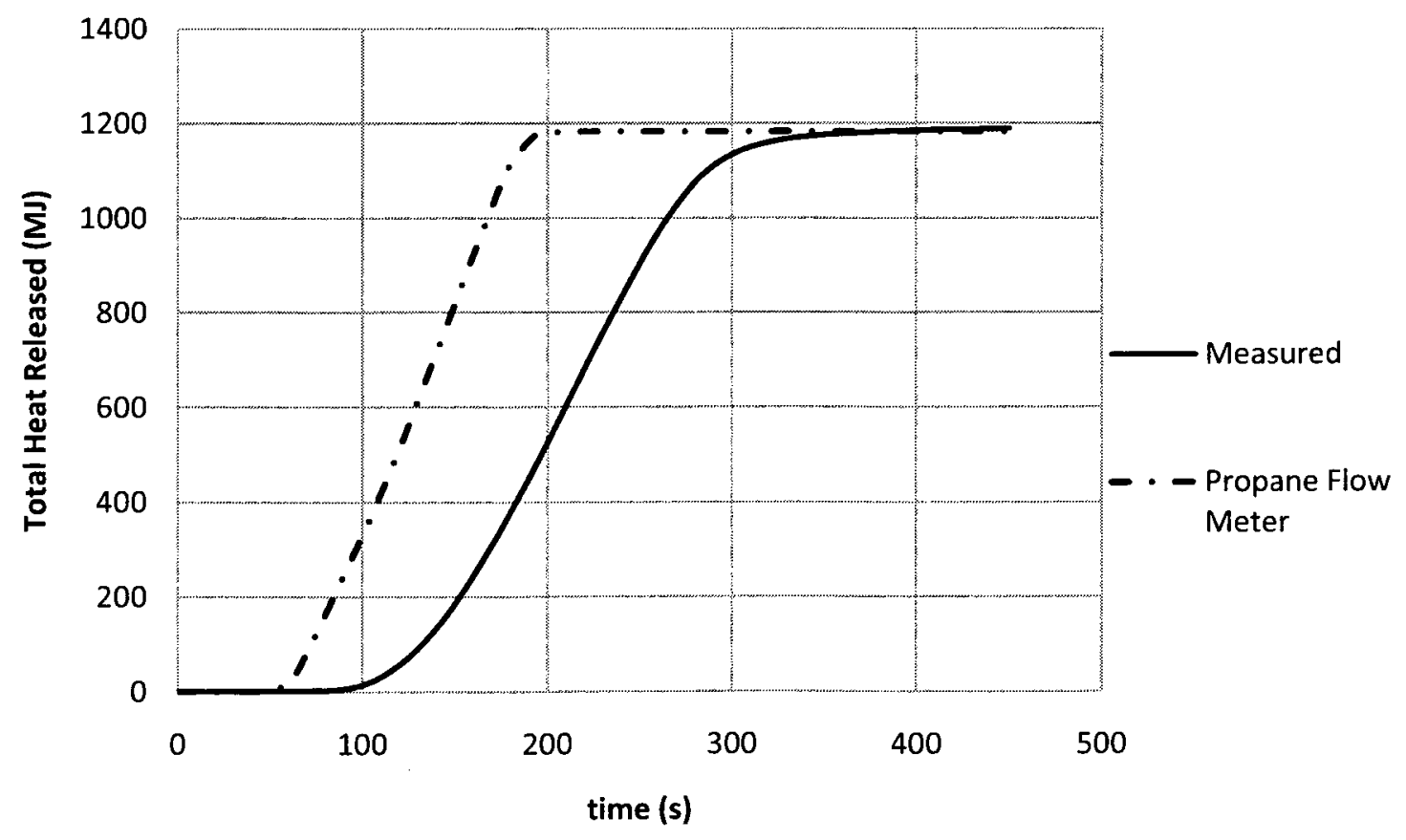

Figure 7.27 THR curves for propane test A10 


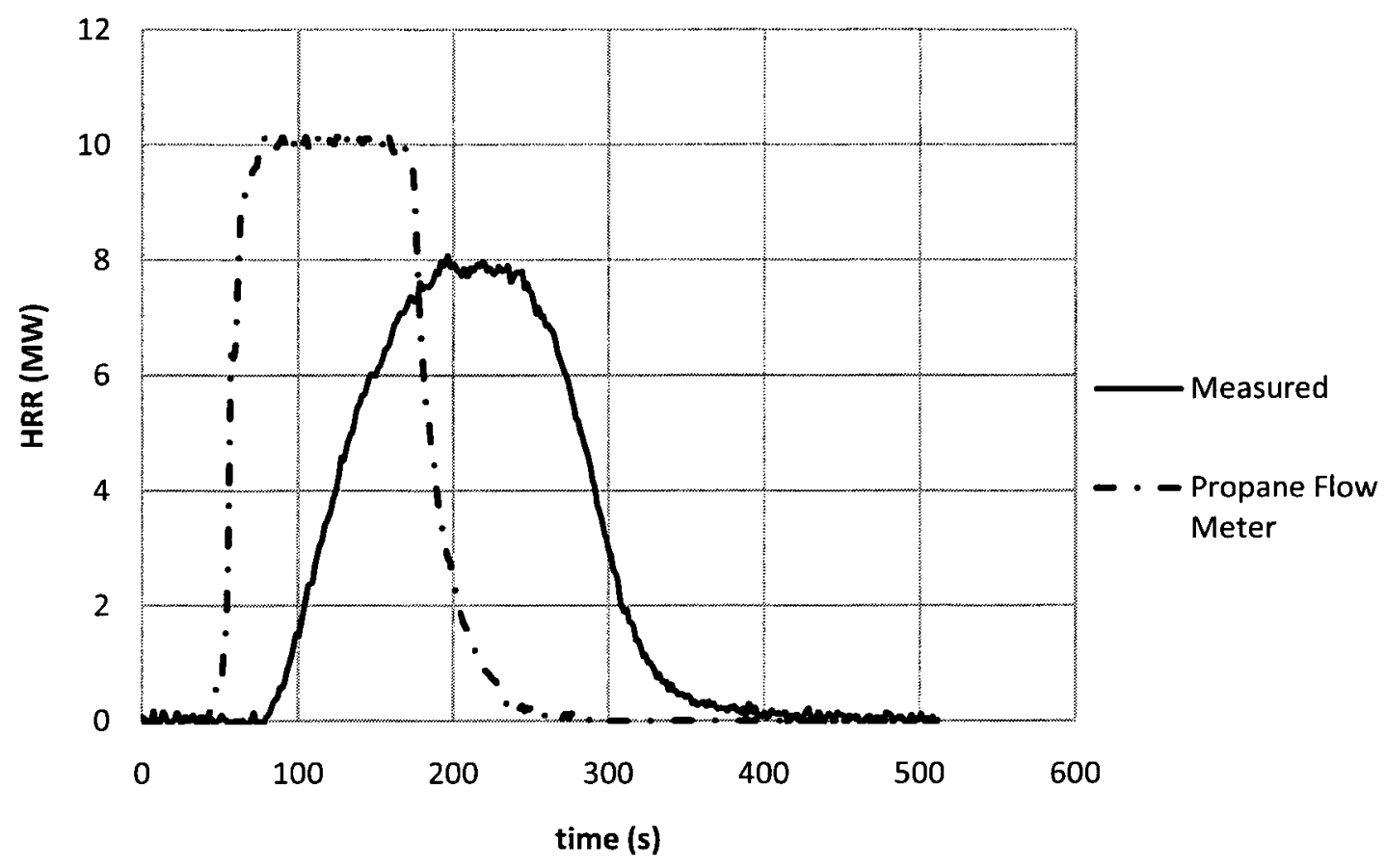

Figure 7.28 HRR curves for propane test A11

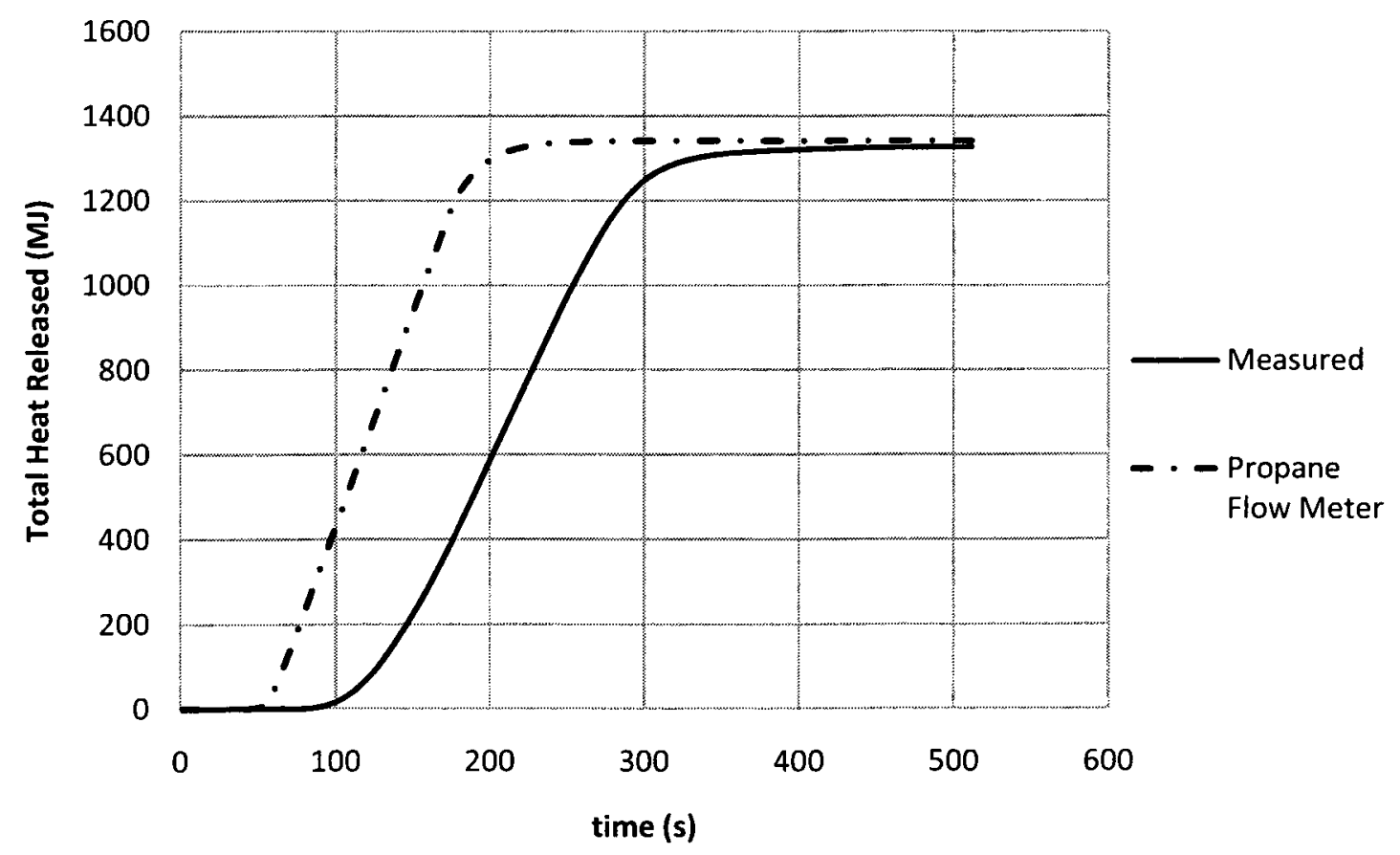

Figure 7.29 THR curves for propane test A11 


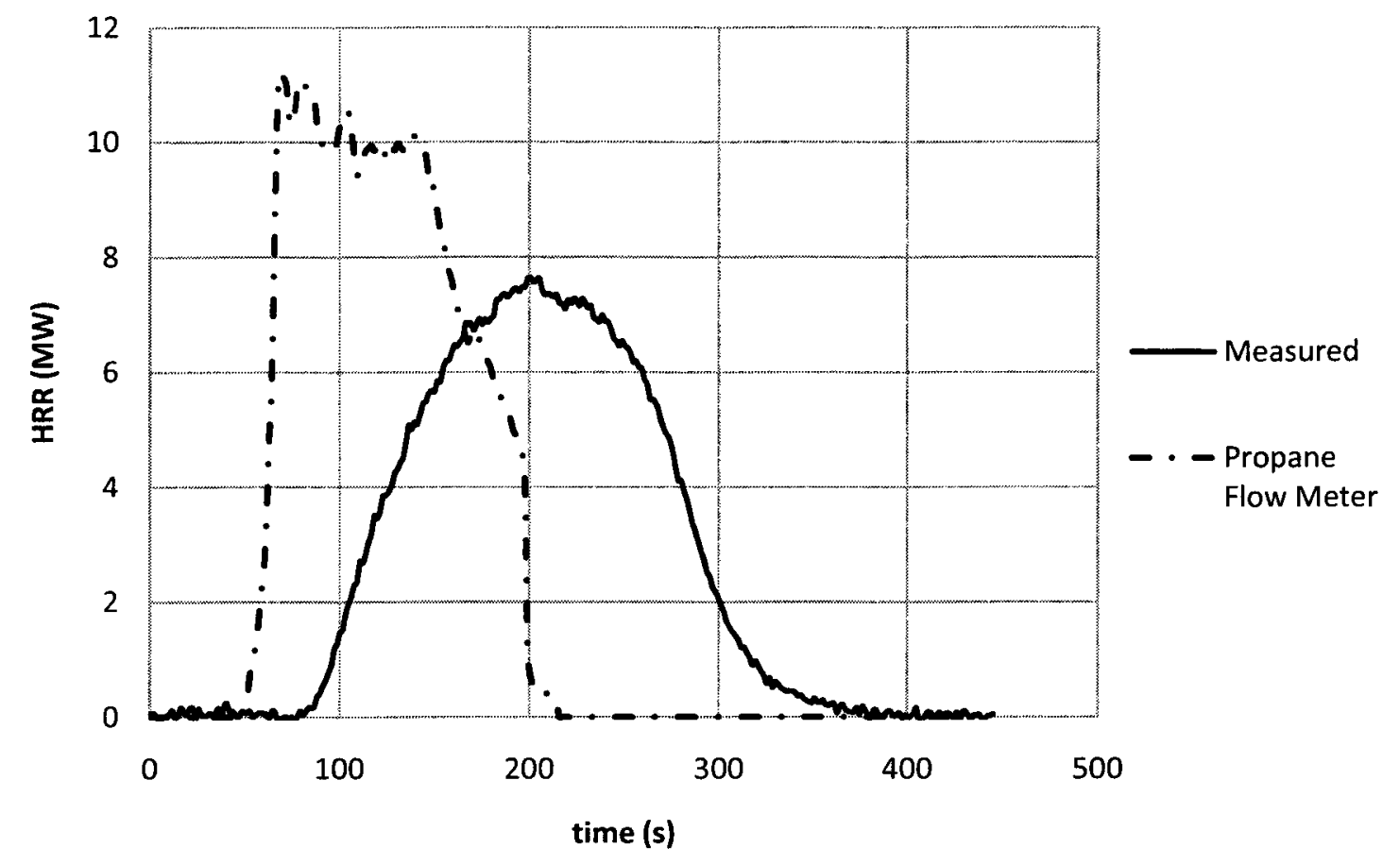

Figure 7.30 HRR curves for propane test A12

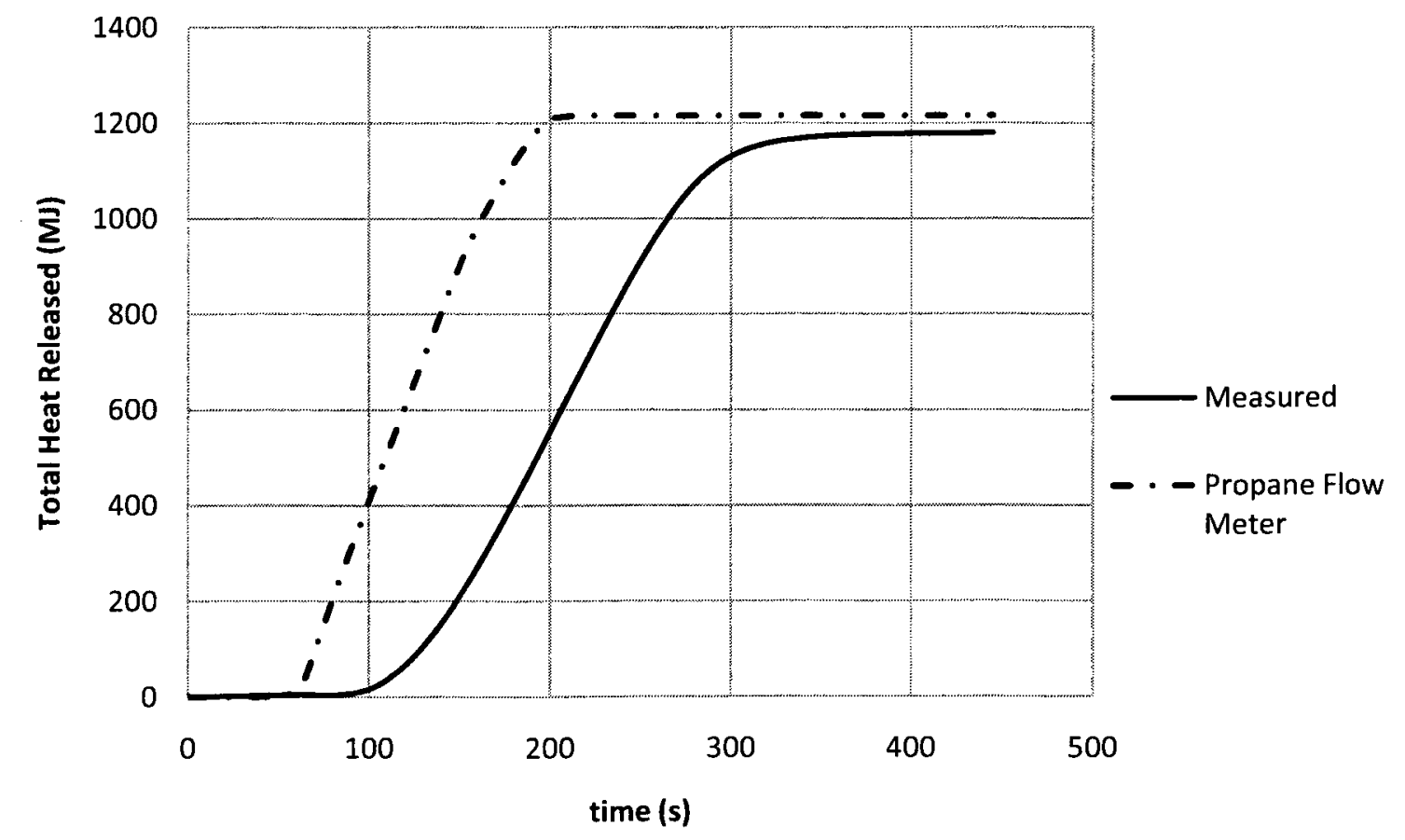

Figure 7.31 THR curves for propane test A12 


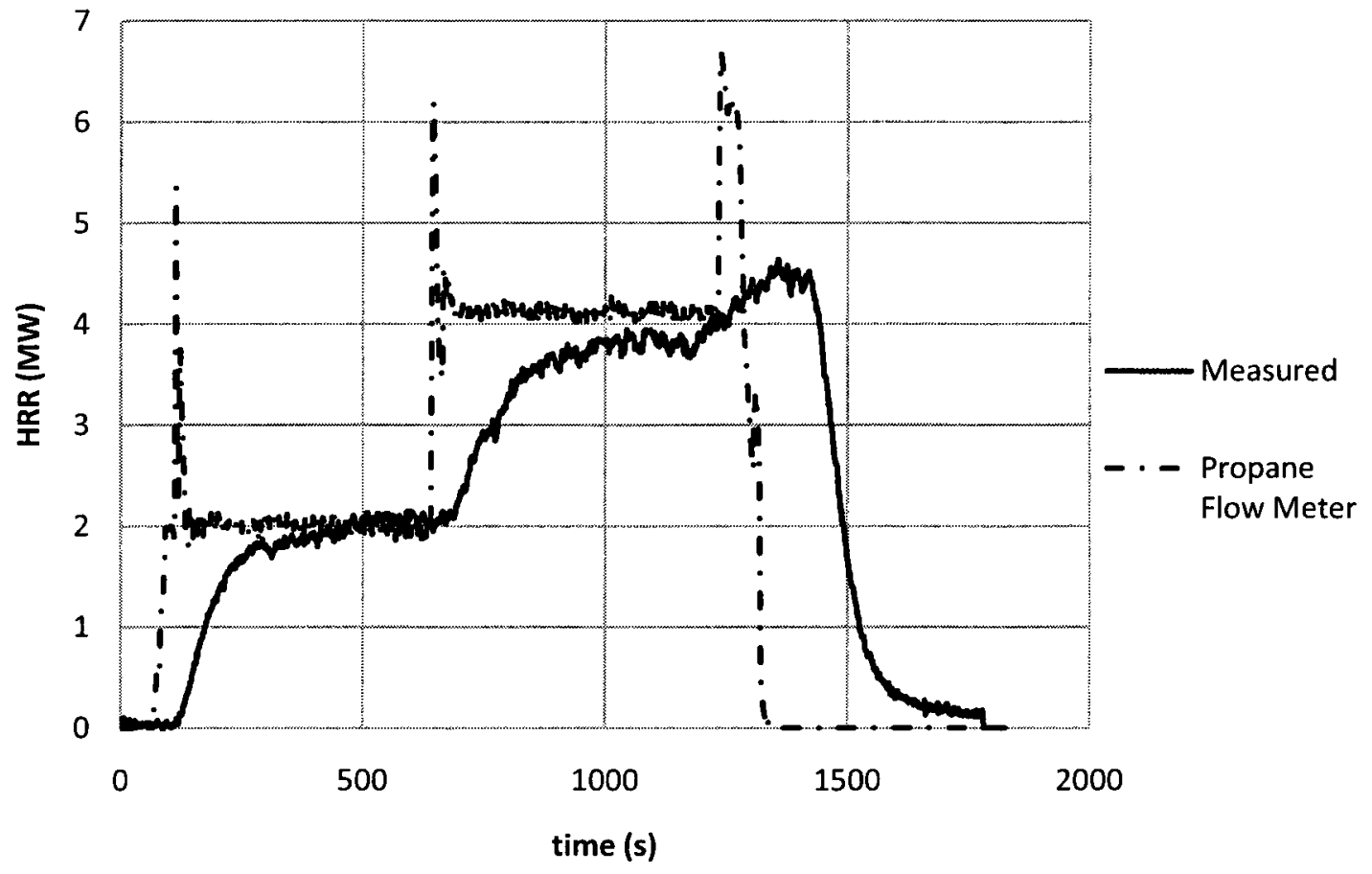

Figure 7.32 HRR curves for propane test B1

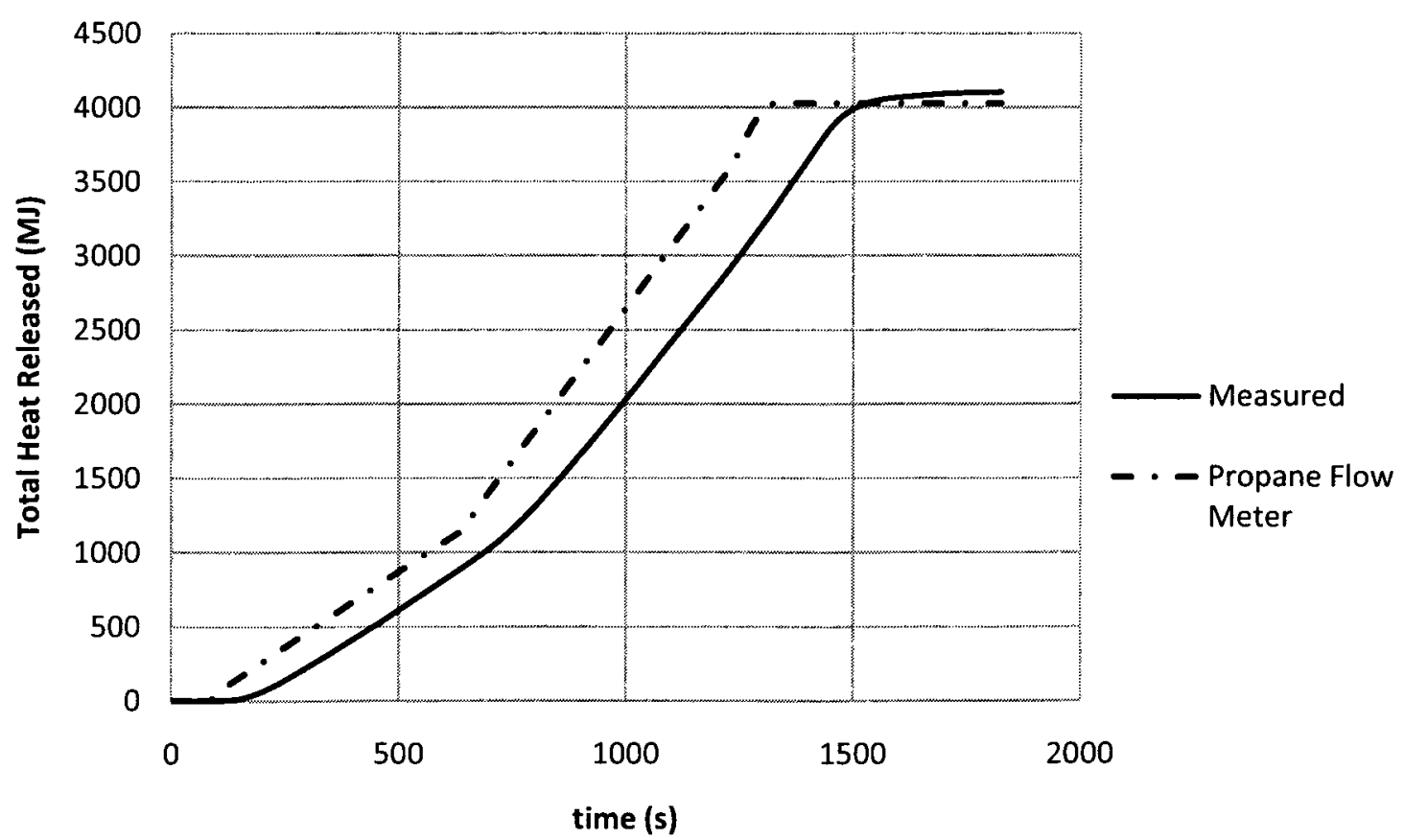

Figure 7.33 THR curves for propane test B1 


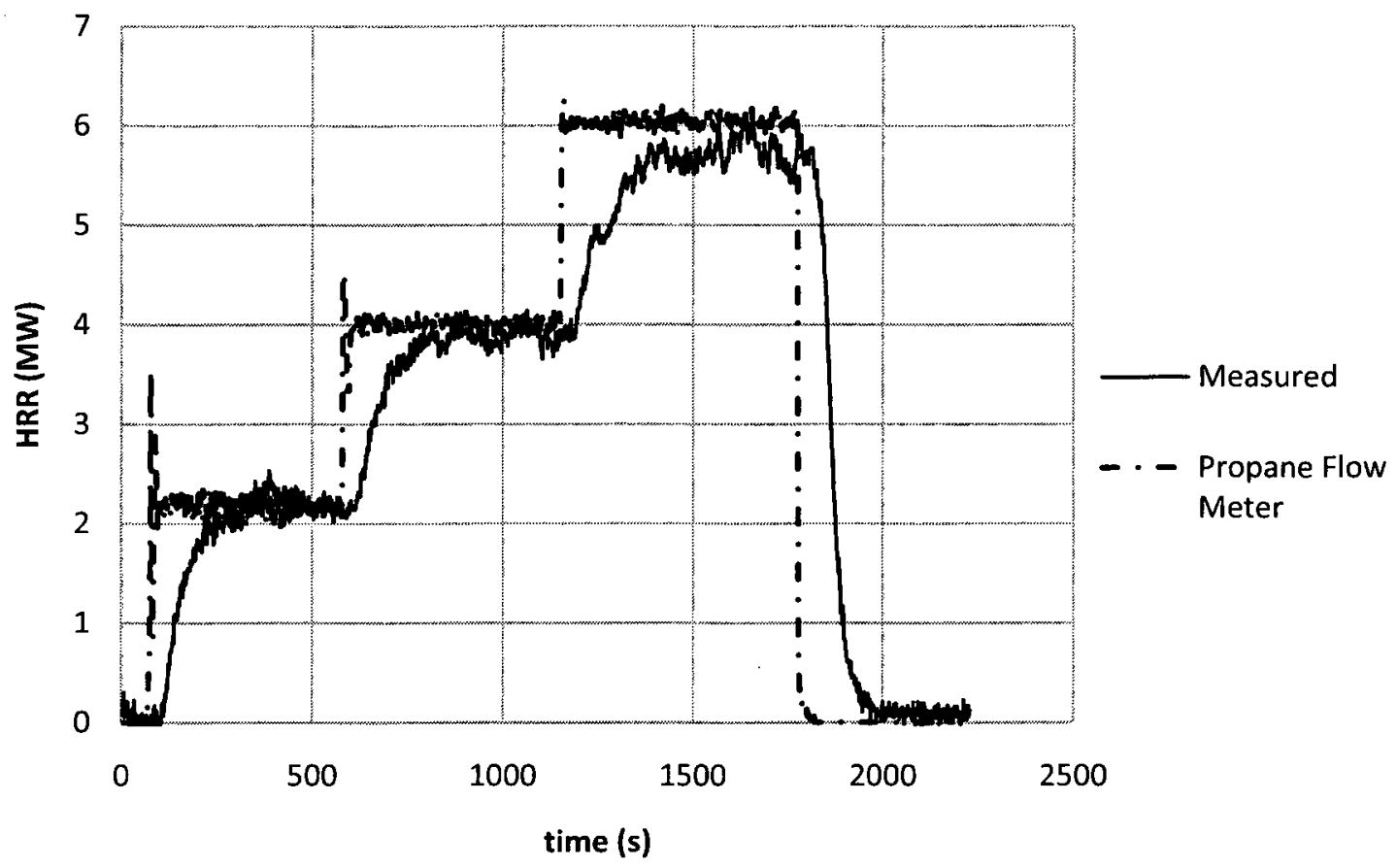

Figure 7.34 HRR curves for propane test B2

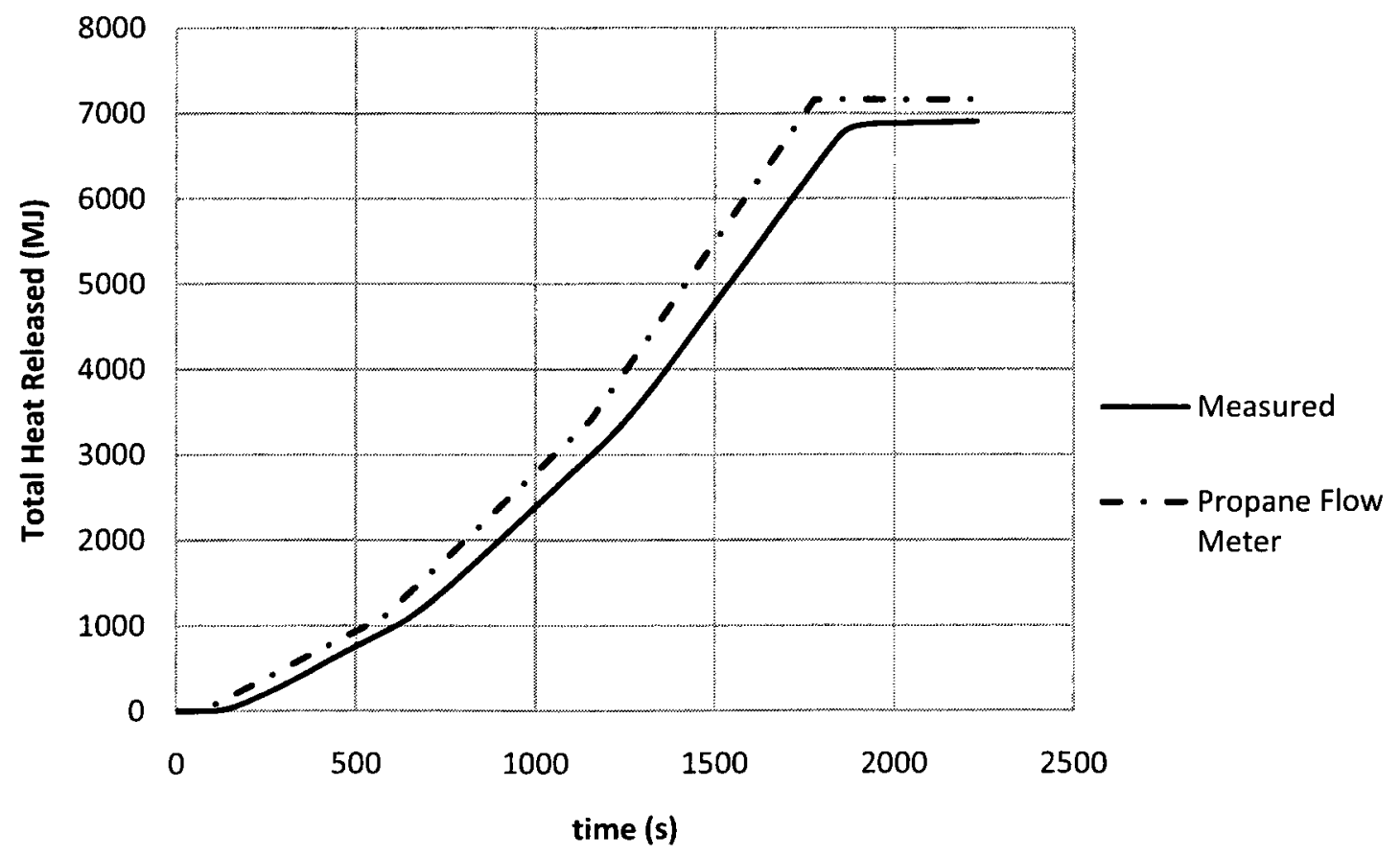

Figure 7.35 THR curves for propane test B2 


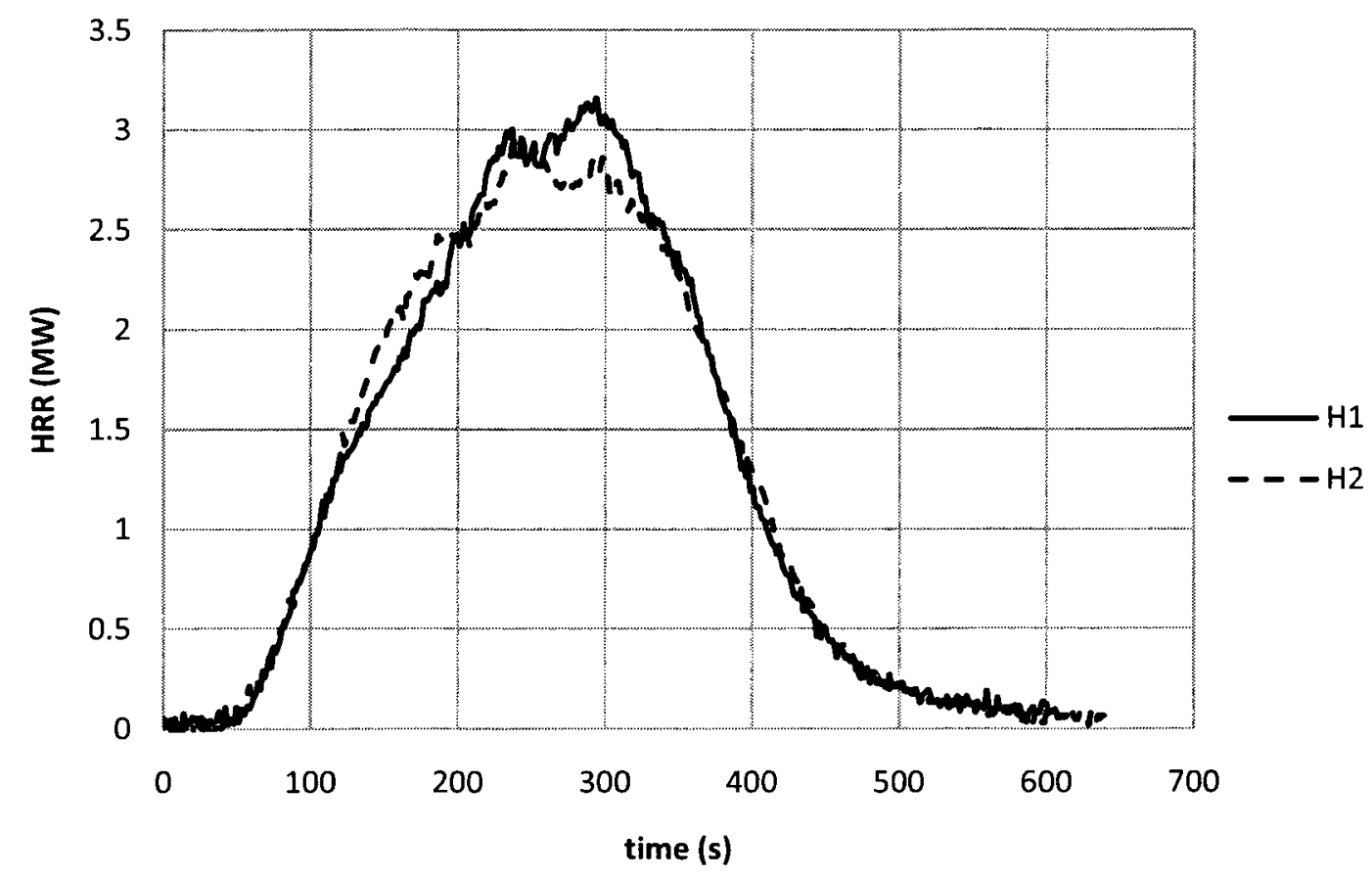

Figure 7.36 HRR comparison of heptane pool fires $\mathrm{H} 1$ and $\mathrm{H} 2$

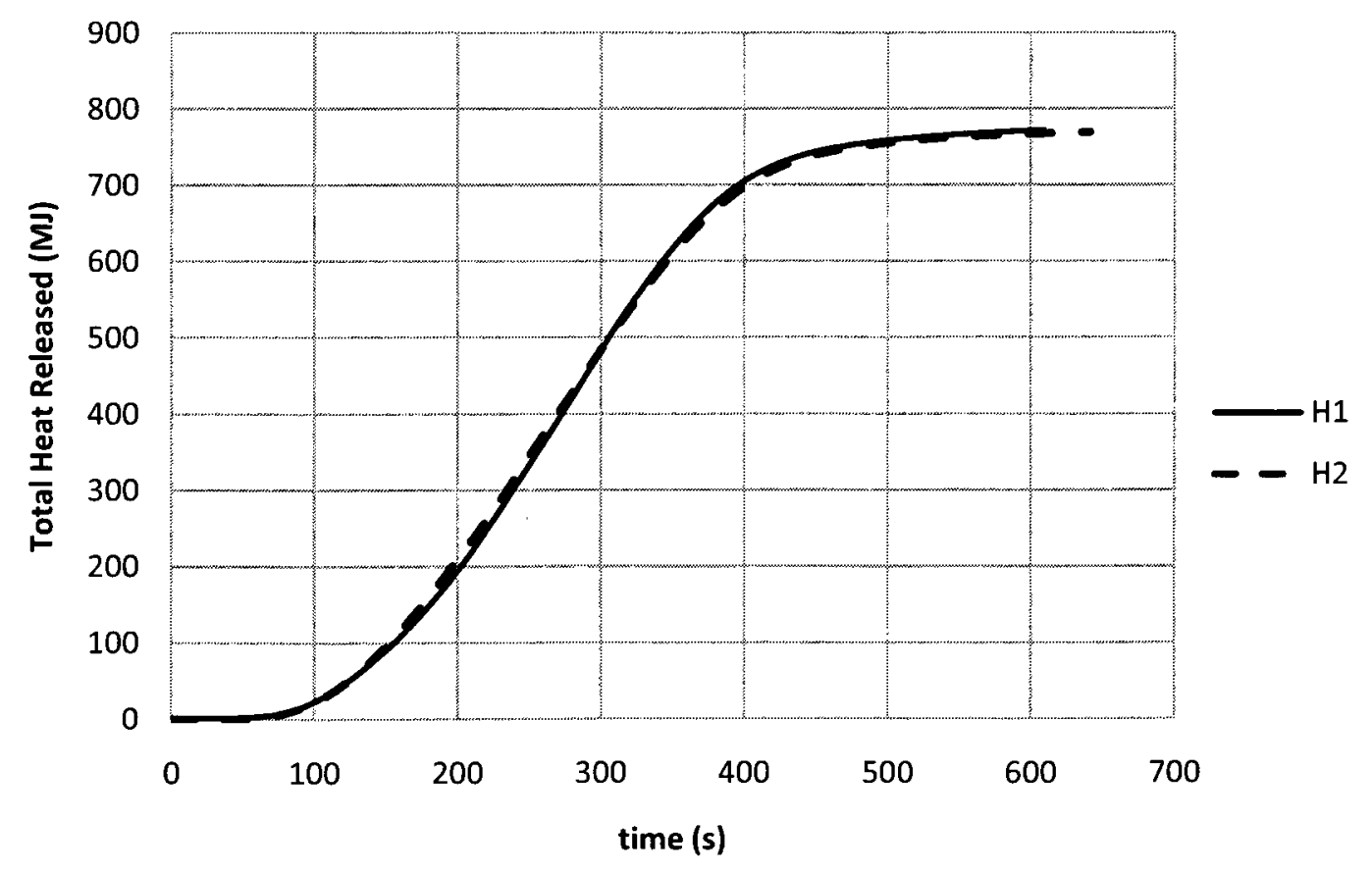

Figure 7.37 THR comparison of heptane pool fires $\mathrm{H} 1$ and $\mathrm{H} 2$ 


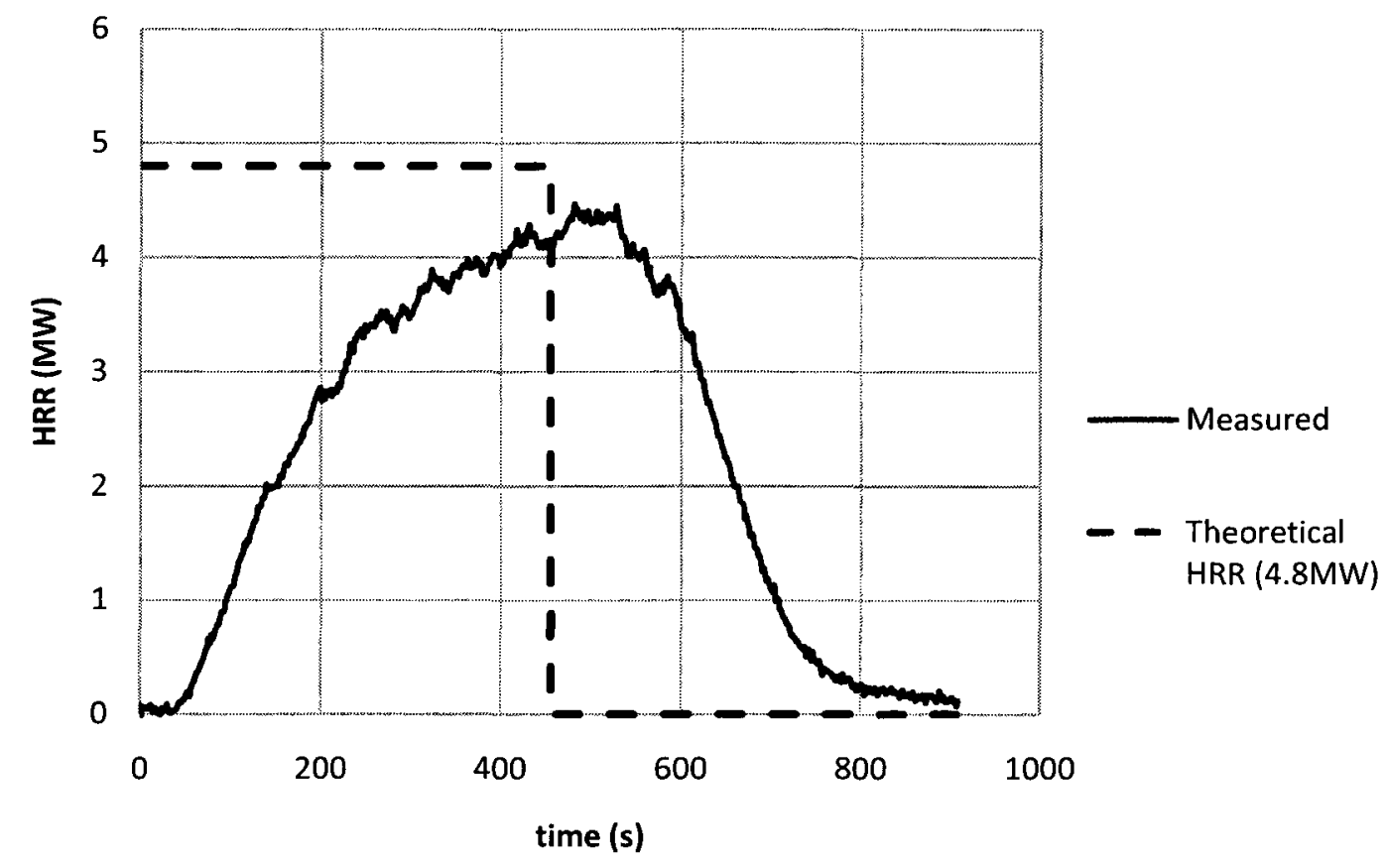

Figure 7.38 HRR curve of heptane pool fire H3

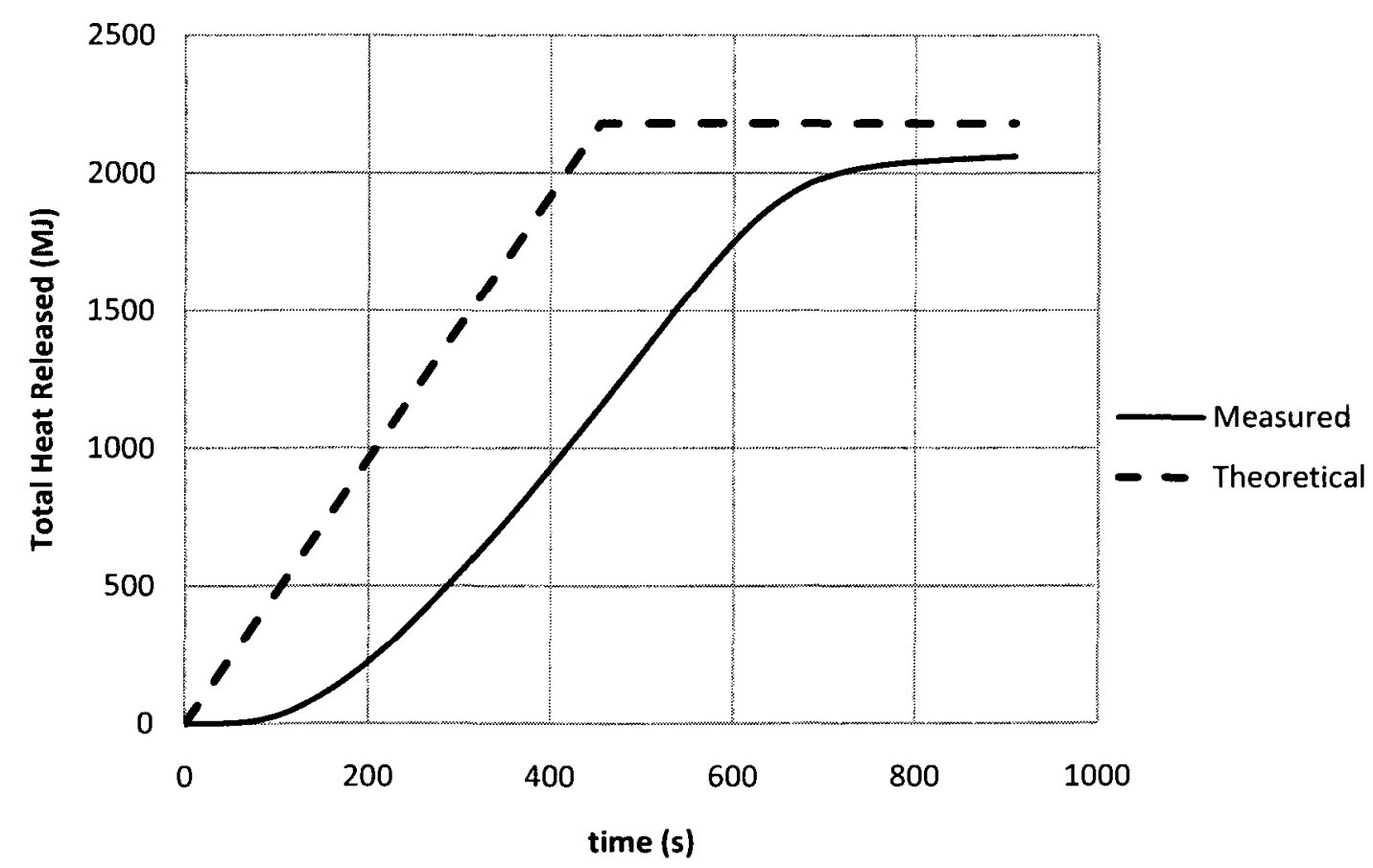

Figure 7.39 THR curve of heptane pool fire H3 


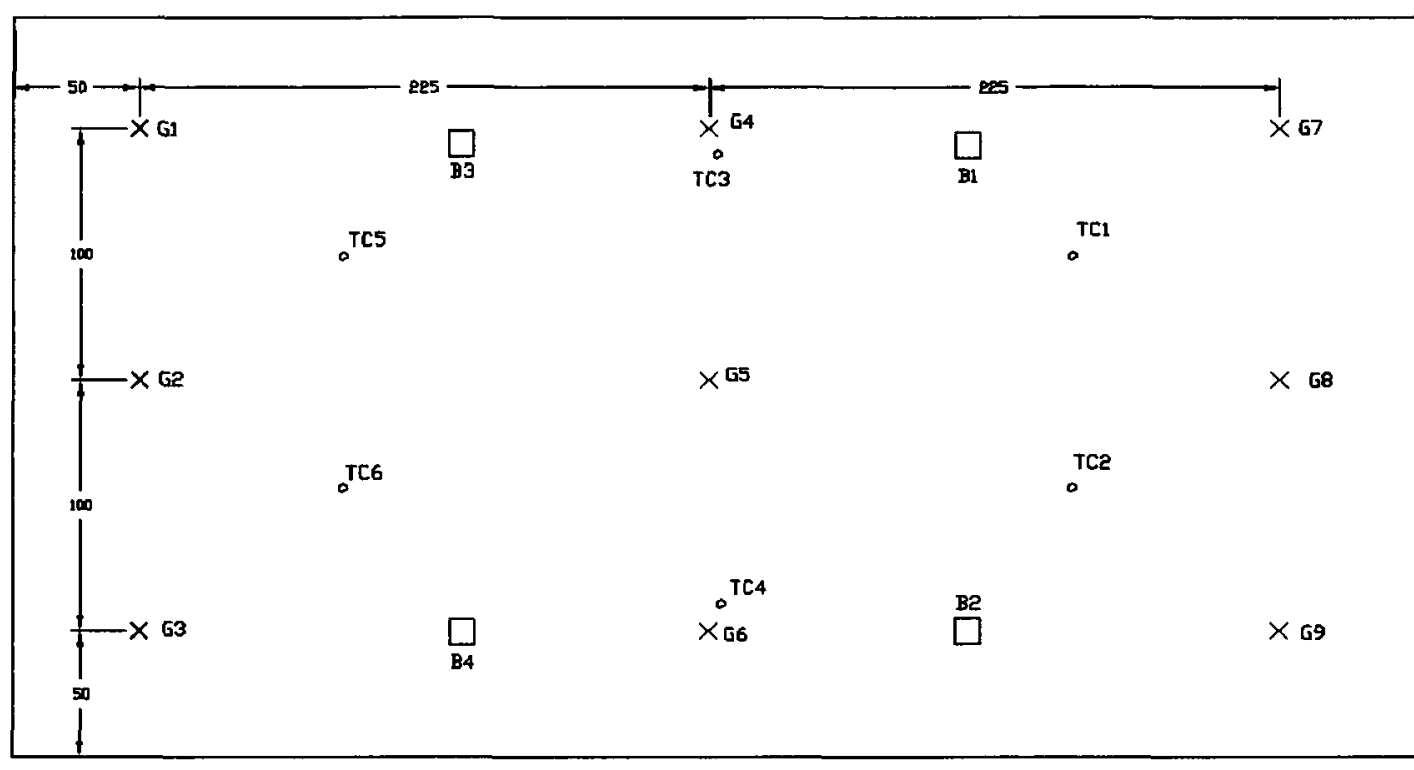

Notei Dimensions in $\mathrm{cm}$
All dilmensions the same as system except gas sampling locations TC - Thermacouple

$\mathrm{B}=$ Velocity
$\mathrm{G}=$ Gas sampling location

Figure 7.40 Instrumentation locations for FDS simulations 


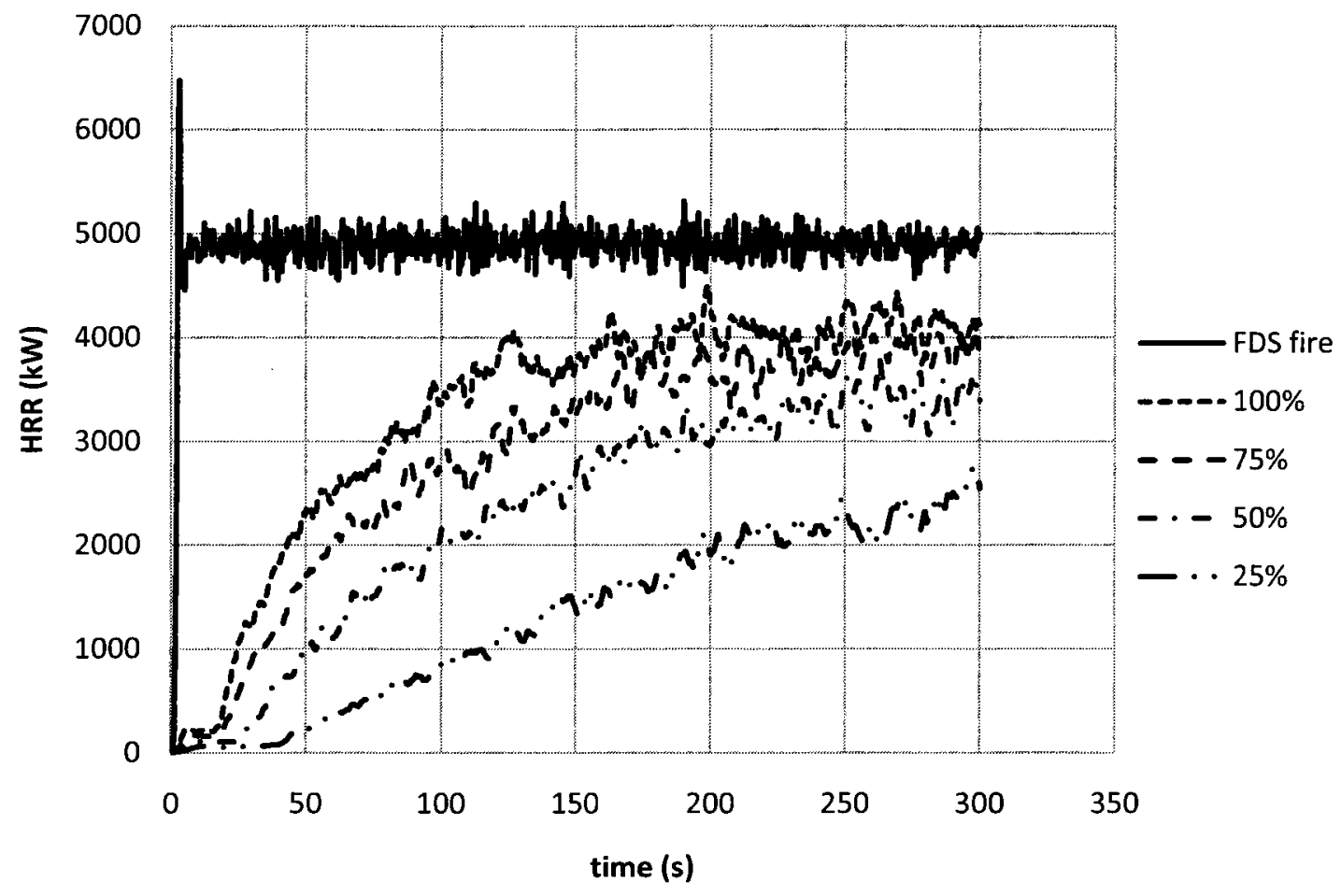

Figure 7.41 Comparison of 300 s $5 \mathrm{MW}$ fire simulations at different fan speeds

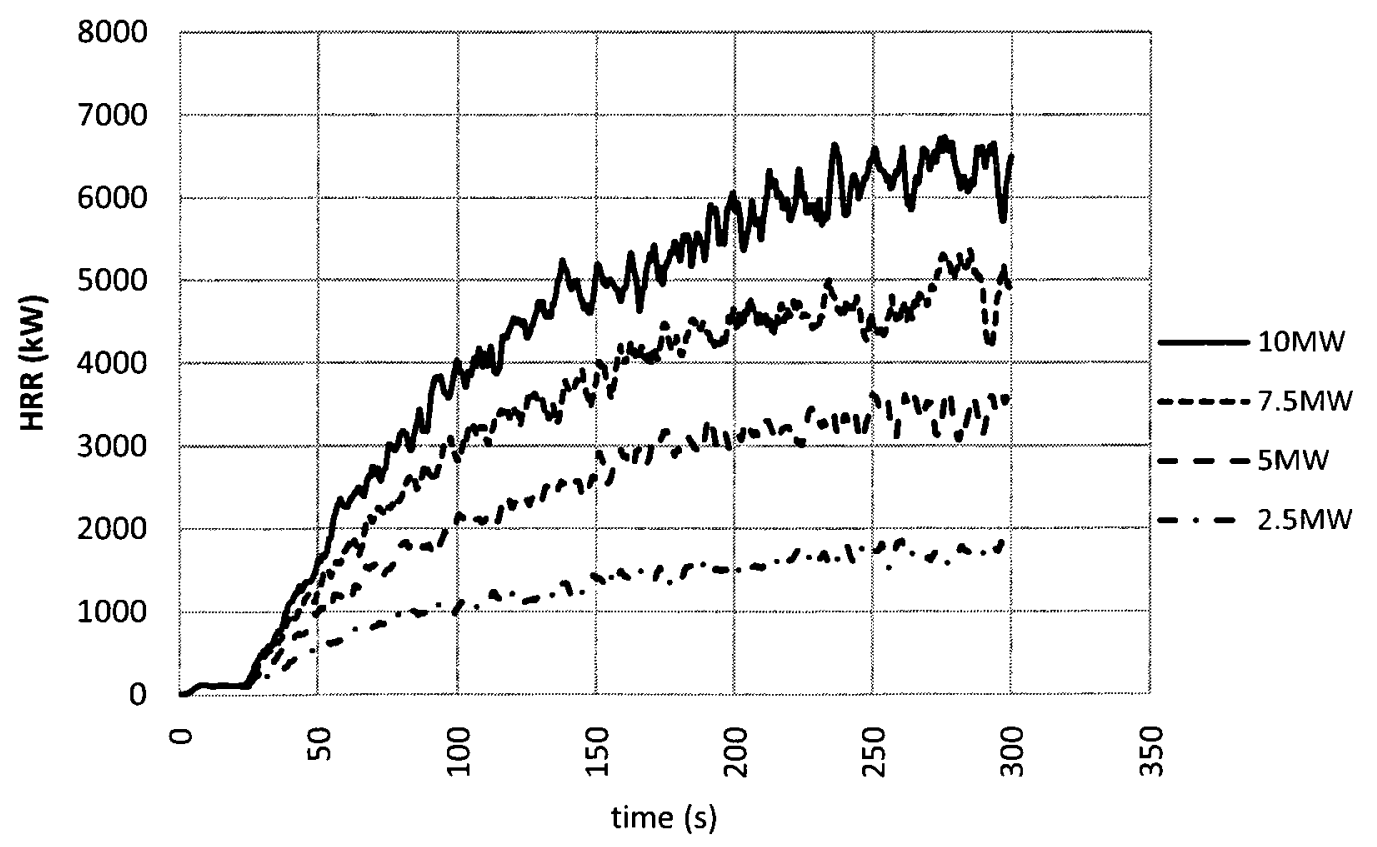

Figure 7.42 Comparison of $300 \mathrm{~s}$ simulations of different fire sizes at $50 \%$ fan speed 


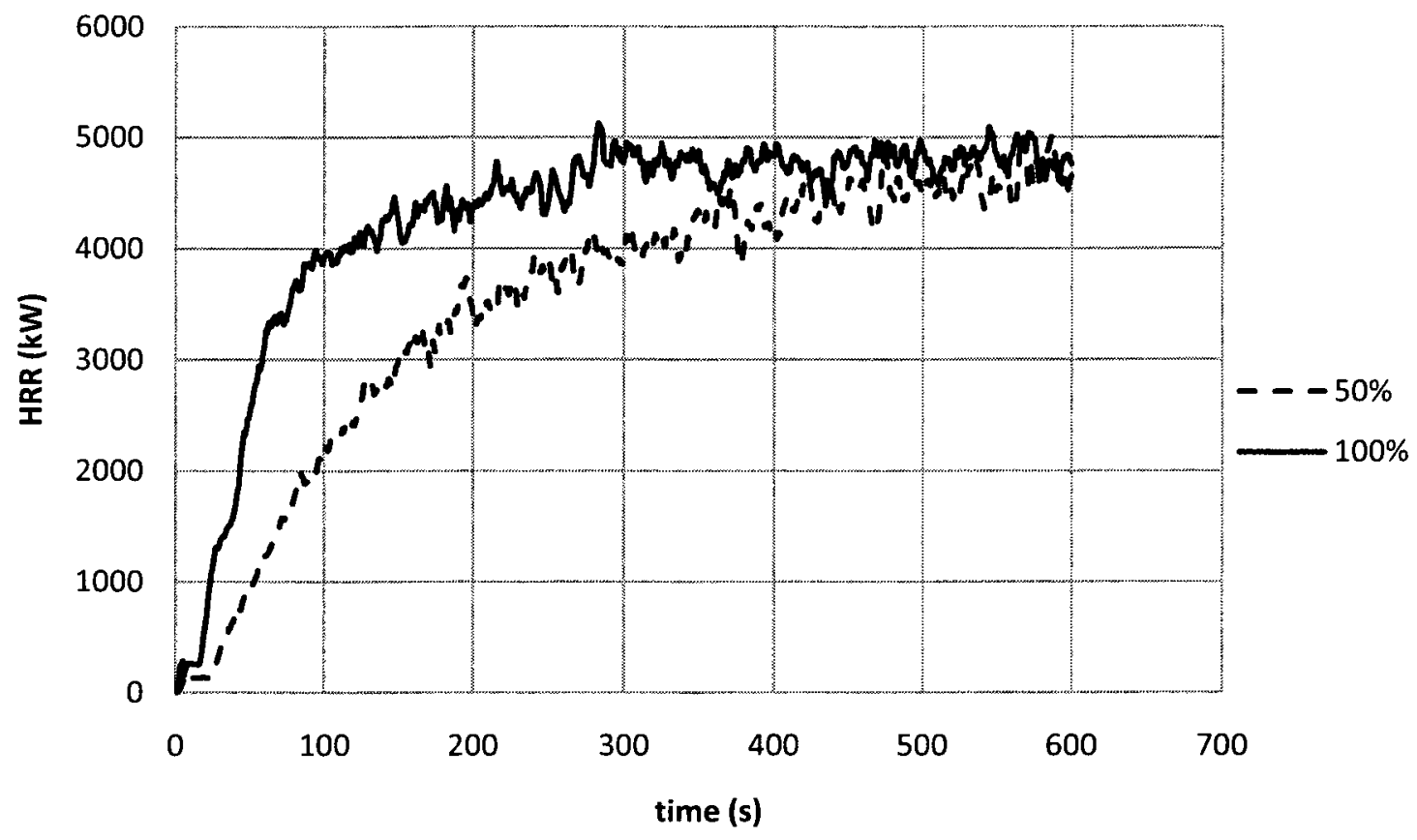

Figure 7.43 Comparison of HRR calculations in simulation of $600 \mathrm{~s} 5 \mathrm{MW}$ fires at $50 \%$ and $100 \%$ fan speeds

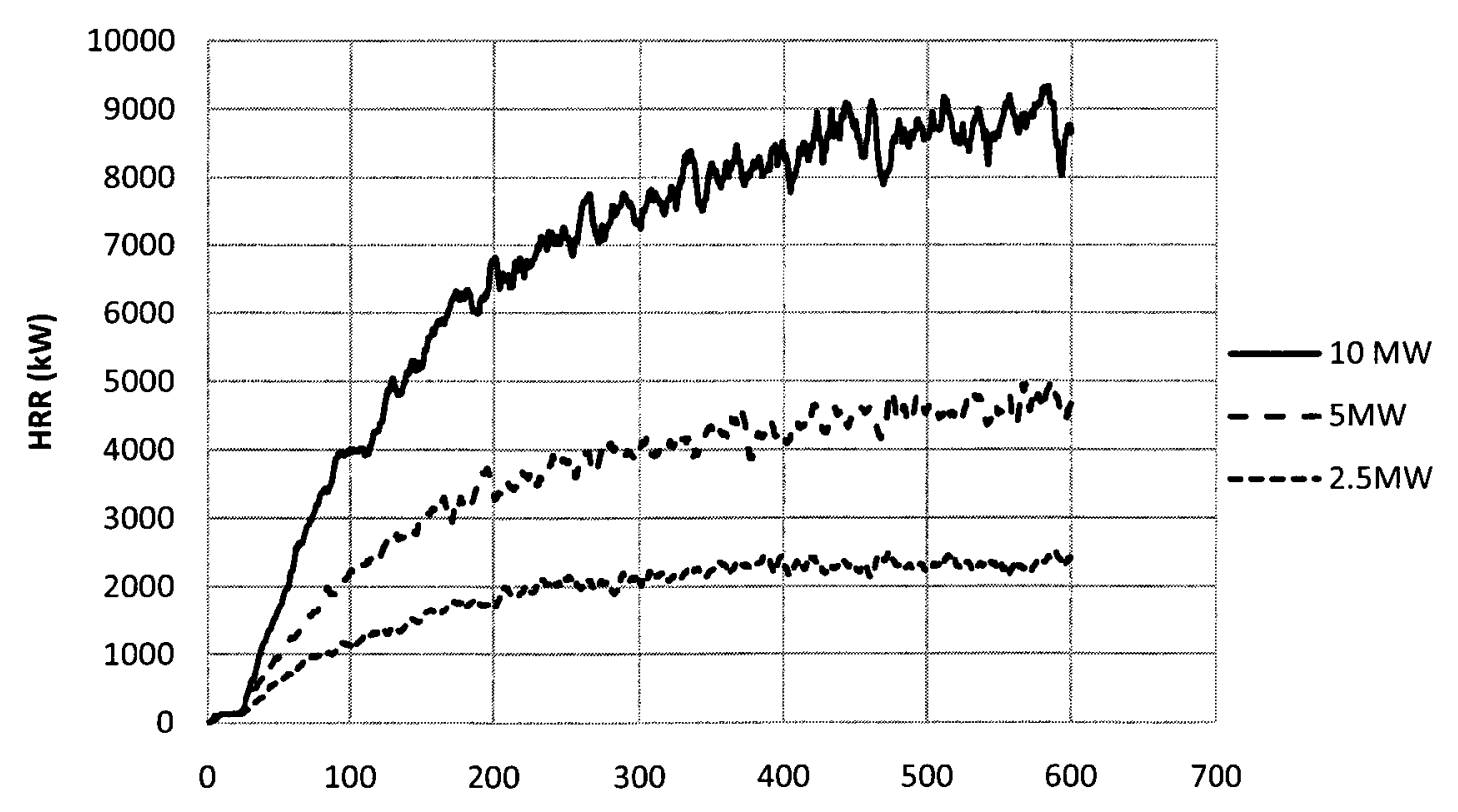

Figure 7.44 Comparison of HRR calculations in simulation of different fire sizes at $50 \%$ fan speed 


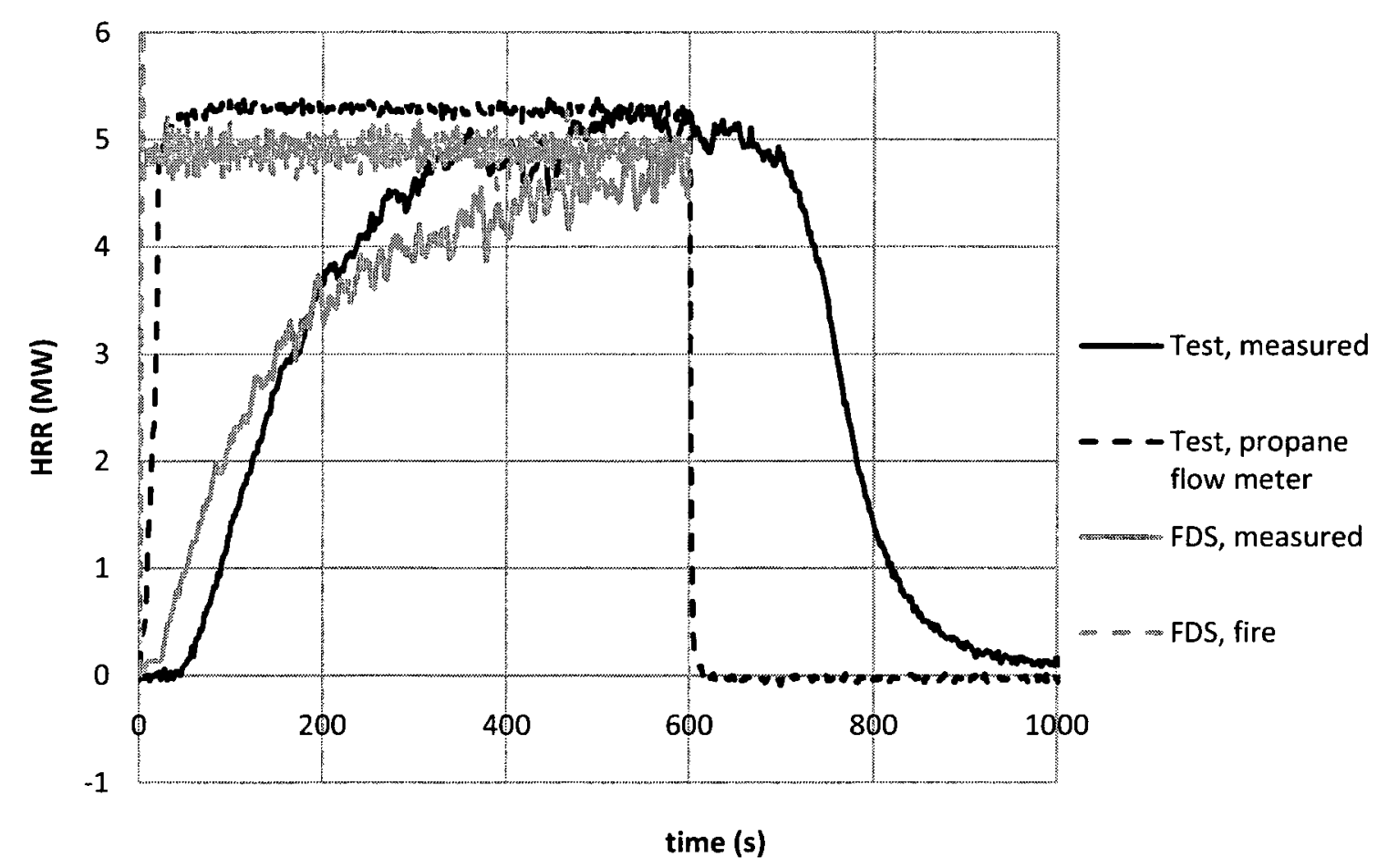

Figure 7.45 Comparison of HRR for simulated and real 600 s $5 \mathrm{MW}$ fires at $50 \%$ fan speed

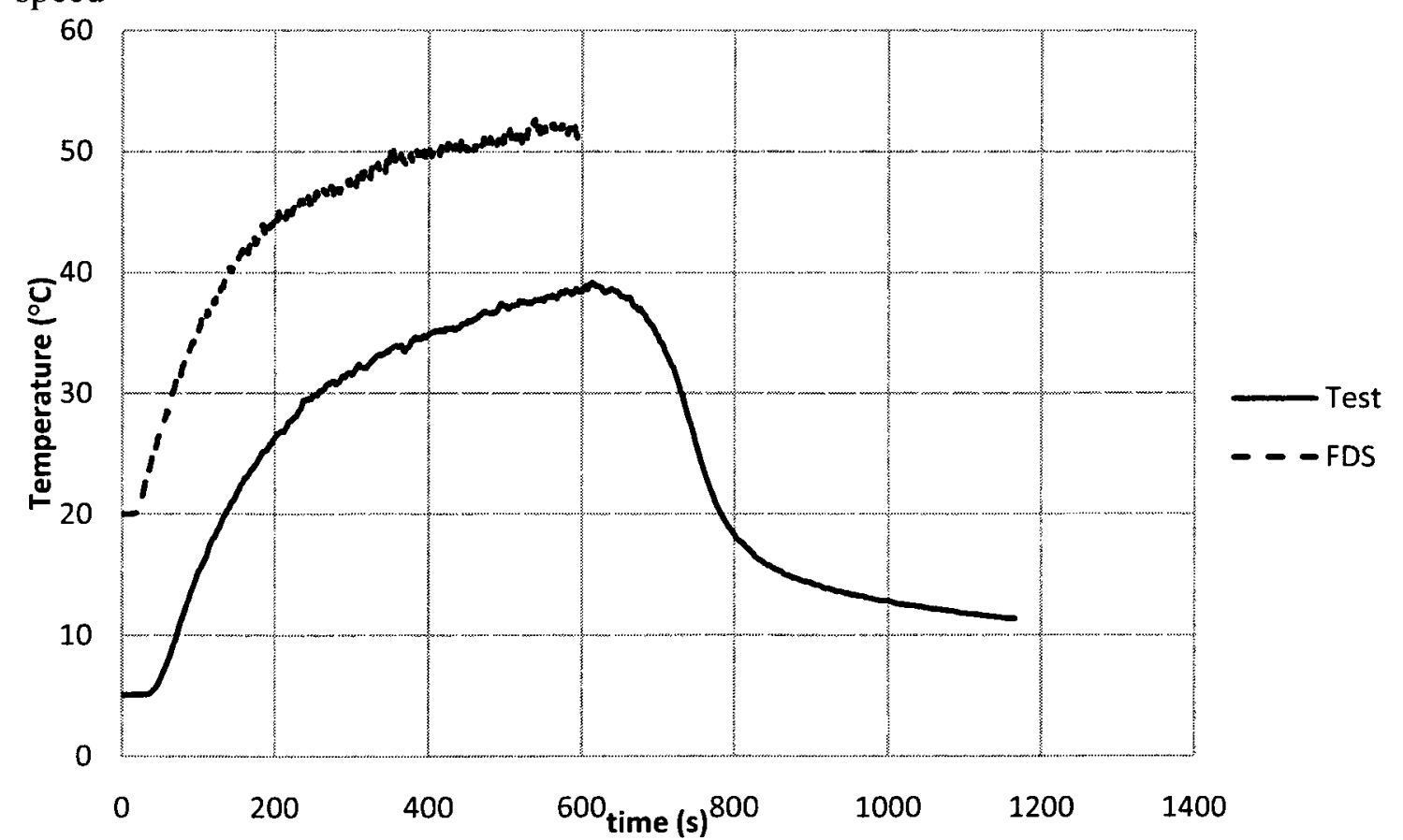

Figure 7.46 Comparison of average temperature for simulated and real $600 \mathrm{~s} 5 \mathrm{MW}$ fires at $50 \%$ fan speed 


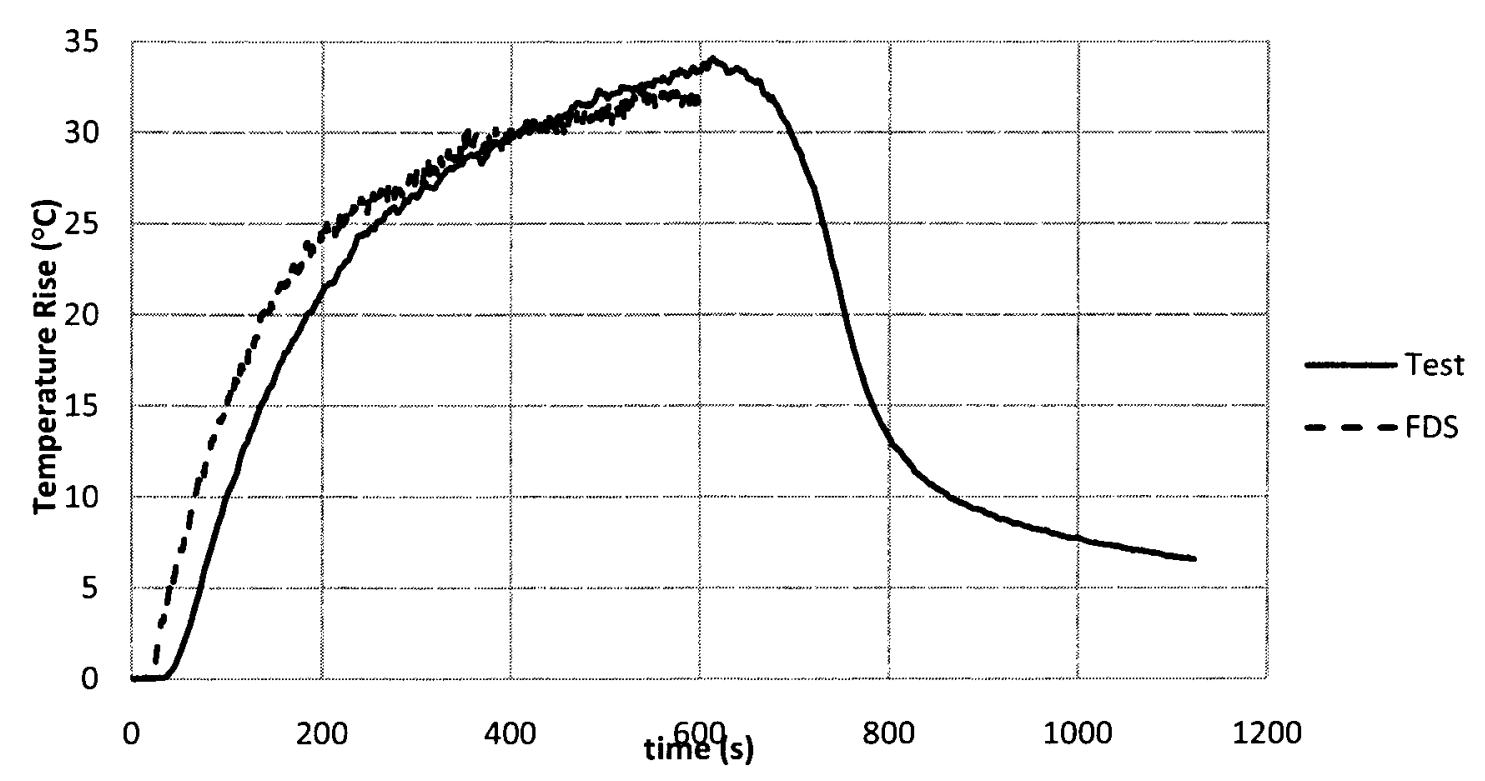

Figure 7.47 Comparison of temperature increase for simulated and real 600 s $5 \mathrm{MW}$ fires at $50 \%$ fan speed

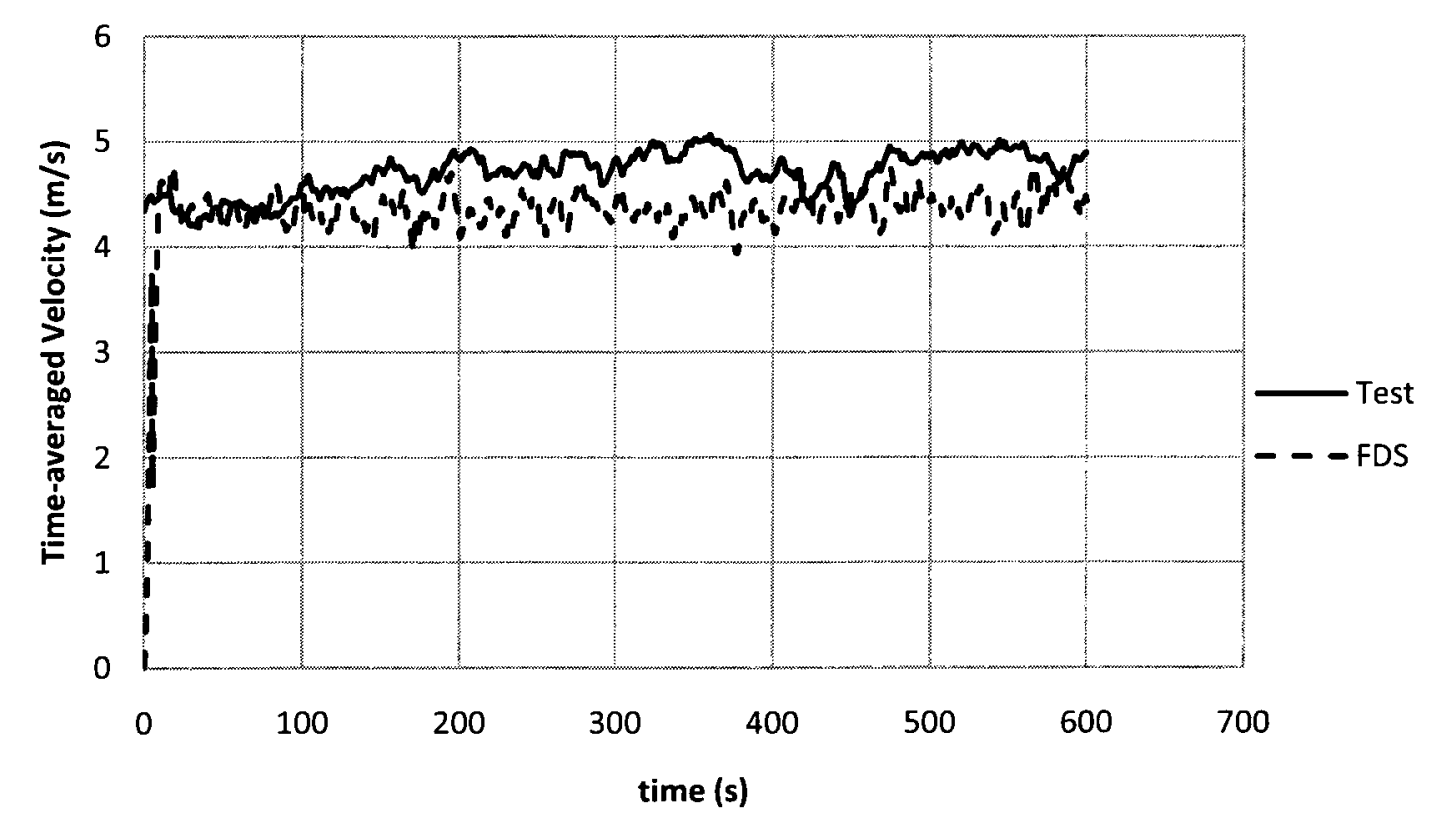

Figure 7.48 Comparison of time-averaged velocity for simulated and real $600 \mathrm{~s} 5 \mathrm{MW}$ fires at $50 \%$ fan speed 


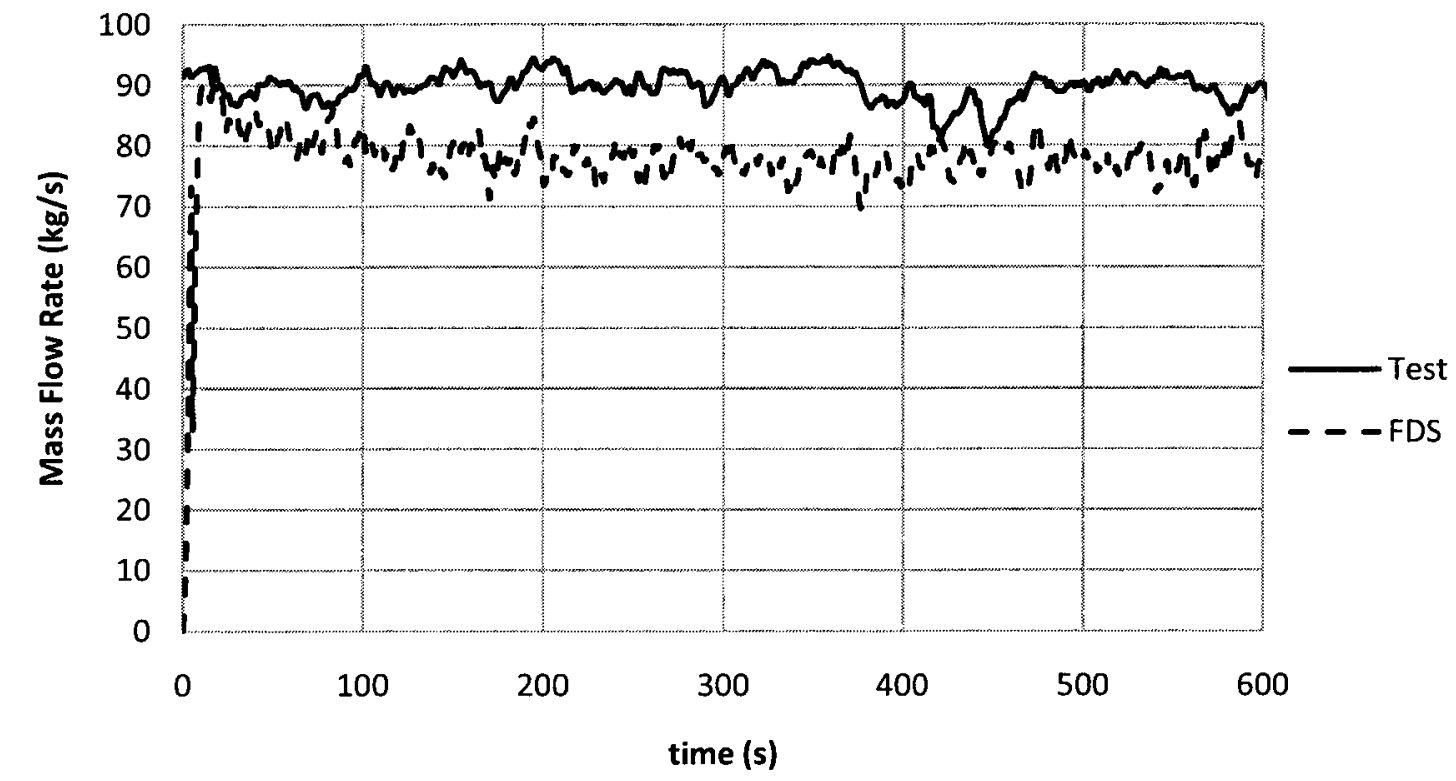

Figure 7.49 Comparison of mass flow rate for simulated and real $600 \mathrm{~s} 5 \mathrm{MW}$ fires at $50 \%$ fan speed

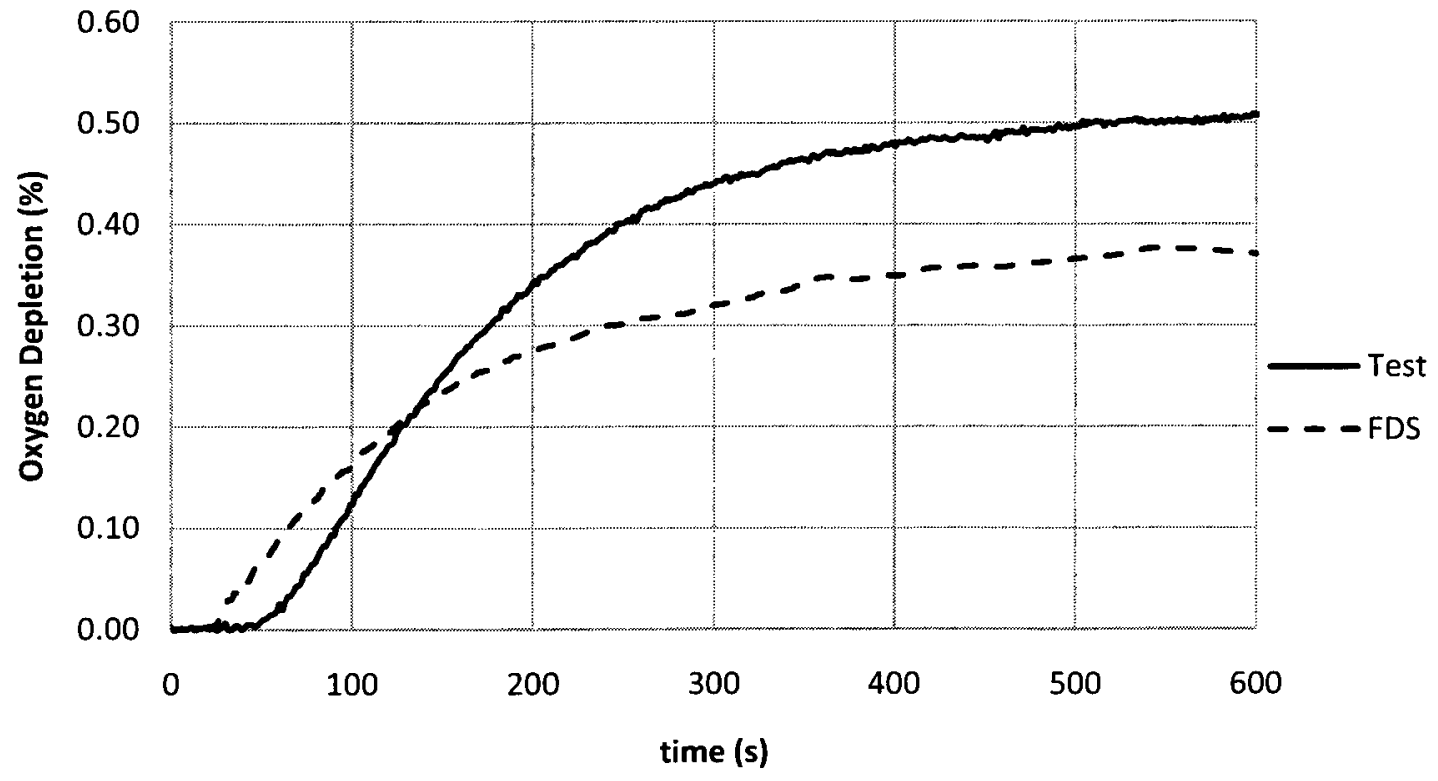

Figure 7.50 Comparison of oxygen depletion for simulated and real $600 \mathrm{~s} 5 \mathrm{MW}$ fire at $50 \%$ fan speed 
Table 7.1 Propane fire test list

\begin{tabular}{|c|c|c|c|c|c|c|}
\hline $\begin{array}{c}\text { Test } \\
\text { Type }\end{array}$ & $\begin{array}{c}\text { Test } \\
\text { ID }\end{array}$ & $\begin{array}{c}\text { Date } \\
\text { Performed }\end{array}$ & $\begin{array}{c}\text { Fire Size } \\
\text { Attempted } \\
\text { (MW) }\end{array}$ & $\begin{array}{c}\text { Approximate } \\
\text { Actual Fire } \\
\text { Size (MW) }\end{array}$ & $\begin{array}{c}\text { Fan } \\
\text { Speed } \\
(\%)\end{array}$ & $\begin{array}{c}\text { Duration } \\
\text { (min) }\end{array}$ \\
\hline \multirow{4}{*}{\begin{tabular}{c} 
A1 \\
\cline { 2 - 7 }
\end{tabular}} & $4 / 22 / 2009$ & 1 & 1 & 50 & 10 \\
\cline { 2 - 7 } & $\mathrm{A} 2$ & $4 / 22 / 2009$ & 1 & 1 & 100 & 10 \\
\cline { 2 - 7 } A & $\mathrm{A} 3$ & $4 / 22 / 2009$ & 2.5 & 2.5 & 50 & 10 \\
\cline { 2 - 7 } & $\mathrm{A} 4$ & $3 / 26 / 2009$ & 2.5 & 2.5 & 100 & 10 \\
\cline { 2 - 7 } & $\mathrm{A} 5$ & $3 / 26 / 2009$ & 5 & 5.3 & 25 & 10 \\
\cline { 2 - 7 } & $\mathrm{A} 6$ & $3 / 26 / 2009$ & 5 & 5.4 & 50 & 10 \\
\cline { 2 - 7 } & $\mathrm{A} 7$ & $3 / 26 / 2009$ & 5 & 5.3 & 100 & 10 \\
\cline { 2 - 7 } & $\mathrm{A} 8$ & $3 / 26 / 2009$ & 6 & 6 & 100 & 10 \\
\cline { 2 - 7 } & $\mathrm{A} 10$ & $3 / 31 / 2009$ & 10 & $10-6$ & 100 & 10 \\
\cline { 2 - 7 } & $\mathrm{A} 11$ & $3 / 31 / 2009$ & 10 & 10 & 100 & $120 \mathrm{~s}$ \\
\cline { 2 - 7 } & $\mathrm{A} 12$ & $3 / 26 / 2009$ & 10 & 10 & 100 & $120 \mathrm{~s}$ \\
\hline \multirow{4}{*}{$\begin{array}{c}\text { Type } \\
\text { B }\end{array}$} & $\mathrm{B} 1$ & $3 / 31 / 2009$ & $2-6$ & 10 & 100 & $150 \mathrm{~s}$ \\
\cline { 2 - 7 } & $\mathrm{B} 2$ & $3 / 31 / 2009$ & $2-6$ & $2-4$ & 50 & 21 \\
\hline
\end{tabular}

Table 7.2 Heptane pool fire test list

\begin{tabular}{|c|c|c|c|c|c|c|}
\hline $\begin{array}{c}\text { Test } \\
\text { ID }\end{array}$ & $\begin{array}{c}\text { Date } \\
\text { Performed }\end{array}$ & $\begin{array}{c}\text { Pan } \\
\text { Area } \\
\left(\mathbf{m}^{2}\right)\end{array}$ & $\begin{array}{c}\text { Fuel } \\
\text { wt } \\
(\mathbf{k g})\end{array}$ & $\begin{array}{c}\text { Approximate } \\
\text { Fuel Depth } \\
(\mathbf{c m})\end{array}$ & $\begin{array}{c}\text { Theoretical } \\
\text { HRR (MW) }\end{array}$ & $\begin{array}{c}\text { Approximate Theoretical } \\
\text { Burn Duration (s) }\end{array}$ \\
\hline H1 & $3 / 17 / 2009$ & 1.49 & 20.34 & 2 & 4.8 & 175 \\
\hline H2 & $3 / 17 / 2009$ & 1.49 & 20.65 & 2 & 4.8 & 175 \\
\hline H3 & $3 / 17 / 2009$ & 1.49 & 52.94 & 5.3 & 4.8 & 450 \\
\hline
\end{tabular}


Table 7.3 FDS simulation list for calibration purposes

\begin{tabular}{|c|c|c|c|}
\hline $\begin{array}{c}\text { Simulation } \\
\text { ID }\end{array}$ & $\begin{array}{c}\text { Fan Speed } \\
\text { (\%) }\end{array}$ & Fire Size (MW) & Time (s) \\
\hline S1 & 25 & 2.5 & 300 \\
\hline S2 & 25 & 5 & 300 \\
\hline S3 & 25 & 7.5 & 300 \\
\hline S4 & 25 & 10 & 300 \\
\hline S5 & 50 & 2.5 & 300 \\
\hline S6 & 50 & 5 & 300 \\
\hline S7 & 50 & 7.5 & 300 \\
\hline S8 & 50 & 10 & 300 \\
\hline S9 & 75 & 2.5 & 300 \\
\hline S10 & 75 & 5 & 300 \\
\hline S11 & 75 & 7.5 & 300 \\
\hline S12 & 75 & 10 & 300 \\
\hline S13 & 100 & 2.5 & 300 \\
\hline S14 & 100 & 5 & 300 \\
\hline S15 & 100 & 7.5 & 300 \\
\hline S16 & 100 & 10 & 300 \\
\hline S17 & 25 & 2.5 & 600 \\
\hline S18 & 50 & 2.5 & 600 \\
\hline S19 & 50 & 5 & 600 \\
\hline S20 & 50 & 10 & 600 \\
\hline S21 & 75 & 5 & 600 \\
\hline S22 & 100 & 5 & 600 \\
\hline S23 & 100 & 10 & 600 \\
\hline
\end{tabular}


Table 7.4 Propane fire error values

\begin{tabular}{|c|c|c|c|c|c|c|}
\hline $\begin{array}{l}\text { Test } \\
\text { Type }\end{array}$ & $\begin{array}{c}\text { Test } \\
\text { ID }\end{array}$ & $\begin{array}{l}\text { Fire Size } \\
\text { (MW) }\end{array}$ & $\begin{array}{c}\text { Fan } \\
\text { Speed (\%) }\end{array}$ & $\begin{array}{c}\text { Duration } \\
\text { (min) }\end{array}$ & $\begin{array}{c}\text { THR Error } \\
(\%)^{\star} \\
\end{array}$ & $\begin{array}{c}\text { HRR Error } \\
(\%)^{*}\end{array}$ \\
\hline \multirow{12}{*}{$\begin{array}{c}\text { Type } \\
\text { A }\end{array}$} & $\mathrm{A} 1$ & 1 & 50 & 10 & 10.6 & 7.8 \\
\hline & $\mathrm{A} 2$ & 1 & 100 & 10 & 12.1 & 7.5 \\
\hline & A3 & 2.5 & 50 & 10 & 0.9 & -0.5 \\
\hline & A4 & 2.5 & 100 & 10 & -1.8 & -2.6 \\
\hline & A5 & 5.3 & 25 & 10 & -3.4 & N/A \\
\hline & A6 & 5.4 & 50 & 10 & 0.8 & -2.3 \\
\hline & A7 & 5.3 & 100 & 10 & -1.7 & -2.7 \\
\hline & $\mathrm{A} 8$ & 6 & 100 & 10 & -5.6 & -4.0 \\
\hline & A9 & $10-6$ & 100 & 10 & -3.7 & N/A \\
\hline & A10 & 10 & 100 & $120 s$ & 0.5 & N/A \\
\hline & A11 & 10 & 100 & $120 s$ & -1.1 & N/A \\
\hline & A12 & 10 & 100 & $150 s$ & -3.0 & N/A \\
\hline \multirow[b]{2}{*}{$\begin{array}{c}\text { Type } \\
\text { B }\end{array}$} & B1 & $2-4$ & 50 & 21 & 1.9 & $2.7,-6.9^{\star *}$ \\
\hline & $\mathrm{B} 2$ & $2-6$ & 100 & 30 & -3.6 & $\begin{array}{c}0.3,-3.0,- \\
3.9^{* *} \\
\end{array}$ \\
\hline
\end{tabular}

Table 7.5 Heptane pool fire error values

\begin{tabular}{|c|c|c|c|c|c|c|}
\hline $\begin{array}{c}\text { Test } \\
\text { ID }\end{array}$ & $\begin{array}{c}\text { Theoretical } \\
\text { HRR (MW) }\end{array}$ & $\begin{array}{c}\text { Measured } \\
\text { HRR } \\
\text { (MW) }\end{array}$ & $\begin{array}{c}\text { HRR \% } \\
\text { Error }\end{array}$ & $\begin{array}{c}\text { Theoretical } \\
\text { THR (MJ) }\end{array}$ & $\begin{array}{c}\text { Measured Heat } \\
\text { Released (MJ) }\end{array}$ & $\begin{array}{c}\text { Total } \\
\text { Heat \% } \\
\text { Error }\end{array}$ \\
\hline H1 & 4.8 & $*$ & $*$ & 838 & 772 & -7.9 \\
\hline H2 & 4.8 & $*$ & $*$ & 851 & 772 & -9.3 \\
\hline H3 & 4.8 & $4.4^{\star *}$ & -8.3 & 2181 & 2061 & -5.5 \\
\hline
\end{tabular}

* - Experiment never reached steady-state

** - Average value over 45 seconds of steady measurements 
Table 7.6 HRR error values for 600 s FDS simulations

\begin{tabular}{|c|c|c|c|c|}
\hline $\begin{array}{c}\text { Simulation } \\
\text { ID }\end{array}$ & $\begin{array}{c}\text { Fan Speed } \\
\text { (\%) }\end{array}$ & $\begin{array}{c}\text { Approximate } \\
\text { Fire Size (MW) }\end{array}$ & $\begin{array}{c}\text { Average HRR in } \\
\text { steady zone (kW) }\end{array}$ & \% Error \\
\hline S17 & 25 & 2.5 & $*$ & $*$ \\
\hline S18 & 50 & 2.5 & 2314 & 5.4 \\
\hline S19 & 50 & 5 & 4633 & 5.5 \\
\hline S20 & 50 & 10 & 8785 & 10.2 \\
\hline S21 & 75 & 5 & 4685 & 4.7 \\
\hline S22 & 100 & 5 & 4797 & 2.9 \\
\hline S23 & 100 & 10 & 9252 & 6.3 \\
\hline
\end{tabular}

* - Steady HRR measurement not reached

Note: HRR was underestimated in all cases

Table 7.7 Observed delay times of propane tests sorted by fan speed

\begin{tabular}{|c|c|c|c|c|c|}
\hline $\begin{array}{c}\text { Test } \\
\text { ID }\end{array}$ & $\begin{array}{c}\text { Fire Size } \\
(\mathrm{MW})\end{array}$ & $\begin{array}{c}\text { Fan Speed } \\
(\%)\end{array}$ & $\begin{array}{l}\text { Delay to first } \\
\text { detection (s) }\end{array}$ & $\begin{array}{c}\text { Delay to } \\
\text { steady (s) }\end{array}$ & $\begin{array}{l}\text { time from first } \\
\text { detection to } \\
\text { steady (s) }\end{array}$ \\
\hline A5 & 5.3 & 25 & 35 & * & * \\
\hline A1 & 1 & 50 & 20 & 450 & 430 \\
\hline A3 & 2.5 & 50 & 20 & 470 & 450 \\
\hline $\mathrm{A} 6$ & 5.4 & 50 & 20 & 450 & 430 \\
\hline B1 & $2-4$ & 50 & 20 & 450 & 430 \\
\hline $\mathrm{A} 2$ & 1 & 100 & 15 & 240 & 225 \\
\hline A4 & 2.5 & 100 & 10 & 210 & 200 \\
\hline $\mathrm{A} 7$ & 5.3 & 100 & 10 & 200 & 190 \\
\hline $\mathrm{A} 8$ & 6 & 100 & 10 & 220 & 210 \\
\hline $\mathrm{A} 9$ & $10-6$ & 100 & 15 & * & * \\
\hline A10 & 10 & 100 & 20 & * & * \\
\hline A11 & 10 & 100 & 15 & * & * \\
\hline A12 & 10 & 100 & 15 & * & * \\
\hline B2 & $2-6$ & 100 & 10 & 240 & 230 \\
\hline
\end{tabular}

* - Steady state HRR calculations never reached for these tests due to low fan speed or short duration

Note: system delay is constant at 45 seconds for all tests 
Table 7.8 Accuracy of instrumentation

\begin{tabular}{|c|c|c|c|c|c|}
\hline Device & Quantity & $\begin{array}{l}\text { Variables } \\
\text { Measured }\end{array}$ & Accuracy & Range & Calibration \\
\hline Gas Analyzer & 1 & $\begin{array}{c}\mathrm{O}_{2}, \mathrm{CO}, \mathrm{CO}_{2} \\
\text { Concentrations }\end{array}$ & $\begin{array}{c}0.01 \% \mathrm{O}^{2}, 0.1 \% \\
\mathrm{CO}^{2}, 0.02 \% \mathrm{CO} \\
(\mathrm{Vol})\end{array}$ & $\begin{array}{c}0-100 \% \\
\text { Vol }\end{array}$ & Daily \\
\hline $\begin{array}{l}\text { Pressure } \\
\text { Transducer }\end{array}$ & 4 & $\begin{array}{c}\text { Differential } \\
\text { Pressure }\end{array}$ & $1 \%$ & $0-254 \mathrm{~Pa}$ & Annual \\
\hline Thermocouple & 6 & Temperature & $0.1^{\circ} \mathrm{C}$ & $0-760 C$ & Factory \\
\hline $\begin{array}{c}\text { Propane Flow } \\
\text { Meter }\end{array}$ & 1 & $\begin{array}{c}\text { Propane Flow } \\
\text { Rate }\end{array}$ & $\begin{array}{l} \pm 1 \% \text { of reading } \\
+0.5 \% \text { of full } \\
\text { scale }\end{array}$ & $0-20 \mathrm{MW}$ & Factory \\
\hline $\begin{array}{c}12.00 \% \mathrm{O}_{2} \\
\text { Calibration Gas }\end{array}$ & 1 & N/A & $0.01 \%$ & $\mathrm{~N} / \mathrm{A}$ & $\begin{array}{c}\text { Supplier } \\
\text { (July 2007) }\end{array}$ \\
\hline $\begin{array}{c}4.98 \% \mathrm{CO}_{2} \\
\text { Calibration Gas }\end{array}$ & 1 & $\mathrm{~N} / \mathrm{A}$ & $0.01 \%$ & $\mathrm{~N} / \mathrm{A}$ & $\begin{array}{l}\text { Supplier } \\
\text { (July 2007) }\end{array}$ \\
\hline $\begin{array}{c}\text { 901ppm CO } \\
\text { Calibration Gas }\end{array}$ & 1 & N/A & $1 \mathrm{ppm}$ & N/A & $\begin{array}{c}\text { Supplier } \\
\text { (July 2007) }\end{array}$ \\
\hline $\begin{array}{l}99.999 \% \mathrm{~N}_{2} \mathrm{O}- \\
\text { point } \\
\text { Calibration Gas }\end{array}$ & 1 & N/A & $0.001 \%$ & N/A & $\begin{array}{c}\text { Supplier } \\
\text { (July 2007) }\end{array}$ \\
\hline
\end{tabular}


Table 7.9 Fluctuation analysis of time-averaged velocities used in HRR calculations

\begin{tabular}{|c|c|c|c|c|c|c|c|c|}
\hline $\begin{array}{c}\text { Test } \\
\text { ID }\end{array}$ & $\begin{array}{c}\text { Fire } \\
\text { Size } \\
(\mathbf{M W})\end{array}$ & $\begin{array}{c}\text { Fan } \\
\text { Speed } \\
(\%)\end{array}$ & $\begin{array}{c}\text { Average } \\
\text { Velocity } \\
(\mathbf{m} / \mathbf{s})\end{array}$ & $\begin{array}{c}\text { Min } \\
\text { Velocity } \\
(\mathbf{m} / \mathbf{s})\end{array}$ & $\begin{array}{c}\text { Max } \\
\text { Velocity } \\
(\mathbf{m} / \mathbf{s})\end{array}$ & $\begin{array}{c}\text { Eifference } \\
(\mathbf{m} / \mathbf{s})\end{array}$ & $\begin{array}{c}\text { Error } \\
\text { Above } \\
(\%)\end{array}$ & $\begin{array}{c}\text { Error } \\
\text { Below } \\
(\%)\end{array}$ \\
\hline A5 & 5.3 & 25 & 2.56 & 2.14 & 2.88 & 0.74 & 12.79 & 16.33 \\
\hline A1 & 1 & 50 & 4.46 & 4.17 & 4.76 & 0.59 & 6.67 & 6.57 \\
\hline A3 & 2.5 & 50 & 4.52 & 4.26 & 4.76 & 0.50 & 5.24 & 5.77 \\
\hline A6 & 5.4 & 50 & 4.67 & 4.19 & 5.06 & 0.87 & 8.44 & 10.16 \\
\hline B1 & $2-4$ & 50 & 4.59 & 4.22 & 4.85 & 0.63 & 5.60 & 8.06 \\
\hline H1 & 4.8 & 50 & 4.50 & 4.26 & 4.83 & 0.57 & 7.44 & 5.17 \\
\hline H2 & 4.8 & 50 & 4.48 & 4.20 & 4.75 & 0.55 & 5.95 & 6.28 \\
\hline H3 & 4.8 & 50 & 4.53 & 4.15 & 4.94 & 0.79 & 8.98 & 8.41 \\
\hline A2 & 1 & 100 & 8.14 & 7.77 & 8.58 & 0.81 & 5.30 & 4.64 \\
\hline A4 & 2.5 & 100 & 8.28 & 7.95 & 8.55 & 0.60 & 3.24 & 4.01 \\
\hline A7 & 5.3 & 100 & 8.28 & 7.68 & 8.83 & 1.15 & 6.55 & 7.29 \\
\hline A8 & 6 & 100 & 8.36 & 7.90 & 8.83 & 0.94 & 5.60 & 5.61 \\
\hline A9 & $10-6$ & 100 & 8.23 & 7.75 & 8.68 & 0.93 & 5.45 & 5.82 \\
\hline A10 & 10 & 100 & 8.13 & 7.70 & 8.61 & 0.91 & 5.86 & 5.27 \\
\hline A11 & 10 & 100 & 8.21 & 7.87 & 8.53 & 0.66 & 3.94 & 4.10 \\
\hline A12 & 10 & 100 & 8.25 & 7.88 & 8.54 & 0.66 & 3.47 & 4.51 \\
\hline B2 & $2-6$ & 100 & 8.21 & 7.81 & 8.63 & 0.82 & 5.21 & 4.79 \\
\hline
\end{tabular}




\section{Chapter 8: Results and Discussion}

The HRR measurement system presented in this Thesis is capable of measuring the HRR of fires in the experimental atrium at Carleton University's fire research laboratory using the principle of oxygen consumption calorimetry. The system has been developed to be user friendly, simple and customizable, but it must be used properly to yield valuable results. A checklist of considerations before using the system to run an experiment has been provided in Appendix D.

\subsection{Instrumentation Design}

After a study of the cross-sectional properties of the measurement variables for oxygen consumption calorimetry, a final design for the instrumentation was developed and implemented in the fan chamber of the facility. The fan chamber is essentially a large concrete duct $5.56 \mathrm{~m}$ wide by $2.94 \mathrm{~m}$ high for a total cross-sectional area of approximately $16.3 \mathrm{~m}^{2}$. Because of the very large scale and the arrangement of the facility, some difficulties arose in the instrumentation design. The instrumentation design had to be suitable for fires both in the atrium and the tunnel. A view of the final instrumentation design is provided in Figure 5.1.

FDS simulations carried out for this purpose indicated that the high level of turbulence with the fans on and the long travel distance of gases from the atrium, gas concentrations and temperatures are essentially uniform across the cross-section. Therefore, measurements could be taken almost anywhere across the cross-section and yield accurate, representative values. However, to ensure accuracy and add a level of 
safety to the system, a gas sampling grid (see Figure 5.15) that spans the cross-section and six type J thermocouples (see Figure 5.4) are used.

Because of the high amount of turbulence and non-uniform velocity profiles, the velocity measurements had to be more carefully considered. After a study using FDS simulations and manual velocity measurements in the fan chamber with the fans running, a combination of only four velocity probes (see Figure 5.10) was found that, when averaged, yield accurate results in all scenarios considered. Because only four probes are used and the turbulence level is very high, these measurements are further refined both by time-averaging them in Labview over 10 time steps ( 15 seconds) and by sampling at a high rate of $2000 \mathrm{~Hz}$ and averaging 400 samples every time step for every variable. Since the fans are always running at one constant speed during experiments and the fire has minimal effect on the gas velocity, the velocity is essentially constant during tests. This means that the time-averaging does not adversely affect the measurements, but only acts to smooth out the velocity curve and therefore the HRR curve.

Because all of the calibration experiments and FDS simulations were carried out with all three fans running at equal levels, it is recommended that this practice is continued in the future. A fan speed of $25 \%$ or higher is recommended for experiments as lower fan speeds can result in phenomena that the HRR measurement system is not designed to consider as discussed in section 5.2.

\subsection{Data Acquisition and Processing (DAS)}

A DAS collects analog signals from the thermocouples, pressure transducers, gas analyzer and propane flow meter and converts them to digital signals which are fed into 
the computer via a USB cable. The DAS used is a National Instruments model that is compatible with Labview software. This software can collect the raw data from the DAS and be programmed to perform any number of functions including real-time displays, calculations and writing output files.

Labview 8.6 was used to program the processing of the signals from the instruments. Where required, signals are converted from raw values to useful values. They are then run through all the calculations required for oxygen consumption calorimetry. The mass flow rate is delayed by 45 seconds to match the delay of gas movement from the sampling location to the gas analyzer and therefore synchronize the data. This means that the HRR displayed on the screen is 45 seconds behind real time. The real-time display shows graphs of useful variables including temperatures, velocities, gas concentrations, mass flow rate and HRR. The maximum and minimum peak values of HRR, temperature and all gas concentrations are shown, including warning lights for critical variables for safety.

The output measurement file provides all raw data and calculated values so that further analysis can be carried out as required. The output key is shown in Table 6.2.

\subsubsection{Signal Considerations}

Signal noise and drift are always issues with sensitive measurement equipment such as this. Some techniques are employed to reduce, as much as possible, both the periodic and the random noise in the system. Shielded wires are used to reduce radio frequency interference. Labview has also been programmed to, instead of taking one data point per time step and processing it, take 400 samples at a frequency of $2000 \mathrm{~Hz}$ 
and average these values at every time step. This reduces the noise significantly, to an acceptable level for the purposes of this system.

A small amount of drift often occurs during the test in the propane flow rate measurement. This cannot be seen or quantified, unfortunately, until after the test is complete when the propane flow should return to zero. The flow often returns to a value slightly below zero. This is likely because the propane flow meter has a very long wire connecting it to the DAS and interference in the air due to electrical equipment and other sources has more of a chance to be picked up. If the drift is significant enough to bear consideration in calculations, it can be assumed that the drift increased linearly throughout the test [18]. However, the drifts observed in the calibration experiments performed for this thesis have generally been very low, showing a maximum average of $82 \mathrm{~kW}$ after test $\mathrm{A} 4$, which was an extreme case of this phenomenon. In most cases there was little or no drift. In all of the figures presented in this thesis, the propane flow values before and after the test were adjusted to zero, as it was known that no flow existed. The purpose of this project is to develop an accurate HRR measurement system so the noise and drift should be removed where possible.

In the future, if significant drift is observed in any of the other variables, the data can be adjusted after the test assuming a linear increase in drift. Before each test, the system should be run for a short time to ensure all the values are correct and the data are as expected. The system can then be stopped and started again so that the extra useless data are not included in the output file. The system should continue to run long enough 
after the test for all measurements to return to ambient values. Only then can the total drift from the test be seen. If the system is stopped early, this information will be lost.

The noise in the signals, most notably the propane flow signal, is significantly higher when the fans are on. This indicates that the fans cause electrical interference in the facility that affects currents in wiring. The methods employed reduce, but do not remove, this noise. This is another reason that it is recommended that the system not be used for fires of less than $2 \mathrm{MW}$ as the noise represents a larger relative uncertainty at lower HRRs.

At very low fan speeds and when the fans are turned off, the velocity values from the pressure transducers cannot be trusted. It is suggested that, while using the measurement system, the fans are run at least $25 \%$. When there is no flow in the fan chamber, ghost values appear that sometimes show up to $1.5 \mathrm{~m} / \mathrm{s}$ velocities. This is likely due to the fact that at very low pressures, the equation used is very sensitive to change and any noise or small amount of drift in the signal will cause a large change in the velocity value. However, when the fans are running fast enough, this sensitivity is reduced and any error caused by noise will be significantly reduced.

It was observed during tests that lower probes yield slightly higher velocities, on average, than the upper probes. This is to be expected because there are two fans pulling gas down and one pulling gas up after the fan chamber.

\subsection{Mass Flow Rate Factor}

After running several propane fires, the system was found to consistently overestimate the HRR when using the raw data from all sensors. Because the gas 
concentrations and temperatures are uniform across the cross-section and the measurement of these variables is very accurate, these variables are not the cause of this error. Therefore, the flow rate of gases is overestimated.

Sette found that changes in angle of the probe or the angle at which the gas impinges on the probe will cause an overestimation of velocity [27]. The large amount of turbulence causes such angular changes. It is also suggested that the way to calibrate velocity measurements is by burning something with known HRR and determining the factor required, such as the case of the propane experiments presented in this thesis.

To determine the required factor, the THR curves, or the area under the HRR curves were plotted and the factor required to match the final values was determined. Using this method ensures that all combustion products and oxygen consumed in the combustion reaction are accounted for by the system and, by extension, the HRR when steady burning is reached, will match the known value. This has been found to be true through several propane experiments to within an accuracy of $\pm 4 \%$ when using a factor of 0.75 . Therefore, this factor is suggested for use with this system and has been programmed into the final Labview VIs.

Using this factor, the system appears to underestimate the HRR and THR of heptane pool fires by between 5-9\%. However, the large amount of smoke produced in these fires indicates that combustion was not complete and the theoretical values in these calculations did not account for this. $5-9 \%$ is a reasonable loss due to incomplete combustion and the values measured by the system are expected to be accurate. 


\subsection{Heat Release Rates}

Depending on fire size and duration and the fan speed, an accurate HRR can be measured by the implemented measurement system. All experiments, using both heptane and propane, indicate an overestimation of HRR and THR when the raw values and formulae are used. Because of this, a factor has been applied to the mass flow rate measurements in the final version of the Labview VI in order to yield accurate results. As discussed in section 8.3, this factor is 0.75 for fires in the atrium. The response time of the system is quite long due to the sheer distance traveled by the combustion gases. During the movement of the gases toward the sampling location, the gases become diluted both from the incoming air from the designated ventilation opening and from leakage along the way. Because of this and because gases may become trapped in different compartments, the system cannot accurately measure the rate of change of HRR, especially sudden changes as were present in all experiments carried out for this thesis. A summary of expected delays are provided in Table 8.1.

At higher fan speeds, the travel time for the gases is significantly reduced and the HRR curve is better approximated by the system. However, a high fan speed may not be desirable for certain tests if a certain flow rate is required or the flames should be disturbed as little as possible. In this case a balance must be met or the most important parameters for the experiment must be determined. At $25 \%$ fan speed, 10 minutes was not long enough for the HRR measurements to reach a steady level. Therefore it is unknown how long is required for this to occur. The THR values do appear to be 
accurate at this low fan speed, however, which means that given enough time at steady burning, the HRR measurement system should be able to give an accurate measurement.

Because $\mathrm{CO}$ is measured and accounted for in the calculations and the oxygen consumption method is used, the effects of incomplete and inefficient combustion are mostly accounted for. Unburned fuel will not cause an oxygen-consuming reaction. Smoke concentration, however, is not measured.

From looking at the HRR curves where a steady state is reached, it appears that sometimes there is still a slight upward trend during the steady part. This could be in part due to smoke slowly building up in the system, whether in the atrium, the ceiling chamber or in the fan chamber. After some time the smoke concentration may still be slowly growing even with the removal of smoke by the fans. This appears to occur more at lower fan speeds, which indicates that the smoke buildup is most likely the cause of this phenomenon.

\subsubsection{Propane Calibration Fires}

A total of 14 calibration experiments using propane fires were carried out with fire sizes from 1 to $10 \mathrm{MW}$ and fan speeds of $25 \%-100 \%$.

Overall, the accuracy of the system in measuring HRRs for the propane fires is very good. In general, an error of less than $4 \%$ can be expected for fires within the capacity of the system that reach an adequate steady state of burning for enough time. The main concern in the HRR measurements is the long delay time of the system due to travel distance and dilution and buildup of gases. The figures presented in Chapter 7 give 
a good indication of the response of the system to fires with constant HRRs and sudden HRR changes.

The calibration fires did not include fires with growth or decay phases. It is expected that slow-growth fires would be measured quite well for the most part.

However, at low HRRs, a slight overestimation of THR would result. Faster growing fires would not be represented as well because of the long delay times as discussed.

\subsubsection{Heptane Fires}

Three heptane pool fire experiments were carried out in a pan with a theoretical HRR of 4.8MW. Two of these were run for about 5 minutes to measure reproducibility and one was run for almost 10 minutes to measure HRR. All used 50\% fan speed.

The measurement system appears to underestimate the THR for heptane fires by between $5-9 \%$ as compared to the theoretical values assuming complete combustion. This 5-9\% likely accounts for the effects of incomplete combustion. Another factor is that some evaporation of the fuel would have occurred in the short time between pouring the fuel and ignition.

The error of THR was calculated for all three tests and error for HRR was calculated for $\mathrm{H} 3$. The error for HRR for $\mathrm{H} 3$ was calculated using the 40 seconds during which the system measured a relatively steady value. These error values are provided in Table 7.5.

For future heptane fires, it is suggested to use a value of 1.105 for $\alpha$ and 13.1

$\mathrm{MJ} / \mathrm{kg}$ for $\mathrm{E}$, as were used in these experiments. This should yield HRR and THR values with high accuracy despite incomplete or inefficient combustion, assuming it burns long 
enough for the HRR to reach a steady level. A higher fan speed will significantly lower delay times, as discussed in section 7.6.

Babrauskas' correlations for pool fires are best suited to wind-free environments

[30]. With the test configuration in the atrium, ventilation was adjusted to attempt to limit the blowing of the flame due to incoming air drawn by the fans, but a fairly strong wind still existed. This increased availability of oxygen causes more intense and faster burning and the blowing means that more unburned volatiles could leave the combustion area before having a chance to react with the oxygen. This is another potential reason for the underestimation of THR.

\subsubsection{General Heat Release Rate Advice}

There is no apparent loss of accuracy of HRR and THR measurements at higher fan speeds. The lowered pressure caused by the fans means that no combustion products will be lost in the system; only additional outside air will be added. However, there is a much faster response of the system due to lowered travel times at higher fan speeds. It is understood that for some tests minimal air flow may be desired for a variety of reasons, including control of the fire behaviour, limiting the blowing of the flames or a decrease in dilution of combustion gases. It is suggested for these cases that the maximum fan speed that will yield good results for their purposes be used to maximize the usefulness of the HRR measurement system. The fan speed also should be high enough to minimize or eliminate the loss of smoke and combustion products through the air inlets. If enough of these products are lost, an underestimation of the HRR and the THR may occur. 
Suggested minimum fan speeds for different fire sizes in the atrium are provided in Table 8.2 .

From running two experiments using $1 \mathrm{MW}$ fires, it appears that the system is not sensitive enough to accurately measure small fires. It is therefore suggested that the system be used for fires of $2 \mathrm{MW}$ and above. The value is also the one recommended by the manufacturer of the propane flow meter, who said that the flow meter is not accurate when measuring fires of less than $10 \%$ of the span (this correlates to less than $2 \mathrm{MW}$ ). Similarly, the largest fire that was run for the full 10 minutes was $6 \mathrm{MW}$, which yielded reasonable results. The $10 \mathrm{MW}$ fires that were attempted did not run long enough to provide a steady HRR measurement. However, the THR values were still accurate. Therefore it is expected that the system can measure HRRs at least as large as $10 \mathrm{MW}$, but this has not been seen explicitly in these experiments.

If the fuel being used for an experiment is either propane or heptane, the advice in this thesis will provide guidance as to how to run the system for the test. However, if the fuel is something else with known or unknown composition, some judgment must be used in the use of the system. For unknown compositions, values of 1.105 and 13.1 for $\alpha$ and E, respectively, should be used [5]. If the composition is known, these values can be found in the literature and used. The results of the test should be analyzed with considerations given to variables such as the delay time of the system and incomplete and inefficient combustion. A load cell to measure mass loss rate should be used when available so that a theoretical HRR can be calculated and compared to the system's results. 
For fires with incomplete combustion, such as the heptane pool fires presented in this thesis, the theoretical values for HRR and THR may be difficult to calculate. The oxygen consumption method of measurement provides an accurate measurement of these values in these cases because the calculation is not based on the mass of fuel and the effective heat of combustion of the fuel. The depletion of oxygen will only occur where a reaction has taken place and therefore the system should provide accurate measurements. Inefficient combustion causing $\mathrm{CO}$ production is accounted for in the calculations. Care should be taken if the products being burned produce other toxic gases such as $\mathrm{HCl}$.

It is probable that this system will be used in the future for realistic fires with complex and unknown fuel compositions having a growth phase, steady burning and finally decay. There are some considerations to take into account for such a test. If the growth is fast, the response of the system may not show an accurate rate of growth. The system is better suited for slow growth fires in terms of response time for HRR.

However, as discussed before, the THR values of small fires under 2 MW appear to be overestimated by the system and for this reason a faster growth rate is desirable. The faster growth rate will bring the system beyond the uncertain level of a fire smaller than 2 MW in less time. Therefore, slow, fast and essentially instant growth fires such as the propane experiments all have different considerations for analysis of the results from this system. 


\subsection{Total Heat Released}

The THR calculation is not programmed into Labview. It can be calculated quite simply in Excel by multiplying the HRR by the time step value at every point and adding it to the previous value. The THR is simply the area under the HRR curve.

Some error can occur in the calculations due to non-zero values either before or after the test due to signal drift. If the ambient oxygen is properly calibrated before a test, the drift in the HRR calculations should be very small and be close to zero even with a non-zero velocity value. Also, before a test the propane flow meter signal should be adjusted so that it shows zero flow. If these steps are done correctly, the non-zero values before the test should be negligible.

After the test, it takes a long time before the gas concentrations reach ambient levels again. There may also be some drift in the signal from the propane flow meter, showing either a positive or negative HRR that does not actually exist.

This type of error can be seen visually on the graphs for THR. If the slope is not zero when the fire is known to be extinguished, then there is a problem. This is especially true if there is a negative slope, as heat cannot be unreleased. Any non-zero values and noise in HRR and THR curves of propane when zero flow existed have been removed in the figures presented in this thesis. 
Table 8.1 Expected delay times of measurement system

\begin{tabular}{|c|c|c|c|}
\hline $\begin{array}{c}\text { Fan Speed } \\
(\%)\end{array}$ & $\begin{array}{c}\text { Delay to first } \\
\text { detection (s) }\end{array}$ & $\begin{array}{c}\text { Delay to } \\
\text { steady HRR (s) }\end{array}$ & $\begin{array}{c}\text { Time from first } \\
\text { detection to steady (s) }\end{array}$ \\
\hline 25 & -40 & Unknown & Unknown \\
\hline 50 & $\sim 20$ & $\sim 450-470$ & $\sim 430-450$ \\
\hline 100 & -10 & $-200-220$ & $\sim 190-210$ \\
\hline
\end{tabular}

Note: system delay is constant at 45 seconds for all tests

Table 8.2 Suggested minimum fan speeds

\begin{tabular}{|c|c|}
\hline $\begin{array}{c}\text { Fire } \\
\text { Size } \\
\text { (MW) }\end{array}$ & $\begin{array}{c}\text { Suggested } \\
\text { Minimum Fan } \\
\text { Speed (\%) }\end{array}$ \\
\hline 2.5 & 25 \\
\hline 5 & 25 \\
\hline 7.5 & 50 \\
\hline 10 & 100 \\
\hline
\end{tabular}




\section{Chapter 9: Summary, Conclusions and Recommendations}

\subsection{Summary}

A system has been designed, installed and calibrated that can accurately measure the HRR of fires in Carleton University's experimental atrium fire research facility. The system uses the concept of oxygen consumption calorimetry, which is based on the principle that the combustion of most materials release almost the same amount of heat per unit of oxygen consumed in the reaction. Therefore, measurements must be taken of mass flow rate and gas concentrations in a location through which all combustion products move. These data are then processed and a near real time display provides various measurements during the test, including gas temperature, velocity, mass flow rate, gas concentrations and HRR of the fire.

A study of the cross-sectional profile of various variables in the fan chamber indicated that the final chosen instrumentation layout would yield results representative of the entire cross-section. This layout includes six Type-J thermocouples, four bidirectional probes and a gas sampling grid. Data from these instruments is processed by Labview software custom developed for this system.

Three heptane pool fires and 14 propane fires using a calibration burner with a known flow rate were carried out in order to calibrate the system. Using the raw data, the system was found to overestimate the HRR due to an overestimation of the mass flow rate through the fan chamber. A factor of 0.75 has been applied to the mass flow rate in the Labview VI developed for the system. This factor has been found to consistently provide accurate HRRs throughout the calibration experiments performed. 


\subsection{Conclusions}

- The developed HRR measurement system can accurately measure HRR and THR for most fires in Carleton University's experimental atrium

- The system is user-friendly and can be customized and adapted for various purposes by adjusting the Labview program. All raw data and calculated values are written to a file to make further analysis and interpretation of test results more convenient.

- The system has limitations, including fast changes in fire size or fire growth and fires under $2 \mathrm{MW}$. It is best suited to large fires that last a long time.

- The largest fire that has been seen to yield accurate HRR measurements is $6 \mathrm{MW}$. However, it is expected that the system is capable of accurately measuring fires of at least $10 \mathrm{MW}$.

- The three exhaust fans should all be running at equal levels at or above $25 \%$ speed when using the HRR measurement system.

- Delays are inherent in the system due to both the travel time of gases to the sample location and movement of gases from the sample location to the gas analyzer. Travel time to the sample location is lowest at higher fan speeds. There is no apparent loss of accuracy due to higher fan speeds.

- The measured HRR may not reach a steady state if the fire does not burn steady for 10 minutes. Even though some tests may not yield useful HRR results if they are outside the limitations of this system, accurate THR values should be obtained as all of the combustion gases will still be accounted for. 


\subsection{Recommendations}

- More experiments should be carried out for further calibration and validation of the system varying different parameters. Different fuels such as wood and other building materials should be used as well as fires with different growth rates in order to further understand the response of the system.

- Fires with HRRs of $10 \mathrm{MW}$ and higher, if possible, should be carried out to determine the upper limit, if any, of fire size that will yield accurate HRR measurements.

- When running propane fires, both the propane flow meter and the system developed in this Thesis should be running in order to obtain more data and insight into the system.

- More FDS simulations should be carried out also varying the fuel and growth properties of the fire. Different ventilation arrangements should also be considered. Simulations where the fire decays should be run with enough time afterwards to allow all combustion products to leave the facility. This will allow for a simulated measurement of THR to be considered.

- The grid sizes of FDS simulations should be studied in more detail. Perhaps decreasing the grid size in key locations such as near the fire and in the sampling location will provide some interesting results. 


\section{References}

[1] C. Huggett, "Estimation of the Rate of Heat Release by Means of Oxygen Consumption," Fire and Materials, vol.4 No.2, pp.61-65, 1980.

[2] W. Thornton, "The relation of oxygen to the heat of combustion of organic compounds," Philosophical Magazine and Journal of Science, vol. 33, pp 196$203,1917$.

[3] A. Tewarson, "Generation of Heat and Chemical Compounds in Fires," in The SFPE Handbook of Fire Protection Engineering, 3rd ed, The National Fire Protection Association, 2002, pp 3-82 - 3-161.

[4] W. Parker, "Calculations of the Heat Release Rate by Oxygen Consumption for Various Applications," Journal of Fire Sciences, vol. 2, pp 380-395, 1984.

[5] M.L. Janssens, "Measuring Rate of Heat Release by Oxygen Consumption," Fire Technology, vol. 27, pp.234-249, 1991.

[6] S. Brohez,C. Delvosalle, G. Marlair and A. Tewarson, "The Measurement of Heat Release from Oxygen Consumption in Sooty Fires," Journal of Fire Sciences, vol. $18,2000$.

[7] V. Babrauskas, "Development of the Cone Calorimeter - A Bench-scale Heat Release Rate Apparatus Based on Oxygen Consumption," Fire and Materials, vol.8, pp 81-95, 1984 .

[8] V. Babrauskas, J.R. Lawson, W.D. Walton and W.H. Twilley, "Upholstered Furniture Heat Release Rates Measured With a Furniture Calorimeter," NBSIR 82-2604, December 1982. 
[9] J. J. Brenden and D. L. Chamberlain, Heat Release Rates From Wall Assemblies: Oxygen Consumption and Other Methods Compared. Res. Pap. FPL-RP-476. U.S. Department of Agriculture, Forest Service, Forest Products Laboratory: Madison, WI, 1986.

[10] H. C. Tran and R. E. White, Heat release from wood wall assemblies using oxygen consumption method, Fire and polymers : hazards identification and prevention : 197th national meeting of the American Chemical Society, April 914, 1989, Dallas, TX. Washington, DC: American Chemical Society, 1990.

[11] J. Urbas, J. Shaw, “Testing Wall Assemblies on an Intermediate-Scale Calorimeter," Fire Technology, vol. 29, pp 332-349, 1993.

[12] R. Bryant et al., The NIST 3 Megawatt Quantitative Heat Release Rate FacilityDescription and Procedures, The National Institute of Standards and Technology, 2004.

[13] R. Van Mierlo and B. Sette, "The Single Burning Item (SBI) test method - a decade of development and plans for the near future," Heron, Vol. 50, pp 191207,2005

[14] International Organisation for Standardisation, ISO 5660-1:2002. Reaction-to-fire tests - Heat release, smoke production and mass loss rate - Part 1: Heat release rate (cone calorimeter method), 2002.

[15] International Organisation for Standardisation, ISO 9705:1993. ISO Room Corner; International Standard - Fire tests - Full-scale room test for surface products, Geneva, 1993. 
[16] European Standard, Reaction to fire tests for building products - Building products excluding floorings exposed to the thermal attack by a single burning item, EN 13823, CEN Central Secretariat, Brussels, 2002.

[17] D. Stroup, L. DeLauter, J. Lee and G. Roadarmel, Large Fire Research Facility (Building 205) Exhaust Hood Heat Release Rate Measurement System, The National Institute of Standards and Technology, 2000.

[18] R. A. Bryant and G. W. Mulholland, "A guide to characterizing heat release rate measurement uncertainty for full-scale fire tests," Fire and Materials, vol. 32, pp $121-139,2008$

[19] R. Yeager, "Uncertainty Analysis of Energy Release Rate Measurement for Room Fires," Journal of Fire Sciences, vol. 4, 1986.

[20] R. Lyon and A. Abramowitz, "Effect of Instrument Response Time on Heat Release Rate Measurements," Fire and Materials, vol.19, pp 11-17, 1995.

[21] J. Axelsson, P. Andersson, A. Lonnermark, P. Van Hees and I. Wetterlund, "Uncertainties in measuring heat and smoke release rates in the room/corner test and the SBI," Fire Technology, SP Report 2001:04, SP Swedish National Testing and Research Institute, Boras, Sweden, 2001.

[22] S. Brohez, "Uncertainty Analysis of Heat Release Rate Measurement from Oxygen Consumption Calorimetry," Fire and Materials, vol. 29, pp.383-394, 2005. 
[23] B. Messerschmidt and P. Van Hees, "Influence of Delay Times and Response Times on Heat Release Measurements," Fire and Materials, vol. 24, pp. 121-130, 2000.

[24] M. Janssens, "Variability in Oxygen Consumption Calorimetry Tests," in Thermal Measurements: The Foundation of Fire Standards, ASTM STP 1427, L. A.

Gritzo and N. J. Alvares, Eds., ASTM International, West Conshohocken, PA, 2002.

[25] American Society of Heating, Refrigerating, Air-Conditioning Engineers, ASHRAE Handbook: Fundamentals, Ch. 2 - Fluid Flow, Inch Pound Edition, 2005 .

[26] B. McCaffrey, G. Heskestad, "A Robust Bidirectional Low-velocity Probe for Flame and Fire Application," Combustion and Flame, vol. 26, pp 1252-127, 1976.

[27] B. J. G. Sette, "Critical considerations on the use of a bi-directional probe in heat release measurements," Fire and Materials, vol. 29, pp 335-349, 2005.

[28] M. Barker, "The use of very small pitot tubes for measuring wind velocity," Proceedings of the Royal Society of London, vol. 101, p 435-445, 1922.

[29] ASHRAE Handbook: Fundamentals. Chapter 14 - Measurement and Instruments. American Society of Heating, Refrigerating, Air-Conditioning Engineers., Inch Pound Edition. 2005.

[30] V. Babrauskas, "Estimating Large Pool Fire Burning Rate," Fire Technology, vol. 19, pp 251-261, 1983 . 
[31] J. Woods, B. Fleck and L. Kostiuk, "Effects of transverse air flow on burning rates of rectangular methanol pool fires," Combustion and Flame, vol. 146, pp. 379-390, 2006.

[32] J. Chatris, J. Quintella, J. Folch, E. Planas, J. Arnaldos and J. Casal, "Experimental Study of Burning Rate in Hydrocarbon Pool Fires," Combustion and Flame, vol. 126. pp. 1373-1383, 2001.

[33] C.S. Lam, J.E. Weisinger, E.J. Weckman, W. Gill and A. Brown, "The Effects of Winds on Liquid Fuelled Pool Fires", HT2003-40535, ASME Heat Transfer Conference, Las Vegas, July, 2003.

[34] H.P. Morgan, "Atrium Buildings: Calculating Smoke Flows in Atria for Smokecontrol Design," Fire Safety Journal, vol. 12, pp 9-35, 1987.

[35] W.K. Chow, Y.Z. Li, E. Cui and R. Huo, "Natural smoke filling in atrium with liquid pool fires up to 1.6MW," Building and Environment, vol. 36, pp 121-127, 2001 .

[36] C. Gutierrez-Montes, E. Sanmiguel-Rojas, A. Kaiser, and A. Viedma, "Numerical model and validation experiments of atrium enclosure fire in a new fire test facility," Building and Environment, vol. 43, pp 1912-1929, 2008.

[37] T.X. Qin, Y.C. Guo, C.K. Chan and W.Y. Lin, "Numerical simulation of the spread of smoke in an atrium under fire scenario," Building and Environment, vol. 44, pp 56-65. 2008. 
[38] A. Tewarson. "Generation of Heat and Gaseous, Liquid, and Solid Products in Fires" in The SFPE Handbook of Fire Protection Engineering, $4^{\text {th }}$ ed, The National Fire Protection Association, 2008, pp. 3-109 to 3- 194

[39] Sierra Instruments, Sierra Steel-Mass ${ }^{T M}$ Model 640S Insertion Mass Flow Meter Instruction Manual, 2008.

[40] Y. Ko and R. Michels, "Instrumentation Design for HRR Measurements in a Large-scale Fire Facility," Submitted to Fire Technology.

[41] K. B. McGrattan, B. Klein, S. Hostikkia and J. Floyd, Fire Dynamics Simulator (Version 5): User Guide. NIST SP 1019-5, NIST Special Publication 1019-5. National Institute of Technology and Standards, 2007.

[42] Y. Ko, A. Kashef, and G. Hadjisophocleous, "Modeling of smoke movement during the early stage of tunnel fires under different ventilation conditions," The International Congress of Smoke Control in Buildings and Tunnels, Santander, Spain, 2008.

[43] The ABB Group, Easyline Continuous Gas Analyers, EL3000 Series, Models EL3020, EL3040, 10/24-4.10 EN, 2007.

[44] "Shielded/Unshielded Cables," [Online]. Available: http://www.connectworld.net/shielded-cables.html. [Accessed Dec 22, 2008] 
Appendix A: Photo Log

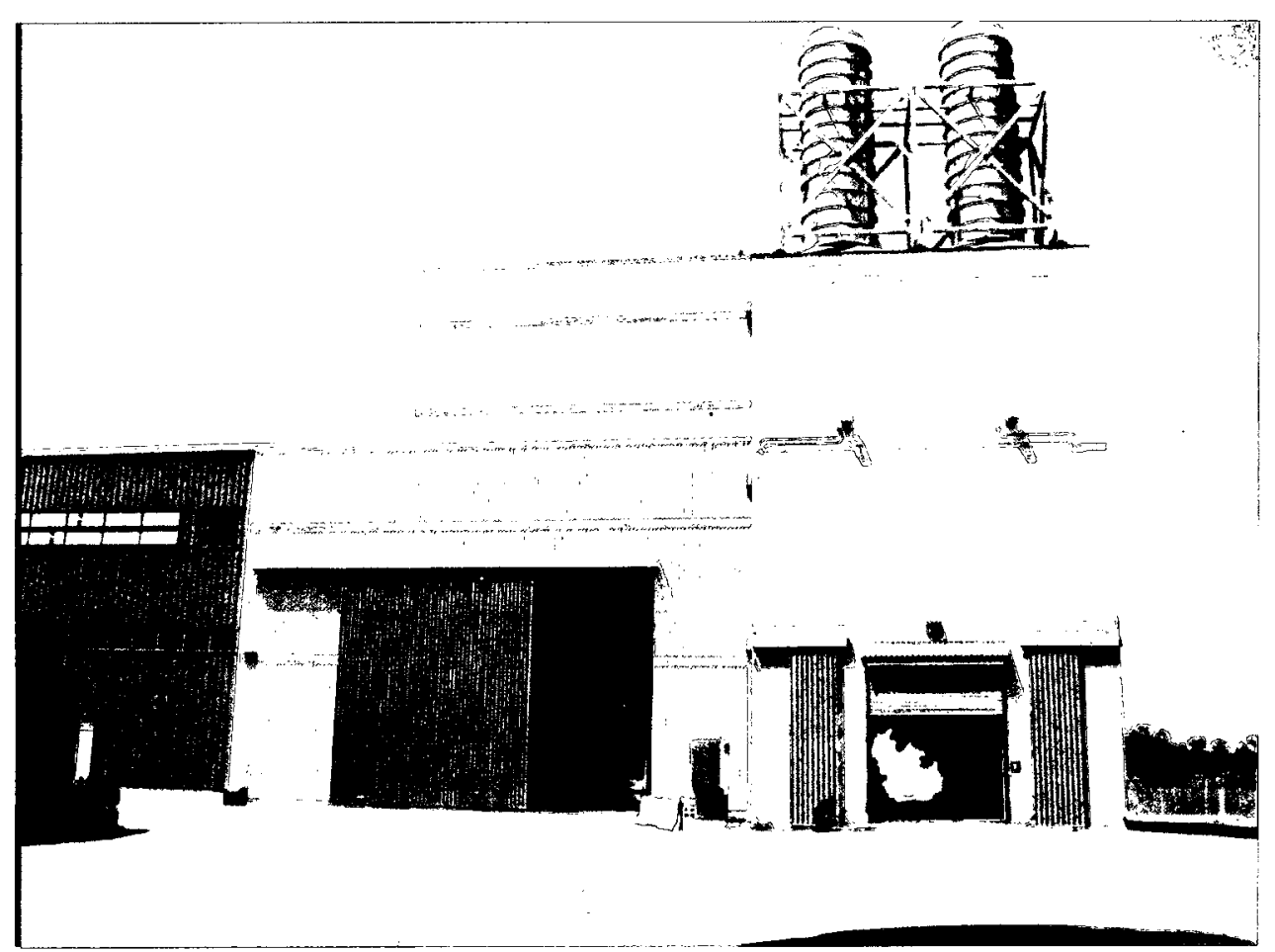

Photo 1: Exterior view of Carleton University's facility with fire in the tunnel
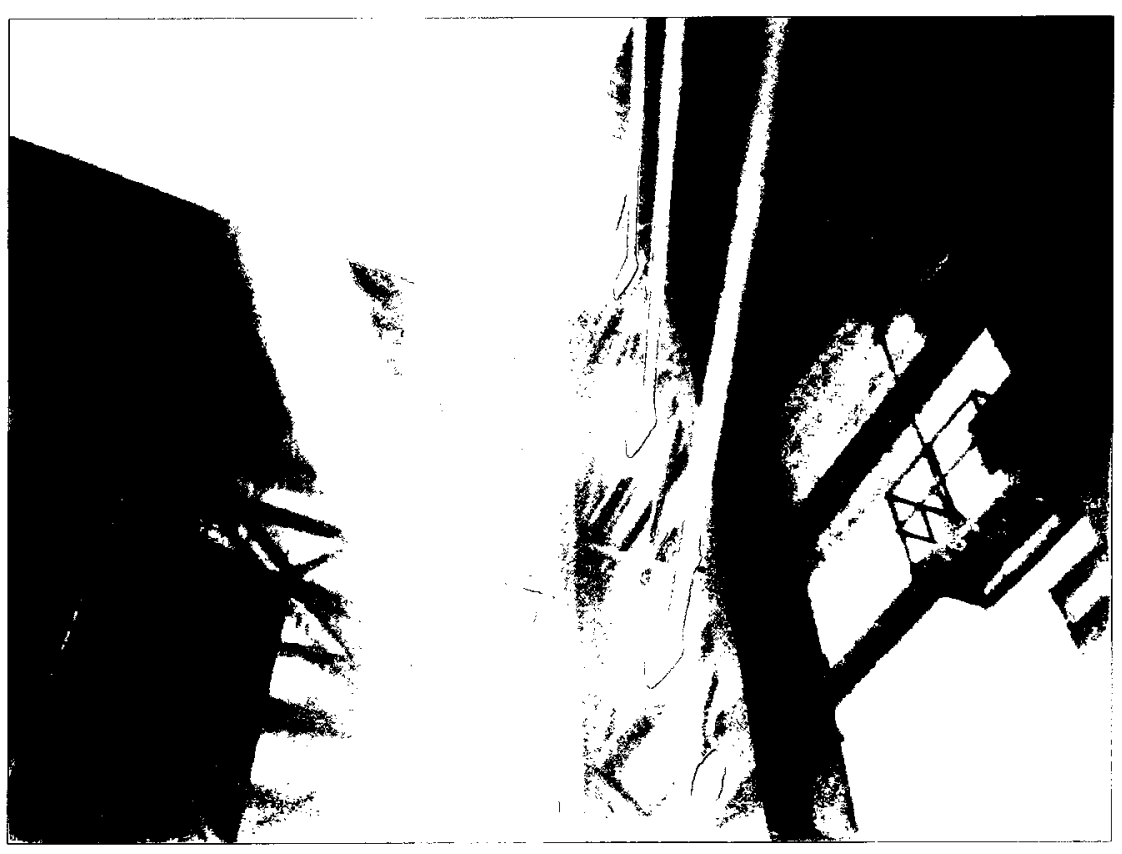

Photo 2: Interior view of the atrium with smoke 
Photo 3: Fan chamber with instrumentation installed
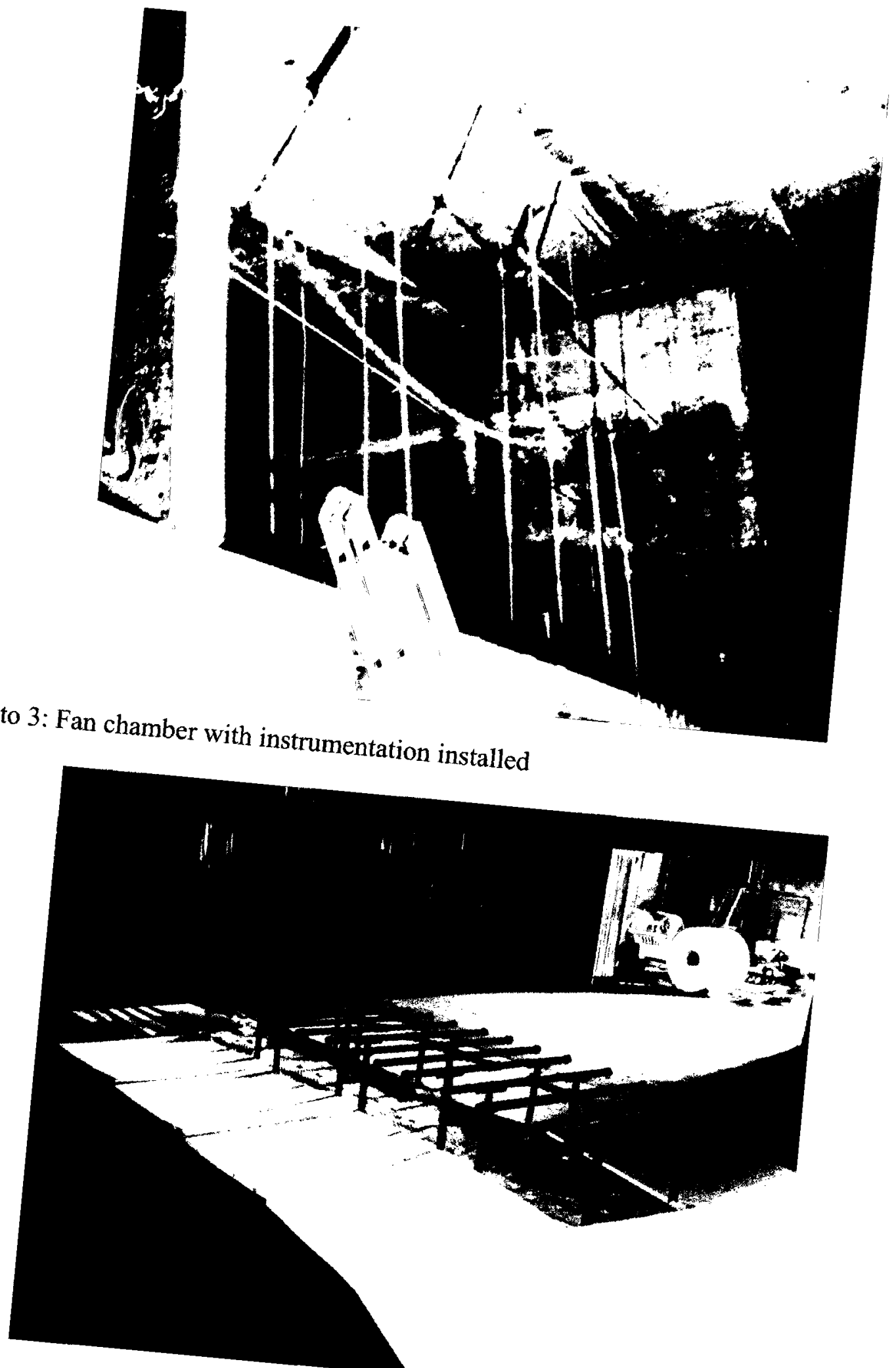

Photo 4: Propane burners in the atrium 


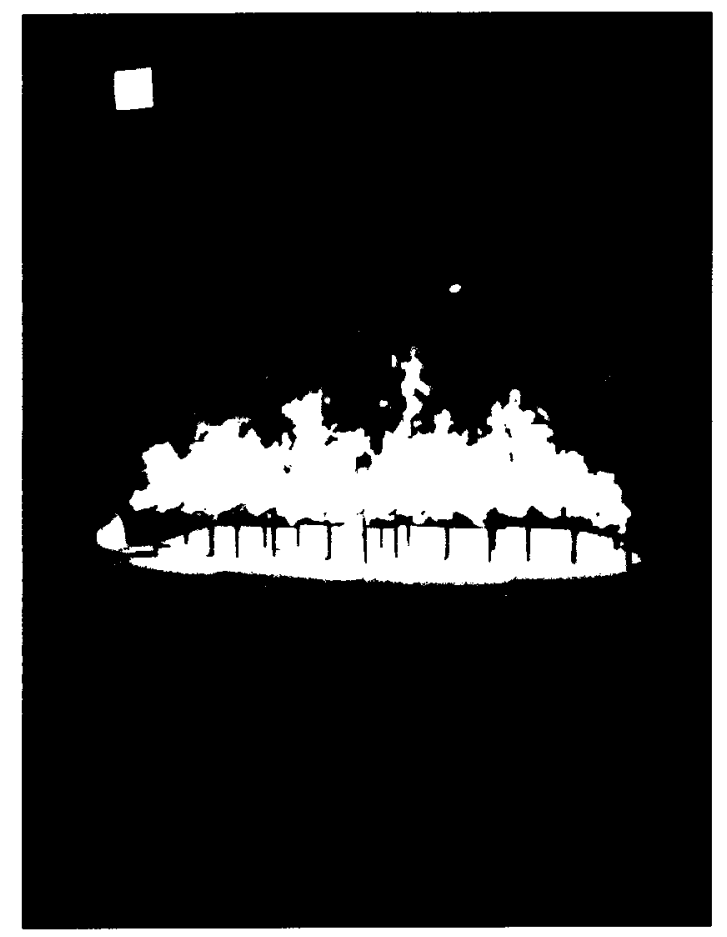

Photo 5: Propane fire in the atrium

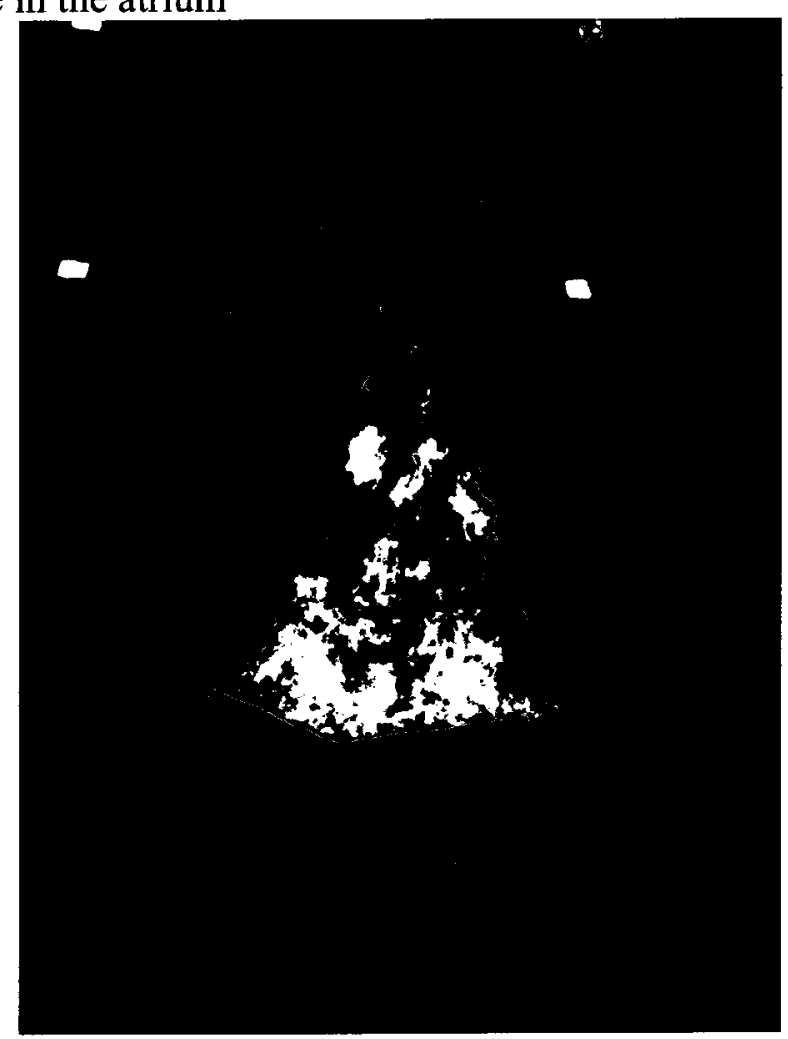

Photo 6: Heptane pool fire in the atrium 


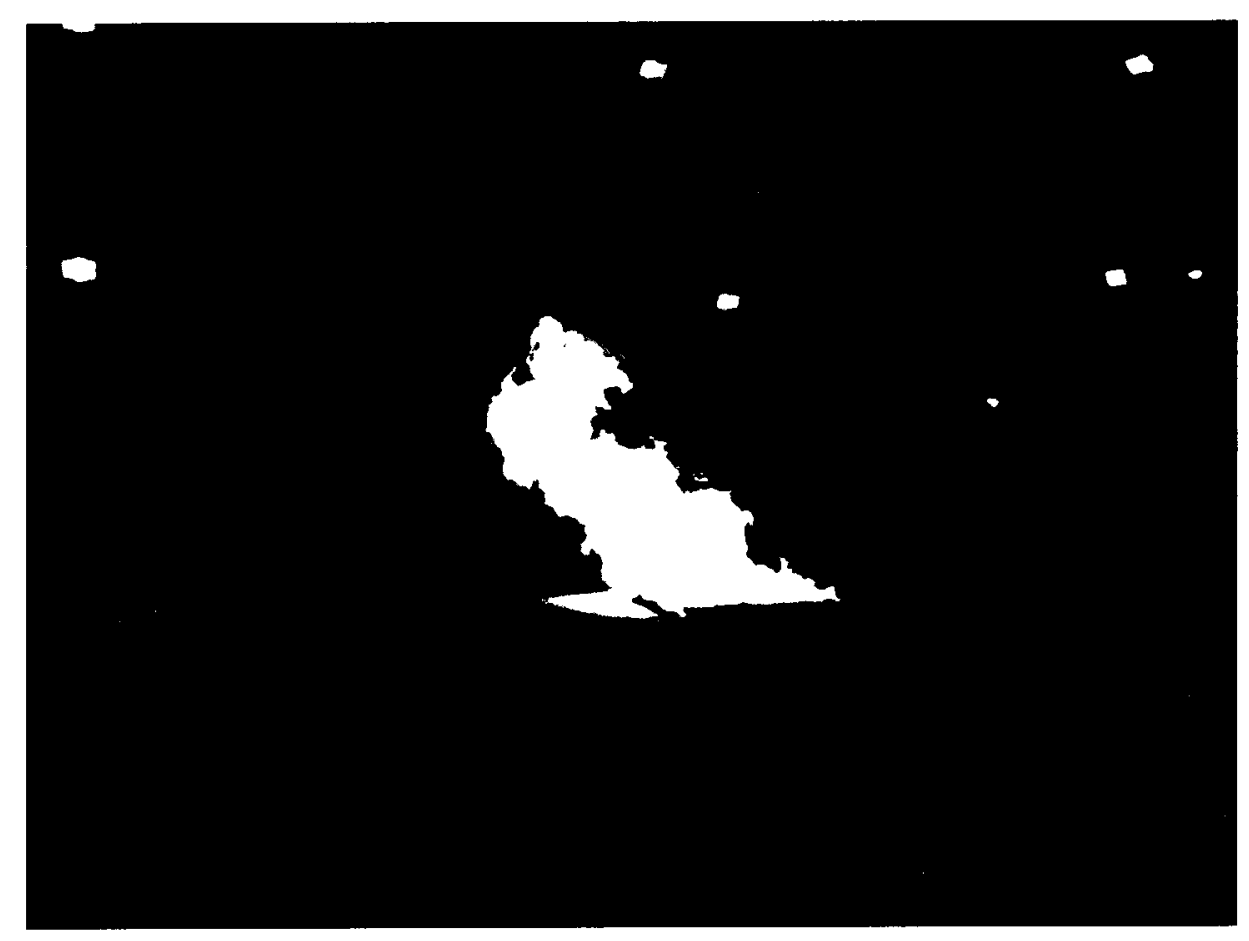

Photo 7: Heptane pool fire being blown by wind caused by exhaust fans 
Appendix B: Sample FDS Input File

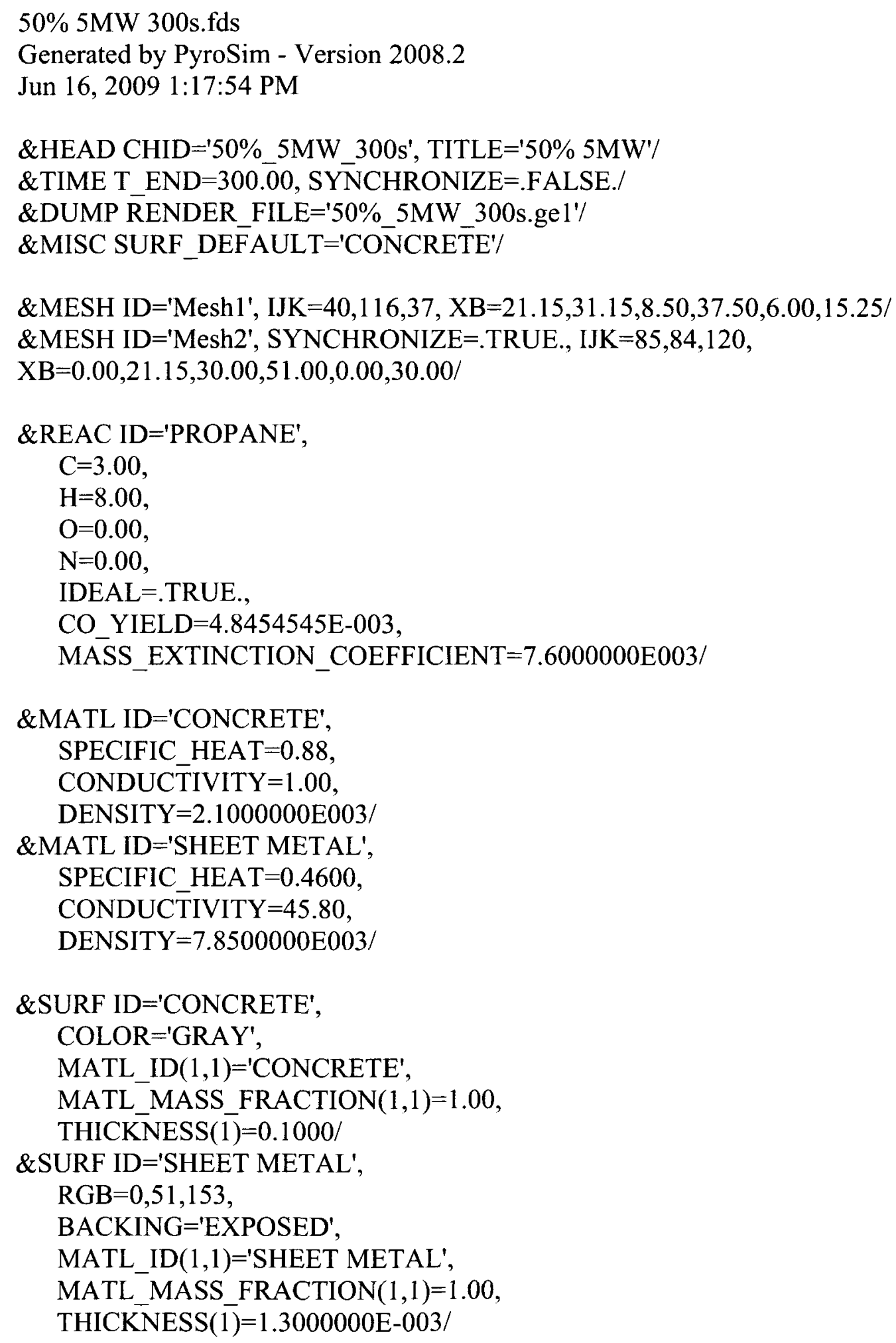




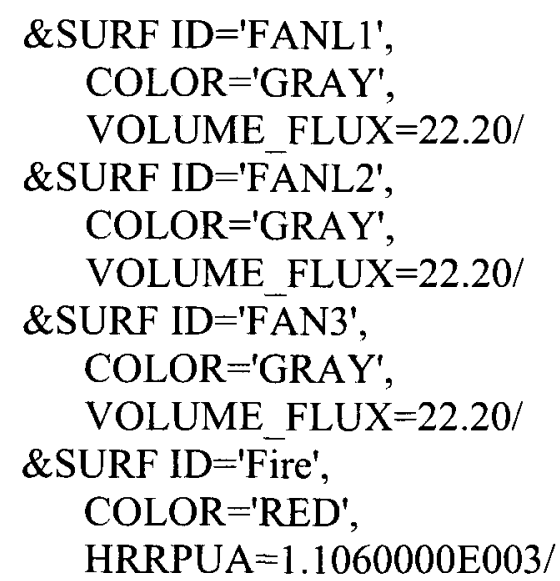

\&DEVC ID='CO 1', QUANTITY='carbon monoxide', $X Y Z=23.90,17.50,10.90 /$ \&DEVC ID='CO 2', QUANTITY ='carbon monoxide', XYZ=23.90,17.50,9.90/ \&DEVC ID $=$ 'CO 3', QUANTITY $=$ 'carbon monoxide', $X Y Z=23.90,17.50,8.90 /$ $\& D E V C$ ID $=$ 'CO 4', QUANTITY ='carbon monoxide', $X Y Z=26.15,17.50,10.90 /$ \&DEVC ID='CO 5', QUANTITY='carbon monoxide', $X Y Z=26.15,17.50,9.90 /$ $\& D E V C$ ID='CO 6', QUANTITY='carbon monoxide', $X Y Z=26.15,17.50,8.90$ / \&DEVC ID='CO 7', QUANTITY='carbon monoxide', $X Y Z=28.40,17.50,10.90 /$ $\& D E V C$ ID $=$ 'CO 8', QUANTITY='carbon monoxide', $X Y Z=28.40,17.50,9.90 /$ \&DEVC ID='CO 9', QUANTITY ='carbon monoxide', XYZ $=28.40,17.50,8.90 /$ \&DEVC ID='CO2 1', QUANTITY='carbon dioxide', $X Y Z=23.90,17.50,10.90 /$ $\& D E V C$ ID='CO2 2', QUANTITY $=$ 'carbon dioxide', $X Y Z=23.90,17.50,9.90 /$ $\& \mathrm{DEVC}$ ID='CO2 3', QUANTITY='carbon dioxide', $\mathrm{XYZ}=23.90,17.50,8.90 /$ \&DEVC ID='CO2 4', QUANTITY='carbon dioxide', $X Y Z=26.15,17.50,10.90 /$ $\& D E V C$ ID $=$ 'CO2 5', QUANTITY='carbon dioxide', $X Y Z=26.15,17.50,9.90 /$ \&DEVC ID='CO2 6', QUANTITY='carbon dioxide', $\mathrm{XYZ}=26.15,17.50,8.90 /$ \&DEVC ID='CO2 7', QUANTITY='carbon dioxide', $\mathrm{XYZ}=28.40,17.50,10.90 /$ \&DEVC ID='CO2 8', QUANTITY $=$ 'carbon dioxide', $X Y Z=28.40,17.50,9.90 /$ $\& D E V C$ ID $=$ 'CO2 9', QUANTITY='carbon dioxide', $\mathrm{XYZ}=28.40,17.50,8.90$ / \&DEVC ID='FLOW atrium door', QUANTITY='MASS FLOW', $\mathrm{XB}=21.00,21.00,34.85,37.30,6.00,7.96 /$ \&DEVC ID='FLOW fanl', QUANTITY='MASS FLOW', $\mathrm{XB}=27.33,30.48,8.50,8.50,6.40,9.45 /$ \&DEVC ID='FLOW fan2', QUANTITY='MASS FLOW', $\mathrm{XB}=21.83,24.98,8.50,8.50,6.40,9.45 /$ \&DEVC ID='FLOW fan3', QUANTITY='MASS FLOW', $\mathrm{XB}=25.08,27.23,8.50,8.50,11.76,15.14 /$ \&DEVC ID='FLOW garagedoor1', QUANTITY='MASS FLOW', $\mathrm{XB}=5.97,9.63,30.00,30.00,0.00,4.26 /$ \&DEVC ID='FLOW garagedoor2', QUANTITY='MASS FLOW', $\mathrm{XB}=10.97,14.63,30.00,30.00,0.00,4.26 /$ 
\&DEVC ID='FLOW Large atr door', QUANTITY='MASS FLOW', $\mathrm{XB}=21.00,21.00,31.00,37.30,8.30,11.00 /$

$\& D E V C$ ID='FLOW M2 to M3', QUANTITY='MASS FLOW',

$\mathrm{XB}=23.10,29.20,13.55,15.40,11.60,11.60 /$

\&DEVC ID='FLOW uppermiddle', QUANTITY='MASS FLOW',

$\mathrm{XB}=23.40,28.90,17.50,17.50,8.40,11.34 /$

$\& D E V C$ ID='FLOW Y=16', QUANTITY='MASS FLOW',

$\mathrm{XB}=21.15,31.15,16.00,16.00,6.00,11.34 /$

\&DEVC ID='O2 1', QUANTITY='oxygen mass fraction', $X Y Z=23.90,17.50,10.90 /$ \&DEVC ID='O2 2', QUANTITY='oxygen mass fraction', $\mathrm{XYZ}=23.90,17.50,9.90 /$ \&DEVC ID='O2 3', QUANTITY='oxygen mass fraction', $X Y Z=23.90,17.50,8.90$ / \&DEVC ID $=$ 'O2 4', QUANTITY $=$ 'oxygen mass fraction', $X Y Z=26.15,17.50,10.90 /$ \&DEVC ID='O2 5', QUANTITY='oxygen mass fraction', $X Y Z=26.15,17.50,9.90 /$ \&DEVC ID='O2 6', QUANTITY='oxygen mass fraction', $X Y Z=26.15,17.50,8.90 /$ \&DEVC ID='O2 7', QUANTITY='oxygen mass fraction', $X Y Z=28.40,17.50,10.90 /$ \&DEVC ID='O2 8', QUANTITY='oxygen mass fraction', $X Y Z=28.40,17.50,9.90$ / \&DEVC ID='O2 9', QUANTITY='oxygen mass fraction', $X Y Z=28.40,17.50,8.90$ / \&DEVC ID='Temp 1', QUANTITY='TEMPERATURE', XYZ $=27.50,17.50,10.40 /$ $\& D E V C$ ID='Temp 2', QUANTITY='TEMPERATURE', XYZ $=27.50,17.50,9.50 /$ \&DEVC ID='Temp 3', QUANTITY='TEMPERATURE', XYZ $=26.20,17.50,10.80 /$ $\& D E V C$ ID='Temp 4', QUANTITY='TEMPERATURE', XYZ $=26.20,17.50,9.10 /$ \&DEVC ID='Temp 5', QUANTITY='TEMPERATURE', XYZ $=24.70,17.50,10.40$ / \&DEVC ID='Temp 6', QUANTITY='TEMPERATURE', XYZ=24.70,17.50,9.50/ \&DEVC ID='V-vel LL', QUANTITY='V-VELOCITY', XYZ=25.15,17.50,8.90/ \&DEVC ID='V-vel LR', QUANTITY='V-VELOCITY', XYZ=27.15,17.50,8.90/ \&DEVC ID='V-vel UL', QUANTITY='V-VELOCITY', XYZ $=25.15,17.50,10.84 /$ \&DEVC ID='V-vel UR', QUANTITY='V-VELOCITY', XYZ $=27.15,17.50,10.84 /$ \&HOLE XB $=26.45,30.00,35.10,37.30,5.40,6.00 /$ slab-2f C4 \&HOLE XB $=22.30,25.85,35.10,37.30,5.40,6.00 /$ slab-2f C5 \&HOLE XB $=28.85,29.15,25.00,26.00,6.00,7.80, \mathrm{RGB}=0,0,0$, TRANSPARENCY $=0.4000 / 2 \mathrm{f}-\mathrm{P} 11$ \&HOLE XB $=23.15,23.45,25.00,26.00,6.00,7.80 / 2 \mathrm{f}-\mathrm{P} 22$ \&HOLE XB $=22.65,29.15,13.05,13.50,6.40,9.45 /$ slab-2f Fan-1 opening $* * * * * * * * * * * * * * * * * * * * * * * * * * * * * * * * * * * * * * * * * * * * * *$ open \&HOLE XB=23.10,29.20,13.55,15.40,11.30,11.85/ slab-4f

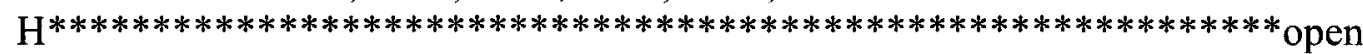

\&HOLE XB $=2.85,4.70,42.94,44.79,25.30,25.80 /$ Hole \&HOLE XB $=17.85,20.85,30.30,37.20,25.30,25.80 /$ Hole $\&$ HOLE XB $=20.75,21.25,31.00,37.30,8.30,11.00 /$ Hole \&HOLE $X B=17.32,21.15,44.61,50.86,25.30,25.80 /$ Hole \&HOLE XB $=0.00,11.00,49.23,50.86,25.30,25.80 /$ Hole \&HOLE XB $=20.05,20.25,40.50,44.16,1.00,5.26 /$ Hole \&HOLE XB $=17.20,17.35,45.60,49.26,1.00,5.26 /$ Hole $\&$ HOLE XB $=20.75,21.25,34.85,37.30,6.00,7.96 /$ Hole 
\&HOLE XB=7.85,9.70,42.94,44.79,25.30,25.80/ Hole[1] \&HOLE XB $=2.85,4.70,35.24,37.09,25.30,25.80 /$ Hole[1] \&HOLE XB=12.76,14.61,42.94,44.79,25.30,25.80/ Hole[1][1] \&HOLE XB $=7.85,9.70,35.24,37.09,25.30,25.80 /$ Hole[1][1] \&HOLE XB=12.76,14.61,35.24,37.09,25.30,25.80/ Hole[1][1][1]

\&OBST XB=21.15,31.15,0.00,37.50,5.60,6.00, SURF_ID='CONCRETE'/ slab-2f thk of slab $=400$ \&OBST XB=23.87,28.43,28.74,30.89,6.00,6.30, SURF ID='SHEET METAL'/ slab-2f $\mathrm{C} 2$ \&OBST XB=29.33,30.95,28.74,30.89,6.00,6.30, SURF_ID='SHEET METAL'/ slab-2f $\mathrm{C} 1$ \&OBST XB=21.35,22.97,28.74,30.89,6.00,6.30, SURF_ID='SHEET METAL'/ slab-2f C3 \&OBST XB=28.90,29.15,17.35,31.38,6.00,8.00, SURF_ID='CONCRETE'/ 2f-P1 \&OBST XB=23.15,23.40,17.35,31.38,6.00,8.00, SURF_ID='CONCRETE'/2f-P2 \&OBST XB=21.15,31.15,17.35,30.00,8.00,8.40, SURF_ID='CONCRETE'/ slab-3f thk of slab $=400$

\&OBST XB $=21.15,31.15,30.00,30.40,7.80,8.20, \mathrm{SURF}$ ID='CONCRETE'/ slab-3f slope \&OBST $X B=21.15,31.15,30.40,30.80,7.40,7.80, \mathrm{SURF}^{-} \mathrm{ID}=$ 'CONCRETE'/ slab-3f slope \&OBST XB=21.15,31.15,30.80,31.20,7.00,7.40, SURF_ID='CONCRETE'/ slab-3f slope \&OBST XB=21.15,31.15,31.20,31.60,6.40,7.00, SURF_ID='CONCRETE'/ slab-3f slope \&OBST XB $=21.15,31.15,31.60,31.78,6.00,6.40, \mathrm{SURF}^{-}$ID='CONCRETE'/ slab-3f slope \&OBST XB $=28.90,29.15,17.35,28.20,8.40,11.34, \mathrm{SUR} \overline{\mathrm{F}}$ ID='CONCRETE'/ 3f-P3 \&OBST XB $=23.15,23.40,17.35,28.20,8.40,11.34, \mathrm{SURF}_{\text {ID }}={ }^{\prime}$ CONCRETE'/ $3 \mathrm{f}-\mathrm{P} 4$ \&OBST XB $=28.90,31.15,23.00,23.20,8.40,11.34, \mathrm{SURF}_{\text {ID }}=$ 'CONCRETE'/ $3 \mathrm{f}-\mathrm{B} 1$ \&OBST XB $=21.15,23.35,23.00,23.20,8.40,11.34, \mathrm{SURF}$ ID $=$ 'CONCRETE'/ 3f-B2 \&OBST XB=21.15,31.15,13.05,13.35,6.00,11.34, SURF_ID='CONCRETE'/ slab-2f Fan-l wall

\&OBST XB=21.83,30.48,8.45,13.35,6.40,6.40, SURF_ID='SHEET METAL'/ slab-2f Fan-1 $0.4 \mathrm{~m}$ bed \&OBST XB=23.10,29.20,8.45,15.40,11.76,11.76,

SURF_IDS='INERT','CONCRETE','CONCRETE'/ slab-2f Fan-1 $0.4 \mathrm{~m}$ bed \&OBST XB=21.83,30.48,8.45,13.35,9.45,9.45, SURF_ID='SHEET METAL'/ slab-2f Fan- $10.4 \mathrm{~m}$ cover \&OBST XB=22.95,22.95,10.45,13.35,6.40,9.45, SURF_ID='SHEET METAL'/ Obstruction \#1 \&OBST XB=22.75,22.85,10.20,10.45,6.40,9.45, SURF_ID='SHEET METAL'/ Obstruction \#2 \&OBST XB=22.55,22.75,9.95,10.20,6.40,9.45, SURF_ID='SHEET METAL'/ Obstruction \#3 \&OBST XB=22.35,22.55,9.70,9.95,6.40,9.45, SURF_ID='SHEET METAL'/ Obstruction \#4 
\&OBST XB=22.05,22.35,9.45,9.70,6.40,9.45, SURF_ID='SHEET METAL'/ Obstruction \#5 \&OBST XB=21.83,22.05,9.20,9.45,6.40,9.45, SURF_ID='SHEET METAL'/ Obstruction \#6

\&OBST XB=21.83,22.05,8.95,9.20,6.40,9.45, SURF_ID='SHEET METAL'/ Obstruction $\# 7$

\&OBST XB=21.65,21.83,8.45,8.95,6.40,9.45, SURF_ID='SHEET METAL'/ Obstruction \#8

\&OBST XB=29.65,29.65,10.45,13.35,6.40,9.45, SURF_ID='SHEET METAL'/

Obstruction \#9

\&OBST XB=29.45,29.65,10.20,10.45,6.40,9.45, SURF_ID='SHEET METAL'/

Obstruction \#10

\&OBST XB=29.55,29.75,9.95,10.20,6.40,9.45, SURF_ID='SHEET METAL'/

Obstruction \#11

\&OBST XB=29.75,29.95,9.70,9.95,6.40,9.45, SURF_ID='SHEET METAL'/ Obstruction $\# 12$

\&OBST XB=29.95,30.25,9.45,9.70,6.40,9.45, SURF_ID='SHEET METAL'/ Obstruction \#13

\&OBST XB=30.25,30.48,9.20,9.45,6.40,9.45, SURF_ID='SHEET METAL'/ Obstruction \#14

\&OBST XB=30.25,30.48,8.95,9.20,6.40,9.45, SURF_ID='SHEET METAL'/ Obstruction \#15

\&OBST XB=30.48,30.65,8.45,8.95,6.40,9.45, SURF_ID='SHEET METAL'/ Obstruction \#16

\&OBST XB=24.98,27.33,8.45,8.45,6.40,9.45, SURF_ID='SHEET METAL'/ Obstruction \#17

\&OBST XB=21.15,31.15,0.00,37.50,11.34,11.75, SURF_ID='CONCRETE'/ slab-4f thk of slab $=400$

\&OBST XB=23.10,29.20,8.45,15.40,15.13,15.13, SURF_ID='SHEET METAL'/ slab-rf Fan-u cover

\&OBST XB=23.00,23.10,12.55,15.40,11.75,15.13, SURF_ID='SHEET METAL'/ slab-4f Fan-u wall 1

\&OBST XB=29.20,29.30,12.55, 15.40,11.75,15.13, SURF_ID='SHEET METAL'/ slab-4f Fan-u wall 2

\&OBST XB=25.08,25.08,8.45,10.85,11.75,15.13, SURF_ID='SHEET METAL'/ slab-4f Fan-u wall 3

\&OBST XB=27.23,27.23,8.45,10.85,1 1.75,15.13, SURF_ID='SHEET METAL'/ slab-4f

Fan-u wall 3

\&OBST XB=27.23,27.55,10.65,10.85,11.75,15.13, SURF_ID='SHEET METAL'/

Obstruction \#18

\&OBST XB=27.55,27.75,10.85,11.05,11.75,15.13, SURF ID='SHEET METAL'/

Obstruction \#19

\&OBST XB=27.75,27.95,11.05,11.25,11.75,15.13, SURF_ID='SHEET METAL'

Obstruction \#20 
\&OBST XB=27.95,28.15,11.25,11.45,11.75,15.13, SURF_ID='SHEET METAL'/ Obstruction \#21

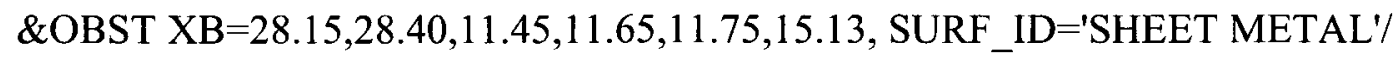
Obstruction $\# 22$

\&OBST XB=28.40,28.60,11.65,11.85,11.75,15.13, SURF_ID='SHEET METAL'/ Obstruction \#23

\&OBST XB $=28.60,28.80,11.85,12.05,11.75,15.13$, SURF ID='SHEET METAL'/ Obstruction $\# 24$

\&OBST XB=28.80,29.00,12.05,12.25,11.75,15.13, SURF_ID='SHEET METAL'/ Obstruction \#25

\&OBST XB=29.00,29.20,12.25,12.55,11.75,15.13, SURF_ID='SHEET METAL'/

Obstruction $\# 26$

\&OBST XB=24.75,25.08,10.65,10.85,11.75,15.13, SURF ID='SHEET METAL'/ Obstruction \#27

\&OBST XB=24.55,24.75,10.85,11.05,11.75,15.13, SURF_ID='SHEET METAL'/ Obstruction $\# 28$

\&OBST XB=24.35,24.55,11.05,11.25,11.75,15.13, SURF_ID='SHEET METAL'/ Obstruction $\# 29$

\&OBST XB=24.15,24.35,11.25,11.45,11.75,15.13, SURF_ID='SHEET METAL'/ Obstruction \#30

\&OBST XB=23.90,24.15,11.45,11.65,11.75,15.13, SURF_ID='SHEET METAL'/ Obstruction \#31

\&OBST XB=23.70,23.90,11.65,11.85,11.75,15.13, SURF_ID='SHEET METAL'/ Obstruction \#32

\&OBST XB=23.50,23.70,11.85,12.05,11.75,15.13, SURF_ID='SHEET METAL'/ Obstruction \#33

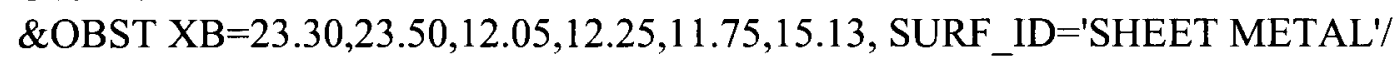
Obstruction \#34

\&OBST XB=23.10,23.30,12.25,12.55,11.75,15.13, SURF_ID='SHEET METAL'/ Obstruction \#35

\&OBST XB=23.10,29.20,11.50,11.83,14.85,15.13, SURF_ID='SHEET METAL'/ Obstruction $\# 36$

\&OBST XB=23.10,29.20,11.83,12.15,14.56,14.85, SURF_ID='SHEET METAL'/ Obstruction \#37

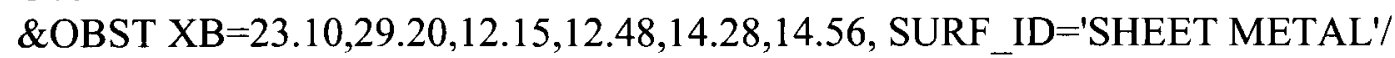
Obstruction \#38

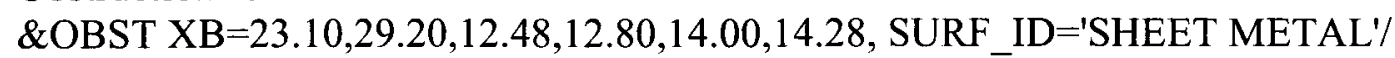
Obstruction \#39

\&OBST XB=23.10,29.20,12.80,13.13,13.71,14.00, SURF_ID='SHEET METAL'/

Obstruction $\# 40$

\&OBST XB=23.10,29.20,13.13,13.45,13.43,13.71, SURF ID='SHEET METAL'/ Obstruction $\# 41$

\&OBST XB=23.10,29.20,13.45,13.78,13.15,13.43, SURF_ID='SHEET METAL'/

Obstruction $\# 42$ 
\&OBST XB=23.10,29.20,13.78,14.10,12.86,13.15, SURF_ID='SHEET METAL'/ Obstruction $\# 43$

\&OBST XB=23.10,29.20,14.10,14.43,12.58,12.86, SURF_ID='SHEET METAL'/ Obstruction \#44

\&OBST XB=23.10,29.20,14.43,14.75,12.30,12.58, SURF_ID='SHEET METAL'/ Obstruction \#45

\&OBST XB=23.10,29.20,14.75,15.08,12.01,12.30, SURF_ID='SHEET METAL'/ Obstruction \#46

\&OBST XB=23.10,29.20,15.08,16.00,1 1.73,12.30, SURF ID='SHEET METAL'/

Obstruction \#47

\&OBST XB=20.85,21.15,0.00,37.50,5.60,11.74, SURF_ID='CONCRETE'/ Obstruction \&OBST XB $=0.00,11.00,48.93,49.23,0.00,30.00, \mathrm{SURF}_{-} \mathrm{ID}={ }^{\prime} \mathrm{CONCRETE} /$ Obstruction \&OBST XB $=11.00,11.30,48.93,50.86,0.00,30.00, S U R \bar{F} \_$ID $=$'CONCRETE'/ Obstruction \&OBST XB=17.22,20.15,44.51,44.61,0.00,30.00, SURF_ID='SHEET METAL'/ Obstruction

\&OBST XB=17.20,17.32,44.61,50.86,0.00,30.00, SURF_ID='SHEET METAL'/

Obstruction

\&OBST XB=20.05,20.15,39.65,44.61,0.00,30.00, SURF_ID='SHEET METAL'/

Obstruction

\&OBST XB $=0.00,21.15,30.00,50.86,25.40,25.70, \mathrm{SURF}$ ID $=$ 'CONCRETE'/ Obstruction \&OBST XB $=17.55,21.15,37.20,37.50,5.70,26.90, \mathrm{SURF}^{-} \mathrm{ID}={ }^{\prime} \mathrm{CONCRETE} /$ Obstruction \&OBST XB $=17.55,17.85,30.00,37.50,5.70,26.90, \mathrm{SURF} I D=' C O N C R E T E ' /$ Obstruction \&OBST XB $=17.55,20.85,30.00,37.50,5.70,6.00$, SURF $\overline{\mathrm{ID}}={ }^{\prime}$ 'CONCRETE'/ Obstruction \&OBST XB=26.45,30.00,35.10,37.30,6.00,6.30, SURF_ID='SHEET METAL'/

Obstruction

\&OBST XB=22.30,25.85,35.10,37.30,6.00,6.30, SURF_ID='SHEET METAL'/

Obstruction

\&OBST XB=20.15,21.15,39.65,39.75,0.00,30.00, SURF_ID='SHEET METAL'/

Obstruction

\&OBST XB=19.95,20.05,40.50,44.16,1.00,5.26, SURF_ID='SHEET METAL'/

Obstruction

\&OBST XB=17.00,17.20,45.60,49.26,1.00,5.26, SURF_ID='SHEET METAL'/

Obstruction

\&OBST XB $=21.15,21.35,30.00,37.50,11.75,25.70$, SURF_ID='CONCRETE'/

Obstruction

\&OBST XB=9.74,10.59,38.26,39.59,0.65,0.65, SURF_ID='Fire'/ Obstruction[3]

\&OBST XB=8.74,9.59,38.26,39.59,0.65,0.65, SURF_ID='Fire'/ Obstruction[3][1]

\&VENT SURF_ID='OPEN', XB=21.15,31.15,0.00,0.00,6.00,11.34/ $2 \mathrm{f}$ open for fan-1 \&VENT SURF ${ }^{-}$ID $=$'FANL1', XB=27.33,30.48,8.50,8.50,6.40,9.45/ slab-2f Fan$11 * * * * * * * * * * * * * * * * * * * * * * * *$ open active

\&VENT SURF_ID='FANL2', XB=21.83,24.98,8.50,8.50,6.40,9.45/ slab-2f Fan$12 * * * * * * * * * * * * * * * * * * * * * * * *$ open active 
\&VENT SURF ID='FAN3', XB=25.08,27.23,8.50,8.50,11.76,15.14/ slab-3f Fan$3 * * * * * * * * * * * * * * * * * * * * * * * *$ open active \&VENT SURF_ID='OPEN', XB=10.97,14.63,30.00,30.00,0.00,4.26/ Vent \&VENT SURF_ID='OPEN', XB=5.97,9.63,30.00,30.00,0.00,4.26/ Vent

\&BNDF QUANTITY='WALL TEMPERATURE'/

\&SLCF QUANTITY='V-VELOCITY', PBY=17.50/

\&SLCF QUANTITY ='carbon monoxide', PBY=17.50/ $\&$ SLCF QUANTITY $=$ 'V-VELOCITY', PBY $=25.00 /$ \&SLCF QUANTITY='TEMPERATURE', $\mathrm{PBY}=25.00 /$

\&SLCF QUANTITY='oxygen mass fraction', $\mathrm{PBY}=25.00$ / \&SLCF QUANTITY='V-VELOCITY', PBY=15.40/ \&SLCF QUANTITY='oxygen mass fraction', $\mathrm{PBX}=26.00$ / \&SLCF QUANTITY='V-VELOCITY', PBX=26.00/ \&SLCF QUANTITY='TEMPERATURE', PBX=26.00/ $\&$ SLCF QUANTITY ='carbon monoxide', $\mathrm{PBX}=26.00$ / \&SLCF QUANTITY='VELOCITY', VECTOR=.TRUE., PBX=9.00/ $\&$ SLCF QUANTITY='TEMPERATURE', PBX $=9.00 /$

\&SLCF QUANTITY='oxygen mass fraction', $\mathrm{PBY}=17.50$ / \&SLCF QUANTITY='W-VELOCITY', PBX=19.00/ $\&$ SLCF QUANTITY='VELOCITY', VECTOR=.TRUE., $P B X=21.00$ / $\&$ SLCF QUANTITY='VELOCITY', VECTOR=.TRUE., $\mathrm{PBX}=7.00 /$ $\&$ SLCF QUANTITY='VELOCITY', VECTOR=.TRUE., PBY=36.00/ \&SLCF QUANTITY='TEMPERATURE', PBY $=36.00 /$

\&SLCF QUANTITY='U-VELOCITY', PBY=36.00/

$\&$ SLCF QUANTITY='VELOCITY', VECTOR $=$.TRUE., $\mathrm{PBX}=29.50 /$ \&SLCF QUANTITY='VELOCITY', VECTOR=.TRUE., PBY=8.75/ $\&$ SLCF QUANTITY='VELOCITY', VECTOR=.TRUE., $\mathrm{PBX}=26.00 /$ $\&$ SLCF QUANTITY='VELOCITY', VECTOR=.TRUE., $P B Y=14.00 /$ $\&$ SLCF QUANTITY $=$ 'TEMPERATURE', $\mathrm{PBY}=17.50 /$ $\&$ SLCF QUANTITY='TEMPERATURE', PBY $=40.50 /$ $\&$ SLCF QUANTITY='TEMPERATURE', PBZ $=28.00 /$ $\&$ SLCF QUANTITY='TEMPERATURE', PBZ $=2.00 /$ \&SLCF QUANTITY='TEMPERATURE', PBZ=9.50/ $\&$ SLCF QUANTITY='soot', PBY $=17.50 /$ $\&$ SLCF QUANTITY='soot', PBY $=20.00 /$ $\&$ SLCF QUANTITY $=$ 'V-VELOCITY', PBY $=20.00 /$ $\&$ SLCF QUANTITY $=$ 'TEMPERATURE', $P B Y=20.00 /$ \&SLCF QUANTITY='oxygen mass fraction', PBY=20.00/ $\&$ SLCF QUANTITY='soot', PBY=25.00/

\&TAIL / 
Appendix C: Views of Labview Front Panel and Block Diagram

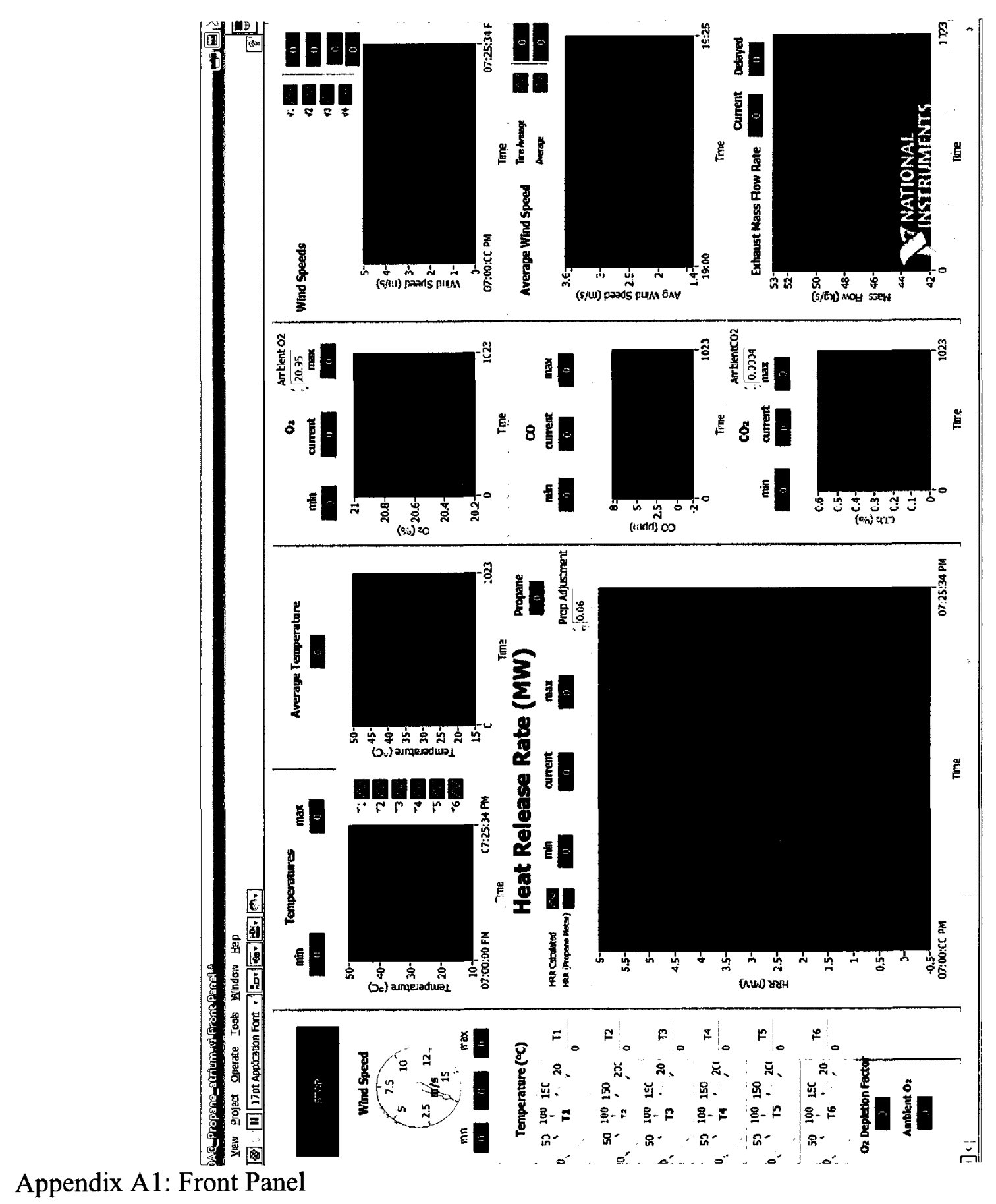




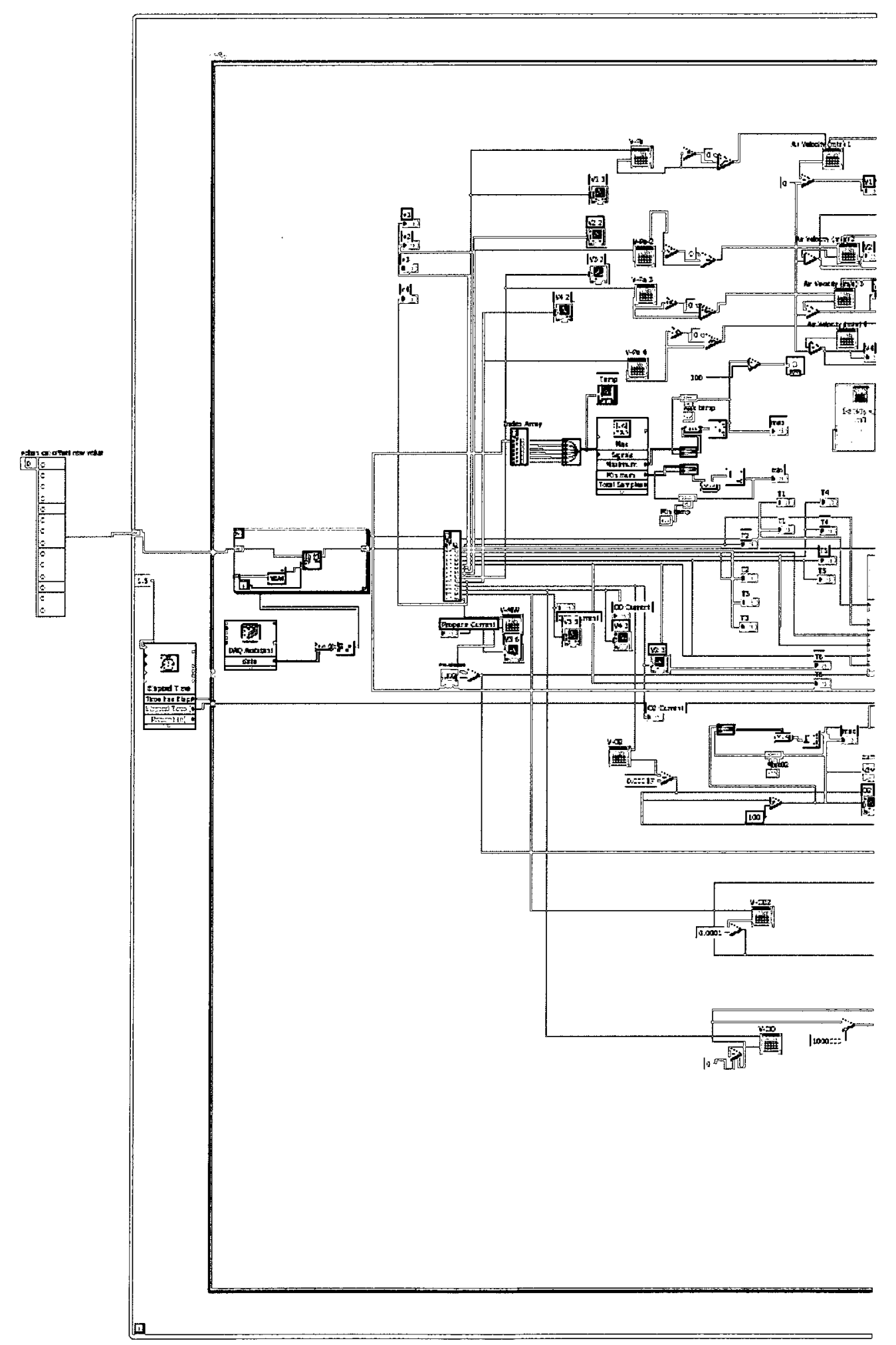

Appendix A2: Block Diagram 


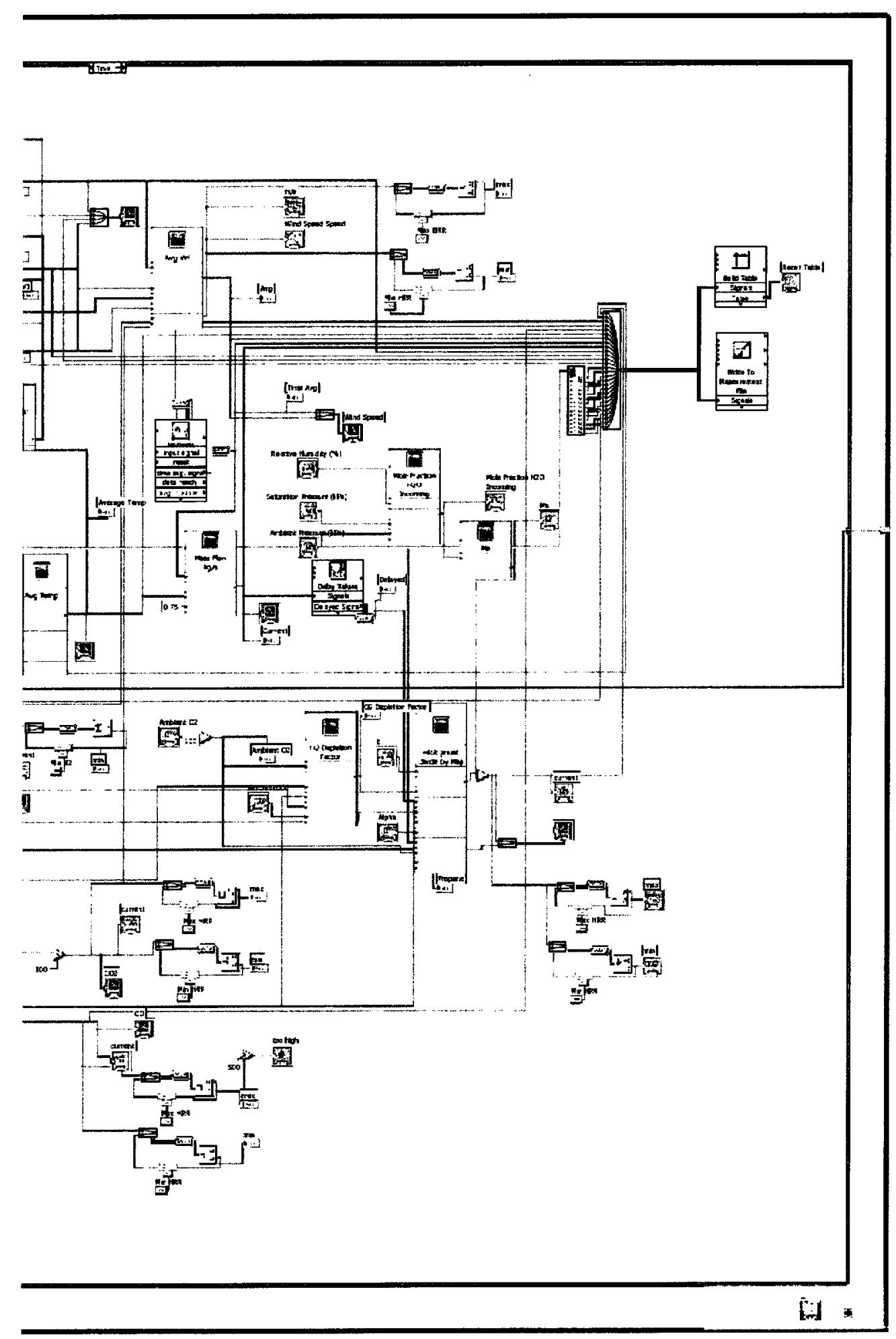

Appendix A2 (Continued): Block Diagram 


\section{Appendix D: Operator Checklist}

\section{General}

- Before running fans, check ventilation arrangement. Ensure air has an intake path.

\section{Data acquisition, measurement files and Labview VI}

- Save the Labview VI being used for the test into a new folder.

- Enter properties of "Write to Measurement" express VI in the Block Diagram

- Set file name and location

- If a file already exists "use the next available file name"

- Set file format as "text (LVM) and segment headers as "One header only"

- Move to Front Panel

If burning propane, set $\mathrm{E}=12.9$ and alpha $=1.084$. For other tests, set $\mathrm{E}=$ 13.1 and alpha $=1.1$. If composition of combustibles is known, other values can be used as required.

- For added precision, set relative humidity and ambient pressure if known

- Before running a test, try running the VI and ensure all measurements are reasonable and all necessary values are being written to file. 


\section{Gas Analysis}

- Leave gas analyzer running for at least 2 hours before test to warm up.

- Put ice and water in bucket with condensation coil

- Calibrate gas analyzer the morning of a test (and throughout a testing day as required)

- Zero-point calibration using $\mathrm{N}_{2}$ cylinder

- Span calibration using $901 \mathrm{ppm} \mathrm{CO}$ cylinder, $4.98 \% \mathrm{CO}_{2}$ cylinder and either $12 \% \mathrm{O}_{2}$ cylinder or fan chamber gas at $20.95 \% \mathrm{O}_{2}$ (Air Cadet pump must be running for this).

- Make sure gas coming from chamber gives reasonable values.

- Check cotton soot filter (use two cotton balls). If cotton is black, replace.

- Turn on internal gas analyzer pump

- Turn on Air Cadet external pump

- Check desiccant gas drier periodically. If entirely pink, replace or dry the desiccant.

- Make sure values on gas analyzer and Labview VI are the same

- Set ambient $\mathrm{O}_{2}$ and $\mathrm{CO}_{2}$ values on Labview Front Panel to match value being received from fan chamber (default is $20.95 \%$ ) 